


\section{Historic, archived document}

Do not assume content reflects current scientific knowledge, policies, or practices. 
352244

\section{LIBRARY}

OF THE

\section{UNITED STATES}

DEPARTMENT OF AGRICULTURE

$$
\text { Book EN } 82 \text { B } 2 \text { no. 6 o, ns, }
$$





$$
\text { . }
$$






\section{$1 / 127$}

U. S. DEPARTMENT OF AGRICULTURE, BUREAU OF ENTOMOLOGY-BULLETIN No. 60.

L. O. HOWARD, Entomologist and Chief of Bureau.

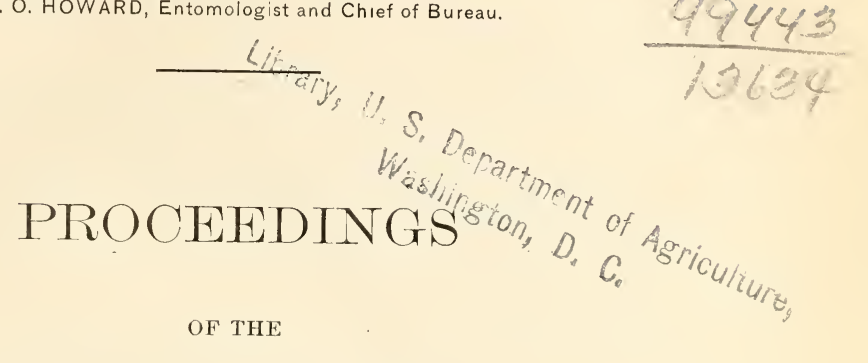

\section{EIGHTEENTH ANNUAL MEETING}

OF THE

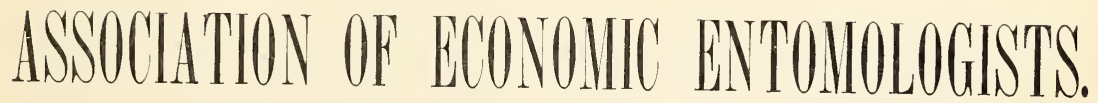

\section{Issued September 22, 1906.}

\section{WASHINGTON:}

GOVERNMENT PRINTING OFFICE.

1906. 


\section{LETTER OF TRANSMITTAL.}

\section{United States Departurent of Agricclture,}

Bureat of Extomologr, Washington, D. C... May S, 1906.

SIR: I have the honor to transmit herewith the manuscripts of the proceedings of the eighteenth annual meeting of the Association of Economic Entomologists, which was held at New Orleans, La., January 1 to 4,1906 . As the papers presented at the meetings of this association are of very considerable economic importance and as the reports of the secretaries of these meetings hare hitherto been published by the Department of Agriculture as bulletins, I recommend the publication of the present report as Bulletin No. 60 of this Bureau.

Respectfully,

Hon. Jayies Wilson, Secretary of Agriculture.
C. L. Marlatt, Acting Chief of Bureau. 


\section{4}

\section{CONTENTS}

Eightemten Annual Meeting of the Association of Economic Entoro: OGISTS.

The Scope and Status of Economic Entomology

H. Garman

Report of Committee on Nomenclature

Report of Committee on Cooperative Testing of Insecticides

The Problem of Wing Origin and its Significance in Insect Phylogeny, ${ }^{a}$

Herbert Osborn .

Preliminary Observations on the Variations of Utetheisa venusta,

Mel. T. Cook.

The Corn Root-Aphis and its Attendant Ant

S. A. Forbes

Observations upon the Migrating, Feeding, and Nesting Habits of the Fall

Webworm (Hyphantria cunea) E. W. Berger.

The Care of Entomological Types_................... T. D. A. Cockerell__

Notes upon a Little-known Insect Enemy of Cotton and Corn,

Wilmon Newell _.

History of Economic Entomology in Hawaii Jacob Kotinshy -

Notes from Texas.

Insects of the Year in Cuba

A. F. Conradi.. Mel. T. Cook

I. F. Burgess.

E. Dwight Sanderson R. I. Smith and A. C. Lewis.

T. B. Symons _

F. L. Washburn.. E. P. Felt

E. Dwight Sanderson _

A Consideration of the Cultural System for the Boll Weevil in the Light of Recent Observations ....... A. F. Conradi.

Laboratory Methods in the Cotton Boll Weevil Investigations_ W. E. Hinds _.

The Work of the State Crop Pest Commission of Louisiana on the Cotton

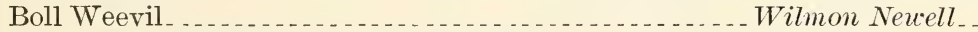

Report of Committee on National Control of Introduced Insect Pests . . . . . Tests of Lime-Sulphur Washes in Connecticut in $1905 \ldots \ldots$. . W. E. Britton _-

Experiments with Insecticides on the San Jose Scale. E. P. Felt -

Sulphur Dioxide as an Insecticide C. L. Marlatt

Notes on Insecticides $a$

A. F. Burgess _-

Some Observations on the Spined Soldier Bug (Podisus maculiventris Say),

Destroying the Woolly Maple-Leaf Scale by Spraying A. W. Morrill_

The Relation of Descriptions to Economical Methods of Eradication in the

Family Aphididæ.

IV. E. Britton

The Currant Root-Aphis (Schizoneura fodiens Buckton)

The Plague Locust of Natal Chas. E. Sanborn ..

Does the Silver-Fish (Lepisma saccharina) Feed on Starch and Sugar?

List of Members of the Association of Economic Entomologists . . . . . . . . 


\section{L LUSTRATIONS.}

PLATES.

Plate I. Fig. 1.-Walnut trees infested by Hyphantria cunea. Fig. 2,Choke-cherry trees defoliated by Hyphantria cunea ..... .....

Paze.

II. Laboratory methods in the cotton boll weevil investigations:

Fig. 1.-Boxes used in breeding parasites and weerils. Fig. 2.-Breeding jar used in life-history work. Fig. 3.-Folding cage used in field experiments. Fig. 4.-Wire-screened cage used in hibernation experiments ........................

III. Laboratory methods in the cotton boll weevil investigations: Fig. 5.-Camera stand designed for both horizontal and vertical work. Fig. 6.-Arrangement used in securing b'ack backgrounds with camera hcrizontal. Fig. 7.-Chart making with stereopticon for projecting image. Fig. 8.-Chart made from negative image projected by electric light through copy-

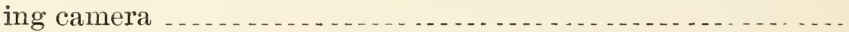

TEXT FIGURES.

FIG. 1. Cicada erratica: Adult female, and male and female details. . ....

2. Cicada erratica: Eggs and egg punctures . . . . . . . . . . . . . . . .

3. Area in Louisiana infested by Anthonomus grandis in December, 1903, and in December, 1904

4. Area in Louisiana infested by Anthonomus grandis in July, 1905 ..

5. Area in Louisiana infested by Anthonomus grandis in December, 1905

6. Podisus maculiventris: Variation of adults in form and size-par-

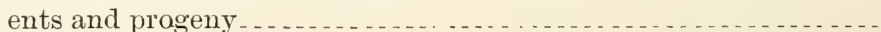

7. Schizoneur a fodiens: Antenna of winged viviparons female . . . .. 167

8. Schizoneura fodiens: Pupal markings _...................... 167

9. Schizoneura fodiens: Antenna of pupa _...................... 167

10. Photographic print injured by Lepisma saccharina ........... 1 . . . 


\title{
THE EIGHTEENTH ANNUAL MEETING OF THE ASSOCIATION OF ECONOMIC ENTOMOLOGISTS.
}

\author{
MORNING SESSION, MONDAY, JANUARY 1, 1906.
}

The Association met in Gibson Hall of the Tulane University, New Orleans, La., on January 1 to 4, 1906. The following members were in attendance at the several sessions:

C. F. Adams, Fayetteville, Ark.; W. E. Britton, New Haven, Conn. ; A. F. Burgess, Columbus, Ohio; R. S. Clifton, Washington, D. C. ; A. F. Conradi, College Station, Tex.; Mel. T. Cook, Santiago de las Vegas, Cuba; E. C. Cotton, Columbus, Ohio; J. C. Crawford, Dallas, Tex. ; C. W. Flynn, Baton Rouge, La.; S. A. Forbes, Urbana, Ill.; J. B. Garrett, Baton Rouge, La.; E. S. Hardy, Shreveport, La.; W. E. Hinds, Washington, D. C. ; L. O. Howard, Washington, D. C. ; W. D. Hunter, Washington, D. C. ; C. R. Jones, Dallas, Tex. ; R. S. Mackintosh, Auburn, Ala.; C. L. Marlatt, Washington, D. C.; W. O. Martin, Shreveport, La.; H. A. Morgan, Knoxville, Tenn.; A. W. Morrill, Washington, D. C.; Wilmon Newell, Shreveport, La.; J. F. Nicholson, Stillwater, Okla.; Herbert Osborn, Columbus, Ohio ; A. L. Quaintance, Washington, D. C. ; C. E. Sanborn, College Station, Tex.; E. Dwight Sanderson, Durham, N. H.; E. A. Schwarz, Washington, D. C.; R. I. Smith, Atlanta, Ga.; H. E. Summers, Ames, Iowa; T. B. Symons, College Park, Md.; F. L. Washburn, St. Anthony Park, Minn.; F. M. Webster, Washington, D. C.

In the absence of the president and the first vice-president the meeting was called to order at $10 \mathrm{a}$. m. by the second vice-president, Mr. F. L. Washburn. The secretary read the annual address of the president, as follows:

\section{THE SCOPE AND STATUS OF ECONOMIC ENTOMOLOGY.}

By H. Garman, Lexington, Ky.

Science in all its aspects, when applied to human affairs, has of late been accorded much more consideration and its devotees more respect than formerly. Economic entomology with the rest has received its share of recognition as a branch of science worthy of the close attention of sensible men. Yet it was not so long ago when we heard much of the pure science of entomology as contrasted with its applied science, as if the two were completely independent of each other; and somehow it was imagined that entomology not applied was a more exalted field of study than entomology made to serve our own wants; the man engaged simply in the study of the science itself, 
though utterly incapable in practical matters, was a greater scientist than one who sought to render his studies of service to his kind.

It was a foolish notion, to be sure, this making of an arbitrary distinction between the science when utilized and when not, and, excepting in the case of certain belated laboratory and museum worker's, no such idea is seriously entertained to-day. Indeed, it seems now that the tendency is to exalt applied entomology to the detriment of the pursuit of its science. Certainly the economic entomologist has had opportunities in the shape of financial support and influential backing that have never been enlisted in the service of the purely scientific side of the subject. Economic entomologists have all good reason to feel proud of this, since it is largely a result of the practical viewpoint and enterprise of the votaries of applied entomology.

It has been the practical sense developed by dealing with affairs that has enabled them to enlist the attention of the public and educate it to the importance of entomology as applied to agriculture and other human concerns. The pure science worker would never have done this, and it thus has happened that the entomologist, who was at one time looked upon by his fellow-worker with something in the nature of disdain, has taken first place in the estimation of the general public and commands attention when the recluse laboratory worker gets little consideration. And this is as it should be. The economic entomologist can claim all entomology as his. Not a fact is there of insect structure or life history or habit that may not at some time prove to be of first importance from the practical point of rier. The history of this science is full of illustrations showing how insects and facts concerning them, regarded at first-like the economic entomologist-as of no great consequence. have proven, when their relations with other facts were known, to have a far greater importance than have those with which attention was mainly occupied. The family Coccidæ, at one time almost wholly ignored in this country by entomologists of all sorts, has, from the accidental introduction of one of its species into California from abroad, and more recently into the fruit-growing States of the East, become of late one of the most conspicuous groups of all insects and one of those most often mentioned and discussed anong people not entomologists. The species just mentioned may be said to have wrought a greater change in the attitude of the general public toward entomology and entomologists than all of the other known species of scale insects together. The family Culicidæ, also very generally ignored by entomologists until recently, and serving largely as a subject for jokes by other people, has, from the discorery of the relations of certain of its species with the diseases malaria and yellow ferer, become one of the most important and interesting of all groups of insects. The discorery of these relations has made necessary careful systematic work 
on the species of mosquitoes - a study of the life history and habits of each, a knowledge of their structure, a knowledge of the life histories of the parasites for which some of them serve as intermediate hosts, and a knowledge of the precise relations which these parasites sustain to mosquitoes. Because of this discovery the entomologist is compelled to acquire knowledge-systematic, ecological, and morphological-and to delve to some extent into the life history and structure of organisms very remotely related to insects.

Again, a study of the structure of an insect has more than once furnished a clue to means of checking its injuries when everything else failed. A single fact concerning a life history has likewise sometimes placed it within our power to avoid mischief from which we had hitherto been unable to protect ourselves. To meet the requirements of his subject, the economic entomologist must, in a word, be an all-round naturalist. He must know species well. He must know anatomy, minute and microscopic. He must know insect life histories as they are known to no one else. He must know remedies for insect injuries and be able to apply them successfully. He must be a skillful microscopist, and should know the literature of entomology. If he has acquired this knowledge and skill, he is surely as broad, as a man and an entomologist, as he whose work is confined solely to the "pure science" of the subject; and it may be easily maintained that economic entomology as here understood is a much broader field and requires as much talent of the same and different sorts for its successful pursuit as that employed by him who studies simply insect taxonomy, insect embryology, or insect morphology, valuable though the results of such studies may be.

All science is "pure," whether it is applied or not. It may be suspected that some of the disfavor bestowed upon economic entomology in the early days of its history in this country arose from the fact that economic entomologists were often more of the practical order than of the scientific; were, in other words, somewhat deficient in scientific knowledge, though this was not true of Riley, Fitch, or Harris, three great pioneer economic entomologists who have had no superiors in any country. Yet it must be said of these men that they were primarily scientists, whose chief interest lay in working out life histories. Remedies for insect injuries as employed by farmers and fruit growers were studied by them, and what appeared to be the best were recommended in their writings, but these remedies were not experimented with in the thoroughgoing manner that has of late become the fashion. This is not to their discredit. They were able men, who felt impelled to do the work most worth doing in their day. The problems to be solved now are different, and the opportunities to solve them in a satisfactory manner are better than they were when these men wrote. 
GROUPS OF ANIMALS STUDIED BY THE ECONOMIC ENTOMIOLOGIST.

It has been my custom in pointing out to pupils the extent of the class Insecta and its relations with other groups of animals to remind them that our legitimate field covers the three classes of Arthropods-namely, Arachnida, Myriapoda, and Insecta, and that occasionally a renturesome entomologist pushes on into the fourth group when some member of it, such as the pill bug. becomes troublesome and requires attention from a practical standpoint. Considering the number of species of true insects alone to be studied-and any one of them may demand attention-the economic entomologist occupies a greater territory than do all his fellow-workers in mammalogy, ornithology, ichthyology, herpetology, malacology, etc., put together.

Compared with other groups of animals, the Insecta at once stands out as the most conspicuous. both in point of numbers and of species. Mammals, birds, reptiles, and fishes, composing the rertebrate subkingdom, include but few. relatively. Mollusks are not especially numerous. The same is to be said of the true worms, of the starfishes, and the sea urchins. Of the corals, sponges, and microscopic Protozoa, also, it may be said that their numbers are small as compared with those of insects, though the Protozoans. especially those of salt water, exist in amazing numbers of indiriduals. Insects, numbering, it is beliered, about 1,000,000 species. surpass all these other groups, and constitute approximately four-fifths of the whole animal kingdom. Here is a great field for the entomological taxonomist, and it is this wealth of material that has kept. entomology somewhat behind botany and some other branches of biological study. To describe properly the adults alone of all these species of insects would require 2,000 octaro rolumes each of 500 pages. To describe the life history of any insect should require at least two octaro pages, which would add 4.000 rolumes more. and perhaps another thousand would give adequately the facts relating to the habits and distribution of each species. Good accounts of the morphology and physiology of typical examples, even of family groups, would add many more volumes. Then we must include as part of the domain of the entomologist the classes Mrriapoda and Arachnida, comprising, say. 10.000 species. A library of not less than 7.000 volumes would thus be required to give merely the important facts concerning existing insects, not including discussions of remedies for insect injuries.

\section{ALL INSECTS OF ECONOMIC IMPORTANCE.}

It may be said of the 1,000,000 insect species estimated as now existing that they are erery one in greater or less measure of interest from the economic riew-point. If carnirorous, they feed upon one 
another, or else upon animals of other groups, and all are so knit together that it is impossible to estimate the far-reaching effects that might follow any change in the numbers of the most obscure species. So, too, in their relations to regetation, while many attack plants of no apparent value to us, it is impossible to say when such plants and their insect dependents with them may become important. But suppose one-half of the existing species of myriapods, arachnids, and true insects were of recognized economic importance, an account of them, together with an adequate discussion of remedies, would require 3.500 or 4,000 volumes of text.

I am sometimes asked to recommend a rolume containing accounts of all the insects. If the 25,000 and more known species from North America were described and the life history of each recorded it would fill not less than 150 volumes; and I have been compelled to refer my friends to such imperfect single volumes as we have, explaining, in apology, that our entomological literature is scattered at present in numerous serials and in volumes relating to special groups of insects, and that no single volume contains more than a small fraction of acquired entomological lore.

And here I may be allowed to say a few words with reference to our special literature. It contains much useful material, some of it representing as good work as is done by any class of naturalists. In six of the best known American publications-the Canadian Entomologist, Entomological News, Psyche, Transactions of the American Entomological Society, Journal of the New York Entomological Society, and Proceedings of the Entomological Society of Washington-over 1,500 pages of matter, largely relating to life histories and descriptions of species, have already been published this year (1905). About as many more pages have been published by our fellow-workers of the British Islands, and the entomologists of France, The Netherlands, Scandinavia, Germany, Russia, and other European countries have contributed numerous others. Even little Japan now publishes at least one creditable entomological journal. Including all nationalities, it seems safe to estimate the number of pages on species and life histories at 8,500. Probably one-half of this published matter is of immediate value as economic entomology, and perhaps 4,000 pages more should be added to this as the output of entomologists engaged on the more strictly practical side of entomology. Say, then, 8,000 pages represents the average annual product relating evidently to practical entomology, and you have 16 volumes published each year on our specialty. Unfortunately, a good deal of this-too much of it-is repetition by compilation. Judging by the publications of our own country, about one-fourth of the matter relating to strictly economic entomology is repetition, being either compilation or repeated observation. At the present 
time both compilation and repetition of work are valuable and necessary. The official practical entomologist is compelled to do this work for the audience for which he is emplored to write. But he should not permit this pressure to dirert his attention entirely from research. The true naturalist is nerer so happr as when pushing into the unknown territory of his domain. His fellows should stand up for him and lend him encouragement when he finds it necessary, in order to do original work. to break a war from short-sighted taskmasters. "Science is nothing if not free" applies with special pertinence to biological science. If the biologist is to become a producer he must not be made a drudge and kept constantly in harness.

OUR FACILITIES FOR PUBLICATION.

Time was when the economic entomologist was cramped for opportunity to publish the results of his studies. At present in this country his facilities are rery exceptional. In the bulletins and other publications issued by our National Gorernment the entomologists possess excellent rehicles for sending abroad anthing ther mar wish to put before the public. and a great deal of raluable economic and other entomology comes from that quarter. The experiment station bulletins, too, are so many journals for the scattering of information of this sort, and hare disseminated during the past ten years entomological information that would not without them hare found the light in the next quarter century.

The workers employed at the Department of Agriculture and at the experiment stations are reaching the public through newspapers and magazines as nerer before. and the influence of this can be perceived by the greater interest shown in such matters by the larman wherever we meet him. No doubt some of the effect on the popular mind now to be perceired is the result of the rears of work in class rooms done for many weary years by teachers of biology in the agricultural colleges. but there has arisen in the past ten rears a quickened interest that can only be credited to the work of the experiment stations and of the Department of Agriculture at Washington since its reorganization.

FALSE HERALDS.

Workers along biological lines hare suffered of late from the writings of people who are not scientists but get what purports to be scientific information at second hand. The misstatements they sometimes make and the sensational stories of results secured which they publish often make the real results published by the real worker appear commonplace by contrast. Profesor somebody is represented as having made a wonderful discovery. which he never 
claimed to have made. With the wide newspaper comment resulting from the remarkable nature of the discovery he is made to appear a very remarkable man. People of a community in which lives an honest and patient seeker for the truth look upon the latter as a failure when such brilliance is flashed in their faces, though their humble fellow-citizen investigator may be worth a dozen of the sort with the manufactured reputation. He must keep his temper, however, since his word, though worth its weight in gold, will not be received until the sensational claims for the so-called discovery are exploded in publications as sensational, or more so, than those announcing the discovery. Economic entomology has not suffered as much in this way as have some related lines of investigation, and it is fortunate that it is so, since the correction of these wild stories costs energy and time that can be better occupied. Such stories are to be discouraged by every means in our power, since their final effect is to destroy confidence of the public in the results of our labors. To take from the average man his belief in a thing having a touch of the wonderful about it and which, therefore, he really likes to believe, always places real results along the same line under his suspicion thereafter.

OUR OPPORTUNITIES FOR INVESTIGATION ARE EXCEPTIONAL.

With increased facilities for publication we have had a very satisfactory improvement of late in the opportunities for experiment and observation along the lines of our favorite study. If we wish to observe the diseases of young trees, the general interest of nurserymen, stimulated by the demand for healthy stock which has been encouraged by State inspection laws, helps such observations along instead of discouraging them, as was sometimes done formerly from shortsightedness and selfish motives. If we wish to test the effect of treatment of any kind we have our experiment farms, where we can arrange carefully planned experiments with the knowledge that our results will not be lost to us by the carelessness or incompetence of others, as sometimes happens when one attempts experiments on premises not under his control. Most of us have some funds at our disposal for the purchase of tools, books, equipment for laboratories, insectaries, and the like, so that we can at this opening up of a new year felicitate ourselves on the enjoyment of privileges not possessed by naturalists at any other period of the world's history. I wish it could be said also that the salaries paid us were commensurate with the labor performed and the self-denial that must be exercised by anyone who devotes his life to such work. It is not a moneymaking profession, and at the end of his working days the official entomologist is left on the world to make shift as best he can on the 
pittance he and his family have been able to save by skimping themselves. The man who spends the best part of his life in honorable service of this sort ought to be able to retire, when his capacity for good work begins to wane, decently, at peace with the world, and with his self-respect unimpaired. He can not do this on a pension. He should be paid a reasonably liberal salary while he is working at the top of his bent for the public good. I have had this feature of the prorisions made for our work somewhat forcibly brought home to me recently by a very severe attack of fever, during which there was a good chance of my earthly labors closing abruptly.

Neither scientists nor teachers receive adequate pay in this country, for their services to the public. Artisans, farmers, tradesmen, physicians, and lawyers are all in a better position as to remuneration.

THE TEACHING OF ENTOMOLOGY IN AGRICULTURAL COLLEGES.

The value of a study of entomology either as training or for the purpose of acquiring knowledge of practical value is far too generally underrated in what may be called our government schools of science. The influence of educational tradition is still mighty throughout the land. In spite of the teachings of the great minds of all periods-of Socrates, Aristotle, Bacon, Comenius, John Locke, Huxley, and Herbert Spencer-the pedagogy in many of our colleges and high schools is not considered well founded unless based on the study of languages, of which Greek and Latin are those of chief importance. This persistent fallacy and prejudice often leads to a crowding out of instruction of much greater value as knowledge, and of equal or superior value as a means of training the mind. Why the study of the two languages named should train the mind better than a study of German and French or English has never been satisfactorily explained by advocates of the classical education. To my mind it has just one advantage, namely, the excellent text-books that have been developed in the long time during which these dead languages have been taught, and the large numbers of well-grounded teachers available. They can be found in most good high schools and colleges, whereas first-class teachers of modern languages are much less common: in fact, skilled teachers in these languages have always seemed to me to be rather rare in our public schools. But if the study of modern languages gires the same kind of training, and in addition opens up a world of useful knowledge bearing on problems of vital concern to us and not to be secured from Greek or Latin, why should anyone hesitate a moment in choosing courses in which moderu languages instead of ancient languages are made the foundation of an education? I am speaking here for a reading knowledge of modern languages and with the good of biological instruction in mind. 
The languages of such men as Oken, H. and Fritz Müller, Sprengel, Heer, Leydig, Weismann, Koch, Schioedte, Ratzeburg, Metschnikoff, Schiner, and Latzel, and of Reaumur, Morren, Lyonet, Lamarck. Cuvier, Viallanes, Signoret, and Pasteur contain more than half of what is new in the science of the times. And what information can the biologist extract from Greek or Latin? Excepting the writings of Aristotle, there is nothing in either language worth a month's study to acquire. They are most excellent training for the memorizing faculty. This must not be denied. But so is German, French, and entomology. "But," some of our friends have argued, "the study of ancient languages furnishes a culture that is not supplied by nature studies." I have known some excellent Hellenists whose culture was obscured by a disposition to tell vulgar stories, and I am told by others that they have observed this trait in Greek scholars. Perhaps we should expect nothing else from the study of the great epics whose scenes revolve about a Trojan dandy who ran away with another man's wife, and the incredibly bloody exploits of the mythical Greek hero Achilles.

I must beg leave to differ, also, as to the accuracy of the thinking developed by this sort of study. In a Greek history used as a textbook in a high school known to me, and in which no provision is made for the study of modern languages, the "Homeric question" is stated, and after remarking that there are differences between the Iliad and the Odyssey which suggest a different author for each, and that some authorities believe both to be collections of lays written by a number of bards, the author concludes: "It certainly seems more reasonable to believe in one Homer than in many," which to an entomologist seems a very lame and indefinite conclusion. The very location of ancient Troy is unknown. Even Schliemann's admirable investigations leave the matter unsettled. Of the remains of the nine cities unearthed by him on the Hissarlik Hill in Asia Minor, he believed the second to be the Troy of the Iliad, but Dörpfeld, his colleague, asserts that the sixth city is Troy. Perhaps neither is right. Looking over the evidence, a naturalist is satisfied of only one thing, namely, that this series of cities, one above another, provides a very good confirmation of the views held by archrologists, from facts learned in other ways, as to the stages in the progress of mankind toward civilization.

It may seem that I am going too far outside my theme in thus calling attention to the uncertainty in the facts and vagueness in conclusions drawn from Greek history, but the difficulty urged by those who have public schools in charge when they are asked to make room for biological or other related instruction is lack of time in the course. At the same time, it may be, instruction in Latin and in Greek history is given. I know one such case. Undoubtedly too 
many things are taught in our public schools, a condition leading to lack of thoroughness in everything. But it does not seem reasonable to exclude in favor of an ancient language subjects which would contribute immediately to the success of scholars when they went out into this modern world of science.

I have already mentioned the claims sometimes made for the superior culture afforded by ancient languages as compared with nature study. Quite frequently it is added that the study of nature leads to irreligion, that study of science tends toward materialism. To this we all dissent. But perhaps this dissent has never been better expressed than by Herbert Spencer in the following:

Suppose a writer were daily saluted with praises couched in superlative language. Suppose the wisdom, the grandeur, the beauty of his works were the constant topics of eulogies addressed to him. Suppose those who unceasingly uttered these eulogies on his works were content with looking at the outside of them and had never opened them, much less tried to understand them. What value should we put upon their praises? What should we think of their sincerity? Yet, comparing small things to great, such is the conduct of mankind in general with reference to the universe and its cause. Nay; it is worsc: Not only do they pass by. without study, these things which they daily proclaim to be so wonderful; but very frequently they condemn as mere triflers those who show any active interest in these marvels. We repeat, then, that not science, but the neglect of science is irreligious. Derotion to science is a tacit worship-a tacit recognition of worth in the things studied; and by implication in their cause. It is not a mere lip homage, but a homage expressed in actionsnot a mere professed respect, but a respect proved by the sacrifice of time, thought, and labor.

The study of entomology and kindred science furnishes knowledge of the greatest value. When pursued with sincerity its effect is refining. It is a culture study. Its tendency is not toward irreligion.

\section{THE STUDY OF ENTOMOLOGY AS MENTAL DISCIPLINE.}

As a training of the mind entomology is superior to the study of any language whatsoever. The man who has mastered LeConte and Horn's Classification of the Coleoptera of North America so as to use it readily and with accurate results has had a training in minute and exact observation, in comparison and in judgment, that very few studies will give. Every great mind that has occupied itself with methods in education has insisted on the supreme importance of the study of objects, of nature, as a foundation for all other studiesupon the natural process of dealing first with objects, then comparing them with other objects, and thus finally acquiring general truths. Observation, comparison, reflection are the mental processes that lead to real knowledge and to the advancement of learning. We may learn lack of respect for authorities by going back to the soil for premises for our thinking. So much the better. Authorities 
differ, as we have seen in the references to the authorship of the Iliad and the Odyssey and to the location of ancient Troy. Show me a man who by training or otherwise has acquired the habit of thinking for himself, basing conclusions upon his own observation as largely as possible, and I will show you an effective man in any of the relations in which men are placed. Show me a man whose observational and reflective faculties have been blunted by a prolonged course of study of authorities as they appear in books, and the chances are that you will show me at the same time a man of vacillating judgment, unable to deal effectively with everyday affairs.

The study of entomology teaches the inductive method of thinking which has made this century notable. The material for use in its study is readily and cheaply obtained in large quantity. No other branch of biology is so completely available for purposes of instruction except botany, and I hold that it should have a place beside botany in every science school. As a corrective to the undue leaning upon authority inculcated by purely literary studies, it should have a good effect on students taking language courses.

\section{THE TEACHING OF ENTOMOLOGY.}

But entomology must be well and thoroughly taught. And herein lies the greatest difficulty in getting for it the recognition which is its due as an agent for education. Our boards of trustees often select teachers upon the assumption that anyone can teach any subject, with a little preliminary coaching, or else go to the opposite extreme and demand a man of exceptional special learning, forgetting that teachers, like poets, are most often born, and if not born, must be made by careful training. No man is fit to teach entomology or any other subject who has no knowledge of modern educational methods and no good conception of the principles and purposes which underlie them as a means of training the mind to its greatest effectiveness. One may be a learned entomologist and be utterly unfit to teach. But the teacher must at least know his subject so well that he can take his pupils straight to nature. This is vital. The man or woman who is dependent on a text-book has no business occupying a position as a teacher of entomology.

We have not enough well-equipped teachers of entomology in our agricultural colleges at present. Nothing is so much needed to pave the way for the experiment-station worker. Until a larger proportion of our farmers have had a taste of the scientific method in the course of their education a great deal of value being done for them will not be grasped and made of use. And let me say again, in leaving this subject, that the training in entomology must be 
thorough, even if to accomplish this it is necessary to confine attention to a single insect. A nucleus of exact knowledge will later attract about it other knowledge of the same and different sorts, and thorough training, though brief, will greatly help to this end.

\section{ENTOMIOLOG AND HUMAN DISEASES.}

I come now to a consideration of a feature of our subject that has only recently assumed prominence. The relation of insects to diseases is a very interesting and important one, and one to which entomologists should derote more attention. Some excellent work relating to species and life histories has recently been published, but I rould be glad to claim for my fellow-morkers more of the credit for the discovery of the relation borne by mosquitoes to yellow fever and other diseases. No inrestigator is better equipped than the entomologist for such investigation. There is opportunity yet for valuable work in this field, and entomologists should at least cultivate all the territory on their side of the line dividing entomology from medicine. It should not be said of us that men who have had no training in our specialty must come orer into our domain and collect for themselves entomological information which we have neglected. This is economic entomology, if erer there was any, and we should demonstrate that we are able to furnish to the world all the facts along the line that may be required. In teaching the subject, too, this relation of insects must receive due attention.

The fact recently demonstrated, that the mosquito Stegomyia fasciata Fab. [calopus Meig.] conveys yellow ferer. and that therefore the disease can only occur as an epidemic within the limits of the distribution of this insect. is one of the most important made known by the study of epidemic diseases in recent rears. This mosquito is known to occur throughout the world between the latitudes $39^{\circ}$ north and about $37^{\circ}$ or $38^{\circ}$ south. In this connection it may be remarked that the rellow-ferer mosquito occur's throughout most of Kentucky, and that rellow-ferer cases originated in Louisville in 1878 to the number of 20. I am informed by the city health officer that the seren cases treated at the Lexington hospital during the fall of 1905 were all refugees from Louisiana. The facts now known with reference to this insect and its relation to yellow ferer show in a very lucid way the reason for the delving for seemingly unrelated knowledge practiced by many entomologists. Herein is the justification of the derotee of pure science. The facts unearthed by him concerning the structure of the beak or stomach of a mosquito, without a thought beyond adding this knowledge to the common stock, may prove, when all is known, to have a very important bearing on the welfare of human kind. 
The relation of flies to cholera has been studied now with sufficient care to warrant the belief that these insects are important agents, if not the chief ones, by which this dread malady spreads. Uffelman's experiment in which he obtained 10,500 colonies of the cholera Spirillum from a fly confined with a culture of the organism, and Macrae's tests of boiled milk exposed to flies in a jail at Gaya, India, where cholera was present, are convincing to most minds as to the pernicious part these insects take during cholera outbreaks.

Flies are accused also of conveying tuberculosis by carrying Bacillus tuberculosis from sputum to milk and other foods. At any rate the bacilli have been found both in their excreta taken from walls and in their alimentary canals.

The part taken by fleas and other insects in conveying leprosy is another subject well worthy of investigation by entomologists favorably situated for the purpose.

The spotted fever of Montana, known to be due to an organism named by Doctors Wilson and Chowning Pyrosoma hominis, should have attention from the entomological standpoint, since this organism is of the same nature as those causing malarial troubles, and this points to an intermediate host, in all probability an insect or a tick.

The relation between malaria and Anopheles maculipennis Meig. is now very well established, but there are other related species and genera, such as Myzomyia funesta Giles and Pyretophorus costalis Loew of Trest Africa, known to carry the disease also, and it is not at all improbable that still other insect agents may yet be discovered in the United States or some of its possessions. Here, in these latter especially, is an opportunity for the study of insects having to do with disease that has never received the attention it deserves.

Quite a good many other diseases are believed to be carried by insects, but the instances given serve my purpose of pointing to the work to be done.

A great field for original work lies also in the study of insects having to do with ailments of stock. We know much of the part taken by Boophilus annulatus Say in conveying Texas fever. But there are many things yet to be learned about the tick, and still more to be made known concerning the life histories and habits of the various insects associated in one way or another with domestic animals, and very probably in some cases concerned with their diseases. We are accustomed to leave this part of our territory to be tilled by reterinarians, but in doing so are making them a gift of a valuable part of our possessions.

$31024-$ No. $60-06 \mathrm{M}-3$ 
INSECTS AND PLANT DISEASES.

In the study of the relations of insects with the diseases of plants we have never shown the interest that this subject deserves from it, very great importance. That insects convey such diseases as pear blight is now rery well established, but I have been impressed more than once in the course of a study of the habits of an insect with the fact that their injuries were not by any means limited to the direct destruction of the tissues of plants. Dr. Erwin F. Smith, of the Department of Agriculture, has called attention to the inoculation of plants of the cucumber family with the virus of a blight carried in the mouth-parts of insects. Undoubtedly the spores of the rots of fruits and of the canker of bark are often conreyed by insects in this manner, and in the case of peaches and some varieties of plums this has seemed to me to be the chief source of infection. All of these matters need more study and experiment. They constitute one of the most inviting fields known to me for the labors of the entomologist who has some knowledge of bacteriological technique.

\section{INSECTS AND FLOWERS.}

Another field for investigation, lying in the border land between entomology and botany. has received but little attention in this country and should soon be occupied by our economic entomologists. Excepting the painstaking work done by Charles Robertson, accounts of which have appeared in botanical journals, and that of the late C. V. Riley on the fertilization of Iucca filamentosa. we have little in the way of published observations on the relations of insects and flowers. The subject is one of rast importance from the standpoint of agriculture, and in this period of activity in all problems having to do with heredity and breeding entomologists should more generally take an interest in the subject and throw upon it what light is to be derived by investigations made from the entomological point of view. Te have left this matter thus far too largely to botanists. and while they have done well with it, no doubt with our different training and knowledge we could, with a little study, add many facts which escape their observation. Riley's work on the pollination of Yucca is but an earnest of the interesting things that fresh study in this field would rery probably bring to light.

\section{APICULTURE.}

In the honey bee we have an insect more completely at our disposal than any other. It is a domestic animal, and was such eren in the drys of ancient Greece. We have no insect that has been given so much care, thought, and observation, and we have learned the facts 
concerning its habits and life history better than we have learned those of any other insect. I venture to say, further, that no other domestic animal is equal to it in interest from a scientific point of view. It is courageous, industrious, cleanly-qualities that we are accustomed to regard as the possession of the best of mankind. In its provision for the future, its laying up stores against days of scarcity, its careful closure of all crannies in its quarters that may admit cold air and allow the escape of heat, and in the care for its young and for the mother of its colony, it affords a lesson in civic virtue furnished by but few, if any, of the so-called higher animals.

It has always seemed strange to me that the honey bee is not more generally employed by teachers of entomology in the illustration of the ways and structures of insects. With the movable-frame hive it is very easy to present to a class all the stages of the bee and all the remarkable facts concerning its housekeeping. It seems to me that the instructors who have a.knowledge of this insect and know how to handle it have an invaluable source of illustrative material, furnishing all the essential facts of insect structure, transformation, nabit, and relations to nature at any season of the year. Why, then, do our instructors so often ignore this excellent material for practical work and fail to draw upon the wealth of accurate information published concerning the habits of bees? It is the most valuable body of knowledge relating to one insect that is available for the illustration of the fundamental truths of their subject. They can not afford to neglect it, although they sometimes do so, much to the detriment of their teaching in entomology, I must believe. What I have just said has no reference to the utility of the honey bee to mankind at large. The honey crop of California and some other States is a valuable one, and it may be doubted whether the demand for good honey at a reasonable price was ever fully supplied in the eastern United States. The subject of apiculture ought on this account to be given attention in every agricultural or entomological course. Every farmer should be taught how to supply at least his own family with honey. Bee keeping is not practiced as generally as it should be on the farm. But to the teacher of entomology I regard a theoretical and practical knowledge of apiculture as of the greatest value. I am risposed to think that most teachers who refrain from acquiring a practical acquaintance with bees are deterred by a fear of the stings. It has been often said before by expert bee keepers, but I think has not so often been said to teachers, that the danger is not at all serious. An old bee-keeping acquaintance once remarked that bees always sting a fool and a coward, and I have sometimes observed myself that when persons of a certain character come near when I am handling a colony they are likely to be sent off at a gallop. Any man or woman of intelligence and reasonably steady nerves, with a few appliances, such as a 
smoker and reil to start with, can open up and take out the frames filled with brood, or honey, and corered with bees, from a hive of Italians or Carniolans with complete safety, and once accustomed to it will often dispense with both reil and smoker. Try it. It is an important part of the outfit of the entomological instructor, and the experiment-station man who has occasion to discourse before farmers' institutes will find it sometimes rery useful in helping out a programme. It is astonishing how little is known by a large proportion of farmers about keeping bees properly. Excellent books on the subject are obtainable. Good special journals may be secured for a trifle. Special columns in agricultural papers are devoted to the subject, and in spite of it all one finds many farmers still keeping bees in box hives and unfamiliar with simple facts in the economy of a colony that have been repeated in one way or another again and again for more than two hundred years. It is for the station entomologist and teacher to remedy this state of affairs. But he will make little impression until after he has acquired such a practical acquaintance with apiculture that he can go through a hive, take out a queen and alip her wings, cut out unnecessary queen and drone cells. hive a swarm deftly, feed his colonies when necessary in fall and spring without permitting robbing, winter them successfully, and produce enough good honey to pay all expenses and leare a small surplus. When he can do all these things he can hold his own with the hardheaded ones who still believe the box hive better than any other and regard the old-style black bee as the greatest honey gatherer and hardiest bee known.

\section{SERICULTURE.}

It is too soon to make rery positive statements about the outcome of the project set on foot at Tallulah Lodge, Ga., having for its object the establishment of silk growing in the United States. Such attempts have been made before and have failed. The chief reason for these failures is believed to be the small wages earned by those who rear the worms. in proportion to the time required. Our people, it has been said, can earn more at other employments. It seems probable, howerer. that this is not the sole or eren the main cause for the failure thus far to establish silkworm rearing as an industry in the United States. People are prone to do what the majority of those about them do. There is a fashion in these things as in wearing apparel. and when most of one's friends and neighbors are enthusiastic in the growing of cotton, oranges, corn, or rice, it is natural that the interest in such things should perrade and dominate every member of a community. It requires time and persistence, under such conditions, to gain faror for other pursuits, and I apprehend that it is this preoccupation of the American mind with other busi- 
nesses, as much as anything else, that has hindered the development of silk growing in this country. Inertia in human affairs is the rock upon which more than one commendable enterprise has gone to pieces.

Let us hope that this will not be the fate of the silk-growing enterprise at Tallulah Lodge.

On a tract of 3,500 acres of land bordering the Tugalo River, Georgia, Mr. Louis Magid has planted large numbers of the white mulberry and has, since 1902, been actively engaged in teaching orally and by the press the essential facts in the rearing of silkworms. His journal, "Silk," has greatly helped in arousing an interest among entomologists and others scattered over the country beyond the immediate influence of his practical operations and personal influence. The prospect seems good for a successful launching of the industry this time, and entomologists should aid him to the extent of getting material, and teaching at the State colleges the life history and best methods of rearing the silkworm. Of the thousands of insect species in existence, the silkworm and honeybee are the only ones thus far appropriated by man as his servants. A thorough practical knowledge of both should be a part of the equipment of every professional entomologist.

It is asserted on the best of authority that our climate and soils are perfectly adapted to the silkworm and its food plant. From my own knowledge, I can say that it is easily reared in any part of the United States in which I have seen it tested. The silk produced here is believed to be not inferior to that produced anywhere else in the world. The rapid development of silk manufacturing in this country, and the large quantities of raw silk that must be imported to keep our factories occupied, is another incentive to those endeavoring to set on foot the production of the raw silk. Among foreign countries, France only is said to manufacture more silk fabrics than this country. Fifty silk mills are reported to have been established in seven States of the Union in 1903 alone. Statistics gathered show that we pay annually something like $\$ 100,000,000$ to foreign countries for raw and manufactured silks. It would, we may suppose, add very materially to our prosperity if silk raising could be developed to such an extent as to keep most of this money at home.

\section{NURSERY AND ORCHARD INSPECTION.}

I come now to a feature of the work of the official economic entomologist that has during the past ten years attracted more attention than any other. Nursery inspection has become one of the most exacting if not one of the most important departments of his work. It has brought him into relation with the machinery of his State government and required of him in this relation duties and a kind 
of mental activity quite foreign to that of the student and scientist. Some of these duties are not pleasant to one of his training and usual character, but the work required has had its value to the people, whether it has been best for the entomologist or not. I suppose no real naturalist with such work in his hands but has at times been led to ponder the question as to whether in this inspection work he was not going too far aside from the investigations in which he is chiefly interested and which by training and disposition he is better fitted than anyone else to prosecute. Can not this purely practical work be done by a class of men who are by nature satisfied with it as an occupation? Experience has, I think, shown that it can not be, in a satisfactory manner, without the help, by supervision or otherwise, of the scientific worker; and I think it is always to be regretted when such work falls into the hands of those who have no interest in it beyond the salaries to be obtained. It seems to me that this organization should take a stand for inspection by the entomological expert, since otherwise the issuing of certificates becomes a farce that will ultimately prove a discredit to the craft. There are many things about this line of work that I should like to dwell upon-the merits and defects of our State laws, the desirability for greater uniformity in such laws, the importance of having a national law providing for such inspection as can not well be carried on by the States, the kinds of insects whose presence should be regarded as of sufficient importance to condemn stock, the desirability of providing for both insect and fungous troubles under one inspection, and. especially, methods of treating condemned stock. Each one of these topics might well afford a programme for an entire meeting of the Association. I am impelled, however, to add a few words concerning fumigation as a means of ridding stock of scale insects. From purely theoretical considerations it was, at the outset of our inspection experience, regarded as a sort of panacea for scale and most other insects. More experience has shown this to be only generally true. There are insects that survive exposure to any of the charges of gas that are commonly recommended by inspectors. What shall we do for them? The nurseryman does not like to apply anything to his trees that sticks and thus tells a story to those who may buy treated trees. The inspector, on the other hand, if he be conscientious and honest, does not wish to certify such stock when merely fumigated. Still another serious difficulty arises under laws requiring fumigation of all nursery stock. Plants vary widely, I find, in their susceptibility to injury from hydrocyanic-acid gas of the strength commonly prescribed, and nurserymen rightfully complain of loss inflicted on them from this source, by the killing and serere injuring of perfectly healthy stock of certain kinds. I must say, as an inspector, that I do not approve of some of the laws enacted, because 
of the hardships of this sort resulting from them, and also because of the restrictions they place upon a free and unhampered competition between dealers in nursery stock in all parts of our country. A greater uniformity in inspection laws seems to me necessary if we are to retain the support and confidence of those whom inspections more immediately concern.

\section{OTHER WORK.}

There are other special developments of our subject upon which one might dwell. We have all been deeply interested in the work being pushed by the cotton-growing States and the Department of Agriculture at Washington with a view to learning how the injuries of the cotton boll weevil may be controlled. Already these investigations have furnished valuable hints in this direction, and we are led to hope and believe that this scourge of the cotton fields will soon be reduced in numbers and destructiveness by measures resulting from the work now in progress.

\section{CONCLUSION.}

In concluding let me say briefly what I consider the important work for the economic entomologist in the near future. In the first place, we must have more capable, enthusiastic, trained teachers of our subject, and the entomologist who is now engaged in such work as a mere makeshift should be made to give place to the teacher who feels the importance of his mission as an educator and is willing to expend labor and thought on his work.

Our nursery inspection laws should be perfected and made more nearly uniform, and a precise method of procedure should be planned for such inspections, subject always to such changes as local conditions may demand.

More attention should be given to the insects concerned with disease, and to their relation to flowers as agents in cross pollenization. Apiculture and sericulture should be cultivated, both because of their instructional value and for their importance in the arts.

The recent progress made in our field of endeavor is most gratifying. We are living in a period of the highest activity and most productive study in the investigation of living things, and may expect soon to see results of knowledge and skill in dealing with such subjects such as have never before been brought together for our benefit. We must not neglect or underrate our opportunities. When it is all done and our time becomes a matter of ancient history, I trust that the part taken by entomologists in contributing to the wealth and learning and culture in this "age of science" may be pointed to by our descendants with gratitude and respect. 
At the conclusion of the president's address the secretary was ordered to extend the thanks of the association to President Garman for his interesting and valuable address, and to send to him greetings of the season and best wishes for his speedy recovery.

Mr. Newell stated that in his opinion entomologists, with but few exceptions, had neglected giving the attention and study to insect problems affecting the public health that the importance of the subject justified. Entomologists have laid great stress upon the importance of their work in combating insects injurious to crops and fruits, and have made many estimates, showing, in dollars and cents, the amount of damage done, yet the public health and human life is of far more importance than the prevention of nere financial loss. The control of yellow fever and of malaria is an entomological problem entirely, yet it has been largely in the hands of physicians; and the medical fraternity, because of the impossibility of obtaining from the entomologists adequate knowledge regarding the life histories of insects instrumental in spreading disease, have themselves been forced to take up entomological and life-history work. The insect problems which are intimately connected with the dissemination of diseases, both of human beings and of live stock, are certainly of sufficient importance to warrant much more attention being paid them by the entomologists. The latter should be able to anticipate, in a measure, the entomological knowledge that is likely to be needed by physicians and should, by study and investigation, prepare themselves to furnish this information when it is needed-oftentimes in dire emergencies, when there is no leisure for investigation and life-history work.

Mr. Britton said that physicians often appear loath to ask information of entomologists. There ought to be an effort made on both sides, however, to get together and work in harmony. It is an important fact that yellow fever may occur in other places than the natural habitats of Stegomyia. In the year 1794, 160 cases occurred in and about New Haven, Conn. It is probable that these originated from mosquitoes brought on a ship from the West Indies. How far north does the Stegomyia occur in the Mississippi Valley?

Mr. Hunter answered that Stegomyia has been found in St. Louis.

At the conclusion of the discussion on the president's address, the report of the secretary-treasurer was read and approved.

An assessment of $\$ 1$ was levied on the members present.

Mr. Herbert Osborn, chairman of the committee on nomenclature, presented the following report: 


\section{REPORT OF COMMITTEE ON NOMENCLATURE.}

At the last annual meeting of the association your committee presented a list of names for adoption as recommended for exclusive use and also a second list for consideration during the year. The secretary distributed them to all members and the first list was also sent to some two hundred agricultural journals and periodicals with the request of the society that these names be used in these publications. With a few exceptions, the names so adopted seem to have been used by all official entomologists, and it is sincerely hoped that the practice may become universal, as it is firmly believed that a uniform practice in the use of the common names of insects will not only favor the distribution of accurate information about insects, but will serve a most useful purpose in the education of the public regarding a subject which appears to them beset with much difficulty. The cordial responses from members is much appreciated by the committee, and it desires simply to state that in a subject where such wide diversity las existed some concessions will be found necessary, and it is hoped that a general agreement on a considerable list of names will eventually lead to a much more universal agreement.

From the list submitted for consideration during the past gear we are now able to select about forty which have been approved by all who have taken the trouble to return their lists with sanction or objections. This list is submitted for the consideration of the Association at this session along with a second list which embraces names quite generally but not universally approved. A general response would help the committee to a more certain conclusion. The lists returned this year were but eighteen in number, but geographically covered the territory from New Hampshire to Hawaii. If we assume that those not answering had no serious objections to the names listed, we may conclude that for quite an extended list we will be able soon to secure general adoption and uniform practice by such a body of entomologists as will make uniformity an assured fact.

Perhaps the greatest diversity now occurs in the matter of hyphenating comround names, and while lack of uniformity in this is certainly much less serious than the use of totally different names, it seems as if some general principle might be adopted which, barring the persistence of printers and proof readers, might secure some degree of uniformity. The greatest number of corrections on the present list consisted in the insertion or the elimination of hyphens, and many entomologists of high repute insisted on exactly opposite practice in a considerable list of names. The committee feels that this matter may be left to the individual taste or to the etymological rule in practice in different printing establishments without sacrificing the main principle for which it is working, but will be pleased to have instruction or expression of opinion from the Association on this point. Some have urged that the committee take up the question of scientific names with the hope that some more uniform and settled practice may result. Doubtless this will follow, but we feel that for this year at least we should concentrate effort on the common names.

We present herewith a list for final adoption and one for further consideration. Unless a name is very generally agreed to, it had better be put on the preferred list and only given final adoption on the exclusive list when general agreement is reached.

The list for further discussion is not to be published, but circulated among members privately. The list printed below includes the names adopted at the seventeenth annual meeting as well as those adopted at the eighteenth: 


\section{List of Names Recomanded for Exclusive Use.}

American cockroach Periplaneta americana $\mathrm{L}$.

American dagger moth Apatela americana Harr.

Angoumois grain-moth sitotroga cerealella $\mathrm{Ol}$.

Apple-leaf skeletonizer Canarsia hammondi Riley.

Apple-aphis Aphis pomi L.

Apple maggot Rhagoletis pomonella Walsh.

Army-worm Heliophila unipuncta Haw.

Ash-gray blister-beetle Macrobasis unicolor Kby.

Asiatic ladybird Chilocorus similis Rossi.

Asparagus beetle Crioceris asparagi $\mathrm{L}$.

Bag-worm Thyridopteryx ephemeraformis Haw.

Bean-weeril Bruchus obtectus Say.

Bedbug Cimex lectularius L.

Black blister-beetle Epicanta permsylicanica De G.

Black scale Saissetia olea Bern.

Blood-sucking cone-nose Conortinus sangnisuga Lec. Boll-weevil Anthonomns grandis Boh.

Boll-wrorm Heliothis obsoleta Fab.

Bronzed cutworm Nephelodes minians Guen.

Brown-tail moth Euproctis chrysorhou L.

Bud-moth Tmetocera ocellana Schiff.

Buffalo tree-hopper Ceresa bubalus Fab.

Cabbage aphis Aphis brassice $\mathrm{L}$.

Cabbage-maggot Pegomya brassica Bouché.

Carpet-beetle Anthrenus scrophulario L.

Carpet-moth Trichophaga tapetzella $\mathrm{L}$.

Cattle-tick Boophilus anmulatus Say.

Cecropia-moth Samia cecropia L.

Cheese skipper Piophila casei L.

Chestnut weevil Balaninus rectus Say.

Chinch-bug. Blissns lencopterns Say.

Clover-hay worm Hypsopygia costalis Fab.

Clover-root borer Hylastimus obscurns Marsham.

Clover-stem borer Languria mozardi Latr.

Codling-moth Carpocapsa pomonclia $\mathrm{L}$.

Colorado potato-beetle Leptinotarsa decemlineata Say.

Corn root aphis Aphis maidi-radicis Forbes.

Cotton-stainer Dystercus suturellus II.-Schf.

Cottony maple-scale Pulvinaria inmumerabilis Rathr.

Cottony cushion-scale Icerya purchasi Mask.

Dingy cutworm Feltia subgothica Haw.

Elm-borer Saperda tridentata Ol.

Fall canker-worm A7sophila pometaria Harr.

Fall web-worm Hyphantria cunea Dru.

Glassy cutworm Hadena devastatrix Brace.

Granary-weevil Calandra granaria L.

Grape leaf-folder Desmia funeralis Hbn.

Grape flea-beetle Haltica chalybea Ill.

Grape-phylloxera Phylloxera vastatrix Planch.

Gypsy-moth Porthetria dispar L.

Harlequin cabbage-bug II urgantia histrionica Hahn.

Hessian-fly IIayetiola destructor Say. 
Hickory borer

Honey-bee

Hop-aphis

Horn-fly

Horse bot-fly

House-fly

Indian-meal moth

Larder-beetle

Leopard-moth

Margined blister-beetle

Mediterranean flour moth

Onion thrips

Oyster-shell scale

Pale-striped flea-beetle

Palmer-worm

Peach-borer

Peach-scale

Fear psylla

Pear-slug

Pea-rveevil

Pigeon-tremex.

Pistol case-bearer

Plum-curculio

Plum-gouger

Potato stalk-borer

Putnam's scale

Rice-weevil

Red-legged locust

Rose-chafer

Rose scale

Saddle-back caterpillar

San Jose scale

Screw-worm

Scurfy scale

Silkworm

Spring canker-worm

Squash-bug

Squash borer

Stalk borer

Strawberry crown-borer

Strawberry leaf-roller

Striped blister-beetle

Tarnished plant-bug

Tomato-worm

Walnut case-bearer

Walnut-sphinx

Wheat-head army-worm

Wheat midge

Yucca-moth

Zebra-caterpillar
Cyllene picta Dru.

Apis mellifera L.

Phorodon humuli Schrank. Homatobia serrata R.-D.

Gastrophilus equi $\mathrm{L}$.

Musca domestica L.

I'lodia interpunctella Hbn. Dermestes lardarius L.

Zeuzera pyrina $\mathrm{L}$.

Epicauta marginata Fab.

Ephestia kuehniella Zell.

Thrips tabaci Lind.

Lepidosaphes $u l m i \mathrm{~L}$. Systena blanda Melsh. Ypsolophus ligulellus Hbn. Sanninoidea exitiosa Say. Eulecanium persice Fab. Psylla pyri L.

Eriocampoides limacina Retz.

Bruchus pisorum L.

Tremex columba $\mathbf{L}$.

Coleophora malivorella Riley. Conotrachelus nenuphar Hbst. Anthonomus scutellaris Lec. Trichobaris trinotatu Say. Aspidiotus ancylus Putn. Calandra oryza L. Melanoplus femur-rubrum De G. Macrodactylus subspinosus Fab. Aulacaspis rosae Bouché. sibine stimulea Clem. Aspidiotus perniciosus Comst. Chrysomyia macellaria Fab. Chionaspis furfura Fitch. Bombyx mori L. Paleacrita vernata Peck. Anasa tristis De G. Melittia satyriniformis Hbn. Papaipema nitela Guen. Tyloderma fragaria Riley. Ancylis comptana Fröhl. Epicauta vittata Fab. Lygus pratensis $\mathbf{L}$. Phlegethontius sexta Joh. Mineola juglandis Le B. Cressonia juglandis S. \& $\mathbf{A}$. Heliophila albilinea Hbn. Contarinia tritici Kby. Pronuba yuccasella Riley. Mánestra picta Harr.

NotE.-The hyphenization in this list differs radically from that in use in tie Bureau of Entomology.-ED. 
The report of the committee was on motion adopted, and the secretary was instructed to have the approved list of names printed and distributed to members. The report of the committee on cooperative testing of insecticides was presented by Mr. Burgess.

\section{REPORT OF COMIITTEE ON COOPERATIVE TESTING OF INSECTICIDES.}

Your committee, appointed at the last meeting of this Association to consider the question of cooperation in testing proprietary insecticides, respectfully submits the following:

It seemed best to the committee as their first step to ascertain how general a desire existed for cooperation in the testing of insecticides. They therefore prepared a circular letter of inquiry on the subject, which was sent to more than fifty persons engaged in economic work in this country. Unfortunately, howerer, circumstances prevented a prompt sending of this letter, and as a consequence the answers are still coming in, and it has not been possible for the committee to go over them and formulate any plan to present at this time. It may be remarked that the answers show about as many different ideas on the subject as there were answers, a condition which will necessitate much more consideration by the committee than would be needed if they were more in agreement. Your committee can, therefore, only make this statement. now and ask either for an extension of time or the appointment of another committee in its place to continue the consicleration of the subject.

On motion, the report was accepted and the committee continued.

Mr. Sanderson brought up the question of the method of publishing the proceedings, regretting that the present method seemed to make it necessary to cut down or eliminate certain papers from the published proceedings. He thought it feasible, if necessary, for the Association to publish its own proceedings. On motion, it was resolved that a committee on publication be appointed to make recommendations before the close of the present meeting regarding the best method of publication. The chair appointed as such committee Messrs. Sanderson, Burgess, and Hunter.

AFTERNOON SESSION, HONDAY, JANTARY 1, 1906.

The Association attended the symposium held under the auspices of Section K of the American Association for the Advancement of Science on "Yellow fever and other insect-borne diseases."

MORNING SESSION, TEESDAY, JANUARY 2, 1906.

The Association met in joint session with Section F of the American Association for the Advancement of Science. Dr. H. B. Ward, vice-president of Section $F$, in calling the meeting to order, said that it seemed to him that the many points of common interest to members of both the Association of Economic Entomologists and Sec- 
tion $F$ were ample warrant for the holding of a joint session. He thought the plan was one that would probably be advisable to continue in the future.

The following two papers, taken from the programme of Section $\mathrm{F}$, were then presented. They will be published in full elsewhere.

\section{THE PROBLEM OF WING ORIGIN AND ITS SIGNIFICANCE IN INSECT PHYLOGENY.}

By Herbert Osborn, Columbus, Ohio.

[To be published elsewhere.]

\section{PRELIMINARY OBSERVATIONS ON THE VARIATIONS OF UTETHEISA VENUSTA DALIMAN.}

By Mel. T. Cook, Santiago de las Tegas, Cuba.

[Abstract.]

The literature recognizes three species ( $U$. bella, $U$. venusta, and $U$.ornatrix) and three varieties (hybrida, terminalis, and stretchii) of this genus. These covel a very wide range. The species and varieties are separated primarily on color characters. After examining a very large number of specimens, many of which were reared in captivity, the writer concludes that the intergradations are such as to reduce these three species and three varieties to one species. The writer has also bred and reared a number of these insects, from the study of which he reaches the same conclusion as indicated above. The work will be continued.

The following paper was presented:

\section{THE CORN ROOT-APHIS AND ITS ATTENDANT ANT.}

(Aphis maidi-radicis Forbes and Lasius niger L., var. americanus Emery.) By S. A. Forbes, Urbana, $17 l$.

Two great dangers threaten the perpetual prosperity of the North American corn belt: one, the gradual exhaustion of some essential element of soil fertility, and the other, the gradual increase of insects especially injurious to the corn crop. Of these two dangers the latter is, I believe, the more immediate and the more difficult to meet.

It is the more immediate, first, because the exhaustion of any ingredient of the soil is a process of subtraction merely, while the increase of insects is a process of multiplication; and, second, because farmers are generally accustomed to return to their farms, in more or 
less appropriate fertilizers, some part at least of the substances which they remove from them in their crops, while they are but little accustomed as yet to shape their farm management or to vary their agricultural practices in a way deliberately to a void insect injuries.

It is the more difficult to meet because each can act for himself in respect to the fertilization of his land, uninfluenced and unharmed by the indifference or ignorance of his neighbor, while the insects bred by any farmer in a community are likely to infest the farms of all, and finally, if continuously ignored, to become generally destructive, like an epidemic of disease. This epidemic condition has, in fact, already been reached in certain considerable neighborhoods of Illinois, and no doubt in other of the corn-growing States as well; neighborhoods measured by hundreds and thousands of acres, where injuries by the corn root-aphis, the corn root-worm, and the common white-grubs have steadily increased until they bid fair to become permanent factors of the situation unless general measures are taken for their control.

The most immediately dangerous of these insects at the present time is the corn root-aphis, which has shown a destructive capacity in recent years easily understood when one knows its life history and ecology. It will be a scandal and a reproach to the American farmer and to the American entomologist if we allow to grow up under our eyes so great and permanent an enemy to corn culture as this insect is capable of becoming, and we ought to raise an earnest roice of warning, instruction, and advice while the difficulty is still local and the insect still controllable.

This aphis was first recognized in 1862 by Walsh, who reported at that time that a farmer at Rock Island. Ill., had discovered, toward the last of May, minute insects in prodigious numbers on the roots of corn in one of his fields, and that they had apparently destroyed from a half to three-quarters of the crop so far as to necessitate replanting. Walsh, visiting the field a fortnight later, obtained many wingless specimens, from which he bred 15 winged females. He noticed many small brown ants among the roots of the corn infested by the aphis, and inferred by analogy an association of the usual form between these two insect species. I first began to study this aphis in 1883, and virtually all the facts now known concerning its life history, ecology, and economic relations have been made out at my office in Illinois by myself and my various assistants.

THE LIFE HISTORY OF THE APHIS.

The life history of the corn root-aphis is in no way peculiar. All the main features of it have been repeatedly published and are doubtless sufficiently familiar to all; and I have to report under this head 
only some minor details made out within the last two years. A highly successful series of breedings made in my insectary by Mr. J. J. Davis, a junior student in my department, working at the time as my assistant, gives us some additional data concerning the rate of multiplication of these insects under what were evidently optimum conditions.

Most of these aphides were reared in small glass vials, each with a layer of moist cotton in the bottom and containing a young food plant. A single aphis just born was placed on each plant, the vial was wrapped with paper to exclude the light, and its mouth was closed with dry cotton. As soon as the plant began to wilt a fresh one was introduced, the aphides being carefully transferred to it by means of a camel's-hair brush. Sometimes a glass tube was placed around a food plant while growing in an earthen pot, the bottom of the tube pushed into the earth and the upper end stopped with cotton as before, the whole being darkened by a paper wrapping. That these artificial conditions were highly favorable to the corn rootaphis was shown by the fact that among several hundred specimens bred and reared in this way not a single one developed wings, although winged aphides were appearing abundantly in the insectary at the time. We have much evidence that the development of winged aphides is greatly stimulated, if not sometimes caused, by some deficiency in conditions for the maintenance of an increasing population-usually by a diminishing food supply.

By the use of these data, together with others already in my possession relating especially to the earliest generations of the year, I am able now to present a virtually complete calendar for this species of the annual succession of its generations, from the so-called stem-mother-the generation which hatches from the egg-to the egg again in fall. Beginning with the first to hatch in the spring, if we follow down the series of the first born of each generation we find that 16 successive generations may appear, counting the eggs laid in the fall as the last. If, on the other hand, we begin with the last to hatch from the eggs in spring and follow down the series of the last born of each generation, there are but 9 generations in all; from which it follows that the number of mid-born generations is 12 the mean number for the year. The average interval between successive generations of the first born is 11 days, that between the successive generations of the mid born is 16 days, and that between generations of the last born is $18 \frac{1}{2}$ days.

The first generation may be found in the field from April 8, our earliest date for the hatching of the eggs, to June 20, our latest date for the birth of the young of the second generation, a period of 73 days. The eighth generation-the longest lived of all, if we except the eggs-continues from July 14 to the last of October, a 
period of 106 days. On the 1st of May aphides of the first tuo generations mar coexist in the field: on the 1st of June, those of the first three generations; on the 1st of July. 5 generations, from the second to the sixth. inclusire: on the 1st of August. 7 generations, from the fourth to the tenth inclusive: on the 1st of September. 9 generations, from the serenth to the fifteenth: and on the 1 st of Cetober. 10 generations. from the serenth to the sixteenth.

The have found eggs hatching in the nests of the small brown ant, Lasius niger americamus, from April $s$ to May 22. a period of 44 days. Our earliest record of the occurrence of the bisexual oriparous generation in fall was September 5, and the latest births of this generation occurred on the 30th of October. A few oriparous females were still living indoors Norember 28. Males and females were first seen pairing September 30, and this is also the earliest date at which eggs have been found.

The oriparous generation does not correspond to any single one of the annual series, but bisexual forms may appear in any generation in existence at the time when conditions are right for their development. In our insectary work of this year sexual forms originated in September and October from representatives of s different generations, varving from the seventh to the eleventh of a series reared in confinement after June 22 . This appearance of the sexes is eridently farored, if not actually produced, by a low temperaturea fact illustrated by the occurrence of sexual forms, September 5 , 1905. when the weather was extremely cool for that time of the vear, the daytime temperature of the insectary usually ranging from $60^{\circ}$ to $66^{\circ} \mathrm{F}$. Te have had two instances of females whose first roung were viviparous and the last oviparous. Another reproductive aberration was exhibited by a viriparous female taken in the field in the pupa stage on the 23d of June. and transferred to the insectary, where within the next few days she gare birth to 6 roung previous to her final molt. She then suspended reproductive operations for a few dars. molted and acquired wings. and afterwards produced 21 more roung.

The number of molts is invariably four, and reproduction follows sometimes within a few hours of the last molt, and usually by the next day. In 36 instances. of which exact record was kept. the number of living young varied from 20 to 4 for each female. with an arerage of 41 . Any one disposed to calculate the theoretical reproductive capacity of this species can easily do so from the data given-12 mean generations and a multiplication ratio of 41.

such a calculation is. of cour'se. worthless for any scientific end, because it involves a phrsical impossibility-that is. the maintenance of optimum conditions for all the progeny of a single female the whole season through. It is conceivable, howerer, if not believable, 
that optimum conditions might continue in an occasional instance for as much as three successive generation periods, and it may help us to understand the facts sometimes observed if we know that the product of reproduction for these three generations under such conditions would amount to about 66,000 descendants for each female.

The average number of young produced in our experiments by a single female in a single day was 4 , and the largest number was 12 . The time elapsing from the birth of the female to the birth of her first young varies from 21 days in early spring to 6 days in August. For a series of 10 generations, beginning June 23 and ending with the appearance of the sexual oviparous generation in fall, the average age of the female at the birth of her first young was 7.8 days, at the birth of her last young it was 16 days, and the female may live from 1 to 6 days longer. The average total life period of a viviparous female was about 24 days, although 30 to 35 days is not unusual. The oviparous generation is rather longer lived, the average for 15 individuals being 26 days, with a maximum of 61 . Life is longer, growth is slower, and reproduction more deliberate in the cooler parts of the season, both spring and fall, than in the warmer. An aphis isolated September 18 began to reproduce in 11 days, brought forth young-56 in all-for 31 days, and died November 7 at the good old age of 51 .

THE A'TTENDAN'T ANT.

The absolute dependence of the corn root-aphis upon its attendant ants is doubtless well understood. It is almost invariably found in charge of that most abundant of all American ants, Lasius niger americanus, the commonest ant of pastures, meadows, and cornfields throughout the greater part of the United States. The life history of this ant was fairly well given by me in the eighteenth report of the State entomologist of Illinois.

It hibernates underground in the fields in comparatively small colonies of workers, 50 to 200 or more in each, often with larvæ of various sizes and sometimes with eggs. A queen will occasionally be found among the hibernating workers, although eggs are sometimes laid by isolated queens for new colonies in fall. The queen seems sometimes to spend the winter entirely alone or else to leave the old colony very early in spring. April 7 of this year, for example, a queen ant was found in a cornfield in her cell, alone, with neither eggs nor aphides near her. Pupation begins during the latter part of May in central Illinois, and winged sexual forms, male and female, begin to emerge about a month later and continue to appear from time to time at least until October.

$31024-$ No. $60-06$ MI- 3 
A single colony of worker ants may extend its burrows in the cornfield under an area 3 or 4 feet in diameter and to depths usually rarying from 1 to 4 or 5 inches, but the deeper chambers are sometimes 6 or 7 inches below the surface. During a summer drought the ants may bury themselves a foot or more, piling up in sluggish heaps in the deeper chambers of their nests.

These ants are thoroughly deroted to the root aphides in their charge. although not wholly dependent on them for food. In ant nests without aphides we have sometimes found the débris of various insect bodies-larræ. beetles, and the like-and in one case a common white grub. Tre have also seen this ant eating an earth worm.

Until this year I have never known it to injure directly the corn plants, among whose roots it mines so diligently, but late last May my attention was called to a field near Champaign. Ill., hearily infested by these ants, which were present in unusually large colonies, and in nearly all cases with no root aphides in charge. Some 4.000 ants in 24 colonies had less than a hundred aphides among them-less than 1 aphis to every to ants. Forty to 50 per cent of the hills of this corn were suffering seriously. because the softened kernels had been eaten out by the ants while the plant was still too small to feed sufficiently by the roots. This field was in oats last year, in corn in 1903, and a meadow in 1902 .

RELATIONS OF ANT AND APHIS.

The relations between the aphides and the ants are so intimate and important that the numbers of the aphis are strictly limited br the numbers. activities, and industry of the ants. That the latter are fully equal to their usual opportunities is shown by the fact that through the spring months a large proportion of the burrows which they have excarated in the fields are without aphides. being eridently prepared in adrance of the existing supply. It is only toward the middle of the summer that one will find, as a rule, erery ant colony with its aphis family in charge.

The care taken of the aphides by the ants is well illustrated by a number of incidents reported to me by one of my assistants. Mr. E. O. G. Kelly, from among his observations in the field last spring. April 12, for example. he watched for two hours and a half an ant nest, near which a few small smartweed plants were growing. An ant coming up with a young aphis in its mandibles, carried this about 2 feet and placed it on a smartweed near the ground. Within the next 20 minutes, six more ants transferred each a single aphis from their nderground burrows to smartweeds abore ground. In about an hour and a half one of the ants returned for its aphis and took it to the nest. and 35 minutes later all had been carried back. One of these ants, which was so marked that it could be recognized on its return, 
carried to the nest the same aphis which it had previously brought out. It was a common thing also to see ants transfer young aphides from the roots of sapped and withered plants to those still young and fresh. May 5, 10 aphides were taken from a smartweed root and placed on the bare ground. They crawled actively about, and 2 of them entered a crack in the earth as if to escape the light. One of these was found by an ant, which carried it away. Two small ones crawled about 4 feet and stopped as if exhausted, but 2 larger aphides traveled more than 10 feet in an hour and twenty minutes without finding any food plant. All were seemingly averse to the light, and crawled away from the sun.

Once a corn root-aphis taken from a plant and placed on the ground was found by an ant and carried away to a distance of 4 feet. It was then left to itself while its attendant ant dug down to the roots of a plant of foxtail grass (Setaria), when the aphis was seized and carried into the burrow, where it was afterwards found by digging, contentedly sucking sap from the root.

Ants often take possession of young aphides as fast as they are born and carry them to new plants, and they are similarly interested whenever oviparous females are producing eggs. Curiously, they pay no especial attention to these females themselves, although the eggs are snatched up and carried away as fast as they appear. They value highly the golden eggs, but take no care of the geese.

\section{INJURY TO CORN.}

What this pair of associate pests may do to a corn crop is well shown by conditions found this year in a field of corn in Ford County, in central Illinois - a great corn year, in a great corn county, in the midst of the great corn belt. This 20-acre field, in corn for only the second year, and in oats two years ago, had been evidently infested the whole season through by the corn root-aphis and by nothing else. Immediately beside it was another field, the first year in corn, and virtually free from noticeable insect injury. For an exact exhibit of the consequences of the aphis infestation careful comparison was made in September of the condition and yield of 2,000 hills, taken at random from each of these two fields. In the infested field 23 per cent of the hills were vacant - that is, wholly without plants-and another 21 per cent contained only small dead stalks44 per cent of the hills either vacant or dead. In the other field 5 per cent of the hills were vacant and none were dead. In the infested field the plants varied from 6 inches to 6 feet in height and numbered 125 per hundred hills. In the uninfested field the corn ranged from 6 feet to 8 feet in height, with 216 stalks per hundred hills. In the infested field only 4 per cent of the stalks bore ears, and in the uninfested field only 4 per cent of the stalks were barren. 
In the uninfested field 2,000 hills bore 4,024 ears, 201 of which were small; in the infested field 2,000 hills yielded a total crop of 95 ears, all nubbins. Sixty-eight per cent of the hills in the first field were still infested by ants and $6 r$ per cent by aphides, while 69 per cent of the vacant hills, in which the corn had died, still showed by the presence of old ant burrows, now deserted, the cause of their deatl. In brief, the one field yielded an excellent crop of corn and the other was wholly ruined by the root-aphis alone, yielding neither fodder nor grain worth taking into account.

This was no isolated instance; it was simply a strongly marked example of aphis injury in that neighborhood, wherever corn had grown on the same ground for so little as two years in succession. The corn root-aphis has simply become epiclemic there. Winged females swarm out of the older fields in late spring and early summer in such overwhelming numbers that any field is likely to be injured by them and to become so hearily infested that aphis eggs enough will be left in the ground in fall to work the complete destruction of the crop the following year if the ground is planted to corn. One year at a time in corn is about the limit under such conditions. Whether even so prompt rotation as that would hold this ant-aphis pest permanently in check will appear from what I shall presently have to say concerning the fate of the aphis if the ground containing its eggs is planted to some other crop than corn.

Furthermore, I regret to say that this Ford County neighborhood is only one of several known to me in various parts of Illinois which are similarly injured and endangered. It is because the conditions here described may become established anywhere that corn is made continuously the leading crop that I have thought my topic an especially appropriate one for this general meeting of the American economic entomologists.

\section{NATURAI ${ }_{2}$ CHECKS ON INCREASE.}

The possibilities of serious permanent injury to corn culture by the root-aphis are greatly increased by the fact that these subterranean aphides, while in no way inferior in reproductive capacity to species of aerial habit, are not nearly so subject to rapid wholesale destruction by rains, or by parasites and other insect enemies. Long-continued or oft-repeated rains sometimes retard their multiplication, it is true, and may even reduce their numbers somewhat, but no changes of weather have any such effect on them as on the grain aphides, for example. While the corn leaf-aphis (Aphis maidis Fitch) is enormously parasitized, and is commonly attacked by the usual kinds of aphidivorous insects, Aphis maidi-radicis is never parasitized, so far as I know, and it is but little subject to destruction by other insects underground. 
An exception should, perhaps, be made to this last statement with respect to the aphis ant itself. The mysterious disappearance last May of all the ant and aphis population of a 20 -acre field of oats in which the food plants of the aphis had nearly all been killed led me to experiment with ants and aphides kept in confinement under starvation conditions. A colony of ants, well established in an artificial nest of the kind devised by Miss Adele M. Fielde, were given a group of aphides on a fresh corn plant. This was then allowed gradually to dry up until it no longer afforded food to the aphides, and these, of course, soon ceased in turn to make their usual offerings to the attendant ant. Seeming to despair, at length, of making any further use of their aphide protegés, the ants finally ate them up, and continued so to do with all the fresh ones given them.

I strongly suspect that the same thing happens sometimes in the field, and that, when the food plants of an aphis family fail them and no more can be readily found, their masters and owners-for such their ant attendants really are-do the best thing possible under these hard conditions and convert their milch cows into beef.

\section{PRACTICAL ECONOMIC MEASURES.}

The most obvious means of lessening or preventing injury by this insect is a rapid rotation of crops, leaving no land in corn more than a single year; but this measure is very inadequate, because, however the field is finally cropped, it will at first spring up to smartweed and pigeon grass and other common weeds, on the roots of which the aphides live and breed abundantly until, say, the latter part of May. Then if the field is sown to oats, the shading and sapping of the ground by the crop plant will dwarf the weeds and thus reduce the food supply of the aphides. One important consequence is shown by a comparative observation made last May on the composition of the aphide colonies in hills of corn, as related to the density of the aphide population. Fifty considerably infested hills contained an average of 105 aphides to a hill, and 225 lightly infested hills contained an average of 5 aphides to a hill. In the lightly infested hills 21 per cent of the adults were winged, or were pupa about to acquire wings, while in the worst infested hills the winged and pupx amounted to 64 per cent of the adults. That is, as the food supply fails the aphides escape starvation, in great measure, by getting wings and flying away. Many of these winged migrants doubtless perish, but many of them are found by the ants, which are mining everywhere as if in preparation for their advent; and whenever one is found a new family presently appears on a newly-infested plant, and, inultiplying at that time at a rate of to to 1 for every week, a fresh start is soon made and the game goes merrily on. The effect of rotation is thus a merely temporary check on increase, followed by a wider 
and more rapid distribution of the attack on corn. We must evidently find something better than this, or something additional to it, at least, if we would get an effective control of this dangerous pest.

Treatment of the seed with kerosene or turpentine before planting completely protects the young plant for several weeks, the odor of shese substances persisting in the ground for a surprising time, but infortunately this treatment often seriously injures the young corn itself-just why and nnder what conditions I have thus far been entirely unable to make out. At any rate, the results are so uncertain and so unaccountable that I think the method much too dangerous for general use.

Much the most promising and successfully preventive method is such a management of the soil, in fall or winter or early spring, as to break up and scatter the nests of the ant and to disperse their contents-the ants and their young and the aphides and their eggsagain and again through the dirt, destroying, at the same time, the young vegetation as fast as it springs up. Thus ants and aphides may be starved together, or, at the worst, the ant may escape from the fields, leaving the scattered and buried aphides behind to perish.

As a test of this method, I carried on various experiments in the spring of $190 t$ and 1905 in several selected localities in different parts of Illinois, giving to a part of each infested field the usual spring treatment as a preparation for corn, 'and giving to the remainder a special additional treatment which stirred the earth deeply and repeatedly and mixed it up thoroughly in the interval between the earliest date for plowing and the usual time for planting corn. These experiments may be summed up by saying that three times disking of a badly infested field, previous to planting late in May, reduced the ants and the aphides in the field by something over 92 per cent, and the number of hills infested by each by 64 per cent for the ants and 82 per cent for the aphides. Disking twice in succession reduced the number of insects by 65 per cent for the ants and 84 per cent for the aphides, and the number of hills infested by each by 59 per cent and 75 per cent, respectively. The most remarkable effect was got by lisking once as soon as practicable after a heary beating rain. This reduced both ants and aphides by 90 per cent in the number of insects and by approximately 60 per cent in the number of hills infested.

\section{A PREVENTIVE ROUTINE.}

The general practical outcome of these observations and experiments may best be given in the form of an agricultural routine for the corn farmer whose crop is liable to injury by the corn root-aphis, either because it is grown on land previously infested by that insect or because of a general abundance of the aphis in his neighborhood. Rapid rotation with an especially short period in corn, limited as a 
rule to a single year; early, deep, and thorough preparation of the soil for corn, with a diligent use of the disk harrow after the ground is plowed, and general measures for the maintenance and increase of soil fertility, are the chief features of this routine. It is better that the land should lie a day or two between successive diskings, and careful advantage should be taken of cold, beating rains to disk the land as soon thereafter as it is fit to work. If to this we add early and continuous cultivation of the crop, as deep in the beginning as the corn will stand, and if we further advise that corn should never, in any event, be grown on land known to have been infested by this insect the year before, wo shall have done all that our present knowledge of this aphis and its attendant ant will warrant.

It is of course also to be understood that each farmer has in his hands, in considerable measure, the interests of his neighborhood, and that no man should be permitted to raise on his own land, by reason of his negligence, insects which will spread to the property of others to their serious injury. The moral and legal principles whose growing recognition we owe to the introduction and spread of the San Jose scale apply just as forcibly to the insect and fungous pests of general agriculture, and some day, I do not doubt, they will be just as thoroughly enforced.

Mr. Burgess asked when, in the case of the field culture experiments, the counts of aphides remaining alive were made. Mr. Forbes answered, as soon after the experiment as it was believed that the ants and aphides had established themselves; usually this was in about a week, but it was sometimes delayed by bad weather.

Mr. Morgan asked if any relation had been discovered between the rate of multiplication of the aphis and the vitality of the corn plants, as influenced by soil or climatic conditions.

Mr. Forbes answered that no experiments had so far been made for this purpose, but that some were planned.

Mr. Morgan said that he had observed that whenever cool nights come on, lowering the vitality of the plant, the common cotton aphis is more abundant.

Mr. Quaintance had observed that they were more abundant during late spring and also in early fall than during the summer.

Mr. Morgan observed further that in new fields cotton was little iffected, but on worn-out ground aphides were abundant. Had this been observed in relation to the corn root-aphis in Illinois corn lands?

Mr. Forbes replied that in that part of Illinois in which the corn root-aphis is abundant it is difficult to find worn-out corn land, and that the condition referred to had not been observed. 
Mr. Sanborn asked what relation the migratory form of this aphis has to the infestation of new fields. If it is necessary for the aphis to be cared for by ants, it would seem as if the chance of its being found when migrating into a new field would be slight.

Mr. Forbes said that ants are such great explorers that the chance was not so small as might appear.

Mr. Sanborn asked how far the aphis flew.

Mr. Forbes said that he did not know exactly; it depended on the strength of the wind.

Mr. Webster stated that Professor Sajö had called attention to the fact that many insects like the aphides would climb to some elerated object, like a stem of grass, and deliberately give themselves to the wind to be carried away by it, perhaps for long distances. He had himself observed that the ants seemed to be always on the watch for the aphis in the cornfields. Thile he was familiar with the experiments and results obtained by Doctor Forbes, he would like rery much to see how they would work out in the hilly country of the South. The corn root-aphis had during the past summer been reported as very injurious in some parts of Virginia. where farmers did not seem at all familiar with it, and he wondered if these cultural methods would apply there as well as in the prairie country of Illinois. He had many times noted that where a field previously in corn had been plowed in spring and sown to oats there would be an occasional ear missed at husking that when plowed under would send up a cluster of young plants, and the roots of these would be infested by the root-aphides, attended by ants. He expressed the hope that Doctor Forbes would experiment with fertilizing ground with barnyard manure as a possible repellent, as he had observed that in portions of fields where this manure had been applied before plowing there were fewer root-aphides.

Mr. Osborn called attention to the fact that since the aphis can not exist without the ant, we have here a condition in some ways analogous to parasitism.

Mr. Sanderson called attention to the fact that in the case of the strawberry root-aphis (Aphis forbesii Weed) the eggs are laid rpon the stems and foliage of the plant and are not cared for by the ants, but that the ants are entirely responsible for carrying the aphides down upon the roots of the plants in the spring, for tumneling around the roots of the plants, and very largely for carrying the aphides from plant to plant and thus spreading the pest. This would seem to be a transitional stage in the care of aphides given by ants from that given the aerial species to that afforded the corn root-aphis. What is the percentage of migrants to wingless insects in the corn rootaphis? 
Mr. Forbes replied that it varies too much to be expressed in averages. The migrants, however, seem to be more abundant in the earlier generations.

In the absence of the author, the following paper was read by $\mathrm{Mr}$. Osborn :

\section{OBSERVATIONS UPON THE MIGRATING, FEEDING, AND NESTING HABITS OF THE FALL WEBWORM (HYPHANTRIA CUNEA DRU.).}

By E. W. Rerger, Ph. D. (J. H. U.), Columbus, Ohio.

The majority of the observations upon which this paper is based were made at Cedar Point, Sandusky, Ohio, during the past summer, while I was at the Lake Laboratory of the Ohio State University. The webs of the fall webworm were abundant on all sides, and those who had spent preceding summers at Cedar Point were under the impression that the webworm was on the increase. After a few days of casual observation it was decided to make a more careful study of its habits and to determine if it is double brooded at that place. While a few specimens pupated in the laboratory during the latter part of July, none of them transformed into adults, and no positive results were obtained in regard to a possible second brood. Acknowledgment is due Prof. Herbert Osborn for his interest and for his generosity in placing valuable suggestions and facilities at my command.

FOOD PLANTS.

The worms were observed upon the following plants: Walnut (Juglans nigra), choke-cherry (Prunus virginiana), common wild black cherry (Prunus serotina), willow (Salix sp.), elm (Ulmus americana), boxwood (Cornus sp.), hackberry (Celtis occidentalis), and wild grape (Vitis vilpina). The webs were abundant everywhere upon the choke-cherry (Pl. I, fig. 2) and the common wild black cherry, some trees of the latter having nearly one-half of their foliage destroyed. Willows were also nearly always populated with a few or many broods. The few walnut trees (Pl. I, fig. 1) present were literally defoliated, and these will be the subject of the next topic. Elm, boxwood, and hackberry were frequently infested, but never to the same extent as the previously named trees. In only two instances did I observe the webworm feeding upon the wild grape, and then only when the grape leaves grew among the leaves of willow and choke-cherry. I did not observe a single instance of the worms feeding upon the poplars at the Point. This is quite at variance with previous observations. In Riley's bulletin upon the web- 
worm in Washington in 1886, ${ }^{a}$ Populus balsamifera and P. tremuloides are named among the trees that suffered most. Both these poplar's occur at Cedar Point, but no webs were observed upon them.

Following I give the first five trees named in Riley's list. 'These are arranged in the order of the damage done:

Acer negundo (box elder).

Populus alba (European white poplar).

Populus deltoides (cottonwood).

Popnlns balsamifera (balsam poplar).

Populus tremuloides (American aspen).

The same report further states that poplars, cottonwoods, and the ranker growing willows were the principal subjects of attack in 1886 in New England.

Of the species of trees attacked at Cedar Point, four (walnut, wild black cherry, choke-cherry, and willow) appeared to be the farorite food plants of the worms, and these are, respectively, 41 (Prmms serotina is not named by Riley), 75 , and 14 in Riley's list of 108 fool plants. In the Yearbook of the Department of Agriculture for 1895, 120 is given as the number of food plants lister. Again, of all the species of food plants named by Riley, 42 genera and about 26 species are represented at Cedar Point, but of these only 8 were observed to be used as food by the worms.

Thronghout the State generally, so far as my limited observations extend, and from a few other reports, the common wild black cherry (I'muns serotina) is the tree most generally attacked; but walnut, eln, hickory, pear, apple, sugar maple, and silver maple suffer more or less. Walnut trees when attacked suffer most, as the following topic will show; and $\mathrm{Mr}$. Cotton, assistant inspector of nurseries and orchards, has informed me of similar conditions near Cadiz, Harrison County, Ohio.

The following observation is interesting and shows how capable the female is in the selection of a farorite food plant upon which to lay her eggs. One day I observed a web upon a hedge of Osage orange. Closer investigation revealed the fact that the web was not properly upon the Osage orange at all, but upon a small wild cherry that grew there and which had escaped my notice. E. D. Sanderson ${ }^{b}$ refer's to the webworm as being particularly fond of a neglected Osage-orange or wild-cherry hedge. I have repeatedly observed it this last summer upon wild-cherry trees that grew along an Osageorange hedge, but I do not recall seeing it upon the Osage orange itself. Professor Osborn ${ }^{c}$ states that he observed the webrorm

a Our Shade Trees and Their Insect Defoliators, Bul. 10, Div. Ent., U. S. Dept. Agric.

${ }^{b}$ Bul. No. 56. Del. Agric. Exp. Sta., June, 1902.

$c$ Insects Affecting Forest Trees. Proc. Columbus Hort. Soc., vol. 17, 1902. 
specially abundant in that year upon the elm. These and the several facts previously noted in regard to the favorite food plants of the worms seem to indicate that the food plants vary from year to year and perhaps from place to place. It has been suggested that there may be several varieties of the worm, but at present $I$ can do no more than call attention to the facts.

ON WALNUT.

There are only a few walnut trees at the Point, but the worms played havoc with these; while of all the great abundance of chokecherry only two instances were noted where the infestation was at all similar and so extensive. A clump of five wahnut trees (Pl. I, fig. 1), each about 6 inches in diameter, became literally defoliated and about 150 nests were counted upon them. I have observed, howerer, that the number of nests does not necessarily indicate the number of broods, since a large brood may desert its web, divide, and each division form new nests. (See Other Observations.) When food becane scarce the worms began to migrate down the trunks of the trees and over the ground, here and there covering the limbs and trunks, and also the ground about the trees, with web. This "migration occurred chiefly at night, when the worms literally covered the ground for a radius of several feet about the trees, and all was activity. The migrating worms generally rested, as is customary for them, during the day. In this case they mainly rested in temporary webs often located at the base of the trees. Many of these webs were of extraordinary size and composed of a number of sucessive sheets of silk arranged parallel with their plane surfaces and about one-fourth inch apart. In this way the capacity of a web was greatly increased, and I estimated that one of the largest contained not less than 2 quarts of the worms.

The worms migrated nuanly eastward to a clump of choke-cherry bushes close by and westward to a large hackberry tree about 40 feet distant. Some webs of migrants were also found in two other hackberry trees about 50 and 100 feet, respectively, to the southwest and northwest. The migration extended over a period of about ten days, from August 1 to August 10. In four days the number of nests in the chokecherry bushes increased from 6 to 25 , and the worms literally stripped the bushes as they advanced. There were only a few native broods upon the choke-cherry bushes. I could always distinguish these from migrants by the presence of dried leaves in the nest, there being none of these in the nests of migrants. Then, again, a nest of migrants almost always contains worms of vąrious sizes. The absence of dried leaves, together with the presence of worms of several different sizes, I consider to be a very good test for distinguishing a migrant nest from a native nest. The advance 
into the choke-cherry bushes (Pl. I, fig. 2) was quite comparable to the exit from the walnut trees. The worms first built large nests at the base of the bushes, with considerable web upon the ground, and then adranced upward from night to night. Many of these nests were of the kind described above-that is, composed of parallel sheets of silk.

The migration to the hackberry was not so striking as that to the choke-cherry bushes, but was eren more interesting. At first the worms congregated in temporary webs in the crotches of the larger limbs, but they gradually advanced upward from day to day and built webs in the smaller branches. I first observed the worms traveling up the hackberry tree at $5 \mathrm{p}$. m. of August 3. I found a few worms climbing up the large tree and two webs with worms in the first and second large crotches about 7 and 10 feet abore ground, respectively. There were also a few worms climbing up one of the main ascending limbs about 20 feet above ground. There was no web spun about the base of the tree, but the caterpillars obserred 20 feet above ground had some web spun upon the limb. This latter web, as also the number of worms within it, increased from day to day until it extended about 8 feet in length and surrounded the greater part of the limb. which was perhaps 7 inches in diameter and free from smaller limbs. This web was apparently not a resting place, but mainly a route of trarel, for the worms seemed to be more or less on the move all the time. The webs in the crotches mentioned, I decided, were resting places for the worms during the day. I think there can be no doubt that the worms in the hackberry came from the walnut trees. Worms were observed upon the ground in the early forenoon headed toward the tree. Again, there were no webs with dead leares in them; in fact, the tree showed no evidence whaterer of having been previously infested, and the worms were of several different sizes.

The next day-August 4-I observed nests upon limbs farther up in the hackberry and fewer caterpillars in the nests in the crotches. I also noticed nests in the very top of the tree among the leares, which showed evidence of being stripped. Four days later-August 8-the number of worms in the lower nests (in the crotches) was rapidly decreasing, while there were more nests in the top of the tree, which could now be seen from the outside and at some distance. I few worms were seen climbing up the trunk, and a few could still be found in the webs upon the walnut trees. This was also the situation upon the following two days, when I left the Point.

The condition upon the other hackberry trees mentioned, 50 and 100 feet southwest and northeast. respectively, from the walnut trees, was quite comparable to that already described. In the southernmost of the trees just mentioned I observed only a few webs. but all the in- 


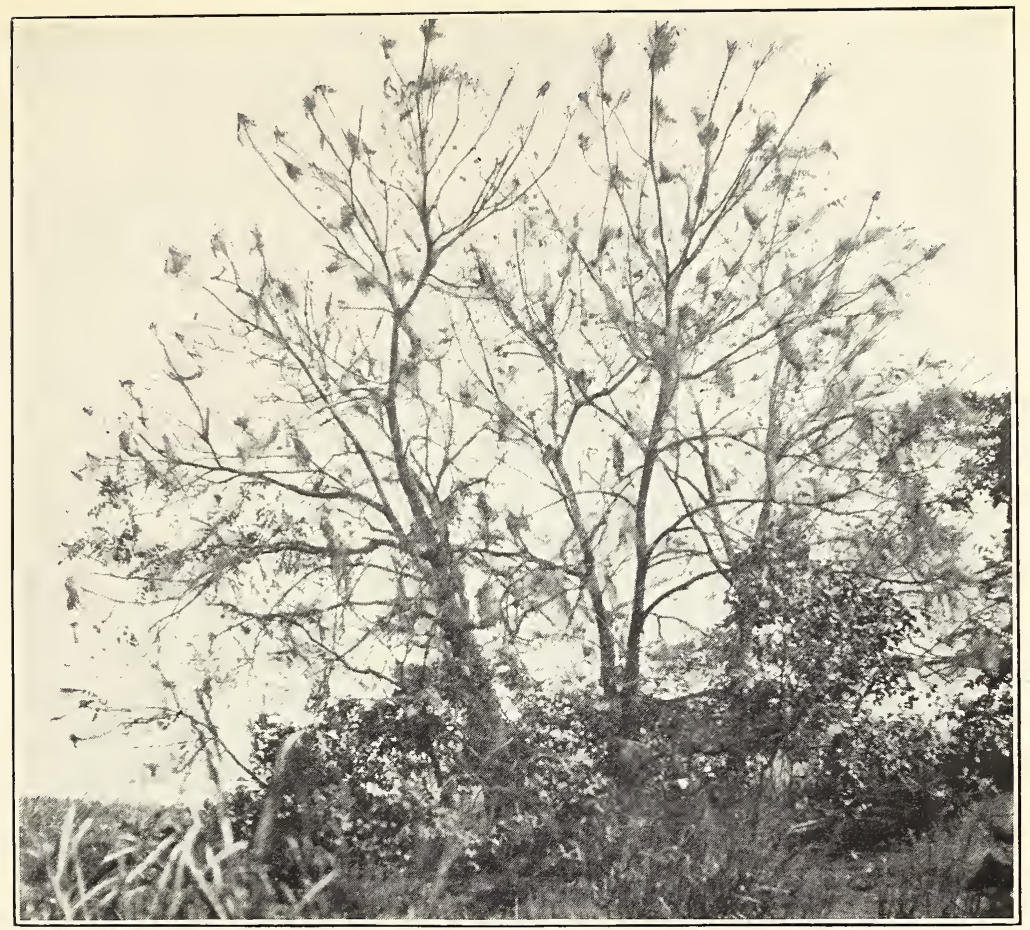

Fig. 1.-Walnut Trees Infested by the fall Webworm.

View looking north, Lake Erie in background; Cedar Point, Sandusky, Ohio. From photograph by Prof. H. Osborn.

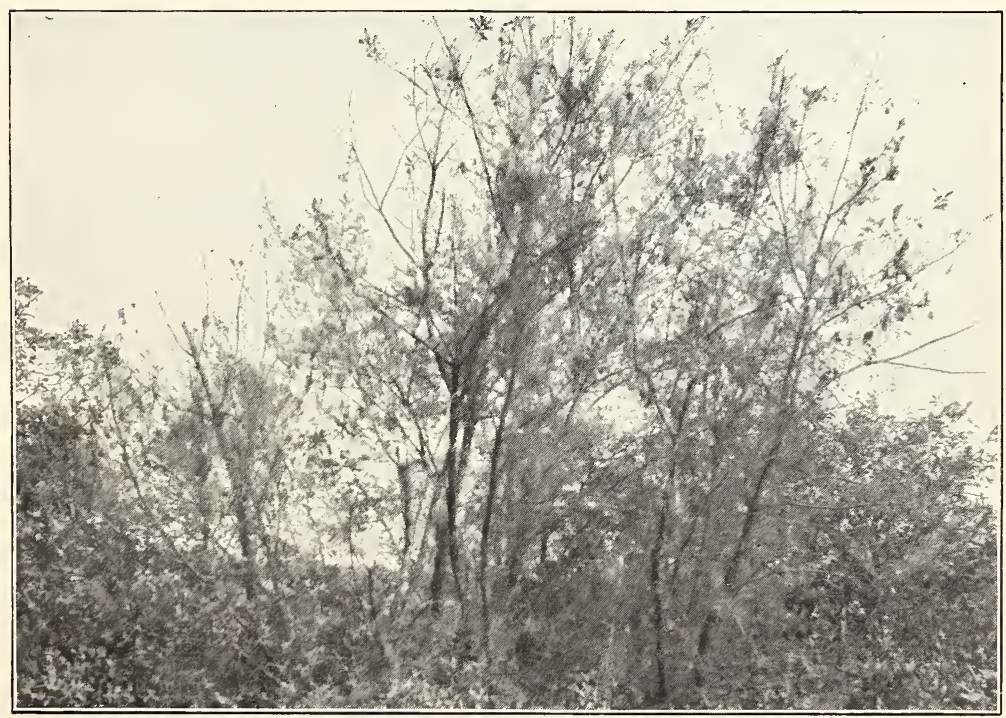

FIG. 2.-CHOKE-CHERRY BUSHES BadLy Defoliated By FALL WEBWorm. Cedar Point, Sandusky, Ohio. From photograph by Prof. H. Osborn. 

dications were that these came from the walnuts. Upon the northernmost one I found five nests in the forks of the tree, with a few other webs quite at the top. This was on August 8 and only two days before the termination of my observations. All the indications were that these were migrants, and I concluded that they came from the walnut trees, because there were no other infested trees near; in fact, no trees of any kind nearer than the walnuts. This fact is interesting, because the worms had to travel not less than 100 feet.

Mr. W. B. Herms, who remained at the laboratory until August 31, was kind enough to observe the worms for me after my departure, and reported that they advanced only a little farther east into the choke-cherry bushes and became fewer in numbers, evidently having wandered off in search for a place to pupate. The trees began to show new life, and by the time Mr. Herms left were quite green again. Riley, in his report, previously mentioned, states that many of the trees even began to flower.

A small hop-tree (Ptelea trifoliata) immediately under the webs in the walnut trees was injured but little, the worms evidently having a decided aversion to it. At one time a small web was spun in it, and some worms were wandering about, but they all soon deserted it.

In the early part of the forenoon I usually found some stragglers upon the ground, evidently en route from the walnut trees, and which had been overtaken by daylight. These were found 10 to 30 feet from the walnuts and invariably headed away from these. The majority traveled eastward to the cherry trees and westward to the hackberry trees. Some, however, were wandering to all points of the compass, the smaller number to the north and the south. To the south was a plot of bare sand, and to the north also sand, but with more grass and no trees. The routes to the east, west, northwest, and southwest were more shaded. I should add, perhaps, that the soil here, as everywhere at Cedar Point, is lake sand, and seldom more than sparingly covered with wild grass. Upon none of the stragglers observed did I discover a trailing thread of silk; in fact, I found but little silk anywhere along the lines of travel except to the east, where the choke-cherry bushes were only a few feet from the walnut trees. I found many dead worms along the line of travel, some plump and fresh, others dried up. Many were found in little pits the size of an ordinary heel. It occurred to me that these worms had died from the heat, since all the lines of travel were exposed, more or less, to the sun's rays during some part of the day. Again, the majority of the dead worms were found to the south, where the sun was hottest. To test my surmise that the dead worms upon the ground died from excessive heat, I placed three in a small pit of the size mentioned. They labored incessantly in an effort to get out, and all died within ten to twenty minutes (one in ten, one in fifteen, and one in twenty). 
As the great majority of the worms traveled eastward to the chokecherry bushes and westward to the hackberry tree. it seems plausible to assume that the worms have some sense of direction. probably being guided by the proximity of the trees to which they migrated. But I do not think that they have the "keen sense to guide " them which Riley states to have been the case for the worms in Tashington. Judging by my obserrations upon the stragglers, namely, that they wandered rery much in all directions from the cherry trees, and would wander 10 and 100 feet when there were plenty of food plants (choke-cherry) within 10 or 15 feet, it appears to me that the caterpillars wander rery much at random. depending upon chance to find some other food plant. In fact. it seems to be rery much of a " cut and try " method. In abundance there probably was a straggler for about every 5 feet of ground surface. In the afternoon I found very few of them.

One may contrast the infestation of a tree by migrants with the normal infestation from eggs by stating that in the former case it is centrifugal and in the latter centripetal. Then it is centrifugal the migrants trarel from the trunk to the larger limbs and then to the smaller ones, building their webs on the limbs or in the crotches. From these webs they go out to the leares to feed. Then infestation is centripetal eggs are laid upon some of the outermost leares, from which the larræ then work toward the center of the tree, eventually trareling down its trunk, provided their number is so great that they require more food than the tree furnishes.

FEEDING HABITS.

MY observations in this direction clearly show that the worms feed but little. if at all, during the day. At night they leare the nests, or thicker parts of the webs, and more about freely upon the leares in the thinner parts or those bordering the rebs. To determine the periods of feeding I made observation at all hours of the day, but rarely found any but young broods, below the second moult, busy feeding. The few exceptions to this rule were several broods lined up to feed at about $11 \mathrm{a} . \mathrm{m}$. on a rainy day and now and then a colony in some shady place.

At night this is altogether different. With the beginning of darkness the worms break camp and move out upon the leares. even to the extent of 2 feet and farther from the nest, to feed. Then they may leave the web altogether and feed unprotected except by the darkness. without even a thread of silk to cover them. ${ }^{a}$ This observa-

a There may have been a fiber of silk connecting the worms with their web, although I have no observations on this point. It is generally understood, howerer, that such is the case. 
tion I believe distinctly indicates that the webs serve mainly for protection from enemies during the day.

I found the caterpillars during July breaking camp at about 7.15 p. n., and by 7.30 they were feeding; at $10 \mathrm{p}$. m. and at $3 \mathrm{a} . \mathrm{m}$. also they were feeding, there being only a few individuals, evidently getting ready to molt, in the nests; at 4 a. m., daybreak found them homeward bound. Younger broods, below the second moult, were observed to be slower in coming home. Only one observation was made at $3 \mathrm{a} . \mathrm{m}$. and two at $4 \mathrm{a} . \mathrm{m}$.; between 7 and $10 \mathrm{p}$. m. frequent observations were made. ${ }^{a}$

The black-billed cuckoo was seen feeding upon the worns at different times. Dr. William E. Kellicott, whose work gave him opportunity to observe the contents of toads' stomachs, kindly consented to make special note of these, in order to determine to what extent the toads at the Point feed upon the webworm. His observations are wholly negative, however, probably because he never used the toads until about twelve hours after collecting, when nothing but the harder parts of beetles, crickets, grasshoppers, and the like could be identified. He expresses doubt that the toads feed much upon the caterpillars. Riley's bulletin states that the toads fed freely upon the worms.

\section{GROWTH AND MOLTING.}

A brood of small worms, which I judged could not be over a few lays old, was transferred to another cherry tree more favorably located for observation. The twig upon which they lived was cut off and tied to a branch in the new location. It was only after several days that the caterpillars migrated to fresh leaves, the old ones in the meantime having become quite dry. They did not seem to thrive after that, and during 22 days, the time that they were under observation, they grew but little, if any, in length, as shown by actual measurement. They began to molt in 12 days from the time that they were first observed. Thus it appears that their first molt occurs 12 or 15 days after hatching. Another slightly older brood (on some willows), which measured one-fourth inch (6.25 $\mathrm{mm}$.) in length measured one-half inch $(12.5 \mathrm{~mm}$.) after 22 days, having thus grown one-fourth inch in that time. This brood became mixed with an older brood with which it went to live, so that nothing in regard to its molting could be determined. Another

$a_{\mathbf{I}}$ tried to corroborate these conclusions upon feeding by an examination of the digestive tracts of specimens collected at different times of the day. Thus I dissected specimens collected at 7 and $10 \mathrm{a}$. $\mathrm{m}$. and at 1 and $5 \mathrm{p} . \mathrm{m}$. Not less than 20 specimens were examined, but little difference was observed except that I concluded that the anterior parts of the digestive tracts of the latter were less gorged. 
brood which had evidently just molted twice when it came under my observation molted again after 12 dars. The observations just noted indicate 12 to 15 days as the interval between molting. Allowing five molts per season, this gives us about 2 months for a worm to mature, which is about the time required at Cedar Point. Mature worms arerage 18.75 to $25 \mathrm{~mm}$. in length (0.75 to $1 \mathrm{inch})$. At the rate of growth abore indicated (6.25 mm. in 22 days) we again get about 2 months for a worm to mature.

Judging from the number of loose heads and headless skins in the nests, I conclude that the head molts first. and that the worm then slips out of the old skin by this opening. I do not recall finding an empty skin with a head. In only a few instances do I recall that the thorax had a small. longitudinal slit dorsally. The last molt occurs after the cocoon-a loose flimsy affair consisting mainly of the hairs of the caterpillar with but little silk-has been formed and lies stored away at the posterior end of the pupa.

In some specimens about to molt, and which I dissected, I found the digestive tract empty and the new hairs formed beneath the old skin.

\section{OTHER OBSERYATIONS.}

It has already been remarked that a brood may diride into two broods, and that two broods may unite. Again. a brood may desert its old web and form a new one. I frequently noticed that many webs contained worms of sereral different sizes, and this fact first suggested to me that two or possibly several broods might unite in a single web. I found later that a brood of smaller worms, somewhat isolated at the end of a branch, trareled 18 inches along a bare stem to reach green leares. Every inch of this distance was corered with quite a dense web of silk. This brood came into close proximity with an older brood, and instead of returning to its own web took up its abode in the web of the older worms. This is a perfect illustration of the mion of two broods. A similar occurrence was observed with another larger brood, which finally had to travel sereral feet to get to its feeding leaves. This brood erentually divided, one division taking up its abode within the web of another brood near by, while the second dirision built a new web of its own. It appears that the worms found it more convenient in this case to take quarters with their near neighbor. or to build a new web, than to return to their old nest. This observation illustrates both the union and the division of broods, as well as the building of a new riest.

The following observations in a measure also illustrate some of the abore points, besides several others in webworm economy: I cut out 
a nest at 3 a. m., while the worms were out feeding. At 4 a. m., when all were coming home, these were wandering about aimlessly. Eventually a portion settled down and spun some web within a piece of folded paper which had been used as a label for the nest. The majority, however, formed a new nest among some dead leaves left after cutting out the old nest. Another paper was then placed near the first piece. The next day a number had located under this and had spun some web, but the paper was not at all folded. Later all the nests were cut out, including the pieces of paper, with the result that a portion of the worms settled down in a new web which they built underneath the largest stem of the branch, while the rest returned to a neighboring nest about 18 inches distant, from which the smaller individuals of this brood-a double brood-had come some days before.

Three nests were cut out and placed on the ground near some choke-cherry bushes. In all three instances the nests were fastened to the ground with web after the first night and some silk spun upon the ground for some small distance about the nests. The first brood built web upon the ground for a distance of 2 feet from its nest to a leafy stem of the choke-cherry, to which it migrated. Only a few worms returned to the nest upon the ground after the first few days. The majority remained in their new quarters and soon had spun quite a dense web.

The history of the second nest is quite similar to the first, except that I could find no web spun upon the ground leading to the chokecherry, a distance of 3 feet. These worms remained for a longer time in their nest, deserting it gradually, and, it is presumed, went to the choke-cherry, where a few specimens were occasionally found, although no new web was observed.

The history of the third nest is somewhat different. The nest was cut off August 5 and placed upon the ground between the porch and choke-cherry bush. The nest was 2 feet from a leafy branch of the cherry near the ground and about 1 foot from the porch. On the morning of the second day apparently all the worms were in the nest, and a web had been spun upon the ground near by and the side of the porch. At $9 \mathrm{p}$. m. of the same day (August 6) the worms were wandering about the web upon the ground and the porch. A few were on the railing of the porch and on the floor near by. On the morning of the third day all had evidently returned to the nest. At $9 \mathrm{p}$. m. the worms were wandering over the nest and the ground near by (the web upon the side of the porch had been destroyed) : there was no evidence that the worms were going to the cherry. On the morning of the fourth day apparently all the worms were again in the nest. On the morning of the fifth day the nest was deserted $31024-$ No. $60-06 \mathrm{im}-4$ 
by all but a few worms. Only a few could be found upon the cherry tree, and the presumption is that they became scattered upon this.

Of 13 webs found in the choke-cherry brush which had been cut and spread about the outside of the laboratory to protect the loose sand against the wind. $t$ were wholly deserted, while 9 contained from 12 to many worms.

\section{COLOR TARLATION.}

A few notes were made upon the different colors on the worms. Mr notes are not sufficient, horrerer, for the determination of any laws or modes of rariation. and the obserrations were only made in order to get a better idea of the color rariation. A careful study along this line would be a subject by itself. requiring all the obserrer's best effort for a number of weeks. But no doubt some rery interesting scientific results would be obtained if a series of observations of this kind were platted and curres made to show general frequencr. mode of rariation. etc.

Eighteen rorms rere examined. and following are the results. In each case the colors are enumerated with a figure in parentheses denoting the number of worms haring that color. I had no standard colors to compare, so that the colors named are probably only approximately correct. which does not invalidate the object here in riew. Under the second. third. and fourth dirisions the body colors giren are the dominant ones. while the "stripes " are narrow lines running iongitudinally. The worms examined were from a lot that I had taken to the laboratory at least a day previous, and none had molted during that time.

Head.-Black (10), brown (4), dark brown (2), light brown (2).

Body (without stripes. 3).-Black (1), blue-black (1), light slate with darker back and renter (1).

Body (with stripes. 1.5).-(I) Dorsad: Lead color (1). black (6). light lead (1), dark lead (2), lead stippled black (1). green slate (3). (II) Laterad:

Light lead (3). lead (2), dark lead (2), green slate (5), greenish rellow (1). black (1), stippled black (1). (III) Tentrad: Light lead (2). lead (2), dark lead (S), blue-black (1), green slate (2)

stripes.-(I) Dorsad: No stripes (7), light (3), cream (6) rerT faint (2).

(II) Laterad: No stripes (1), 2 cream ( 4 ), 3 cream (6). 2 faint light (3), 1 faint (2). 2 light (1), 1 cream (1).

Feet.-(I) Thoracic: Black (13), dark brown (1), brown (2), light brown (2).

(II) Anterior abdominal: Black (T), dark gray (4). gray (1). gras-brown (2). dark green (1), olire green (2), light (1). (III) Posterior pair: Black (5). gray (1), dark gray (4), light gray (1), gray-brown (3), dark green (1). olive green (2). light (1).

Tubercles.-(I) The two dorsal rows: Black (7). dark (2). brown (4). dark brown (1). light brown (2). light orange (1). light (1). (II) The tro dorso-lateral rows: Black (10). black and orange (2), brown (2), dark brown (2), light brown (2), (III) The four lateral rows: Orange (S), light 
orange (6), dark orange (1), brown (1), light brown (2). (IV) The four ventral rows: Black (1), dark (4), light orange (1), brown (1), light brown (1), gray-brown (2), lead (4), green-yellow (1), green slate (2), light (1), Hairs.-(I) Dorsad: Golden brown (1), white (8), brown (5), light brown (2), gray (1), black and white (1). (II) Laterad: White (13), gray (3), brown (2).

While writers generally mention the great color variability of the larve and that there are light and dark colored ones, I do not know that anyone has attempted to put the variability in a tabular form.

The appreciable economic loss from the webworm is generally not great and but few trees are ever endangered. Small trees can, of course, easily be defoliated by one or a few broods. In localities where the worm is double brooded the situation may become serious and considerable loss ensue. But by a little attention with a torch or by cutting out and destroying the webs a great deal can be done to eliminate this pest.

The following paper was read by the secretary:

\section{THE CARE OF ENTOMOLOGICAL TYPES.}

By T. D. A. Cockererc, Boulder, Colo.

It has long seemed to me that something ought to be said about the duty of museums, universities, etc., in properly caring for and rendering accessible the types and cotypes of insects in their possession. I do not refer to the institutions where the collections are systematically neglected, but to the best we have, where everything is supposed to be just as it should be. Quite too often we hear that a given type "can not now be found," and I suppose that few museums could at a moment's notice produce a list of types in their possession. Within the last few years I have visited two of the largest collections of insects in the world, one in Europe and the other in America, and have found types and cotypes which I had myself sent hidden away among the unassorted accessions, where nobody knew where to find them. They were not in any danger of destruction, to be sure, but they were for the present forgotten, and with the lapse of years they might well be in danger of complete oblivion.

The trouble comes, of course, from the fact that in most institutions certain orders are neglected from the lack of men to care for them. My own favorites, the bees and Coccidæ, are specially unfortunate in this respect, and I ver'y rarely have the happiness of seeing collections of them that are in any way satisfactory. When recently in Washington I found the Coccidx of the Department of Agriculture in process of arrangement, according to an admirable plan, so that here at any rate it will be easy to find any specimen upon the premises. 
I was, of course, delighted at the sight; but it is exceptional and indicates a noteworthy reform. It is not to be supposed that every institution can follow it, because it means practically the entire time of at least one man.

I do not suggest that it is practicable to put all the collections in order everywhere; the thing is manifestly out of the question. I venture to propose, instead, two things:

(1) That all types and cotypes of groups not yet perfectly arranged shall be kept apart themselves in perfect order, pending the classification of the whole series to which they belong. In this way it would be possible to examine them, both for purposes of study and to see that they were not being injured.

(2) That all institutions receiving types and cotypes should publish annually lists of them, so that students might know what was available. These lists should include types based upon specimens already in the collection. Such lists would be far more valuable for practical purposes than the usual accession catalogues of museums, which remind one of the inventory of some old-fashioned curiosity shop. They would also amount to the public acknowledgment of the types received, with the accompanying recognition of responsibility. As a model of such a list as I propose, I can not do better than refer to the list of type fossils now being issued by the United States National Museum.

Those who describe new insects often have long series of cotypes which they would gladly distribute for the benefit of students if they could feel more certain that they would be properly cared for and made readily accessible.

The following paper was then read:

\section{NOTES UPON A LITTLE-KNOWN INSECT ENEMY OF COTTON AND CORN.}

By Wilmox Newell, shreveport, La.

The cotton crop probably numbers among its insect enemies as many different species as any other crop of equal importance, and the literature treating of cotton insects has now become voluminous. With the study and attention that has been given cotton insects during the past few years one would not expect to encounter a species. seriously injurious to the cotton plant. concerning the habits of which little or nothing has been written.

a Cicada crratica Osborn, The Ohio Naturalist. Vol. VI. No. 6. pr. 49ד-498, April [14], 1906. At the time Mr. Newell's paper was presented this insect was considered as a rariety of Cicada nigriventris Walker.-ED. 
During the past summer a Cicada (fig. 1) was found doing serious damage over a considerable area in the Ouachita Valley of Louisiana. A search through the literature available to the writer has not revealed any reference to such a species as of economic importance, and although we are far from familiar with the details of its life history, it seems advisable to call attention to its destructiveness when occurring in considerable numbers, especially in view of the possibility of its becoming a serious pest should it become distributed over the cotton belt and occur in as great abundance as it does at present in the Ouachita Valley. In addition to this consideration, the habits of the insect are, so far as observed, decidedly interesting.

While collecting insects around an electric light in Shreveport on the evening of June 7,1905 , five Cicadas, two of which were males,
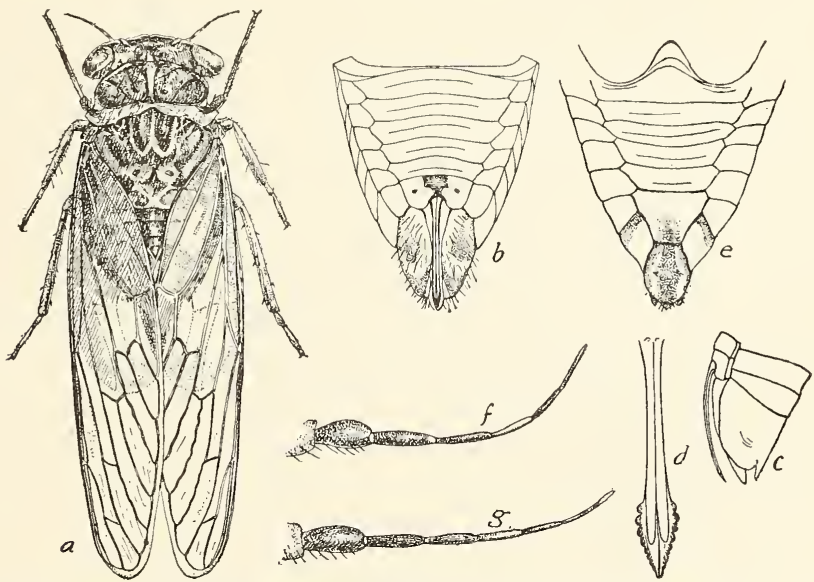

FIG. 1.-Cicada erratica: $a$, female; $b$, ventral view of female abdomen; $c$, side view of ovipositor and sheath; $d$, ovipositor; $e$, ventral view of male abdomen; $f$, antenna of female; $g$, antenna of male. All more or less enlarged (drawing by Miss Charlotte M. King).

were taken, and as they were new to the writer they were sent to Prof. Herbert Osborn, of the Ohio State University, who identified them as $C$.nigriventris Walk. var. (?) ${ }^{b}$

The work of the insect was first called to our attention by Mr. August Mayer, a well-known planter of Shreveport, who brought to the office of the crop-pest commission early in June cotton plants containing numerous egg punctures. While Mr. Mayer had not succeeded in locating the insect making the punctures, he had found the injury well distributed over his entire cotton field, although the damage was by no means excessive and did not compare with the more serious and extensive injury found in the Ouachita Valley later.

$b$ Afterwards described by Osborn as Cicada erratica, n. sp., as stated in the preceding footnote.-ED. 
The punctures in the cotton plants brought by Mr. Mayer were later identified as having been made by the species referred to.

On June 15 a number of adults were taken in a field of alfalfa at Tanceville, 7 miles north of Shreveport, and here. for the first time, the empty pupal cases were found. These occurred singly in various parts of the field, sometimes upon the ground, but more often clinging to the alfalfa plants a few inches above the ground. Their condition indicated that the adults had emerged from them not more than a few days previous.

About the middle of June newspaper reports told of serious damage to corn and cotton crops in the Ouachita Valley by "locusts," and these reports were of so unusual a nature that Messrs. E. S. Hardy and J. B. Garrett, assistant entomologists in the employ of the commission, were dispatched to that region to make an investigation. Mr. Hardy repaired to Columbia, Caldwell Parish, and Mr. Garrett to Logtown. Ouachita Parish, each conducting his investigation independently of the other. Neither gentleman was apprised of the findings of the other until after the reports of both had been submitted, and on all features of the problem which came under the observation of both their reports were identical. Local conditions, however, made it possible for each of the investigators to observe phases of the situation inaccessible to the other. and from the reports of both these gentlemen the following notes are taken.

The area of principal damage was found to extend from a short distance south of Monroe to a point several miles south of Columbia, and was confined, so far as could be learned, to the alluvial lands of the Ouachita Valley.

Near Logtown Mr. Garrett found the damage to both cotton and corn to be general orer the farm of sereral hundred acres upon which he made his observations, the owner of the plantation estimating that about 20 per cent of his young cotton plants had been killed as a result of the egg punctures of the Cicada. Through this section and as far north as Monroe $\mathrm{Mr}$. Garrett observed the insects in such abundance that they were continually seen flying against the windows of moring passenger trains.

In the vicinity of Columbia Mr. Hardy found the insect eren more abundant and destructire. Upon one farm a cotton field was found in which the damage was so heary that the orner found it necessary to plow the field and make a second planting. and on a large plantation the injury orer the major portion was such as to render the prospects for a crop rery uncertain.

Mr. I. C. Bridges, owner of a large plantation near Columbia, stated that the Cicada had done more or less damage each season for the past twenty years, but had not at any time been as destructive as 
during the season of 1905. In fact, Mr. Bridges furnished the only authentic account of the insect's prevalence during previous seasons that we were able to obtain. According to his observations the adults usually appear in June and, after egg deposition, disappear before the middle of July. Mr. Bridges, as well as others, was unanimous in saying that the insects were most abundant during dry seasons and in believing that prolonged rainy weather was fatal to the adults.

No predaceous enemies of the Cicada were noticed, but one farmer furnished a graphic description of an insect "with two stings," which sometimes caught and killed as many as 20 to 30 locusts "in a few minutes." Neither Mr. Hardy nor Mr. Garrett was able to locate the friendly insect corresponding to this description.

The cicadas were found in abundance in both corn and cotton fields between June 18 and 23, their preference for the corn being evident. The males were relatively scarce, for out of 80 specimens taken at random only 3 were males. This may possibly be accounted for by the fact that the females, preferring corn in tassel for egg deposition, were localized in the corn and cotton fields, while the males may have been generally distributed through the fields and forests and therefore much less in evidence. In case the adult males are shorter lived than the females, this would also account in part for the relative scarcity of the former.

Adults were not at any time found feeding, and the damage done was exclusively by the puncturing of twigs and stems by the females for egg deposition. In the case of the young cotton plants the punctures were made in the side limbs, in the main stem, and occasionally in the leaf stems. Punctures in the latter resulted in death of the leaves, and any considerable number of punctures in the principal stem was invariably followed by the death of the entire plant above the point of injury. The bud just below the injury sometimes gave rise, after the death of the top, to a sprout which gave promise of developing into a plant, much as a peach bud develops into a tree.

In the case of corn the attack was confined entirely to the stem supporting the tassel, death of the tassel resulting. Practically the only real damage to the corn is the diminution of the amount of pollen available, the ultimate damage in a case of injury of this kind being hard to even surmise. The egg punctures (fig. 2) were much more abundant upon corn tassels than upon the cotton stems and were located much nearer together, possibly because of the corn presenting less resistance to the ovipositor of the female than the more fibrous stalk of the cotton plant. A number of tassels, showing about the average damage, were taken to the laboratory and the eggs and punctures counted. The stems supporting three tassels contained 297, 181, and $215 \mathrm{egg}$ punctures, respectively. A count of the number of eggs 
in each of many punctures in corn gave an average of 4 to 5 within each. The three stems referred to therefore contained in the neighborhood of 1,188, 724 , and $860 \mathrm{eggs}$, respectively. It seems not unlikely that the eggs in each tassel represented the quota of a single female. Four females, which were taken while ovipositing on corn, were dissected and found to contain 192, 461, and 410 eggs, respectively, all of which were of nearly full size and apparently ready for immediate deposition. There was, of course, no way of determining

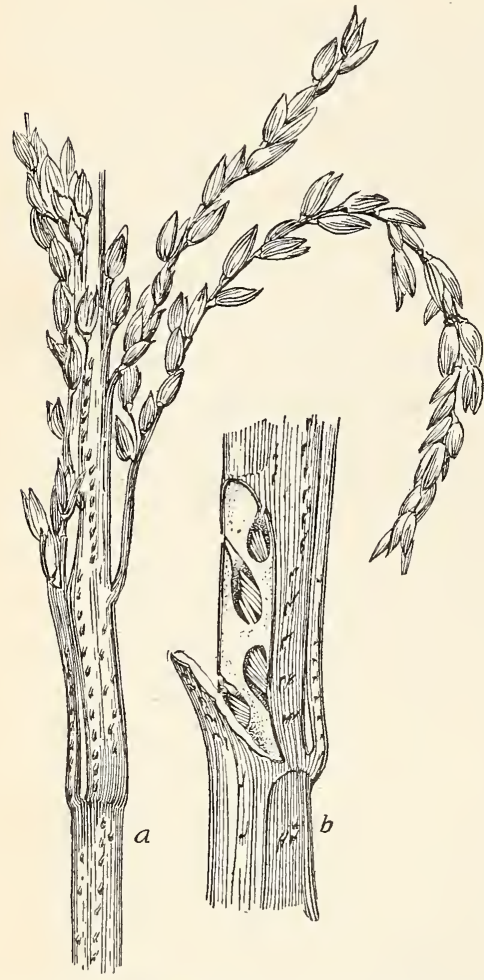

Frg. 2.-Eggs and egg punctures of Cicada erratica: $\alpha$, egg punctures in stem of corn tassel; $b$, partial cross section of stem, showing eggs within cavities made by female. (Drawing by Miss Charlotte M. King.)

how many eggs had been deposited by each of these females before her capture, nor how many more might have developed in the ovaries had she been left to continue depositing. It does not seem likely that the average number of eggs deposited by each female is less than 350 , and if all the punctures found immediately adjacent to each other prove to be the work of only one female, the average number of eggs deposited will be found to be in the neighborhood of 1,000 .

Upon the cotton plants, which were still small, the females were very timid, taking flight whenever one came near them, but in the cornfields they were much easier to approach. Mr. Garrett timed a number of females which were ovipositing upon corn tassels and found that the average time taken by the female to make an egg puncture and place from 3 to 6 eggs in it was from two and one-half to three minutes.

By June 23 Mr. Hardy found that in the vicinity of Columbia the adults were becoming less numerous, many dead cicadas being found in the fields and in the axils of the corn leaves. Large numbers of females, which had in some manner lost their ovipositors, were found flying in the cornfields, and occasional individuals, deprived of the entire abdomen, were found alive and active.

In the selection of places for egg deposition the females are decidedly cosmopolitan. Although the corn tassels were the preferred 
places, with the stems of young cotton plants as second choice, egg punctures and eggs were found also in the twigs of pecan trees, fruit trees of various kinds, cottonwood, sweet gum, honey locust, coffee bean, wild cherry, and in practically every variety of shrub or weedlike plant in or around the infested fields. Mr. Hardy found punctures and eggs in abundance in the boards of a roof covering a " cotton-seed house" in one of the infested fields. It is said in the infested neighborhood that when the laborers leave tools in the field while gone to dinner, the cicadas puncture the hoe handles so liberally that it is necessary to sandpaper the latter before they can again be used. We have not yet verified the existence of such an interesting habit on the part of the insect, although it is not entirely outside the realm of possibilities, for between barn roofs and hoe handles as host plants there does not appear to be any great difference.

In the roof of the shed-like building referred to, Mr. Hardy found old punctures, containing no eggs, evidently made the previous season, and this may possibly point toward one year as being the developmental period of the insect.

The egg is white, approximately cylindrical, bluntly rounded at the ends, and has its greatest width a little nearer one end than the other. The egg is slightly conformable to the cavity in which it is placed and is sometimes permanently distorted by unequal pressure against the surrounding tissues or against other eggs in the same cavity. In plants of a woody nature, having relatively tough bark, the upper end of the egg (next to the epidermis of the plant) was usually noticed to be more bluntly pointed than the lower. Eggs taken from punctures in corn tassels -averaged $2 \mathrm{~mm}$. in length by $\frac{3}{8}$ $\mathrm{mm}$. in diameter. Within the puncture the eggs (fig. 2, b) are arranged side by side, not always parallel with each other, and usually extending downward at an angle of about 45 degrees with the surface of the stem in which they are placed. The egg punctures present an outward appearance not unlike those made by Ecanthis niveus De G. The puncture is rounded at its upper extremity and is pointed at the lower end. Punctures in young and tender cotton stems measured from $1 \frac{1}{2}$ to $2 \mathrm{~mm}$. in length by about $\frac{1}{2} \mathrm{~mm}$. in width.

In cotton stems the punctures were not, as a usual thing, placed directly in a vertical line, but were arranged spirally, each puncture being placed a little to one side of the one next above it.

The number of eggs inserted through each puncture seems to be governed largely by the resistance offered by the tissue through which the ovipositor must be forced. Punctures in cotton stems contained from 3 to 5 eggs each, those in corn from 4 to 8 , while in a weed having a hollow stem 75 eggs were found, all of which had been inserted through a single puncture. 
We have not succeeded in determining the period of incubation, as eggs kept in the laboratory failed to hatch. The nymphal stage is not positively known to us.

The remedy for this insect will doubtless be found upon further study to consist of cultural measures. All of the cotton fields in which the injury was most severe were fields in which corn had been grown the year previous, and one farmer, in plowing a cornfield in the spring, noticed large numbers of insects which, from his description, must have been the nymphs of this species. If the nymphs are found to subsist upon the roots of corn or other regetation in the cornfields, plowing at the proper time may prove to be an effective measure. The use of trap rows of an early variety of corn in the cotton fields, planted so as to come into tassel at the time of emergence of the adult cicadas, may serve to lessen the damage to the young cotton plants. Further studies of the insect's habits are necessary before satisfactory remedial measures can be suggested.

The following paper was then presented by the secretary:

\section{HISTORY OF ECONOMIC ENTOMOLOGY IN HAWAII.}

Ву Јасов Котімsкy, Нопоlulu, H. I.

"KOEBELE" METHODS IN ECONOMIC ENTOMIOLOGY.

Entomology is never more fascinating to the interested layman in Hawaii than when presented in the alluring light of fighting pests by means of their natural enemies. In fact, this is the only kind of entomology that appeals to him. To the reteran economic entomologist such methods saror too much of "playing to the gallery" to sanction their adoption. And yet, reflected in sober thought, if ioy his manipulations man has overlooked the danger lurking in introduced insect enemies, has upset the balance of nature, can we not hope that by further manipulation he can further adjust nature with the balance in his faror? In other words, when plants or animals of a country are suffering unremittent serious injury from an insect pest it is reasonable to suppose, first, that the pest is of foreign origin, and, secondly, that the natural check to that enemy has been in some way eliminated. It is evident, therefore, that given the check species and with the elimination of its enemies we must succeed in creating a balance of nature in our favor.

INTRODUCTION OF INJURIOUS INSECTS INTO HAWAII.

When in 1820 the Boston missionaries came to the Hawaiian Islands they recognized the latent capabilities of the soil for yielding good crops, provided the plants were there. Taro and cocoanuts were 
good, but many more at least as useful plants were known to grow in other tropical and subtropical countries. There remained but the necessity to import them. And so, from that day to this the crusade of useful plant importation has been carried on in a most energetic fashion. Catalogues of dealers in ornamental and useful plants and seeds from the world over were diligently perused, and whichever pleased the fancy of the individual, and later the Government, was introduced, expense notwithstanding. Until comparatively recent times little was it suspected what evil pests these plant importations brought in their train. Fast as the country was being stocked with useful plants, the best from all over the world, it was equally fast being populated with most troublesome and injurious insects and fungi. Failures directly due to some of these were no doubt attributed to unsuitable climate, soil, etc. Time came when introduced regetation, itself profusely inhabited by insect enemies that followed in its train about the world, drove the native flora and fauna into the mountain recesses. Time came also when the growing of one crop on immense areas-sugar cane-became a staple industry of the islands. Other crops were sought, and coffee growing seemed promising. But when their natural food increased the insects, too, began to prosper and multiply. The sugar-cane borer (Sphenophorus obscums auct.) and cottony guava scale (Pulvinaria psidii Mask.), both introduced with their hosts, inaugurated a campaign of destruction. To save cane and coffee from imminent ruin some active measures against their insect depredators became imperative. The amount and variety of tropical vegetation adorning his dooryard has been from time immemorial the pride and delight of every resident of Honolulu. But these have of late years been marred by "blight." Cutworm, Japanese beetle, scale insect, aphis, and fungus are all "blight" to the Hawaiian. The streets were lined and yards were full of trees and shrubs dead and dying from the effects of a host of species of scale and other insects. Citrus trees and casuarinas were white with the cottony cushion scale (Icerya purchasi Mask.) and unsightly black with the dripping honey dew and consequent sooty fungus. Bad as the plants about some deserted residences still look, they stand no comparison with what they must have looked prior to 1890 . The success attained by Mr. Koebele with Vedatia cardinatis Muls. was still proclaimed by the press, and about 1889 or 1890 this species was introduced into Honolulu. Here, too, this valuable little ally accomplished its mission and lent enthusiasm to the idea of the new economic entomology. In a note in Nature ${ }^{a} \mathrm{Mr}$. Perkins records the fact that Coccinella abdominatis Say has been introduced, probably accidentally, from California years ago. It would probably have 
accomplished its task of execution among the aphis here had not its parasite (Centistes americana Riley ${ }^{a}$ ) unfortunately been introduced with it. On his way to Australia. in 1891. Mr. Koebele released in Ionolulu sereral specimens of Chilocorus biculnerus Muls. Specimens of these he observed, though in limited numbers, in 1894 and 1897. None was seen since. So much for economic insect rork up to the last decade of the last century.

THE ADTENT OF MR. KOEBELE TO THESE ISLANDS.

Although the sugar-cane industry was rearly growing more prosperous, the people of this Territory always feared the posible consequences of depending wholly upon a single industry. The continual agitation for another industry, which, because of the geological character of the islands, must be of an agricultural nature, almars brought into prominence now one thing. now another. In the early nineties coffee growing was at the summit. Kona (so named from the district on the island of Hawaii where it was grown) coffee had acquired fame on the market for its exceedingly good flaror, and ererybody was planting coffee. To one took into account the preralence of Pulinaric psidii Mask., which seems by that time to have been an old inhabitant of the island. But the das of reckoning was bound to come. and by 1892-1893 coffee fields were ererrwhere literally white with this scale. Some strenuous measures rere ineritable or the ner pet industry was doomed. It was useless to attempt to fight the pest with artificial means, because to erery acre of cultirated cotfee there are hundreds of acres orerrun with wild guara. and much coffee groms wild, like cotton in the Southern States.

The Hawaiian sugar planters had by that time begun to learn the ralue of securing the best to be had of what ther needed: Ther were ever, and still are, a set of progressive and aggressive men and the guiding spirit in morements of the kind tre are considering. Mr. Koebeles work in the introduction of Tedalia was an inspiring illustration to them of what could be accomplished by means of natural enemies. And so ther were determined to repeat the experiment of the Californians and secure Mr. Koebele to carry it out for them. Thus, conditions haring attained a climax, the serrices of Mr. Koebele, the chief exponent of the net school, rere engaged in October: 1893. He began. very wisely, by first shipping to Hawaii consignments of beneficial insects, native and introduced, from California. These consignments included sereral species of Hyperaspis. one of which, H. undulata Say, was obserred some ten months later. though nerer seen here again since then. Many scrmnids also were introduced. of which Scymnus debitis Lec., an enemy of Pseudococcus sp..

a Now recognized as a srnonrm of Euphorus sculptus Sas.-Ed. 
is now fairly common. Chilocoms bivulnerus was again sent in large quantities; yet, though observed as late as 1897 , it was never abundant, and the writer doubts whether it exists upon the islands at present. Rhizobius ventralis Er. and R. lophantho Blaisd., which are still here and do valuable service, were then introduced. In his report for 1894 to the provisional government of the islands (pp. 98-101) Mr. Koebele lists the coccids found here and the coccinellids introduced from California. It that time, too, he sent several consignments of the toad, which was established here and, with as much cheer as is in the humor of a toad, performed the task imposed upon him of eating Adoretus umbrosus Fab. Much good would have resulted from the toad had not the mongoose proven so destructive to it.

About December, 1893, Mr. Koebele came to these islands and made a hasty tour of inspection to determine the nature and extent of the insect invasion. He reported his findings in the 1894 report, above referred to, and in March, 1894, sailed for Australia. During this trip " he has visited Australia, China, Ceylon, and Japan " ${ }^{a}$ and sent from those countries many thousands of coccinellids, comprising some 200 species. More species, no doubt, would have been established then had Mr. Koebele had a competent entomologist stationed here to breed and take care of his consignments. For the same reason Mr. Koebele refrained from attempting to introduce parasites, as he states $^{b}$ that he sent coccinellids only, principally because he feared introducing new scale insects with the parasites. A very poorly concocted list of coccinellids, sent by Mr. Koebele during that trip, appears in the 1894 report to the minister of interior, pages 31 to 33 . Of these coccinellids, perhaps no other species excelled Cryptolamus montrouzieri Muls. Until this day its work of execution is evident on a good many species of Coccidæ. Pseudococcus flamentosus (Ckll.), otherwise a very ugly pest on many varieties of plants, dares not show its face for this useful ladybird. Pulvinaria psidii, once a threatening enemy of coffee, guava and other plants, is now far from a common species. Curiously enough, it will not touch the females of Pseudococcus nipa, though it devours males with avidity. Few species of Pseurlococcus are immune to it, in fact. The large variety of species of Coccidre that it preys upon makes this coccinellid, it seems to the writer, a more valuable insect even than Tedalia cardinalis. Platyomus lividigaster Muls. and Coccinella repanda Thunb., the two most common and efficient aphis-eating coccinellids here, have alone saved many plants, especially citrus, Hibiscus, and sugar cane, from utter destruction. Unfortunately, the latter is subject to attack by Ceniistes americana. Strange to say, this parasite, while scarce in the 
city. is fairly common in sugar-cane fields. Additional material of Rhizobius ventratis, too, seems to have been imported about this time. This useful ladybird is still in eridence, especially during the winter months of the year, upon trees infested with Pseudococcus nipce Mask.

Unfortunately, the entomological reports published by Mr. J. Marsden are of too rague a nature to gire one an accurate idea of the exact results of $\mathrm{Mr}$. Koebele's importations. But in his roaming style Mr. Koebele gives, in his report to the minister of the interior, ${ }^{a}$ a mine of information on the injurious insects, native and introduced, and their enemies found here. Orer two years (159t-18:6) seem to hare been consumed in that trip of exploration, the results of which are no less a triumph than the original introduction of Tedatia cardinatis into California.

The shade, citrus, and coffee trees cleaned of their worst scale insects and plant lice, and the sugar-cane aphis materially checked in its progress. the intrepid fighter and acute observer and collector next turned his attention to Lantana and the hornfly (Hamatobia serrata R.-D.). the two great impediments in the way of the cattle ranchman. Mexico being the native home of the former, and the latter being a common pest in the United States. Mr. Koebele turned toward the American mainland in 1898. California, Arizona. Mexico, and Peru were risited, and numerous insects shipped from there, as related in the entomologist's report to the minister of the interior for 1898. page 105. These comprised principally enemies of cow-dung maggots and parasites of the cabbage butterfly (Pontia rapce Schrank). Some 20,000 specimens of Copidosoma truncateltum Dalman were liberated with the hope that they would prey on the larræ of the numerous lepidopterous enemies here. From California a species of rock lizard (Gerrhonotus carinatus) was introduced and liberated on Lihue plantation.

In Morelos. Mexico, Lantana enemies were studied, but apparently none were then introduced. The introduction of plant parasites is always fraught with danger, and having been warned by authorities against such an attempt, Mr. Koebele seems to have refrained from the responsibility.

It is interesting to note that in the report last referred to Mr. Koebele derotes nearly two pages to remedial measures against the hornfly ( $I I$. semata). This brings us to an interesting point in the activities of an economic entomologist in Hawaii. Granting that most of our insect pests. consisting. as they do. of introduced species. are most easily and as effectively kept in check by their natioral enemies. we must remember that these are not always to be had at the entomologist's bidding. Repeated attempts to discorer effective 
enemies of $H$. serrata have not met with success. ${ }^{a}$ Ten years have passed in the meantime, and only temporary relief has been gained about barnyards by means of artificial remedies. Accordingly, the work of the official entomologist of Hawaii would embrace the following: (1) Efforts at introduction of specific enemies of the various noxious insects; (2) an all-embracing study of the pests, particularly those not checked by natural enemies; (3) experiments with cultural methods and remedies to be employed against injurious insects not otherwise taken care of; (4) a campaign of education along all lines, of those whose material interests are affected by insects.

We must reach the happy medium between the two extremes of exclusively " natural" and exclusively "artificial" fighters of insect enemies. In order to render aid to those whose crops or live stock are afflicted with pests not naturally bridled, we must study and prescribe cultural and insecticidal methods. By means of popular, well-illustrated publications we must acquaint our clientele with their enemies and friends in nature. Take clean culture, for example. In so far as it affects the life of the injurious insect we must advocate it. This, of course, implies a knowledge on our part of the methods of cultivation pursued in a certain crop, though on the face of it such knowledge seems beyond the range of our activity. In the absence of an effective enemy of sphenophorus obscurus we advocate the stripping of cane and the burning of trash as a check upon that pest.

We have, it is true, some enemies of the purple scale (Lepidosaphes beckii Newm.) in Chilocoms circumdatus Gyll., Orcus chalybeus Boisd., and Aphelinus diaspidis How., but their economic value is very slight, and we should doubtless follow in wisdom's course by advising to shake the orange tree in order to expel what ladybirds there may be upon it and then spray it with an effective contact wash. Of course wherever possible we must bend our energies to import the natural enemy of every insect that is injurious. If funds for personal importation of such enemies can not be obtained we must resort to whatever other means are available. But we must bear in mind that the planter wants immediate, effective, and inexpensive means of fighting his enemies.

In autumn, 1899, Mr. Koebele went with Mr. George Compere to Australia and Fiji "to collect beneficial insects and plants for these islands," and the results are published in the report to the minister of the interior for 1900, page 36. Ceroplastes mubens Mask., once so common here, has been hardest hit by internal parasites sent during

a Since writing the above, Spalangia hirta Haliday, kindly determined by Dr. Wm. H. Ashmead, was bred from $H$. serrata pupa collected on each of the islands. 
this trip. The report just mentioned also includes obserrations on fruit flies. on the "Olinda bug" or Fuller"s rose beetle (Aramigus fulleri Horn). on tineids bred from cotton. on silk culture in Hawaii, and on forest-principally koa (Acacia koa)-insects on Hawaii and Maui. From a scientist's standpoint the last report referred to is perhaps the most raluable of all. From this trip Mr. Koebele returned to Honolulu April 10, 1900. where he remained some two rears. Inspection for insects on imported regetation, which forms so important a rork upon these islands at present. was up to that time either entirely neglected or placed in the hands of incompetents. This work seems to have been attended to by Mr. Koebele personally during these two years, and naturally was performed intelligently.

\section{LANTANA IXSECTS.}

In 1899 the lantana scale (Orthezia insignis Dougl.) was discorered at Mailuku. Maui. by Mr. Gerrit P. Milder. This discorery seems to have alarmed everrbody but the ranchers. whom Mr. Koebeite found distributing the insect in order to kill their lantana. Knom. ing the perniciousness of the animal and its destructireness in Cerlon. Mr. Koebele, too, seems to hare been considerably exercised orer the coming of this unwelcome guest. Without much delay he rushea off to Mexico in the spring of 1900 . His mission there seems to hare had a dual nature. First. to find and introduce an enemy of 0 . insignis: second. since the ranchmen are so desperately anxious to kill off lantana as to place all regetable life on the islands in jeopardy: to forestall an additional importation of this kind br introducing enemies of lantana not likely to affect other plants.

In Mr. Koebele's absence Mr. R. C. L. Perkins performed the functions of port inspector. Moreorer. it was realized that the introduction of lantana insect enemies must be guided with the greatest possible caution, first. because of the absolute necessity of introducing species that are certain to confine their attention to lantana. and secondly. because Mr. Koebele had discorered that most of the lantana enemies in Mexico are infested with numerous parasites-primary, secondarr, and even. I believe, tertiary. Mr. Koebeles superlative caution on the mainland had to be supplemented by a trained, careful entomologist here. For this work. too. Mr. Perkins was called upon, and he performed it. I believe, without remuneration. The tact. wisdom, and painstaking care he displayed in this trying task is borne out fully by the appearance of lantana everywhere at present.

That was accomplished during that trip is little short of marrelous. Perhaps a thousand species found on that plant in its native home were bred. examined. and their possible effects in their new home carefully weighed and considered. After due deliberation a 
number of them were selected to fight man's unequal battle with lantana. Ifter eliminating their innumerable parasites they were sent on, and, after a second weeding out, liberated here by Professor Perkins. The result of their work is too evident to require comment. As a result of the combination of seed, flower, and leaf insects the lantana is now everywhere decidedly sick. In the lower places, where the water supply is more liberal, the plant is more resistant, but even there it is doomed. It is not our mission here to forecast the activities of these insects when lantana is no more. The primary object of ridding the country of lantana is well-nigh accomplished, and "apres nous le deluge."

While in Mexico it would seem Mr. Koebele prepared an article on $O$. insignis, which was published in the report of the commissioner of agriculture and forestry for 1902, page 5t. Therein the author delineates the past history of the insect, its habits, plants likely to be attacked by it, and remedies against it, should they become necessary. In conclusion he urges strongly against its dissemination over the islands, although it was already known to exist on Maui and Oahu. Locally it is referred to as the "Maui blight."

THE SUGAR-CANE LEAF-HOPPER.

(Perkinsiella saccharicida Kirk.)

In Volume XXII, page 123, 1902, of the Planters' Monthly, Mr. Perkins sounds the alarm to the sugar industry in consequence of the sugar-cane leaf-hopper (Perlinsiella saccharicida Kirk.). This insect seems to have been introduced from Australia some time in 1897 and confused with the corn leaf-hopper (Peregrinus maidis Ashm.), which occasionally frequents cane fields. Ever since its introduction it has been on the increase, enjoying almost perfect freedom from natural enemies. Upon inquiry Mr. Koebele was informed that Mr. Otto H. Swezey had bred some parasites on leafhoppers at Columbus, Ohio. Mr. Koebele, therefore, journeyed thither, and bred and shipped many specimens to Mr. Perkins, who was left in charge here. Neantime, a native parasite (Ecthrodelphax fairchildii Perk.) was found attacking the cane hopper on Kauai, and numerous specimens of that insect were bred and distributed. Mr. Koebele also shipped hopper parasites from California, which were bred here and released. In the spring of 1903 the Territorial Board of Agriculture and Forestry organized a division of entomology, with Mr. Koebele as superintendent and Mr. Perkins as his assistant. In August of the same year the entomological arm of this Government was considerably strengthened by the addition of such powerful sinew as Messrs. G. W. Kirkaldy and F. W. Terry. 
The introductions from the continent, as well as the native parasite, seemed to arail little, and a journey to Australia, the origiral home of the small but formidable hopper, was undertaken by Messrs. Koebele and Perkins in the spring of 1904. Nany predaceous and parasitic insects of innumerable species were sent during this expedition, which closed about a rear ago with apparent success. Sereral egg parasites (names published in Bulletin No. 1, division of entomology, Hawaiian Sugar Planters' Association Experiment Státion) were introduced which promise to deal the death knell to the hopper host. In August, 190t, a reorganization of the entomological force took place, the Hawaiian Sugar Planters' Association having determined to fight its own battles by establishing an entomological division in connection with its experiment station. For this purpose they have secured the services of all the former entomologists of the Territory, adding Messrs. O. H. Swezey and F. Muir to the force. The Territory on the other hand, while retaining the partial services of Mr. Keobele. has reenforced itself by engaging Mr. Alexander Craw, of California port-inspection fame. for the work of inspection and general supervision of its entomological division. Mr. Jacob Kotinsky was secured as his assistant, and Mr. C. J. Austin to help in inspection work.

Not a little credit for this entomological activity accrues to the Hawaiian Sugar Planters' Association. Irith a munificent liberality and with intelligent. well-directed efforts. in view of the urgent iriportance of the work, they have spared no pains to secure the best entomological help arailable to accomplish the desired ends, namely. the exclusion of noxious insects and the introduction of those which are beneficial.

Our history will be far from complete if we fail to record the creditable work in economic entomology accomplished by Mr. D. L. Tan Dine of the United States Hawaii experiment station, since its organization four years ago. A follower of methods pursued by the " fathers" of economic entomology on the continent nearest us. he has done much work of ralue to the inhabitants of these islands in general and to Honolulu in particular. In one respect he has 110 doubt excelled all other entomologists here, namely, by his popular publications and lectures. Our comparative immunity from mosquito onslaughts is due to his undaunted efforts in organizing a mosquite brigarle and keeping the pest in check. With his popular bulletins and numerous lectures he has enlightened the lay mind on various entomological topics of immediate interest to everyone. The most regrettable fact in connection with the twelre-rear history of economic entomology on these islands is the scarcity of popular literature. but with the present force at work it is to be hoped that this deficiency will be made good. 
AFTERVOON SESSION, TUESDAY, JANUARY 2, 1906.

The following papers on miscellaneous insects were presented, discussion being postponed until the completion of the series:

\section{NOTES FROM TEXAS.}

By A. F. Conradi, College Station, Tex.

Toxoptera graminum Rond.-The southern grain aphis made such a thorongh impression on the wheat farmers of northern Texas during that memorable outbreak of 1901 that at every recurrence of a sporadic attack the office of the State entomologist is flooded with letters. During two seasons we have been justified in consoling stricken sections with the forecast that the parasites were abundant and would no doubt hold the pest in check. The spring of 1904 was begun with good growing weather, but 1905 was one of the wettest in the history of the wheat belt of Texas. During both seasons the parasites were effective. Should therefore a cold, moist spell set in, it is a question whether these parasites would do the work, and the outcome could not be foretold. The writer has faith in crop rotation in checking the ravages of this pest. His observations tend to show that the attacks are much more serious on old wheat fields, while frequently rotated fields are entirely free. Thus the pest migrates from old wheat fields to rotated lands. Northern Texas has a good range of agricultural crops for systematic rotation. Many of the wheat fields have been sown to wheat for over fifteen years. A systematic rotation of cotton, wheat, corn, and alfalfa no doubt would greatly check the ravages of the "green bug." We furthermore have faith enough in the value of the parasites to establish a laboratory at College Station, hoping to be able to breed these natural enemies in sufficient numbers to supply these sections where sporadic ontbreaks of the "green bug" occur. The value of the parasites in checking the outbreak of injurious insects is often so unmistakable in our work here in Texas that operating such a laboratory is fully justified. The chief outbreaks occur in the territory lying between mericlians 95 and 98 and parallels 32 and 34 .

Uranotes melimus Mbn.-This is a widely-distributed cotton pest in Texas. It threatens to be equally serions each spring. It is most injurious over the same area as the "green bug" (Toxoptera graminum), and sonthward between meridians 94 and 97 to the Gulf and westward between parallels 31 and 32 as far as Howard County. It is also seriously destructive in Nueces and Dural counties. Only the first brood is injurious, the second being generally checked by natural parasites. Should these parasites fail to appear some season, serious damage to cotton could only be avoided by most thorough application of Paris green or some other equally effective arsenical. 
Loxostege similalis Guen.-During the spring of 1905 this insect was terribly destructive over many of the cotton-growing counties of Texas east of the ninety-eighth meridian. In Texas it is primarily a cotton insect. It can be controlled with Paris green.

Epicauta vittata Fab.-In Texas this insect is associated with alfalfa. It appears in June and continues to the middle of July. Severe injury was wrought during the season of 1905 , owing to the fact that growers were reluctant to use Paris green on alfalfa. Paris green dusted in the usual manner is thoroughly effective, and there is little danger of injury to stock by poisoning, especially where rain occurs before harvesting. The chief trouble in the application of Paris green by Texas farmers is that it is applied too profusely. Very often a hundredth part would be sufficient. The chief injury is done in the area between Austin. Wharton, and Houston.

Aphis gossypii Glov.-This aphis is the most destructive insect to garden crops in Texas. There is no satisfactory remedy known. Spraying with kerosene emulsion in the early stages is very effective, but reports of injury rarely reach the entomologist before the insect has become very destructive. The Texas department of entomology has experimented considerably with a dry tobaceo fumigant, which gives promise, provided it can be operated practicably on a large seale. The chief source of reliance in securing a melon crop is in the abundance of parasitic enemies of the aphides. Experiments have been inaugurated for the coming spring to determine whether a supply of these parasites can be kept on hand to supply regions where they are scarce or absent.

Pomphopa texana Lec.- This blister beetle is a serious plum and peach pest in the territory lying between meridians 98 and 99 and between parallels 33 and 34 . Its chief injury is done in Clay County, where it is spreading from Thornberry as the chief center of infestation. It feeds on the petals, doing greatest injury at night. It is noticed when the plum and peach blossons are in their prime. Feeding, mating, and egg laying go hand in hand. The female when engorged with several hundred eggs moves clumsily from blossom to blossom, scattering her yellow eggs as she goes. No observations on the larve are recorded in our notes on account of the impossibility of visiting the infested area at the proper time. The best remedy known at present is to jar the insects from the trees in the morning. They are clumsy, drop rery easily, and are conspicuous, which makes it an easy matter to gather and destroy them.

Scolytus megulosus Ratz-During 1904 and 1905 this pest has spread considerably, and is now infesting nearly all of northeastern Texas east of Fort Worth and as far south as Terrell. It attacks chiefly apple and peach. 
Nysius sp.-The species of Nysius which caused so much damage in 1904 were remarkable for their absence during the past season. They attack all of the cruciferous plants, and have injured Irish potatoes, wheat, and mesquite. No remedy is known to me.

Plectrodera scalutor Fab.-This beetle is the most serious drawback to the growing of cottonwood as a shade tree. Its life history was worked out in northern Texas last season. The eggs are laid in cavities made by the adult on the trunk of the tree in June and are easily located by their cottony appearance. The larvæ become full grown by the following May. A tree less than 2 inches in diameter will invariably be killed. Thousands of young cottonwood trees are killed annually in this manner. A thoroughly effective method of destruction is the crushing of the eggs in spring and digging out the young larvæ. Examination should be made in southern Texas in the middle part of May, and in northern Texas in the first part of June.

Conotrachelus nenuphar Hbst.-The plum curculio is becoming very destructive to the peach orchards of Texas and the injury increases every year. In many cases over 25 per cent of the crop has been injured to such an extent as to be rendered unmarketable.

Corn weevils.-The rice weevil (Calandra orya L.), Angoumois grain moth (Sitotroga cerealella Ol.), and granary weevil (Calandra granaria L.) are the most injurious insects of stored corn in Texas, and are here named in the order of their destructiveness. During the past two seasons the rice weevil has caused serious injury in the field and in the bin. During the past season it was found that the rice weevil began to migrate into the field during the second week in June. The Angoumois grain moth became very active a week later. On June 17 over 75 per cent of the adults of the rice weevil, as well as the grain moth, were entirely willing to leave the corn in the bin and migrate to the field. It is therefore important that the bins be fumigated twice after the warm weather sets in in spring, making the fumigations twelve days apart. In like manner, before the corn is stored in the fall the bin should be thoroughly cleaned and fumigated and every wagonload of corn before leaving the field should receive a charge of carbon bisulphid at the rate of 3 pounds to 50 bushels of corn. The wagon bed should be gas tight and covered with canvas or with a muslin previously saturated in linseed oil and dried. The fumigation should be continued while the grain is hauled home, as the shaking and jolting of the load will enable the fumes to penetrate every crevice. As soon as these recommendations are observed, the loss to corn in Texas will be considerably lessened. 


\section{INSECTS OF THE YEAR IN CUBA.}

By Mel. T. Cook, Santiago de las Vegas, Cuba.

[Abstract.]

Of the field crops, the tobacco always suffers greatly from Feltia annexa Tr., which also attacks corn, velvet beans, cabbage, tomatoes, etc. Prodenia commelince S. \& A., P. eudiopta Guen., Chloridea. virescens Fab., and the larvæ of click beetles (Elateridæ) also do considerable damage. Comparatively little damage is done by Phlegethontius sexta Joh. Stored tobacco suffers greatly from Lasioderma iestaceum Dufts.

The corn suffered greatly, and in some cases entire fields were destroyed by Laphygma frugiperda S. \& A. Heliothis obsoleta Fab., Feltia annexa Tr.. Diatraa saccharalis Fab., and certain coleopterous larvæ also did some damage.

The sugar cane suffered to some extent from Diatraa saccharalis Fab., Heliophila inipuncta Haw., and coleopterous larva. Both corn and cane suffered greatly from hemipterous insects.

Coffee suffered greatly from Leucoptera coffeella Stain., especially in the low lands.

Cotton was destroyed in various localities by the boll weevil ( $A n$ thonomus grandis Boh.) and in one place by Eriophyes gossypii Bks.

Vegetables suffered more or less from crickets, aphides, and coleopterous larvæ. Among the most common lepidopterous insects were Pontia monuste L. and Plutella maculipennis Curtis, on cabbage; Diaphania hyalinata L. on cucumber, pumpkin, etc.; Lineodes integra Zell. on egg plants; and Papilio polyxenes Fab. on umbelliferous plants.

Among the fruits, the oranges always suffer greatly from Atta insularis Guer., and in some parts of the island from Solenopsis geminata Fab. One of the most injurious enemies is Pachnous iitus Germ. The Coccidæe were numerous but usually kept in check by fungous and hymenopterous parasites. Among the other fruit insects were the Robinsmia formula Grt. on the canestel (Lucuma rivicoa), Melanchroia geometroides Walk. on grosella, ${ }^{a}$ Gonodonta maria Guen. on custard apple (Anona). IIypocala andremona Cram. on Japanese persimmons, and A pate carmeîita Fab. on avocado (Persea gratissima).

Among the most conspicuous enemies of the ornamentals were Calpodes ethlius Cram. on cannas, Eudamus proteus I. and Erebus odora L. on Leguminosa, Agraulis vanilla L. on passion flower (Passiflora), Ithobalus (Papilio) polydamas L. on Aristolochia. and Pseudasphinx tetrio L. on Plumeria. 


\title{
SOME ECONOMIC INSECTS OF THE YEAR IN OHIO.
}

\author{
By A. F. Burgess, Columbus, Ohio.
}

The most serious pests observed or reported during the year will be considered under the following heads: Grain insects, orchard insects, and forest and shade tree insects. Some remarks will also be included concerning the mosquitoes of the State and a few other insects that caused injury.

\section{GRAIN INSECTS.}

The yield of wheat in Ohio for the year 1905 was above the average, but the acreage sown was considerably reduced. Very slight injury by the Hessian fly (Mayetiola destructor Say) was reported. Late in June complaints were made in nearly all sections of the State that the wheat heads were not properly filled out at the tip, and most farmers attributed this condition to the "weevil," which is more properly known as the wheat midge (Contarinia [Diplosis] tritici Kirby).

Several samples received with crop reports sent to the Department of Agriculture were examined, but no trace could be found of insects or insect work. Apparently the grain in the tips of the heads had failed to mature. On July 7 growing wheat near Columbus was examined and many heads found in this condition. Many of the straws and leaves had been attacked by the wheat rust, and a considerable number of plants were found which were injured by the work of larvæ of a species of Isosoma. Usually a hard spot was found between the second and third joint from the ground, which encircled the stem, cutting off the sap, and light yellow larvæ were found within.

Straws similarly infested were collected from shocks and stubble in Wood, Ottawa, Erie, Fairfield, Miami, Montgomery, Franklin, and Greene counties during July and August, which indicates that the injury caused this year was quite general throughout the State. As some farmers claimed that the actual amount of grain was from onethird to one-half less than the prospective yield, it is evident that a large loss resulted.

Parasites that were bred from these infested straws were determined by Prof. F. M. Webster as Eupelmus allynii French, which is a very common one, also a new species of Eupelmus and of Cryptopristus. The latter have not been described, but similar specimens have been bred by Professor Webster during the present year. The largest number of any of the parasites bred was of the latter species, and it is undoubtedly of considerable importance as a natural check of Isosoma. 
ORCHARD INSECTS.

The San Jose scale (Aspidiotus perniciosus Comst.) has not caused so much damage to orchards as usual, owing to the amount of spraying that has been applied. Many gratifying results have been obtained with the lime and sulphur wash and its use has increased during the past year. Owing to the poor prospects for an apple crop, many orchardists believed it would not pay to spray in order to control the colling moth (Carpocapsa pomonella L.). The experience of the past three years indicates that, in spite of the many assertions concerning the ease with which this insect can be controlled, that frequent and careful spraying must be applied, and that orchards in unsprayed localities must receive special attention, particularly if the crop is light.

The plum curculio (Conotrachetus nenuphar Hbst.) caused considerable injury to apple orchards in the eastern part of the State according to observations made by Mr. Rumner, one of the assistant inspectors. In cases where the greatest damage was done, the trees had not been systematically sprayed during the past few years. Eighty-five per cent of the fruit on one tree showed curculio marks and many of the apples had been punctured so many times as to be practically worthless. (One spraying with Paris green during May gave little evidence of value for controlling the insect. Other orchards in the same section of the State that had been systematically sprayed for several years with arsenate of lead showed very slight injury.

During the past year the injury caused by the grape root-worm (Fidic viticida Walsh) has been slight and vineyardists have pair little attention to it. In several sections of the grape-growing area of the State serious losies resulted from the attacks of the grape berry moth (Polychrosis botrana Schiff.). In some vineyards examined the Concord. Niagara, and Catawba varieties were almost completely ruined and the actial loss was greater than last year.

FOREST AND SHADE TREE INSECTS.

The leaf-mining locust beetle (Odontota dorsalis Thunb.) has been notably abundant in the Ohio River counties during the summer. Hundreds of locust groves were practically defoliated, and the infested area was much larger than during the preceding year. The recent interest which is being taken in planting locust groves as a means of supplying posts. poles, and small timber is increasing. and this insect, unless checked in the future by some natural enemies, may be the means of causing great injury to young plantations of these trees. 
Contrary to expectations, the elm leaf-beetle (Galerucella luteola Müll.) has not increased to an alarming extent during the present year and is known in only one locality of the State, viz, the city of Dayton. During the early summer many larve were present in localities that were badly infested the previous year, and many trees were defoliated. Large numbers of eggs were laid in July, but many of them failed to hatch. The weather after the middle of July was rery dry and many larva of the second brood disappeared after molting once. An examination made in several sections of the city indicated that many of these larvæ died immediately after molting, and in such cases the trees were covered with fine dust, and the air was full of it. The only explanation for the general mortality of larvæ seemed to be that the dust had acted as a contact insecticide, thus effectually checking the increase of the pest. Some spraying was done during the summer, and this was, as a rule, effective.

The catalpa sphinx (Ceratomia catalpe Bd.), an insect which has not previously been reported in Ohio, ${ }^{a}$ was sent in from the southern part of the State this summer by Mr. G. A. Runner. A few large trees near Proctorville were almost stripped of foliage, and trees near Huntington, on the West Virginia side of the river, were seriously injured. On July 29 a new crop of leaves had been developed, and newly hatched larvæ of the second brood were feeding upon them. Many pupa were found about 4 inches below the surface of the soil beneath the trees.

An investigation of the condition of catalpa trees in the city of Jackson, where they have been planted extensively along the streets, showed that this insect was present in large numbers and had been numerous for several years. Many owners were dissatisfied with the trees on this account, and some were cutting them. Quite extensive parasitism had appeared in Jackson, the species responsible for it being Apanteles catalpa Riley, but large numbers of hyperparasites (Hypopteromalus tabacum Fitch and a few specimens of Horismenus microgastri Ashm.) were bred from larva. The record of the parasites reared from infested larvæ shows that they were outnumbered 4 to 1 by the hyperparasites; hence it was apparent that only a moderate amount of good was done in holding the sphinx larvæ in check.

Later in the season Mr. Runner observed the same species in Athens, Vinton, Meigs, and Gallia counties, all of these being located in the southeastern section of the State. He also found a small

a Prof. F. M. Webster informs me that he found this insect on catalpa trees in Lawrence County about the year 1896. The only published reference I have been able to find concerning it is a note that it occurs in "extreme southern Lawrence County, in Ohio," which he published in the Proceedings of the Indiana Academy of Science, in 1902, p. 100. 
block of catalpa nursery stock which had been killed. oming to repeated defoliation by this insect.

The bagworm (Thyridopteryx ephemeraformis Steph.) has been found in the southern part of the state to a greater extent than usual this year, and Melasoma scripta Fals. has caused considerable injury by defoliating poplars in nurseries.

The willow borer (Cryptorhynchus lapathi L.) contirues to spread. and the orster-shell scale (Lepidosaphes ulmi L.) is a serious pest in the extreme northern section of the State.

During the past year a preliminary list has been published of the mosquitoes of the State. This has been accomplished through cooperation with Professors Osborn and Hine, of the Ohio State University. Serenteen species are known thus far to occur here. but no srstematic collecting has ret been done with special reference to this family. Although the yellow-ferer mosquito (Stegomyia calopus Meig.) has not been taken in the State. it is known to occur at Lexington and Louisrille. Kr., and Eransrille, Ind.. the former locality being less than 100 miles from Cincinnati.

\section{NOTES FROM NEW HAMPSHIRE.}

Bỹ E. Dwight SAxdersox. Durham. I. H.

An interesting feature of the past season has been an outbreak of Cingitia catenaria Cram.. or " chain-dotted geometer." and commonly known as an "inchrorm." The normal food plant of the caterpillars is the so-called " street fern " (Myrica asplenifotia). which often corers the rocky hillsides of New Hampshire. belonging to the same genus as the bayberry. During August these plants were stripped orer considerable areas in many sections. Then they had been defoliated the caterpillars spread to birch. wild cherry. apple, or whatever presented itself. including many common weeds. August 9. 1905 , a piece of some 25 acres of stripped land. corered with scrub growth, was observed, upon which practically all of the sweet ferri had been defoliated. The line of adrance of the army of caterpillars was clearly risible, though at this time they were far less abundant than the previous week. Numerous predaceous and parasitic insects rere found preying upon them. but probably s0 or 90 per cent were dring from disease. The exact nature of the disease remains unknown. The dead caterpillars became attached to the twig upon which they clung by means of fine threads-evidently of a fungous disease. Through the courtest of Dr. L. O. Howard, specimens trere submitted to the bacteriologists of the Bureau of Animal Industry. who reported that four organisms were isolated from the diseased larre, the most important being a bacterium. Preliminary experiments with a culture of the latter have been made upon larra of 
Datana ministra Dru., without definite results, and further tests will be continued on the tent caterpillar (Malacosoma americana Fab.) in the spring. The effective work of this disease or diseases was quite miraculous, and we had great difficulty in rearing adults on account of it. Pupation took place August 10 to 12, and the moths emerged September 5 to 16 . Moths were most abundant about the third week in September, when they occurred in such numbers as to attract attention generally, and could be seen in large numbers along the edges of streams and ponds. Moths were observed as late as December 1 . Oviposition took place from about September 20 to the middle of October. The females alight on a weed or branch of any low-growing plant, and to this the egg may be temporarily attached, but it soon falls, and usually is merely dropped to the ground. The eggs are of a light-green color. The only previous record of outbreak by this insect that we have found is that by Doctor Packard in his Forest Insects, ${ }^{a}$ of an outbreak in Pennsylvania nearly thirty years ago. The insect will hardly ever be of much economic importance unless its food habits change. Old residents in southwestern New Hampshire inform me that they remember three or four such outbreaks of this species during the last generation, but that each time the outbreak lasted but one season.

All of the common apple caterpillars, including the tent caterpillar (Malacosoma americana Fab.), red-humped apple caterpillar (Schizura concinna S. \& A.), yellow-necked apple caterpillar (Datana ministra Dru.), and fall webworm (Hyphantria cunea Dru.) have all been unusually abundant this season.

The melon aphis (Aphis gossypii Glov.) also seemed to be more abundant than usual in the field and is possibly the most important enemy of cucumbers grown under glass. It is controlled very satisfactorily by fumigating houses with " the fumigating kind" tobacco powder.

During the summer of 1904 the brown-tail moth (Euproctis chrysorrhoea L.) spread as far north as Holderness and North Conway, N. H., nearly to the White Mountains. The spread for the present season has not been fully determined, but nearly all the southern part of the State is now infested. Although in many towns practically all of the nests were gathered last winter, there is a very noticeable increase this fall, and there can be little doubt that the moths again migrated northward from Massachusetts into New Hampshire as they did in 1904, when they spread over 60 miles in a few days.

The gypsy moth (Porthetria dispar L.) has, during September, been found for the first time in the towns along the New Hampshire coast. Every town from the Massachusetts line to Portsmouth was found infested, some 49 cases being found altogether in a merely 
partial inspection along the main road. corering only a small part of each town. In tro cases colonies were found which had been introduced in 1901. As far as re are at present able to ascertain. the infe-tation is confined to the coast towns. There can be no doubt that the insect was mostly introduced by the unusually heary automobile traffic during the past summer. This suggests the possibility of introduction by automobile into Nert York or Net Jerser. These infestations in Ner Hampshire represent an arerage spread of about 60 miles from the point from which the caterpillars must have been carried. This shoms the possibility of a much more rapid spread of this dreaded pest than has been previously observed.

In the two cases where the pest was clearly introduced in 1.904. from 25 to 30 nests were found in each instance this rear. This is interesting as showing the possible annual rate of increase where the insect occurs in only small numbers. There abundant, the increase is undoubtedly more rapid. though we hare seen no obserrations upon the matter. for the predaceous enemies would not be relatively as effectire. Then it is considered that an egg mass contains 400 or more eggs. the mortality which allors but 25 or 30 females to mature is rather surprising.

An interesting case of injury by the toothed Dermestes beetle (Dermestes culpinus Fab.) was brought to our attention in the fall of 190t. One of our largest manufacturers of ice-cream freezers sent us specimens of stares from tubs which they had exported to Germany for which parment had been refused on account of their haring been badly injured by this dermestid. The Germans claimed that the insects probably laid their egg- in the uncut lumber and that they remained unnoticed until they dereloped in transit. This was. of course. impo-ible. The shipment was some six reeks in transit. The infested tub returned showed rery clearly that the larra had eaten short burrow- into the end- of the stares in which to pupate. some of the pupa being found dead in them. but no larra. Undoubtedly the tubs were stored either at the dock or in the ressel near infested hides or other animal product-. the larra strarming from them to pupate boring into the soft mood of the tubs. Previous records of such injury to wood are known. ${ }^{a}$

The entomological eridence furnished the company enabled them to settle the bill satisfactorily without loss. The incident brought out the present lack of exact knowledge of the life history of this and allied species and its importance to commerce: for as in this case. the entomologist: eridence might fix the liability for loss upon the consignor. consignee. or transportation company.

a See Insect Life. III. p. 311; Ent. Mo. Mag., IV. p. 161, 1Sst. 


\section{SOME INSECTS OF THE YEAR IN GEORGIA.}

By R. I. Smith and A. C. Lewis, Atlanta, Ga.

Insects of the peach, apple, cotton, corn, grass, and grain crops are the ones that command the most attention each year in Georgia. During the season of 1905 several injurious forms have appeared on each of these crops, while in addition many insect pests of minor crops have been brought to our attention.

The San Jose scale (Aspidiotus perniciosus Comst.) still heads the list of scale insects in Georgia as being the best known and the most pernicious. The winter application of lime-sulphur-salt wash has proved to be an effectual remedy for this pest. One spraying in late winter is usually sufficient, though badly infested orchards are sometimes treated twice during the winter, preferably in December and February. For summer treatment of the San Jose scale we recommend the use of 20 per cent kerosene-soap emulsion on peach trees when the fruit is about 1 inch in diameter, or just after the fruit is gathered. Soluble petroleum oils have not been sufficiently tested in Georgia to justify our either recommending or condemning their use.

The cherry scale (Aspidiotus forbesi Johns.) is common in many orchards, but not often numerous enough to require spraying.

The peach lecanium (Eulecanium nigrofasciatum Perg.) has been found in a few peach and plum orchards this year. It is generally kept in control where lime-sulphur-salt wash is used during winter.

The West Indian peach scale (Aulacaspis pentagona Targ.) is still present in a few localities in middle and southern Georgia.

The peach borer (Sanninoidea exitiosa Say) continues to be one of the most dreaded of peach insects. Repellent washes have not proved to be satisfactory in preventing the depredations of this pest. Work done by Prof. H. N. Starnes, of the Georgia experiment station, goes to show that mounding the earth around the base of peach trees about August 1 to compel the borer larvæ to establish themselves well up on the trunks, and the early removal of these mounds, about the last of October, followed by thorough scraping and worming and application of some caustic wash is the most satisfactory way of fighting this insect. This work may be supplemented by spring worming if necessary.

The fruit-tree barkbeetle (Scolytus rugulosus Ratz.) has been more in evidence this year than commonly; and this we think is due largely to the fact that many peach trees were injured by the cold winter of 1904-5, rendering them more susceptible to attacks from this insect. During June and July many letters were received from all parts of Georgia stating that this barkbeetle, or shot-hole borer, as it is more commonly called in Georgia, was killing numbers of trees in the 
young orchards. Investigation of several of these cases revealed the fact that many of the trees thus reported as being killed by the shothole borers had been previously injured and weakened by peach borers, cold weather, or through injury by cultivation or lack of same. In a few cases, however, apparently healthy trees were being badly attacked, leading us to the conclusion that healthy trees are sometimes seriously injured by the barkbeetle, in spite of opinions by eminent authorities to the contrary.

Numerous orchards last spring showed the work of the peachtwig borer (Anarsia lineatella Zell.), but the damage resulting was not great. Orchards which had been sprayed the winter before with lime-sulphur wash were for the most part uninjured.

The plum curculio (Conotrachelus nenuphar Hbst.) was abundant during 1905 in many orchards and caused considerable loss of fruit. Much good work toward controlling this insect in Georgia is done each year by gathering all fallen fruit every two or three days, this practice being followed by many of our largest orchardists. The jarring method for capturing the beetles is practiced in some fer orchards with good results, but this method of fighting the curculio is not generally accepted because of the amount of labor necessary to successfully carry out the operation.

The southern June beetle (Allorhina nitida L.) was observed June 29, 1905, at Baldwin, Ga., eating the leaves off the young shoots of peach trees.

On April 8 a nurseryman at Rome, Ga., sent specimens of the tarnished plant bug (Lygus pratensis L.), and stated that they were severely injuring young pear stock in the nursery rows. May 22 a similar report came from Buff, Ga., except that the insects were work. ing on young apple grafts. We advised spraying with kerosene emulsion at 15 per cent strength, which was found to be successful.

The gloomy scale (Chrysomphalus obscurus Comst.) is found in nearly all parts of Georgia on the oaks and maples. In the city of Atlanta it is almost impossible to find a tree not infested.

Several common apple insects have been injurious in Georgia this year, among which the following are the most important:

The woolly aphis of the apple (Schizoneura lanigera Hausm.) is nearly everywhere abundant, and particularly in the older apple orchards. The aerial form is not serious, nearly all the injury from this insect coming from the ground form, in which it is too often allowed to increase unmolested. Tobaceo dust has been used with some success on the young orchards, but we have found it necessary to make at least two applications of dust each year to insure even partial success.

A series of experiments was started by our department with a view of finding a good remedy for the underground form. The work was 
mainly conducted by Harper Dean, jr., field assistant entomologist, and the result of the first year's work has been reported in the proceedings of the Georgia State Horticultural Society for 1905. The work with tobacco dust was not entirely successful; other forms of tobacco, alone and with kainit, also gave doubtful results. Kerosene emulsion at 20 and 30 per cent was found to be the best remedy, but further tests will be made before it is generally recommended. We have found that kerosene emulsion may be used as a dip for the roots of nursery stock without apparent injury to the trees. We have controlled the aerial form in the usual way.

The codling moth (Carpocapsa pomonella L.) has been noticed more or less in all apple orchards. In the best apple orchards of Georgia proper spraying methods are followed, and this insect reduced to a considerable extent.

The apple aphis (Aphis pomi L.) was present in a number of orchards, and in a few cases the damage to young trees was quite severe. We have found that a strong tobacco decoction is somewhat superior to kerosene emulsion for controlling this insect. Much good work could be done in young apple orchards during winter by finding and removing the twigs bearing the winter eggs.

The oyster-shell scale (Lepidosaphes ulmi L.) occurs in several apple orchards, and one report this year stated that a few trees had been killed at Rome, Ga.

The apple-tree tent caterpillar (Malacosoma americana Fab.) was reported from Washington, Ga., with specimens, on April 21, and from caterpillars collected at Hapeville, Ga., we reared adults, which emerged May 8. This caterpillar is apparently not very abundant in Georgia, though appearing every year.

Eariy in April the newspapers of Georgia began to report a serious invasion of caterpillars in Chatham County, near Savannah. These reports said that the caterpillars were present in such numbers that people had to dig ditches around their homes to stop the caterpillars from entering their houses, and that they got on the railroad tracks so thickly that trains could not pass. We immediately investigated these reports and found that the caterpillars in question were the forest tent caterpillars (Malacosoma disstria Hbn.), and that they were really present in alarming numbers in the swamps about 12 miles from Savannah. The caterpillars on April 27 had nearly stripped the trees over several acres, leaving only the evergreen species. The following forest trees were attacked: Oak (all species), sweet gum, hickory, willow, and also plum, peach, and apple trees. They did not attack the cultivated crops in the gardens, except cabbage. which had been eaten a little in one place. It was true that the caterpillar's got into houses and caused much discomfort 
to the inmates, and in one place they got on the railroad track, rendering it slippery, so that trains had a hard time getting past. Many caterpillars were collected and placed in a breeding cage. May S, caterpillars were beginning to pupate; May 24 , moths were emerging rapidly; May 27 , females were depositing eggs.

An interesting occurrence of injury to pecan trees was first brought to our attention April 7 , when we received a letter from Monticello, Ga., stating that some insect was eating the buds and leaves as fast as they appeared from a grove of pecans, which areraged 10 to 12 feet high. Investigation brought out the fact that the damage was caused by two species of Lachnosterna, namely, inversa Horn and hirticula Knoch. The adults worked on the trees mainly at night, eating the opening buds and entirely preventing the foliage from developing. A method of jarring the trees at night and capturing the beetles on a sheet was suggested as a remedy.

Among the cotton insects several common forms have been present this year, and at least one species not heretofore considered of importance in Georgia.

The cotton caterpillar (Alabama argillacea Hbn.) was not as abundant as usual, though present in a number of counties in middle and southern Georgia. Its late appearance in considerable numbers rendered it of almost no consequence.

The bollworm (Heliothis obsoleta Fab.) was also rather unimportant this year, though we were expecting its appearance in considerable numbers, because of the great amount of injury reporter? in 1904. Remedial measures were not necessary so far as we are awre.

Luperodes brunneus Cr. made its appearance in nine places in at least six different counties in the period between June 20 and July :5. The counties in which it appeared were rather widely separated, thus rendering the outbreak the more remarkable. The beetles appeared in great numbers in all cases, feeding on the leares, squires, blooms, and young bolls of the cotton plants. Their favorite place for feeding was in the opening blooms, from which they would eat the entire center and sometimes the petals. At night they would gather in solid masses on the under side of the leaves and in the squares. It was not uncommon to find as many as 100 on a single leaf. Untold damage was reported, the letters received stating that whole fields of 50 acres or more would be deroured in a few weeks if the bectles were not checked. The reports, of course, were sadly exaggerated, but the excitement caused by the appearance of this beetle was intense, while it lasted, and led us to investigate. We found it true that some plants were entirely destroyed and sometimes sereral hundred in a spot badly injured. Just where the beetles came from we could not tell. Paris green in dry and wet form was recommended as a remedy and was used in a few places. It was our intention to 
give the poison a thorough test, and a special trip to Vienna, Ga., was taken for the purpose of making an experiment. Upon arrival, however, the beetles had so far disappeared as to render poisoning unnecessary. Further investigation showed that the beetles disappeared in two or three weeks as suddenly as they had formerly appeared. For want of any accepted common name we have given this beetle the name, "the new cotton beetle," for it is new to the cotton growers of Georgia, and for a time it certainly looked as though the damage caused by it might be serious. The ultimate injury was not great, as the beetles did not spread far from where they first ?ppeared.

The cotton red spider (Tetranychus gloveri Bks.) appeared in several cotton fields this year, sometimes covering 2 or 3 acres in a field. Dusting with sulphur and spraying with kerosene emulsion was said to give relief in some places.

Among other cotton insects collected in Georgia this year may be mentioned the sharpshooter (Oncometopia unduta Fab.) and the cotton leaf-bug (Calocoris rapidus Say); also Nezara hilaris Say and the cotton aphis (Aphis gossypii Glover). None of the last four insects mentioned have caused serious damage, although the cotton aphis was abundant as usual.

On July 24 a letter came to the office from Statesboro stating that some worms had destroyed a 4-acre field of German millet: This insect proved to be the fall army-worm (Laphygma frugiperda S. \& A.), as determined from one half-grown larva. Unfortunately, we could not get specimens to rear, as the worms all disappeared within a few days after the report. Our correspondent stated that the English sparrows devoured thousands of them, though we believe that they were then entering the ground to pupate. This same worm was observed in a pear and plum orchard in Augusta feeding on the crab grass. From larvæ collected at this point adults were reared September 9 .

The Hessian fly (Mayetiola destructor Say) is found in all the wheat fields of Georgia. The spring brood appearing in many fields last spring must have come mainly from the volunteer wheat, as nearly all the wheat in the fall of $190 t$ came up so late-owing to dry weather-that it was not then infested. Wheat planted early this fall has been found infested to the extent of 96 per cent. Many of our wheat growers are being brought to see the value of late planting and destruction of the volunteer wheat.

Crambus pascuellus L. was reared from one larva collected from a corn field near Atlanta. Apparently larvæ of the same species were collected from corn at Ringgold and Summerville, though we were unsuccessful in rearing adults. This species, we understand from Doctor Chittenden, has never been reported as feeding on corn before.

$31024-$ No. $60-06 \mathrm{M}-6$ 
At first its work was mistaken for that of the common Southern corn budworm (Diabrotica duodecimpunctata Ol.), which was noticed at sereral points in Georgia besides the places mentioned above.

Specimens of the common potato beetle (Leptinotarsa decemlineata Say) came in the mail frequently during April and May.

The harlequin cabbage-bug (Murgantia histrionica Hahn) was very abundant on cabbage, collard, and turnip during 1905 .

On July 18 a crib of corn containing over 200 bushels of ear corn was found by Harper Dean, jr., at Cycloneta, infested with thousands of weevils (Calandra oryza L.). The destruction of the corn was almost complete when the weerils were discovered. The use of carbon bisulphid at the proper time would have saved many dollars to the owner of this corn. We mention this partly to show what little attention is given to many insects until the damage becomes so apparent that it can not be overlooked.

Several garden and field crop insects have been more or less common in Georgia this year. but space will not be taken here to mention them.

\section{ENTOMOLOGICAL NOTES FROM MARYLAND.}

By T. B. Srmons, College Park, Md.

Insect depredations in Maryland the past year have not been out of the ordinary. The annual visitors have appeared, inflicting their usual injury to a greater or less extent.

The San Jose scale (Aspidiotus perniciosus Comst.).-As in many other States this is the paramount pest to combat. IThile the insect is now generally distributed throughout the State, there is every evidence of confidence among the orchardists that the pest can be successfully controlled. The State entomologist is here confronted with like troubles as, I presume, in other States as regards the patent insecticides which are being placed on the market. It is really amusing at times to observe how easily the orchardists and farmers are taken in by a smooth-tongued salesman. It seems difficult for them to wait and allow the proper authorities to experiment with any new solution and report the results. In regard to treatment employed in Maryland, we continue to find the lime, sulphur. and salt wash to be the cheapest and most effective remedy, and one universally used. Our experiments with the wash the past year lead us to believe that where only one application of the wash is made it should be applied as late in the spring as possible. Further. that it is advisable to use a stronger wash in treating badly infested apple trees. Say 25 pound of lime and 20 pounds of sulphur to 50 gallons of water. It was also demonstrated further that salt is not a necessary ingredient to the wash. The patent insecticides prominent on the 
market in this State have been given a fair trial, and in no case did the results prove satisfactory, while in making and applying the same we were particular to follow explicitly the directions given by each manufacturer. Rather extensive experiments were conducted in. fumigation of nursery stock the past year. The strengths used varied from the normal $1-2-4$ formula to six times the normal strength, and the time of exposure one-half and one hour in each case. The results were very satisfactory, as in many cases not a single tree in a lot of ten exposed in the strongest gas for one hour appeared to be injured.

The oyster-shell scale (Lepidosaphes ulmi L.) has been reported irom several localities as doing much injury. It is peculiar that in the extreme western part of the State, where the San Jose scale is not present except in a few places, the oyster-shell scale seems quite generally distributed, especially on apple trees. We have observed many orchards to be very badly infested with the pest. Many reports and specimens have been received of this insect injuring and killing maple trees in several parts of Maryland. We are now conducting experiments with different treatments for this insect on maple trees.

The codling moth (Carpocapsa pomonella L.).-This, one of our annual pests, inflicted its usual injury in Maryland the past year. The results of our experiments in testing the profit to be gained by spraying apple trees with an arsenite at the proper time were very encouraging. The comparison of the per cent of good and wormy fruit from sprayed and unsprayed trees in the experiment station orchard shows the ratio of 1 to $10 \mathrm{in}$ favor of the treated trees. This result to a greater or less extent was very plain in all the different varieties that were included in the experiment. No comparison could be drawn between Paris green and arsenate of lead for superior use as an arsenite.

The little leaf-hoppers of the family Jassidæ were especially numerous the past year. Of these the grape leaf-hopper (Typhlocyba comes Say) did considerable injury to grapevines. Several other species were observed doing unusual injury to various other plants.

The army worm (Heliophila unipuncta Haw.).-The appearance of this insect in early fall in injurious numbers, as observed by the writer on one farm in Prince George County, was one of the novel entomological features of the year. The insect was brought to our notice by a report that "a field of millet was being destroyed by some worm." We were unable to visit the place for some time afterwards. Upon investigation, however, we found several larra and a great many pupæ, which were located under rubbish around and in the field. The insect did not spread from this field, as is usually their habit. At the time of our observation it was too late to employ remedial measures except to prevent, as far as possible, their reappearance next season. 
Several pupæ and larvæ were taken, one adult appearing a short time afterwards. As far as I am aware this insect has not been reported in injurious numbers in Maryland for many years past.

The cabbage hair-worm (1Mermis albicans Diesing).-Four specimens have been sent to the office of the State entomologist for identification. Accompanying each the usual distress has been expressed as regards eating affected cabbage.

The southern corn root-worm (Diabrotica duodecimpunctata Ol.).'This insect has caused apparent total destruction of a small field of sweet corn on the experiment station farm. The fact that the piece of land was low and uncultivated for some time is an explanation for the severity of the attack.

The catalpa sphinx (Ceratomia catalpe Bdv.).-The larve of this insect were especially numerous the past season. Many specimens were received at the office and much injury observed to catalpa trees in many parts of the State.

The woolly apple aphis (Schizoneura lanigera Hausm.).-This insect continues to cause injury in orchards as well as in the nurseries. The results of the use of two applications of tobacco dust in the nursery on Ben Daris apples were very encouraging.

Mosquitoes.-A preliminary investigation of this class of pests was begun in Maryland the past summer. The work was conducted by Mr. A. B. Gahan, assistant entomologist, and Mr. T. Homer Coffin. About 23 species were found in and around Baltimore. It is hoped that we may be able to make a thorough investigation of the number of species occurring in the State and employ means for suppressing them.

\section{INJURIOUS INSECTS OF 1905 IN MINNESOTA.}

By F. L. Washburs, st. Anthomy Park. Minn.

This has been a year of surprises in that certain destructive pests have been unexpectedly active, while others, which we will always have with us and which usually work havoc each year, have done little or no injury during the past season. The Hessian fly (ILayetiola destructor Say) has been present on grains and grasses, but to a limited extent, not sufficiently noticeable to cause complaint. The chinch bug (Blissus leucoptems Say). companion pest of the Hessian fly, has been conspicuous by its absence. though a few were reported from one or two localities.

I have to report quite a serious loss to farmers who would raise alfalfa seed, through the roracious appetite of the red-legged locust (Melanopus femur-rubrum De G.), which prevented the formation of seed on many acres in Hennepin County. This was not reported to the entomologist until the damage was done. In fact, the farmers themselves did not realize the havoc which was quietly going on in their 
fields until too late to prevent it. I have little doubt that next season, forewarned as we are, a repetition of this can be prevented.

Early in the summer various species of cutworms were reported bad in certain sections, flax-growing districts being perhaps the worst sufferers. No specimens reached us with the complaints. In June many inquiries were received regarding galls on plums. This trouble was caused by a small mite known as Eriophyes padi Nal. It has been troublesome before this date, being reported from Minnesota in 1884. The cottony maple scale (Pulvinaria innumerabilis Rathv.) has been again a serious pest. The stalk borer (Papaipema nitela Guen.) was again destructive, as was the corn-ear worm (Heliothis obsoleta Fab.). A serious report of this pest reached us from Cannon Falls, where "every other ear" was said to be infested. We have had our usual quota of green cabbage worms, potato beetles, and insects affecting squashes and melons. Potato beetles were reported as being especially bad in the northern part of the Red River Valley. The white grub, larva of Lachnosterna sp., has ravaged lawns to a marked extent, its injuries being particularly noticeable in cemeteries and like situations, where large tracts of grass make it a difficult pest to conquer. In the course of our experiments we discovered that the grub could stand immersion in a very strong tobacco solution for several hours without serious results, apparently. Hellebore was used in various ways without success. We have in mind two preventive measures, which we shall test next season if opportunity offers.

Bruchophagus funebris How. was reared in quantities from crimson clover in July. Varieties of thistles, among them the Canada thistle, were noticeably preyed upon by the larvæ of Vanessa cardui L. and many of these weeds were killed thereby. While abundant, these caterpillars were not sufficiently numerous, of course, to eradicate thistles, and, it must be confessed, also turned their attention to garden plants-hollyhock, Calendula, etc.

Mention has been made above of a troublesome gall-producing mite on the leaves of plum. We have to report also, in this connection, cecidomyiid gall makers again injuring leaves of soft maple and boxelder; and the cockscomb gall locally abundant on leaves of white elm. In one county we secured specimens of the peculiar globe-like galls on red elms, caused by Pemphigus ulmifusus Walsh. The plum curculio (Conotrachelus nenuphar Hbst.) made its appearance felt on apples, as well as plums, and the New York weevil (Ithycerus nove-boracensis Forst.), working on fruit trees, was complained of in some sections. A lepidopterous borer (Podosesia syringa Harr.) attacked young ash trees near Adelaide, so weakening their trunks as to cause them to be broken down by the wind. A green sawfly larva worked 
on the leares of ash trees. and is at present in our breeding cages, a waiting its transformations, that we may identify it.

Four houses in the Twin Cities-Minneapolis and St. Paul-to our certain knowledge. and there were doubtless others. hare been overrun with the so-called "book-lice" (Troctes divinatoria Mïll.). In these particular cases these tiny pests swarmed in bureau drawers and closets. orer clothing on walls, and the backs of pictures, and, in fact. in every place where their presence was likely to disgust a sensitive housekeeper. The made an effort to free two houses of this untrelcome guest. and partial success was attained by the use of hydrocranic-acid gas. the families racating the premises in question for about thirty hours. Te rere unable to locate the starting point or breeding place of the insect in these two cases. It is significant that all of the residences known to be infested are new houses. built within a rear. the present occupants being the first to use them. Te are constrained to believe. from our observations, that these insects came from the space between the walls or under the floors. or both. A curious fact ras noted in connection with this piece of work. I have alwars been led to suppose that this hydrocranic-acid gas will not affect metal, if it is perfectiy dry. The had every reason to believe that the silver and other metallic objects in these houses rere free from moisture. and ret when we finished we found that the silver which was out-ide of the drawers in the dining room was tarnished, as was all the nickel on the range in the kitchen. and the exposed plumbing in the bathroom. which was plated with nickel. The silver was restored to its pristine brightness by a jetreler. but the family has been unable to get rid of the dull-brown discoloration on the nickel work. This could be easily prevented by the use of raseline. if one had reason to suspect a recurrence of the trouble. Before this fumigation re suspected that these insects might hare their origin in the filling between the floors. This filling is made of a dried seameed. But if this was so. we failed to discorer it upon taking up some of the flooring and examining the filling in question.

Another family. which for two rears or more has been troubled by that rery common household pest. the little red ant (Ionomorium pharaonis $\mathrm{L}_{\text {. }}$ ). has appealed to the entomologist for relief. Tre find that these insects come from the walls of the furnace room in the cellar. supposedly haring their nests between the double walls in this locality. or in the soil outside far below the frost line. It date of leaving St. Anthony Park we are still fighting this ant. haring used many pounds of bisulphic. with an apparent lessening of their numbers, ret we still find some coming through cracks and crevices of the plastering.

An interesting piece of work of the rear. and perhaps the largest operation of the kind erer conducted with hydrocyanic-acid gas, has 
been done in the elimination of the Mediterranean flour moth (Ephestia kuehniella Zell.) from a large mill. This mill is six or seven stories high, and we fumigated not only the mill proper but the warehouse, cleaning house, and elevator, amounting in all to over $3,000.000$ cubic feet of space. Te used a ton of cyanide of potash and a ton and a half of sulphuric acid. The operation was in every way successful. The bags of cyanide were lowered into the crocks on all of the stories from the outside without a hitch, and ventilation secured equally easily on all the stories.

A curious accident, if it might be called such, occurring after the fumigation-an accident which might happen in any such operation, probably, but since it would occur when the building was open for ventilation, would hardly result disastrously-came to our attention. We were in the mill, and the men were removing the crocks, when one of them came running to me, with a somewhat pale face, stating that when he took hold of the string to lift the fragment of the bag from the jar a piece of cyanide almost as big as his fist dropped into the acid and gas began immediately to be given off. It was an easy matter to shut off that room from the other part of the mill, where the men were working, and the open windows soon carried off the deadly fumes. Apparently, in tying the cyanide up in the paper bag a piece, probably not as large as the man in his excitement supposed, had become fastened in the conical top of the package and was held there by the paper until the bag was shaken.

A question of some interest to entomologists was raised in connection with this work, upon which I should be glad to hear your opinion, namely, as to what constitutes successful fumigation in a flour mill. After the operation to which I refer was finished, several of us made a careful search through the mill, and in some of the fine flour which had gathered at the base of the spouts on the first floor we found two living worms among the thousands of dead ones, and later one living moth was found flying in the mill. This firm at first made the absurd claim that the operation was not successful, since they had found these three living insects. I believe I convinced them, however, that they were mistaken in their judgment, arguing that in a mill infested as theirs was there were many millions of moths in some stage before the mill was in such a condition as to call for the radical treatment we had just given it, and that even if we found twenty times that number of larva after fumigation, and half of those larvæ should, barring accidents, transform into female moths and lay eggs, it would nevertheless be a number of years before the mill would be sufficiently infested from this source to need another treatment. They finally yielded my point. Since this matter may present itself to any one of us, it may be worthy of a moment's consideration upon your part. Of course, the best time to 
fumigate a mill is in the spring or summer, nevertheless in any season there are bound to be some larra or pupæ secreted around the crerices of the windows or in other situations where the gas does not affect them.

Out of the $i \tau$ nurseries in this State we have inspected, according to law, 45. As you will see by looking at the Minnesota law, inspection of all nurseries is not obligatory. Te found the nurseries for the most part in excellent condition. A weak point in our law, however. has been brought to our attention. One or more nurseries eridently buy trees from the South, from a region affected by the San Jose scale, and sell to Minnesota patrons. It does not follow, necessarily, that their trees are infested with this dread scale, because those districts are fairly well controlled by inspectors, but it is not, as we know from experience, a difficult matter for an infested tree to be overlooked. 'The present law gives the entomologist no option; a man may orn only a single acre of ground, or none at all; he may have only a thousand trees or less, on rented ground, his entire business consisting of buying and selling. yet the entomologist's certificate goes upon all trees handled by his agents. no matter from what part of the country the trees may come. This is probably a matter which can not be remedied here, and at any rate it would be more properly discussed in a meeting of horticultural inspectors, and not before this association.

Experiments against the leaf-hopper (Empoasca mali Le B.) in large nurseries have been continued during the past season. The have used kero-water-1 part kerosene to 15 parts of water-with considerable success. Te find. howerer, that, although we killed the young hoppers, and the old ones also when well treated, nevertheless the trees are again infested from sources outside of the sprayed portion. The work will be continued another season. This pest has not apparently been as troublesome this year as in preceding years.

Our chief experimental work during this summer has been against the cabbage maggot (Pegomya brassicu Bouché), and a report deroted to this pest will be made later. As far as we have gone with the work. we feel that the maggot can be controlled by the use of the well-known carbolic emulsion. Tarred paper disks are not practicable in Minnesota for many reasons. In the first place. cabbages are undoubtedly raised in much larger numbers here than where the tarred paper has been found successful. Secondly, the nature of the ground where cabbages are for the most part planted is such that the paper can not be so applied as to prevent the fity from oripositing beneath it. Further. in cultivation the earth is thrown over the paper. and the men can not or will not keep the surface of the paper free from earth. Finally, cabbages are for the most part set so deep in Minnesota as to make it impossible to put the paper around the root and 
have it lie flat on the ground. In other words, cabbages are set below the origin of the leaves. In some instances we found that tarred papers had pinched the roots of young plants so as to apparently check their growth. In the burrow of one maggot we captured a cynipid parasite (Pseudencoela gillettei Ashm.). To the best of our knowledge this parasite has not hitherto been reported from Minnesota. A number of predaceous beetles which were observed to feed upon the larve and pupa of this fly were also captured. In the course of this experiment, and in spite of negative results obtained with the same substance in the East, we used air-slaked lime on a field cont:ining several thousand cabbages. We thought it ought at least to act as a repellent to the fly and as an irritant on the surface of the maggot, if it were kept dry by sufficiently frequent applications. There was so much rain, however, that it required constant work to remedy the results of the dominating wet weather. Nevertheless, the cabbages made a fine showing, a much better showing, I believe, than other fields not limed. In my opinion this was due, however, to the fertilizing power of the lime, since cabbages are among the comparatively few plants which respond energetically to lime. The recent Holland cabbage, so far as I can make out, is never affected by the cabbage maggot in Minnesota.

\section{NOTES FOR 1905 FROM NEW YORK.}

By E. P. FeLt, Albany, N. Y.

The season of 1905 in New York was notable because of two unusual though fortunately limited outbreaks. Webworms (probably Crambus vulgivagellus Clem. and others) were exceptionally destructive to grass lands in Albany, Columbia, and Rensselaer counties in the latter part of May, and army worms (Heliophitr. unipuncta Haw.) appeared in large numbers in some Erie County localities.

Among fruit pests the codling moth (Carpocapsa pomonella L.) was exceptionally abundant and, on account of the light apple crop, inflicted considerable loss. The second brood appears to have caused the greater part of the injury. The apple maggot (Rhagoletis pomonella Walsh) is becoming destructive to fruit in New York State, particularly to the early varieties. Its work is so prevalent at Newark that sound early fruit was a rarity. Its depredations in the large orchards of Mr. Hart, at Poughkeepsie, were confined very largely to sheltered hollows. The rose beetle (Macrodactylus subspinosus Fab.) was exceedingly abundant in various sections of the State, depredations being reported from Staten Island, from the vicinity of Rochester, and at Grahamsville, Sullivan County. The scurfy scale (Chionaspis furfura Fitch) has been unusually prolific and 
destructre for the last two or three rears in Dutchess County. The grape root-worm (Fidia viticida Walsh) is generally distributed in the Chautauqua region and quite injurious to rinerards here and there. especially to those on the lighter soils. The last season has been marked by the insects becoming decidedly more abundant in rineyards on the hills back from the lake that were previously comparatively free from the pest. The experiments in 1903 and 1904 were continued by general observations upon the rinerards in 1905 . The result has shown beyond all question the practicability of prerenting serere injury by means of timely cultivation for the destruction of pupæ and by the collection of the beetle.

Grass lands in rarious sections of the state hare suffered. in addition to army worm and webworm outbreaks mentioned abore. from injury by white grubs: and the abundance of spittle insects (presumably Phitcrus lineatus L. and P. spumaria L.) was remarkable.

Shade trees in a number of our principal cities have been rery severely injured by larræ of the white-marked tus-ock moth (Hemerocampa lencostigma S. \& A.). The fall webworm (Hyphantria textor Harr.) has been somewhat common, particularly in the fruit sections of western New York. The elm leaf-beetle (Gatemrella Tuteola Mïll.) continues to be a serious enemy in the Hudson Rirer Talley and is now said to be generally distributed throughout Glens Falls. The European elm case-bearer (Coleophora limosipenella Dup.) has become firmly established on Long Island. It has spread from Brooklyn to Oyster Bay. in which latter place it is nearly as destructive to elms as the elm leaf-beetle. The general appearance of injured foliage is somewhat similar in spite of this species being a miner. The work of this lepidopteron is at once recognized by the circular feeding orifice and the more rectangular shape of the semitransparent areas. The maple Phenacoccus (Phenacoccus acericola King). first noticed as abundant and injurious in this section in 1.901. continues to be somewhat destructive in the lower Hudson Taller. The rare woolly maple leaf aphide (Pemphigus arevifolii Riley) is unusually numerous on Long Island and in the Hudson Talley.

The economic results of applying oil to stramp and woodland pools was strikingly brought out this summer by the statement that at Lawrence the green-headed horsefly (Tabums lineola Fab.) was decidedly more abundant than a few year's ago when this community applied petroleum to many pools for the purpose of destroying mosquito larræ. Later ditching operations have rendered the use of oil largely superfluous. and as a consequence horseflies are much more abundant than they were when the oil method was in force, a striking confirmation on a somewhat extended scale of Professor Porchinski’s observations in Russia. 
Mr. Washburn said he had found that carbon bisulphid as ordinarily used will not kill the eggs of the Mediterranean flour moth.

Referring to Mr. Conradi's paper, Mr. Webster said that a study of weather conditions would often enable us to, in a measure, forecast the abundance of insects. Thus, a cold, wet spring was likely to be followed by invasions of aphides, army worms, and cutworms. He had thought that the cold weather prevented the parasites of aphides from becoming abundant early in the season, but did not so affect the aphides. He had found the poison-bran mixture to work well in practice against invasions of cutworms. He had used it in large onion fields with success. He fully agreed with Mr. Burgess as to the importance of the jointworm in Ohio. From information received during the past season, he was quite certain that much of the damage charged up to the wheat midge had really been due to the work of jointworms. In northeastern Indiana some farmers had hesitated about sowing wheat last fall through fear of its ravages another year. The Cryptopristus had not seemed to him to fulfill expectations in holding the jointworm in check. He was rather surprised that Professor Washburn should have found no Hessian flies in Minnesota. One of his assistants, Mr. George I. Reeves, had been stationed in North Dakota during the entire summer, and had been assigned to Hessian fly investigations. Mr. Reeves had found that there were, in 1905 , probably two well-defined broods of the Hessian fly, besides a continual reenforcement by adults continuing to emerge from last year's stubble (190t). The past might have been an unusually favorable season, but another year ought to give definite results. irrom present indications the maps showing distribution of the Hessian fly in the United States will have to be greatly modified. As yet there is no ground for believing that the pest occurs south of the Arkansas River, and rarely, if at all, west of the one hundredth meridian, except, of course, on the Pacific coast.

Mr. Hinds said that in recommending fumigation of corn with carbon bisulphid Mr. Conradi had said that it was not recommended for corn intended for seed. Was the unusual strength recommended the reason for this exception?

Mr. Conradi answered that in one experiment, in which soft corn was subjected to the carbon bisulphid for twenty-four hours, the germ seemed to be injured to a great extent. Under such conditions, therefore, it would seem advisable to lessen the strength somewhat in the case of corn that was to be used for seed. In the rase of cowpeas he had used 2 pounds to 50 bushels of grain without injury.

Mr. Marlatt said that in the experience of the Seed Section of the Bureau of Plant Industry of the Department of Agriculture fumigation with carbon bisulphid was deemed perfectly safe and not 
affecting, when properly carried out, the germination of grains or miscellaneous seeds. The very large stock of seeds and grains of all sorts carried by this office is submitted to fumigation with carbon bisulphid as often as necessary to keep it free from insect pests, and usually several times a year.

Mr. Morrill said that he had made a small test on cotton seed, which was actually immersed in the liquid carbon bisulphid for a few minutes without injury to its germinating power.

Mr. Marlatt considered the use of 3 pounds of carbon bisulphid to 30 bushels of grain, as recommended by Mr. Conradi, as excessive and unnecessarily expensive. The fumigation in the manner. suggested in the loose wagons seemed to offer the worst possible conditions for effectiveness, owing to the fact of the quick dissipation of the carbon bisulphid.

Mr. Conradi said that the corn nsed had not been husked when treated, and that because of this, as well as the rapid loss of the insecticide through the cracks of the wagon boxes, it was necessary to use the large amount recommended.

Mr. Marlatt said that some doubt had been expressec regarding the efficiency of tobacco dust for the woolly aphis of the apple. He quoted from memory the substance of a letter reporting the rery successful use of this substance received from Mr. M. B. Wraite. a pathologist of the Bureau of Plant Industry, who is also the owner of a large commercial orchard in Maryland near Washington. The test was made in a 6 -year-old apple orchard containing about 1,800 trees, a good many of which (about one-fourth) showed more or less injury by the woolly aphis. Mr. Waite's description of the condition of his trees and of the treatment is here quoted:

The trees had a wiry, slender, and somewhat wore feeble growth than their uninfected neighbors, and the aphis could be found in varying quantities by digging up the roots. I bought a ton of tobaceo dust ia Baltimore, costing \$25, and applied about a peck in a circle of 2 to 3 feet around each of the trees. which were on the arerage about $2 \frac{1}{2}$ to 3 inches in diameter, while the uninfected trees usually were 4 to 5 inches in diameter. Some smaller replanted trees. from 1 to 3 years old, in the orchard we gave about a gallon, and placed the tobacco dust in a smaller circle immediately around the little tree. The result was quite satisfactory. The growth this season has been more vigorous and the twigs strong and stubby. I think I an safely saly that the remedy was a success. Perlaps it will pay me to repeat it anotler year, and I am sure I am going to go over all my young orchards, whether they are affected or not, and give them, say, a gallon per tree to trees inder 2 inches in diameter and a greater amount to the larger ones.

Mr. Burgess said that it had giren with him rery satisfactory results in a small orchard of 5 -year-old apple trees.

Mr. Washburn asked why Mr. Smith preferred the tobaceo water to kerosene emulsion.

Mr. Smith replied that the kerosene emulsion was usually poorly 
prepared, while the tobacco water seemed more easily made by the ordinary grower, which was the main reason for the preference.

Mr. Sanderson said that he had found tobacco water was more efficient, more particularly the prepared tobacco extracts.

Mr. Smith said that in Georgia he could not get good results with tobacco dust for woolly aphis. On trees 10 to 12 years old he had found living aphis an inch underneath the dust six weeks after the application. This dust was analyzed and found of fair quality.

Mr. Washburn felt especially interested in Mr. Webster's remarks on the Hessian fly. He said that it had not been reported to him as injurious in any portion of Minnesota last season. He was confident that this was the state of affairs, because he had correspondents in almost every county in the wheat-raising district, and he further got clippings from all the county papers in the State, and he was certain that if it had been found injurious he would have been informed of it. He had claimed for several years that there might be more than one brood in Minnesota in favorable seasons, and Mr. Webster's corroboration of this as regards North Dakota was gratifying.

Mr. Sanderson, referring to Doctor Felt's statement regarding Pemphigus acerifolii, said that while this had formerly been regarded as a rare insect, it was certainly not now rare in some localities. He knew it was common in Delaware, Maryland, and Texas. He had regarded arsenate of lead as inefficient against the rose beetle, but a New Hampshire graduate had found that used at the rate of $t$ pounds to the barrel it would kill them. Perhaps this was due to a difference in climate.

Mr. Marlatt said that it was a common experience at these meetings to have conflicting or opposing results from different sections of the country from what is claimed to be the same treatment for different insect pests, and the theory is commonly hazarded that the effectiveness or ineffectiveness in different localities of standard insecticides or methods of control is due to climatic differences. While there might be occasionally some basis for this belief, the theory did not appeal very strongly to him, and he thought it was being rather overworked. He believed that if a poison or other insecticide killed an insect in one locality it was very apt to accomplish the same result in another if applied in essentially the same way. The only climatic variations which were likely to affect the insecticide action are conditions of moisture or rainfall which would remove the insecticide before it had time to have its full effect; but certainly food poisons and contact insecticides, unless so influenced, should have the same results on ordinary insects within the range of the latter, and he believed that most of the differences alleged were to be explained on variations in the poison or methods of application rather than climate. 
Mr. Sanderson differed from this view, expressing the belief that there were important physiological differences due to climate. This had been forcibly illustrated by the differences in effectiveness of various insecticides on the San José scale in the Southern and Northern States in the percentage of oils required to kill the scales.

Mr. Newell, referring to previous remarks on the factors influencing the abundance of aphides, said that he had noticed that the application of Paris green to the cotton plants caused an enormous increase in their numbers.

Mr. Summers said that he believed that the number of aphides was related more closely to the number of their predaceous enemies than to any other factor. When these were absent from any cause, either by chance or because of unfavorable climatic conditions, the aphides had such enormous powers of reproduction that they would soon become abundant.

Mr. Hinds said that in using Paris green for the boll weevil the Coccinellidæ were killed and the aphides multiplied in consequence.

Mr. Schwarz said that he was very much surprised that among all the insects mentioned in the preceding papers there was not a single new importation from a foreign country; neither were there any new American species. He could not regard Cicada nigriventris ${ }^{a}$ as new. It has been received by the Department at Washington from southern Louisiana. He believed that when fuller collections were made it would probably be found that a complete series could be obtained, extending from the present noted locality in Louisiana westward through Texas into Mexico, where the species is common.

Mr. Osborn thought that while Cicada nigriventris might possibly have been incidentally noticed heretofore, Mr. Newell's paper had brought out in great detail some entirely new habits of the family. So far as is known, no other Cicada has a similar method of oviposition. It is true there is one prairie species that is known to live miles from timber, and which therefore presumably must oviposit in herbaceous plants. While there is some doubt about the determination of Mr. Newell's species, it certainly belongs to the nigriventris group, and may be merely a variety of it.

Mr. Newell said that it seemed very improbable that Cicada nigriventris should be found to extend continuously through Texas and into Mexico. A strip of territory about 50 miles wide along the western side of Louisiana and extending from Arkansas to the Gulf had been watched very carefully during the past year, and large general collections of insects made in different localities, and if the species had occurred anywhere in it in abundance it would certainly have been found. 
Mr. Washburn called attention to the large number of carabids sometimes found in cabbage fields. He had found them extremely abundant where cabbage maggots were present and believed that they destroyed these, as he had found that when taken into the laboratory they would feed freely on both maggots and puparia. He could find no reference to this in the literature.

The following paper was then read:

\section{NATIONAL CONTROL OF INTRODUCED INSECT PESTS.}

By E. Dwight Sanderson, Durham, N. H.

At the close of a paper upon the cotton boll weevil, delivered before the last meeting of this association, the writer offered the following points for consideration:

The boll weevil in Texas and the gypsy and brown-tail moths in New England are raising some points in the relations between States which before long will need careful discussion and broad-minded treatment. Here we have insects which the infested States fail to control, either through inability or neglect, and they spread beyond their boundaries. Quarantines against them are comparatively useless unless the insects are controlled in the badly infested regions. The National Govermment makes appropriations partly to aid in the study of the pests for the information of the inhabitants of uninfested States and partly to prevent spread, but it can have no authority in the latter respect without State legislation. *** But why should one State tax itself to subdue a pest which is causing it loss and others gain from increased prices, as in the case with the boll weevil, to prevent it from spreading to them? On the other hand, if it is possible for the State to do so, is the General Government justified in assuming the task if it had the authority? These are questions of a broad nature which it seems to the writer are rather new and which must be met sooner or later. In their solution an association such as this should take a leading part.

Pardon the repetition of these remarks, but they form a fitting introduction to the present discussion. Further study of this subject in relation to the Federal control of similar matters has forced the writer to the conclusion that his statement above, "but it (the National Government) can have no authority in the latter respect without State legislation," is essentially incorrect and that the Federal Government may have full authority conferred upon it by Congress for handling the whole situation. The writer's attention to this whole subject has been brought about by the invasion of New Hampshire by the gypsy moth during the present season, to which he will refer later.

The history of legislation against insect pests in this country is too well known to the members of this association to need review. Some few points may, however, be mentioned to show its present status. Legislation against insect pests in the East was undoubtedly brought sibout by the introduction and dissemination of the San Jose scale on nursery stock in the early nineties. State after State passed laws 
concerning nursery inspection and the importation of nursery stock, and some concerning inspection of orchards, etc. Some of these laws were good, others bad. Confusion for the nurseryman resulted. In late years we have been engaged in attempting to secure as much uniformity as possible in these laws, and in this effort the organization of the National Association of Horticultural Inspectors has been of the greatest value. From the first it was seen that the matter of the control of nursery stock was properly a matter for control by the National Government, being strictly a matter of interstate commerce. As a result, on March 5, 1897, there assembled in Washington. D. C., a National Convention for the Suppression of Insect Pests and Plant Diseases by Legislation. The writer finds that but few of the present members of this association were present at that meeting, though all are probably familiar with its deliberations. This convention represented the horticultural interests of the entire country. It adopted a measure which it recommended to Congress, empowering the Secretary of Agriculture to establish an inspection of all importations into the United States of nursery stock, plants, etc., and of all which were subject to interstate commerce, and also recommended an outline for State legislation upon the same subject. This proposed legislation seems to the writer to cover the matter of the inspection and control of insects disseminated on nursery stock, plants, etc., in a most satisfactory manner, taken as a whole, though some minor points might now need modification. At this meeting Dr. L. O. Howard presented a paper, in closing, in which he is reported to have said:

In conclusion the writer expressed his firm conviction that the establishment of such a service at the Eastern ports $* * *$ would many times repay the horticultural interests of the country.

In the next Yearbook of the Department of Agriculture (1898), in a most interesting and valuable article upon the Danger of Importing Insect Pests, Doctor Howard again urged the importance of such legislation. He said:

The remedy for this condition of affairs is obvious. Laws must be passed establishing a system of inspection of dangerous classes of merchandise, just as has already been done in the case of live stock, and just as has already been done in a partial way by the State of California. The passage of some such national measure as that recommended by the conrention of horticulturists and agriculturists held in Washington, D. C., March 5. would seem. from a cousideration of the facts here presented, to be abundantly justified by the constant danger which threatens our agricultural and horticultural interests.

The writer is not familiar with the inside history of the work of the committee on legislation appointed by this convention. In any event nothing came of it. It is the writer's impression that the matter at first received the opposition of influential nurserymen. Later, howerer, when it became necessary for the nurserymen to com- 
ply with many and diverse laws to their great inconvenience and annoyance, they evinced interest in securing national legislation on the matter. The chairman of their committee on legislation recently expressed to the writer his earnest desire that national legislation might be enacted upon the subject, but after practical experience in presenting the matter to Congressional committees seemed to feel that there was but little prospect of securing such action in the near future. The writer does not remember any serious discussion of the matter by any entomologist since Doctor Howard's article in 1898.

In many States the nursery and orchard inspection is now handled by separate State officials, relieving the entomologists of the experiment stations and State entomologists of this onerous police work. But in many States it is still a burden to the entomologist who would prefer to devote his time and thought to problems of research. That this work has impeded the development of economic entomology in many respects can not be doubted, though on the other hand it has undoubtedly had the effect of bringing many of us into closer touch with the people whom we are trying to serve. It would seem therefore that the entomologists of the country should be most interested in securing national legislation for this phase of insect control at least. That it is perfectly constitutional and practicable can hardly be doubted. The present work could be accomplished with much more efficiency, with greater protection to the horticultural interests, and with far less annoyance to the honest nurserymen of the country, and probably to the greater detriment of the man who fails to clean up his nursery. Why the economic entomologists have failed to interest themselves in this matter has always been a mystery to the writer.

But at this same national convention of 1897 a resolution was passed concerning Congressional appropriation to aid Massachusetts in its fight against the gypsy moth, as follows:

Resolved, That this is a question of national importance, and that the National Government should assume the work of extermination or render substantial financial assistance to the State of Massachusetts for that purpose, that the work may be carried to a successful conclusion and this continent be thus saved from the ravages of another terrible insect pest.

In passing this resolution the convention recognized the responsibility of the Federal Government in protecting the uninfested States from the spread of the gypsy moth, which by precedent would involve the same aid for all other insect pests of sufficient importance to warrant it. It is in this phase of the question that New Hampshire is now particularly interested. We can probably, with the aid of an appropriation from the State legislature, which would not be burdensome and which the writer has no doubt will be made at the next session, 
prerent the spread and increase of the grpst moth in New Hampshire by annual inspections along all highwars liable to infestation. But without the expenditure by the State of Massachusetts of a rery much larger sum and in a more efficient manner than is now possible under its present law, it will be but a few rears until the gypsy moth will be so abundant in Massachusetts up to the New Hampshire line that it will be practically impossible to prevent its spread or to control it in New Hampshire.

New Hampshire is thus ultimately helpless to prerent the invasion of the grpsy moth, and the possible destruction of her grand old elms. shading the highways. her important lumber interests. and forest-clad mountains - the features which make the State one of the most beautiful and attractive in the Union-unless Massachusetts may be aided by liberal appropriations from the Federal Gorernment. so that the further spread of the pest may be checked and it may be increasingly controlled where it is worst. To this end bills have been introduced during the present session by Hon. E. W. Roberts, of Massachusetts (H. R. 285 and 286 ). appropriating $\$ 250.000$ for the extermination or control of the grpsy moth and $\$ 15.000$ for the importation of parasites and predaceous enemies, to be administered by the Secretary of Agriculture. These measures have the hearty support of New Hampshire. and, the writer belieres. of all the best interests in New England, and we trust that they may be indorsed by appropriate resolution by this association.

Yet. although we earnestly desire this appropriation for immediate use. it seems to the writer that the whole matter of the relation of the National Gorernment to the control of insect pests is in an unsatisfactory condition. Who can guarantee that this appropriation will be repeated? How can it be administered under present laws. except through the officials of the State of Massachusetts? In New Hampshire we have no legislation upon the matter at present. and aṇ action would have to be taken entirely with the permis-ion of property owners-as at present no damage to property would be involved-and by the approval of the goremor. If the National Gorernment has the power to make an appropriation for this purpose. why has it not the right to provide the proper machinery for its administration. whenerer the necessity may arise. from other pests in rarious parts of the country. without special subsequent action of Congress authorizing same: and if Congress has such perogatives. why should they not be exercised for the benefit of the agricultural and horticultural interests as well as for the city trees and for the entire country? To show the propriety, feasibility. and desirability of such legislation is the writer's purpose.

That national control of introduced insect pests would be of the 
greatest value can hardly be doubted after a brief glance at the history of the worst introduced insects of the last twenty-five years. Had there been a Federal official with authority to proceed and stamp out and control the San Jose scale when it first appeared in the East, could not its spread have been to a very large extent prevented, if not, indeed, entirely stopped? Or, similarly, if a Federal official had commenced the extermination or control of the gypsy moth in the eighties, before the work was taken up by Massachusetts, and had supervised the work of that State, being ready to step in and prevent the subsequent spread of the pest sufficient to endanger the neighboring States, would not the alarming conditions now existing have been to a large extent prevented? The same is true of the brown-tail moth. The gypsy moth committee of Massachusetts fully appreciated the danger of this pest, which in many respects is worse than the gypsy moth, but they had no funds with which to combat it. Later, a small appropriation was made, but it was entirely inadequate and was made too late to control the pest. Had the money been available when the brown-tail moth was first discovered, and efficiently administered, we have no doubt that it might have been effectively controlled. How much loss it will now cost in years to come is entirely problematical, unless the European parasites become of immediate value, for there is nothing to prevent its sprear! over the entire East within a few years. Last year it spread over 100 miles in New Hampshire. Again, when the boll weevil was discovered in southern Texas, a representative of the United States Department of Agriculture appeared before the legislature of Texas and advised legislation which would prevent for a few years the growing of cotton in the infested counties-which grew but a small amount-so that the pest might be exterminated; but he was literally laughed down. Had the Federal Government been able to step in at this time and enforce whatever measures seemed best to prevent the subsequent spread of this insect throughout the cotton belt, the subsequent loss of at least $\$ 22,000,000$ to Texas alone in 1904 and the present certainly unpropitious outlook for the cotton interests of Louisiana and the Mississippi Valley might have been averted.

Might not the introduction have been prevented of the despicable little New Orleans ant (Iridomyrmex humitis Mayr) which is now becoming such a nuisance here in New Orleans and southern Louisiana and whose spread through the South it would now seem well-nigh impossible to prevent or restrict, and might not its spread have been controlled when it was first discovered had we had such national legislation and organization?

Other instances might be cited, but these are well known to all. Who can tell what pest may not invade some one of our boundary 
States at any time and increase to such numbers that it will be impossible to prevent its spread before State legislation copes with it? It is to be regretted. but we may as well frankly admit that the present tendency toward Federal control of all of these police duties is almost entirely due to the inefficiencr of most of our State legislatures in dealing with such matters. Until very recently the States have been very reluctant to delegate any power to make and enforce regulations to any board or official. In doing this the Gulf States in general have the most desirable type of legislation, permitting effectual work against any insect pests which may arise. In most of the States which have legislation upon insect pests the official administering the laws is hampered by petty restrictions and has no funds at his lisposal for coping with any new pest which may require immediate action. The arerage State legislature is rery wary of intrusting such powers to any scientist, assuming in many cases that it knows much more about the subject. The debates of the Texas legislature upon the boll weeril and the information giren the writer by some of its members would prove amusing reading to the entomological fraternity. Congress, on the other hand, has consistently recognized that it must depend upon experts in such work and must give them sufficient latitude so that they can take immediate action when necessity arises. To this has been largely due the efficiency of the Federal law in very many matters in which the State laws hare been conspicuously inefficient.

How many of our seaboard or frontier States have at the present time any system of inspection which will enable them to prevent the importation of injurious insect pests, or how many. eren. could proceed to eradicate such a pest when actually within the borders of their State when orer a few hundred dollars were necessary for its eradication? As far as I know. California is the only State having any adequate machinery for such work.

But it is objected that such work of exterminating an insect within a State would be unconstitutional. an interference with the rights of the State. etc. So it would seem. and so it at first appeared to the writer; but the present laws of Congress concerning the control of cattle and human diseases and the regulation of the importation of noxious animals effectually dispel this objection.

At the present time the Public Health and Marine-Hospital Serrice has charge of most of the maritime quarantine stations and may take charge of any others it sees fit when they are inefficient under State or municipal management. It furthermore may enforce interstate quarantines or may quarantine any portion of a State, and take such measures as it sees fit to eradicate disease in any locality when the local or State health officials, either through lack of legislation or 
inefficiency, fail to control disease, so that it threatens neighboring States. This has actually taken place in several instances. ${ }^{a}$

At the present time the Southern States are petitioning Congress for the National Government to take entire control of maritime and interstate quarantines, owing to the proven efficiency of the Government service in handling the yellow-fever outbreak during the past season. Surely there can be nio better proof of the desirability of Federal control of quarantines than the present attitude of the Southern States, for no section of the country has had their experience with quarantines and no section has been more opposed to Federal quarantines in the past. ${ }^{b}$

By the Lacey Act ${ }^{c}$ Congress has conferred upon the Secretary of Agriculture the power to make and enforce regulations to prevent the importation of noxious animals, and this act has now been enforced for five years. In essence, the law proposed by the convention of 1897 would cover the same ground for the prevention of the importation of insect pests.

But more stringent, sweeping, and effectual than either of these laws are those establishing and defining the duties and powers of the Bureau of Animal Industry of the Department of Agriculture. ${ }^{d}$

These laws and regulations empower the Bureau of Animal Industry to inspect all import and export domestic animals and all subject to interstate commerce for dangerous diseases. They empower it to proceed to stamp out such diseases as are deemed dangerous, and to purchase diseased animals at a fair appraisal when necessary to stamp out a disease. In this work the Bureau may and has repeatedly quarantined different States and sections of States. At the present time the regulations of the Bureau prohibit the movement of cattle from counties south of the Texas-fever line to other counties

$a$ For a full discussion of Federal quarantine measures, see an article by James Wilford Garner, of the University of Illinois, in the Yale Review for August, 1905, pp. 181 to 205.

$b$ See the Congressional Record of March, 1893, vol. 24, H. R. 9757, second session, Fifty-second Congress, debate, House, 717, 750, 793 ; Senate, 1037, 1243, 1337, for the lengthy debates in the Ilouse and Senate upon the present national quarantine law, which was admittedly a compromise measure.

$c$ See Circular 29, Biol. Surv., U. S. Dept. Agric.

$d$ See Regulations of the Secretary of Agriculture governing the Inspection, Disinfection, Certification, Treatment, Handling, and Method and Manner of Delivery and Shipment of Live Stock which is the Subject of Interstate Commerce, 1905. Issued under authority conferred on the Secretary of Agriculture by the acts of Congress approved May 29, 1884, Feb. 2, 1903, and Mar. 3, 1905, which acts are printed in it. Also see Administrative Work of the Federal Government in Relation to the Animal Industry, by G. F. Thompson, 16th Annual Report Bureau of Animal Industry, 1899, pp. 102-125, and Federal Inspections of Foreign and Interstate Shipments of Live Stock, by D. E. Salmon, D. V. M., 18th Ann. Rept. Bur. Anim. Ind., 1901, pp. 23i-249. 
within the same State, whether the cattle are for interstate commerce or not. These laws and regulations have been tested in the courts. and so far have been held constitutional.

Furthermore, Congress appropriates for the Bureau of Animal Industry a sum which is specifically for the control of outbreaks of disease. By this means the Bureau was able to proceed at once against the foot-and-mouth disease in New England in 1902. A deficiency appropriation was at once authorized by the next session of Congress (for $\$ 500,000$, approved December 22, 1902), which enabled the work to proceed without delay. A similar amount was included in the regular appropriation for the Bureau for the fiscal year ending June 30, 190t, but the work had been so thoroughly done under the previous appropriation prior to that time that but little of the last appropriation of $\$ 500,000$ was used. It was a portion of this unused balance, $\$ 250,000$, which was subsequently appropriated for the investigation of the boll weevil and cotton culture, I believe.

Not only do the regulations prohibit the movement of diseased cattle or any cattle from a quarantined State or section, either by shipment or driving, but they prohibit allowing cattle to drift from one section to another. Furthermore, any hay, straw, or other material which may harbor disease from a quarantined area may be entirely regulated by the Bureau. (See Regulations 1, 6, 8, 19, and 43 , particularly.) Further enumeration of the powers and methods of administration of this Bureau is unnecessary, but a perusal of the references cited may prove interesting to those unfamiliar with them.

If, therefore, Congress through these agencies is preventing the introduction of human and animal diseases and noxious animals, and their interstate movement, and eradicates or controls them in sections where their presence threatens the commerce and welfare of other States, why may not the spread of imported insect pests dangerous to plants be similarly regulated? The writer has studied the principles involved with some care and fails to see that they are not identical.

An interesting phase of the whole discussion, and one of local interest here, arises from the recent convention of the Southern States, which passed resolutions not only praying Congress that the National Government take charge of all quarantines. but that it proceed to the extermination of the yellow-fever mosquito. Whether extermination of this pest is possible or not I am not informed. From experience with other insects it would seem doubtful. There can be no question, however, that in order to control the yellow fever the breeding of Stegomyia calopus must be prevented. In the control of yellow fever the Federal Government would therefore have a perfect right to proceed against this insect as a menace to human health. 
We have then the anomalous condition that the National Government can control the introduction and spread of insects which affect the health of man and the domestic animals, but that it has no laws against those affecting crops or plant life. Will the opponents of such legislation show wherein the principles involved differ? Is not the loss to plant life from insect pests far greater than to either human or animal life? How do the values of animal and plant products compare? According to the Report of the Secretary of Agriculture for 1905, the domestic animals of the United States were worth $\$ 2,995,370,277$ in 1904 . There are no figures as to the exact value of animal products, but estimating a similar increase from 1900 , they would be worth approximately $\$ 2,000,000,000$. 'The total value of farm products is estimated by the Secretary for 1905 at $\$ 6,415,000,000$. Plant products would therefore be worth approximately $\$ 1,415,000,000$, the ten staples alone being worth $\$ 3,515,000$,000, while the value of all domestic animals and their products would be $\$ 4,885,572,394$. In short, the plant products are more than twice the value of the animal products, and practically equal in value both the live animals and the products which they produce. These estimates include the value of the products of so-called "farm forests," but do not include the value of lumber or the virgin forests not on farms. Nor is the inestimable value of city shade trees and parks nere considered. The losses occasioned by insects, exclusive of those to animals and stored products, have recently been estimated by $\mathrm{Mr}$. C. L. Marlatt at $\$ 520,000,000$, which is entirely conservative.

We would venture the assertion, therefore, that the annual losses occasioned by imported insect pests far exceed all losses of animals from disease and of those human diseases which are subjects of National quarantine. Of course we can place no money value upon human life, but were that possible, we have no doubt that the loss of plant products from a half dozen insect pests imported during the last quarter century would far exceed all losses from animal and human diseases which within that time have been the subjects of National quarantine.

The gypsy moth at present threatens the welfare of New Hampshire, Rhode Island, and, indeed, all New England, and, if unchecked, ultimately the whole country. Massachusetts has done, is doing, and we believe will do all in her power to check the pest within her borders. But why should her citizens be taxed sufficiently to prevent its spread to neighboring States? And what recourse have the other States if Massachusetts does not prevent such spread? It would seem that Massachusetts is maintaining a public nuisance as far as the neighboring States are concerned, but it is doubtful whether a suit could be entered against her on that ground even theoretically. 
while actually it is, of course. entirely improbable. Ner Hampshire and other States can not appropriate to aid Massachusetts. Why, then, is it not the duty of the Federal Gorernment to protect the interests of the neighboring States by checking the spread of the grpsy moth and aiding in its control. The same reasoning will apply to all other introduced insect pests of serious importance. Te will all admit that the Federal Gorernment may prevent their importation, but some of us would claim that as soon as a pest has come upon the territory of any State that the National Government is then powerless to prevent its spread to other States. This same argument has been fully thrashed orer in Congress concerning human disease, and the present law as above outlined and administered seems to the writer to have fully demonstrated that the Federal Gorernment has such a right and may make and execute such regulations as seem necessary. With such national laws and regulations we believe that the introduction and spread of insect pests, either by transportation or natural agencies, could be largely prerented. At present under the State laws they are not and can not be.

Your serious consideration as to whether it is not entirely feasible for Congress to so legislate as to empower the Bureau of Entomology, or such agency as it may deem best. to make and enforce such regulations as will prevent the introduction and dissemination of insect pests, and to appropriate sums sufficient to allow such work to be done at once, without awaiting special appropriations, is therefore urged. It would seem to the writer that only in this manner can we have efficient means of preventing the future importation and spread of insect pests which will cost the Nation millions upon millions of dollars, as those have done with which we are now familiar.

If such legislation seems desirable. no one association in the country could have more influence toward bringing it about than the Association of Economic Entomologists. through the wide acquaintance and close touch and influence with the interested organizations of its members in their respective States.

In conclusion, might not this association invite the officers of the National conrention which met in 1897 to call a second meetivg of that convention at such time as might seem best, and urge the organizations represented in it to rote sufficient sums so that wise counsel might be secured and the legitimate expenses paid of men who might work toward the passage of such legislation. To secure such another meeting would require at least sereral months, possibly a year's work. Is the time not ripe for such a morement? should not the Association of Economic Entomologists be sponsor for it? 
Mr. Webster said that as one of the original promoters of the horticultural gathering in Washington in 1897-he having drawn up the call for this meeting, as secretary of the executive committeeand with others joint author of the quarantine and inspection bill afterwards presented in Congress, and after two conferences with Senate and House committees, he had a pretty good opportunity to become acquainted with these matters. The failure of this measure was not the fault of Congress, as that body was ready to do what was necessary, but there was a lack of unanimity among the people as to just what ought to be done, and Congress had wisely decided not to do anything under such conditions of public opinion. The fact seemed to be overlooked that there was vast difference between an element that threatened human health and life, and one that only threatened certain products of the soil. Neither the boll weevil nor San Jose scale threatened human life or health, and therefore was not to be considered in the same light as Texas fever or yellow fever, and it was doubtful in his mind whether the Government could proceed in the same way to quarantine against or control the spread of the same. Certainly Congress had no authority to legislate regarding insect pests and plant diseases within the boundaries of any State, except as articles of interstate commerce. Congress might order a man to inspect certain premises in any State, but without legislative permission from that State he could not legally obey his instructions, except upon Government reservations. He was not opposed to any measure the object of which was the control of insect pests, but had learned from experience that not all reasonable or seeming necessary projects of this sort could be carried out. He always had and still believed that national legislation should come first and State legislation in uniformity therewith follow afterwards.

Mr. Marlatt said that he was in accord with most of the suggestions presented in Mr. Sanderson's paper and that he believed there was a distinct tendency on the part of the Federal Government to undertake legislation for the direct protection of people, both in the line of food products and in the protection from insect and other natural enemies, but that this would undoubtedly first be in the direction of protection or quarantine from foreign countries, and later looking to interstate control. Personally, however, he doubted the advisability of Congress spending large sums of money for the local control, or particularly attempts at extermination, of such well-established pests as the San Jose scale, the boll weevil, or the gypsy and brown-tail moths. It is perfectly legitimate, however, to provide for the checking or prevention of the spread of such pests, at least wherever there is a chance of accomplishing something in a practical way, and to attempt to stamp out any newly introduced enemy before 
it has become so distributed or well established as to make a successful outcome improbable.

Mr. Morgan called attention to the Texas-fever problem, which seemed to him of national importance. This problem. for reasons which are at once evident on considering the history of our knowledge of the disease is largely in the hands of the reterinarian. Since, however, its relation to the cattle tick has become known. it seems that entomologists, throughout the quarantined section at least, could aid rery materially the problem of tick extermination by devoting some time to life history and habit study and by cooperation with farmers willing to eradicate the cattle tick from their places. The extermination of the cattle tick from the United States is quite possible under an aggressive educational and cooperative campaign.

Mr. Sanderson, referring to an objection of Mr. Webster"s, said that it was true there was a sharp distinction between plant diseases and human diseases, but that he thought the comparison ought to be made rather between the diseases of domestic animals and plant diseases. The laws concerning the diseases of domestic animals are eren more drastic than those relating to human disease. He agreed that it was too late to attempt the extermination under national control of such well-established insects as the San Jose scale or the brown-tail moth.

Mr. Rolfs thought the time more favorable for national legislation than 1897. Nurserymen take a very different riew of the matter now from that held then.

Mr. Hunter believed that the time was ripe for national legislation. He felt that there had been arising for sereral years a stronger and stronger belief in its advisability. He mored that a committee of five be appointed to report before the end of the present meeting. making recommendations regarding the National control of introduced insect pests. The motion was carried. The Chair appointed as such committee Messr's. Hunter. Sanderson. Morrill. Howard, and Hinds.

MORNING MESSIOY. WEDYESDAY, JANTARY 3, 1906.

BOLL-IVEENIL SYMPOSIUM.

The following papers on the boll weevil were presented. the di-cussion being postponed until the entire series had been read:

\section{THE PRESENT STATUS OF THE MEXICAN COTTON BOLL WEEVII.}

By W. D. II cuxter. Washington, D. C. 


\section{A CONSIDERATION OF THE CULTURAL SYSTEM FOR THE BOLL WEEVIL IN THE LIGHT OF RECENT OBSERVATIONS.}

By A. F. Conradi, College station, Tex.

The past season marked an epoch in cotton growing in Texas. Ever since the advent of the cotton boll weevil there has been a general inclination on the part of the cotton growers to the application of sprays or the operations of various kinds of machines and nostrums for the rapid suppression of the pest. The disappointments were many, yet people continued to hope along that line. They had almost superhuman faith that scientists would discover some simple boll-weevil exterminators. These hopes could not be satisfied, and the boll weevil was at one time regarded as the greatest curse in the cotton-growing section of the State. The various entomologists and the boll weevil commissioner's received many requests for testing machinery. The most recent agitation was in regard to the efficacy of Paris green.

Although the cultural system had been recommended by the Bureau of Entomology of the United States Department of Agriculture as the chief source of reliance in securing a cotton crop, something simpler and quicker was desired. Now, however, the people are ignoring the different machines and nostrums and have ceased to look to such measures for relief. At the same time good cultivation is so thoroughly appreciated that many are at a loss to know whether the boll weevil ought to be regarded as a friend or an enemy. The progress of the boll weevil has created a revolution in cotton culture of far-reaching importance. This fact is fully realized by the thinking public, who are accepting the cultural system as the most reliable and rational procedure in the production of a cotton crop. The inquiries received by us bear out this point very forcibly. No longer do we hear the monotonous questions: "Which is the best machine with which to destroy the boll weevil?" "Which is the best arsenical with which to poison the boll weevil?" Not one such question was asked during the past season-not even questions similar to those. At present, however, inquiries received are: "Where can I get a good early cotton seed?" "Should the seed bed be flat-broke or ridged?" "Which is best-shallow or deep cultivation of cotton?" Other general information on cotton culture is often asked for. Again we are frequently in receipt of letters asking for advice as to the prudence of shipping cotton seed from infested to uninfested localities and for the method of fumigating the seed, showing that the farmer desires to take every precaution to avoid dissemination of the weevil through the markets. A great many inquiries regarding the fall destruction of cotton stalks reach 
us. Thus we are a mare that in the future the cultural system will be the main reliance in the cultivation of cotton in Texas.

The first recommendation in the cultural system is early planting. Early maturing rarieties should be obtained from territory uninfested by the reeril. The ralue of this recommendation is fully recognized and can be carried out in normal seasons in Texas. Last season. however, a great part of the cotton was planted late on account of the prolonged wet weather during the late winter and spring. The department of entomology of the Texas experiment stations planted its cotton on March 18. The weather was open for four successive days, and a considerable amount of cotton could have been planted orer the State if the seed bed had been previously prepared. As it was, however. many farmers had to plow. It is thoroughly advisable that cotton be planted at such intervals of good weather in the rainy season, but the seed bed must first be prepared properly. The writer had an experience during the past season with the experiment station cotton referred to abore that fully convinced him of the ralue of this recommendation. The seed bed had been flat-broken in winter and was in excellent condition at planting time. Without ridging the seed bed the cotton was planted. On March 21 another prolonged wet season set in and one-half of the cotton washed away. The other half germinated, and in spite of the prolonged saturation of the atmosphere and soil held its own, and when the weather cleared, about April 2. made rapid progress and was squaring April 18, the first lock opening July 15. As a rule, all cotton made in the locality of College Station should be made July 15-that is to say. any squares forming after July 15 stand a poor chance for making bolls in a weevil year.

The cultivation of this cotton was shallow. but repeated every ten days. This operation served as a mulch. It requires less labor than the deep furrowing by the middle busters. and was a better moisture conserver on account of the fact that the smallest possible surface was exposed to the drying action of the sun and wind.

\section{FALL DESTRLCTION OF COTTON STALKS.}

During three successire seasons we have closely watched the hibernation of the boll weeril. These observations were made during the fall, and checks were kept in cages. In the fall of 1903 the reeril went into hibernation. beginning Norember 17 at College Station. This was the night of the first heary frost. In $190+$ hibernation hegan Norember 7 . following the night of the first heary frost. During the fall of $190 \mathrm{~s}$ the entering into hibernation differed from those of $190 \pm$ and 1903 in that it was gradual and not so abrupt as in 
the other seasons mentioned. It was due to the prevailing temperature conditions. The killing frost was preceded by several light freezes, which, however unpleasant to the weevil, would not induce the insect to enter hibernation, since the days were invariably warm enough for the weevil to continue feeding. The experiment-station cotton was thoroughly frozen on the night of November 27-two to three weeks later than in the last two years - after which the weevil disappeared from the cotton field in the course of three days. These observations were made on the experiment station's own cotton. During the fall of 1903 observations were made on cotton stalks burned before frost, the effect of which, however, could not have been fully brought out on account of the miscellaneous purposes for which the plat was used the following year. During the season of 1904, in addition to the weevils already present in the fall, thousands of specimens were brought in from other fields to be used in experimental work, so that there was every opportunity for a large percentage of hibernating weevils to pass through the winter, a wooded ravine very near the cotton plants offering shelter. During the early days of September the cotton leaf-worms (Alabama aryillacea Hbn.) made their appearance. They increased rapidly, and about October 10 there was not a green particle of cotton left in the field. The great number of weevils present disappeared. No opportunity was given the plants to put forth leaves again during the next rain, but all stalks were destroyed, put up in piles in the field, and burned about a week after the first frost, when it was certain that all weevils nere in hibernation. The ravages of the cotton leaf-worm gave us the same condition as though we had destroyed the stalks about October 10. It followed that the injury to cotton this season amounted to nothing, notwithstanding the fact that we were delayed in planting in spring.

The cotton leaf-worm gave us a rery conclusive demonstration of the value of the fall destruction of cotton stalks. It the cotton had not been destroyed the previous fall, damage would have been done by the weevil, yet without the thorough cultivation the absence of the weevil would not have secured us such a heavy cotton crop, which was fully shown by observations made on other plantations during the dronght. The cotton leaf-worm, which for many years has been a great enemy to the cotton planter in the cotton States, was a very efficient ally during the fall of $190+$ in destroying the hibernating brood of boll weevils on Upland cotton at College Station. During 1905 its efficacy in this respect amounted to nothing. The frequency with which it can be depended on varies in different localities. Some planters report that the worm is destructive in their localities during fall nine years out of ten. The writer has given careful attertion to the study of the practical side of predaceous and parasitic 
insects, and is frank in saying that the extent to which this subject has been ignored under Texas conditions is regrettable. And, although this problem of enabling the cotton leaf-worm, whenever possible, to become an ally in boll weevil destruction is almost unimportant when compared with the value of many predaceous and parasitic species affecting other insect pests, it should be made clear to the farmer that if judiciously managed he may enable the leaf-worm to help him combat the boll weevil by allowing it full liberty in the cotton plantation during September and October. It is evident that where the caterpillars are not destroyed in late fall they will pupate and many more will successfully pass the winter. With the fall destruction of stalks, however, and a thorough cleaning of the fields, this obstacle could be removed.

\section{WHAT IS MEANT BY THOROUGH CULTIVATION.}

Frequently we are asked what is meant by thorough cultivation in the cultural system of the Bureau of Entomology. Attempts have been made to give as specific answers as possible, but we soon found that this would become a very intricate procedure on account of the varying conditions in different sections. Some seasons we must cultivate often; others less frequently. Again, cultivation varies with localities and soils.

The two principal results to be obtained by thorough cultivation are (1) a mulch: (2) the keeping down of weeds. When a crop of weeds has gained the advantage over the farmer's industry on account of a prolonged wet season, it is for the farmer to conclude what kind of cultivation he shall give the field to remore this stand of weeds. When this is accomplished, all his attention should be given to the maintenance of a mulch between the cotton rows. In bottom cotton, where moisture is abundant and heary rains may occur during the growing season, the cultivation with a shorel plow may sometimes be best, as it serves as a drainage system. On Upland cotton, however, the problem is entirely different, and when the drought begins the cotton will suffer least in the well-mulched field. Thus by thorongh cultivation we mean the maintenarce of a surface layer of soil cultivated with sufficient frequency so as to form a blanket of dry soil at the surface. This will retard the evaporation of moistire. This blanket of dry soil must be the criterion for the intelligent farmer to judge how many cultivations he should give his cotton. This loose surface soil may be affected by light showers of rain. The crust which is then formed at the surface will destroy the mulching power of the soil blanket, and cultivation should therefore follow at once. 


\section{FERTILIZERS.}

Our experience in experimenting with fertilizers has been limited. It was strictly confined to a very small part of the experimental cotton plats at College Station. We are fully convinced that acid phosphate is the all-important fertilizer under our conditions-the soil being about 2 feet in depth, of a sandy nature, and underlaid by an impermeable clay pan.

Summarizing what has been said, we come to the following conclusions, which must guide us in our work at the present time: First, that the cultural system is the only reliable procedure in the prorinction of a cotton crop in Texas; second, that this system, in order to be effective, must be intelligently carried out in all of its important details; third, that the fall destruction of stalks is less generally practiced than other recommendations made, as embraced in the cultural system, and needs effective campaigning; fourth, that shallow cultivation on uplands should be more universally practiced, because it forms the most perfect mulch and saves labor and expense; fifth, that by thorough cultivation is meant such a number of cultivations as will insure the maintenance of a blanket of dry soil at the surface of the ground.

\section{LABORATORY METHODS IN THE COTTON BOLL WEEVIL INVESTI- GATIONS.}

By W. E. Hinds, Dallas, Tex.।

By way of introduction, let me state that I shall interpret my subject as including not only the methods in the cotton boll weevil investigation which may be classed as strictly "laboratory," but also those field methods which have been employed in checking laboratory results and in determining under the most natural conditions many of the most important answers to questions regarding the life history, habits, enemies, etc., of the weevil. 'Though used in the field, these are, in a broad sense, "laboratory methods," and will be so considered. Unless indoor results are checked by observations made in the field, important points are sure to be overlooked and serious errors are apt to creep into conclusions drawn from the work. I shall touch briefly, as is necessary, upon methods employed in three divisions of the work-namely, research, record, and illustration. Though no claim for originality can be made for many of these methods, I shall endeavor to avoid taking up time with that which is the common practice of economic entomologists, and confine myself to those methods which contain some suggestion of newness either in theory, practice, or equipment. 
As a foundation for the study of any insect pest from an economic standpoint, there must be a rather accurate study and knowledge of at least the main points in its life history. The same apparatus and methods are not likely to prove equally well adapted to the study of widely different species, and there must be therefore more or less of an adaptation in these respects to the specific study of each insect.

From the beginning of the boll-weevil investigation much attention has been given to obtaining "individual records." To obtain these, isolation of specimens was essential, and as the nature of the food supply was very perishable, requiring its frequent renewal. some form of breeding jar was required which would facilitate the work of daily examinations. After trying several forms of cage, we settled finally upon the following type as best suited to our needs (see Pl. II, fig. 2) : The base was formed of a 4 or 5 inch flower-pot saucer, filled level full with earth. On this was placed an ordinary lantern globe, covered above with a single thickness of cheese cloth held in place by a rubber band around the top. In general practice it was found advantageous to place a cotton leaf large enough to cover the saucer upon the dirt before placing the food supply and covering with the globe. The principal advantage of this cage lay in the facility with which the specimens might be moved from place to place and the ease with which the top might be removed, giving free access to the Equares or bolls within the bracts of which the weevils were, as a rule, hiding. The cloth cover rarely required remoral, and if weevils had crawled to the top of the globe they were there safely inclosed while the necessary examination of the food supply was being made. 'These globe cages were found to be equally well adapted for work with from one to ten weevils. A larger number than this would require a larger cage.

An adaptation of the type of box used in capturing parasites of scale insects and described in the First Biennial Report of the Commissioner of Horticulture of the State of California has been found very useful in the breeding of parasites and also of the weevils themselves. The box (Pl. II, fig. 1) may be of any size desired, but must be tightly joined throughout. Te have found a box about 6 or 8 inches deep and wide by 10 or 12 inches long a convenient size for our work. In one side are two rows of holes cut to fit almost any size of glass tube at hand. The number of holes depends partly upon the number of insects to escape, but unused openings may be easily closed with cork stoppers. Small crevices around the tubes are closed with a few thicknesses of cheese cloth or cotton wound around the tube. The cover should fit tightly but be easily removable. The escaping insects naturally make their way to the light, and may be removed by exchanging tubes without danger of losing valuable specimens or the necessity of handling those that might be easily crushed. An 

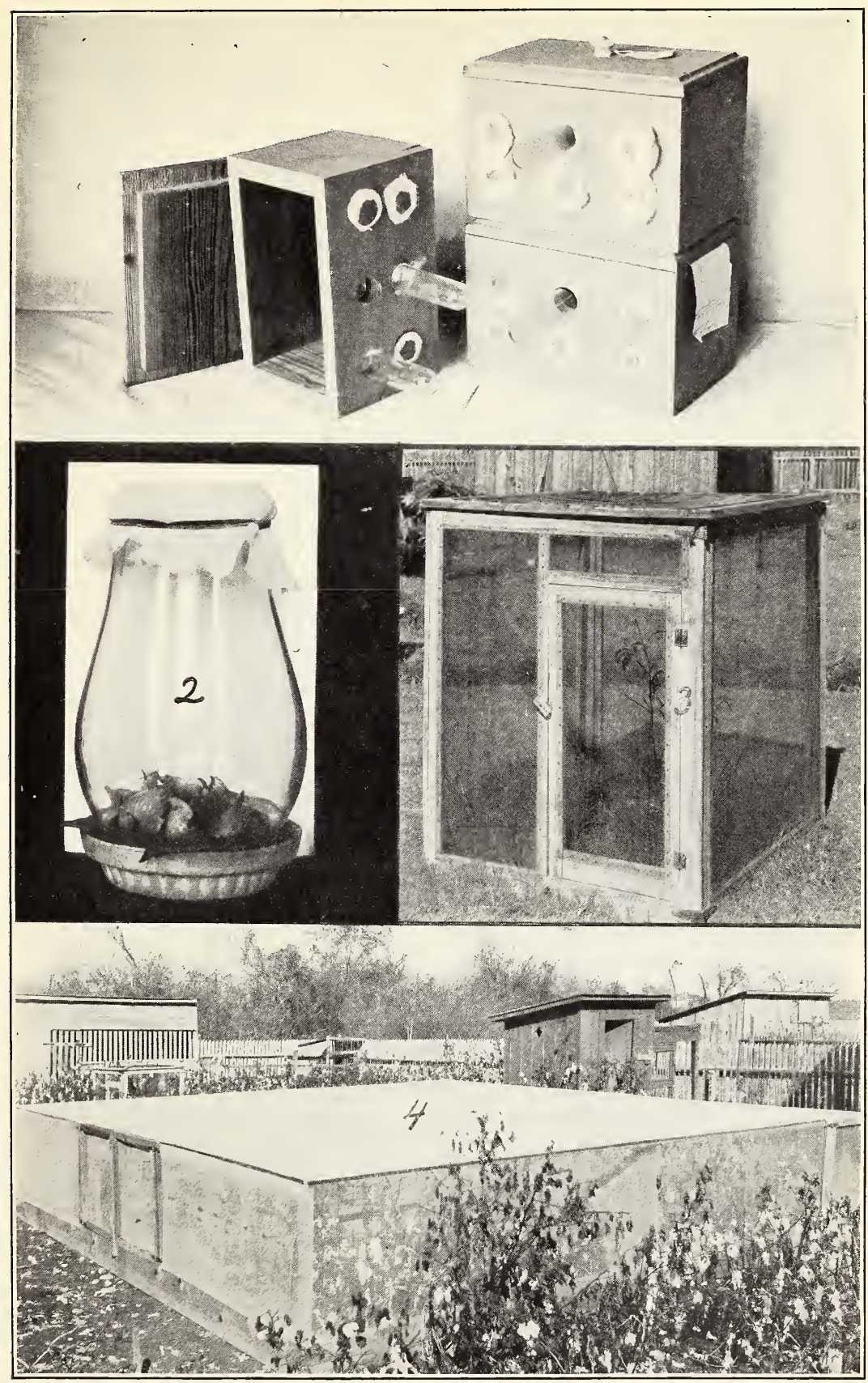

Laboratory Methods in the Cotton Boll WeeVil inVestigations.

Fig. 1.-Boxes used in breeding parasites and weevils. Fig. 2.-Breeding jar used in lifehistory work. Fig. 3.-Folding cage used in field experiments. Fig. 4.-Wire-screened cage used in hibernation experiments. (Original.) 

added improvement to this box as described, for some purposes, has been made by Mr. Wilmon Newell, secretary of the Louisiana crop pest commission, who has been cooperating with the Bureau of Entomology in the fight against the boll weevil. It consists of a plate of glass fitting smoothly upon a narrow projecting ledge formed by a wooden strip tacked around the box on the inner side and near the top. This allows the removal of the cover and facilitates inspection without the danger of allowing the escape of insects which have not entered the tubes.

Since its first advent into Texas there has been more or less speculation as to how far north the weevil might be expected to spread. The probable influence of the lower average temperatures encountered in more northern latitudes also became a question of much importance. To obtain a safe basis for forming conclusions upon many important questions of this kind, it became necessary to secure much data relative to temperature effects under conditions which could be kept uniform and under the absolute control of the investigator. For observations at temperatures ranging above the normal, a small-size incubator has been found to answer well; such questions as those of ventilation, humidity, etc., being carefully guarded. For temperatures ranging below the normal ready-made apparatus can not be so easily secured. Ordinary refrigerators may give temperatures as low as $40^{\circ} \mathrm{F}$., but their construction is not such as to allow of approximate control of the temperatures intermediate between that of the ice box and that of the outside atmosphere. To meet this need it was found that a box must be built to order, and one was designed having three compartments below the ice box in which the temperature could be varied at will in each compartment without affecting the others. Two compartments were dark, while the third was lighted through double glass windows. When desired a thermograph could be placed in any one of the compartments and an siccurate record obtained of the temperature prevailing for any desired period. The temperature above all compartments was kept uniform by the retention of the water from the melting ice. IVith the incubator and this ice box the development of the weevil could be tested for any temperature, and from the periods found the total effective temperature required to allow complete development at any mean temperature could be quite accurately determined. This work led to the prediction that around Dallas, Tex., there would be one less generation of the weevil than at Victoria, and such has since been found to be the case. One of the most important results of this work has been the demonstration that the number of generations, the period in each developmental stage, and, in a general way, the destructiveness of an insect, can be thus determined for any new locality $31024-$ Yo. $60-06 \mathrm{M}-8$ 
where the ITeather Bureau records make available the general facts as to temperature and rainfall.

Passing, now, from the indoor to some of the outdoor phases of the work, I would say that the field cages covered with 14-mesh wire netting have been of great value. These cages (Pl. II, fig. 3) are about $3 \frac{1}{2}$ feet square by about 4 feet high. The latest type is so constructed that the top may be remored and the four sides folded flat. This is quite essential where the cages may need to be shipped or moved from one place to another. All fastening to set up the cages and fix the top in place is accomplished by screw hooks and eyes. In one side of the cage is a door about $1 \frac{1}{2}$ by 3 feet in size and opening outward. Within there is ample room for the investigator to work. The field cages have been found useful not only in life-history work, but also in remedial work as well. As an illustration of one way in which the outdoor work in the cages proved of great value as supplementing the observations made in the laboratory, I would describe very briefly the experiment made to determine the average number of eggs deposited daily by the average weevil. The first laboratory records obtained indicated that between two and three egos were deposited daily by the arerage weeril. Five females which had begun laying were confined in one of the field cages placed over a plant which had not been attacked by the weevil. The daily observations extending over several weeks showed that these weevils were depositing an arerage of between 5 and 6 eggs a day. This difference in results led to a further investigation, which showed that the rate of egg deposition depended in a considerable measure upon the abundance of squares which had not been attacked, and also that during a period which may be spoken of as the "prime of life" the rate is considerably higher than it is when nearer the end of life.

Much larger cages than those described have been built at various times for special use in the boll-rreeril work. The largest of these is the cage constructed according to plans of Mr. Newell by the Louisiana crop pest commission at Keatchie, La., for the use of Capt. B. W. Marston in making tests of Paris green as a practical insecticicle for the control of the weevil. This cage covers one-fourteenth of an acre and was originally divided into three sections of equal size by partitions running through the length of the cage. The height of this cage is about 8 feet, and the cost of building it was somewhat over $\$ 350$. This is probably the largest cage that has ever been constructed for economic entomological work, and for that reason its size and cost are of especial interest.

For the purpose of allowing a larger number of hibernation experiments this cage has been further divided by cross partitions in each of the original sections into 18 rooms, and here in the various experi- 
ments have been placed about 35,000 weevils. Each compartment presents varying conditions, with proper checks for testing the most favorable and the most unfavorable conditions for the successful hibernation of the weevil.

At Dallas, Tex., a cage 20 feet square by 4 feet high (Pl. II, fig. 4), having 4 sections, has been built at a cost of slightly over $\$ 20$, for additional hibernation tests and also to serve as a check upon the experiments at Keatchie, La. In the Dallas cage have been placed more than 10,000 weevils, and as many more have been distributed in smaller cages at various points in Texas. From the large number of conditions represented and the more than 50,000 weevils under test, it is hoped that valuable data may be obtained upon the hibernation of the boll weevil.

In the work done in the field cages it was found that whenever possible each individual in a lot should be so marked as to be easily recognizable. The definiteness of the record work was also largely increased by the practice of attaching a tag to each square or boll as it was attacked by a weevil. Upon the tag was recorded all data as to date and nature of attack. Daily examinations were then made of all these tagged squares or bolls and additional data recorded as it developed. In this way the full data for thousands of cases have been obtained and from it many important conclusions have been drawn. The tags in any series of records are numbered consecutively, that it may be possible to know when the series is complete and to give at any time an approximate idea of the number of records already obtained. If a number of experiments with varying conditions are to be made, each portion of the experiment is described and given a serial number by which it may be designated upon the tags. After the experiment is completed the data from the tags is transferred to permanent record cards for incorporation in the card catalogue system. Wherever possible the data is recorded in tabular form and the tables followed by cards giving a full summary of the results obtained.

The record cards for general note work are 4 by 6 inches in size. The sheets are arranged in books of 50 leaves each, making the convenient pocket size of 4 by 7 inches. Perforations across the bases of the sheets make it easy to remove them as desired. Across the lefthand end of the sheet is space for the name of the writer of the notes. It the top of the sheet are spaces for "Subject," "Date," and "Locality." The body of the page is cross ruled, giving 12 by 22 lines for the records. These cards have been found adaptable for practically all the permanent record work of the investigation. The cards have been arranged by subject and alphabetically, but it is our purpose to arrange the entire catalogue upon a decimal system during the present winter. 
Quite extensive use has been made of photography as a supplement to the records made in the note work of the investigation. Many things can be easily shown which can only with difficulty be described, and a photograph, together with the notes, will undoubtedly convey a clearer idea to any person not making the actual observation than can be given in any other way. Methods in photography may be briefly considered later, but it will not be out of place here to say that our photographic file now shows over 900 negatives as the result of three seasons' work. These are kept in a card catalogue cabinet designed for commercial reports, thus accommodating both 4 by 5 and 5 by $\tau$ negatives. All negatives are numbered and arranged consecutively. A card catalogue of the negatives with abundant cross references refers readily to the numbers of negatives illustrating any subject photographed, and a series of albums is kept in which is a sample print from each negative taken. In this way it is possible to know at any time exactly what negatives can be of use in making any desired illustrations. While very many of these negatives can never be of use for publication, few of them are thrown away, as the photographer may learn as much from a failure as from a success in the making of a desired negative. Careful record is kept of the particular brand and speed of plate used in each exposure, also of the lens, the light conditions, the stop used, the length of exposure given, the developer employed, and a general criticism of the result obtained. These records give the operator a clear idea of the conditions under which he has secured the best results and frequently enable him to correct mistakes, thus raising materially the standard of the results obtained.

During the past season, following the suggestion of Mr. Wilmon Newell, we have made photography do the work of the printer in the preparation of labels for a large part of the specimens collected by members of the boll-weeril investigating force. When a series of labels for a new locality, food plant. or collector is desired the typewriter is used to write in columns each desired label a proportionate number of times. A black ribbon is used with a clear white paper. If possible each column should be composed throughout its length of the same number of spaces, and a single space is sufficient to separate the columns. Attention to these points facilitates the cutting up of the labels. Prints are made upon special portrait paper, and if the work of negative making and printing has been well done a rery good and durable label may thus be obtained. One of the chief advantages of this photographic system in the preparation of labels is that the delay involved in printing may be largely aroided. The entire process from the typewriting to the finished label may be completed, if desired. in a few hours. Each series of labels is kept in an envelope by itself, and all are arranged alphabetically in a drawer of the card-catalogue cabinet. 
It may be needless to say that insect photography stands in a class quite apart from any other branch of the art. The methods of either the ordinary "kodaker" or the professional portrait maker will not produce good illustrations of insects. Right here allow me to express my appreciation of the valuable address given by Prof. M. V. Slingerland at the meeting of this association in St. Louis in 1903. I shall not presume to add much of value to the advice and suggestions of one who has done much more work than I have in this field, but even the novice may be allowed to mention some of the things he has found helpful in his work.

Owing to the small amount of room which could be set aside for photographic work and the constant necessity of working where others were more or less continually moving around the room, I have been forced to devise a camera stand that would accommodate at the same time both the copying and enlarging camera and the 5 by 7 hand camera, with which most of our views have been taken. This stand (Pl. III, fig. 5) consists essentially of a horizontal baseboard 18 inches wide, 1 inch thick, and 6 feet long, strongly braced so as to prevent warping. To one end of this board is hinged another, 3 feet long, of equal width and thickness, so that it can be dropped and fastened in a vertical position, or at right angles to the baseboard. In order to prevent the bad effects of floor vibration, the stand is suspended in a horizontal position from the ceiling by four ropes hooking into screw eyes at the four corners. On each side of the drop front, 1 inch in from the outer edge, is cut a half-inch wide slit, along which may. pass the thumbscrew holding an adjustable right-angular bracket. Along the middle line of the drop front is cut another slit for the screw holding the hand camera when that is to be used. Both camera and object table are thus adjustable independently of each other, and either camera may be used as desired. If it is desired to use the copying camera with the object in a vertical position, the drop front may be raised to the plane of the base board and firmly secured in that position. This brings the brackets into such a position that they serve well as a vertical background, the distance of which from the front of the camera can easily be varied from a few inches to several feet. If the nature of the subject is such that it may be better taken in a horizontal position, the front is dropped and a right-angular prism is used, allowing the camera to remain also in a horizontal position. (See Pl. III, fig. 6.) The distance from the center of the lens to the plane of the object is still as easily adjustable by the slicling side brackets supporting the object table.

If an enlargement of less than four diameters is desired, I generally use the hand camera, owing to its easier manipulation and more accurate adjustments. This is adjustably placed upon the middle 
of the vertical front board and secured by the usual tripod screw. The height of the entire apparatus from the floor may be easily regulated to suit the convenience of the operator. The vertical position of the camera allows convenient focusing. while the horizontal position of the object table makes it easy to place the object upon glass, as may be done over a white background to obviate shadows, or to so arrange the background as to make it absolutely black. I have found greater difficulty in securing the black background with a properly lighted subject than in getting a shadowless background. 'The following method has been gradually developed: Upon the board resting on the side arms I first place a sheet of thick cork. Over this I spread a piece of heary black relvet. The object is elevated a few inches above the relvet ground upon a dissection needle held in the cork, and the background below the object may then be shaded from the light in such a way as to render it absolutely black. (See Pl. III, fig. 6.) I have found that mirrors may be used in illuminating an object with this arrangement without having difficulty with the background. Medium i-ochromatic plates have proved to be the best for general use, and the double-coated plates of this brand are also an improvement upon the single coated. For label work or any subject consisting of black and white the contrast plates hare given best results.

While I have found little use for photomicrography, the stand described serves very well for the combination of the camera with the microscope.

Frequently in the experience of the economic entomologist there arises the necessity for making enlarged views or charts for illustrative work under conditions when lanter'n slides can not be used. As I do not know that the process which we have used in making such charts has ever been used elsewhere, I will give an outline of our method.

The essential idea is to transmit a strong light through a negative of which an enlargement is desired, projecting the image directly upon the chart surface in a darkened room. The arrangement for securing the projection (see Pl. III, fig. 7 ) may consist of a stereopticon lantern. or if only a cheap stereopticon is available, it will do better to use only the portion of the stereopticon necessary for lighting the negative and then use the camera lens in front of the negative for the projection of the image. An arrangement such as is often used in making lantern slides may be adapted to this work, the negative-holding end of the camera being exposed to daylight at a window which is entirely darkened around the camera box, and the image projected upon the chart surface instead of upon the lantern slide. The great advantage lies in the fact that all outlines and 


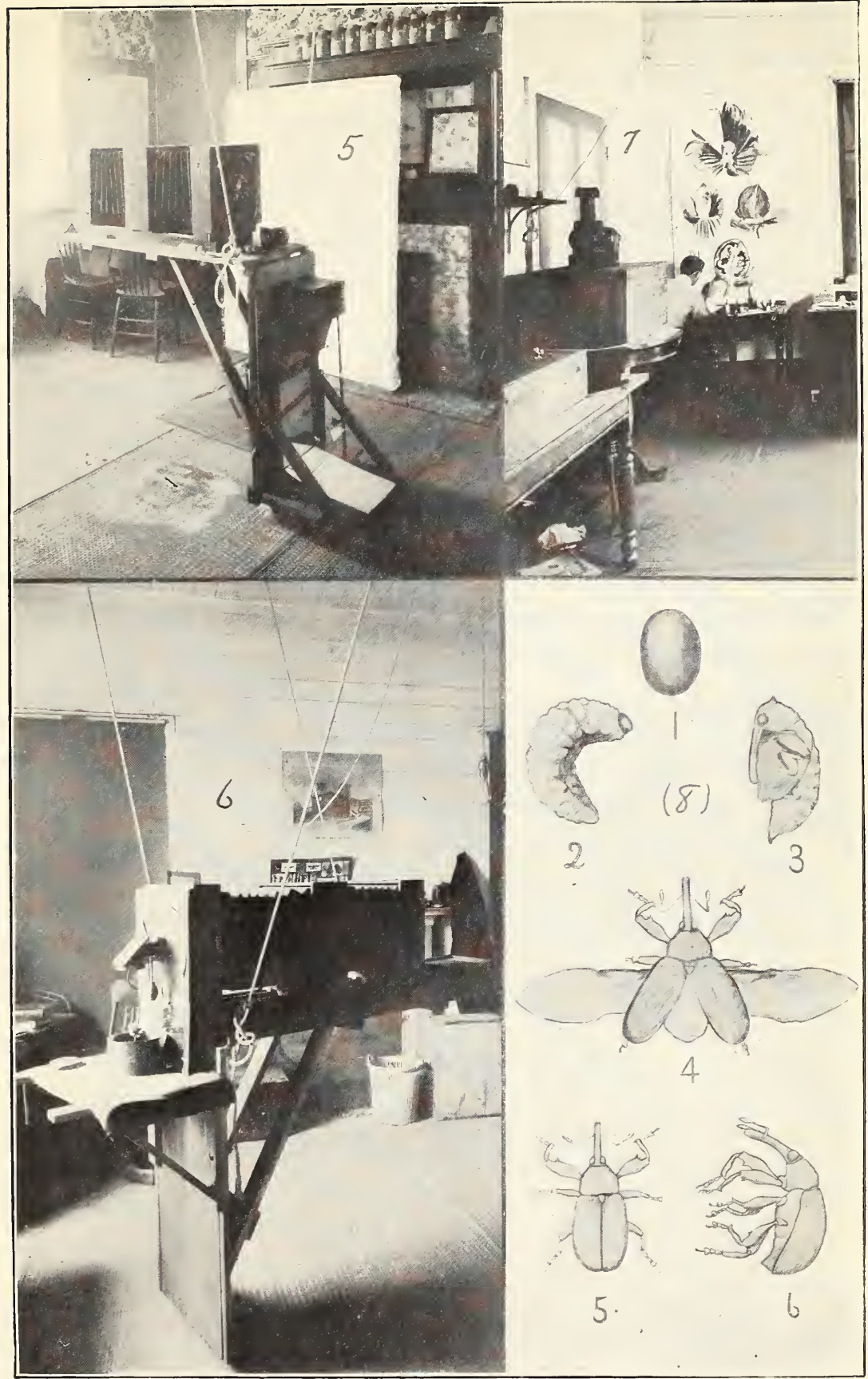

Laboratory MEthods in the CotTon Boll WeEVIL INVEstigations.

Fig. 5.-Camera stand designed for both horizontal and vertical work. Fig. 6.-Arrangement used in securing black backgrounds with camera horizontal. Fig. 7.-Chart making with stereopticon for projecting image. Fig. 8.-Chart made from negative image projected by electric light through copying camera. (Original.) 

details are shown in their correct position upon the chart, and the worker has simply to ink them in as he sees them. No other apparatus is positively requirad beside the ordinary hand camera. Either daylight or strong artificial light may be used. Of course, in this work a positive image such as is used in a lantern slide is desirable, but if not at hand the negative will serve to give all outlines, and the positive image may be filled in much more easily and accurately than the a verage worker could do by making a freehand enlargement from a print or object. (See Pl. III, fig. 8.) With some such arrangement as I have outlined a man does not need to be an artist to secure a fairly good chart of any subject that he can photograph.

\section{THE WORK OF THE STATE CROP PEST COMMISSION OF LOUISIANA ON THE COTTON BOLI WEEVIL.}

\section{By Wilmon NewelL, Shreveport, La.}

The work of the State Crop Pest Commission of Louisiana, in the campaign against the cotton boll weevil, is being conducted along three rather distinct lines: (1) Preventing, so far as possible, the spread of the boll weevil to new territory; (2) reducing the weevil damage in the area already infested, by disseminating information regarding the cultural methods to be employed in producing profitable crops of cotton in defiance of the weevil, and by experimental and demonstration work with the cultural methods upon different soils and under different conditions; (3) investigating and disseminating information regarding insects other than the boll weevil, in order that the production of crops other than cotton may be rendered more profitable than heretofore and the adoption of a diversified system of farming be encouraged among the farmers in the weevilinfested territory.

Before proceeding with a discussion of any one of these three lines of work, a brief résumé of the boll weevil's progress through the State of Louisiana up to the present time will be advisable in order that the problems with which the Commission has had to deal may be more clearly understood.

The boll weevil first reached Louisiana in 1903. In all probability the 1903 infestation was by a migratory flight, although some little evidence that the insect was introduced in other ways is not entirely wanting. The territory which was known to be infested in the fall of 1903 is shown upon the map in figure 3, the infested district comprising a comparatively small area in the western poltion of Sabine Parish.

No diminution of the infested area was noticeable as the result of the climatic conditions prevailing during the winter of 1903-1904. 
Acting upon the knowledge of the weeril's habits arailable at that time, the Commission undertook the complete extermination of the weeril in this limited area and undertook to prevent the spread of the insect by a rigid quarantine upon cotton seed, hulls. and seedcotton, as well as upon household goods, hay, grain, forage, cotton sacks. baled cotton, etc.. from the weeril-infested sections.

The extermination of the Sabine Parish colony was nndertaken in the spring of 1904 , by prohibiting the farmers in the affected terri-

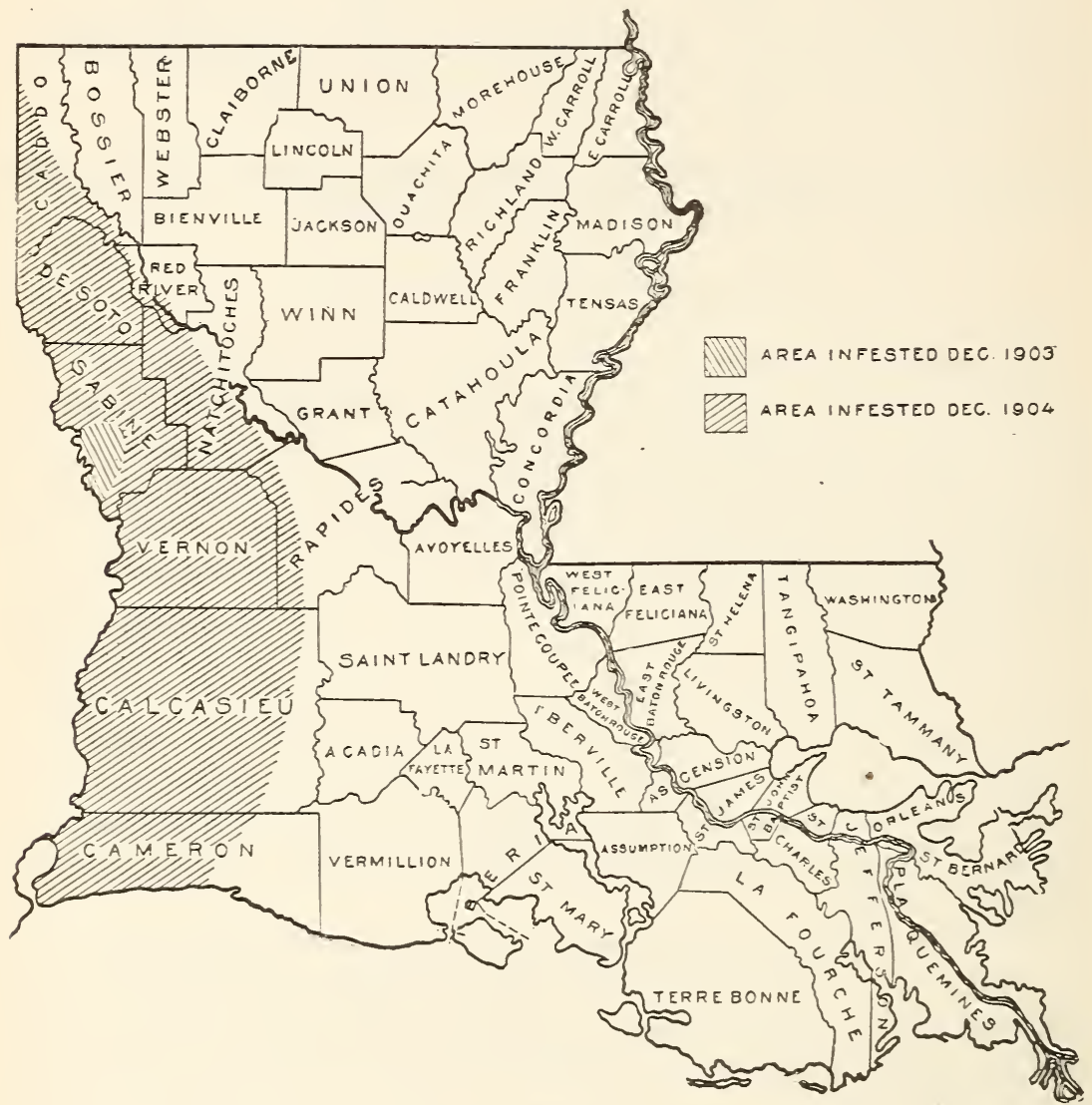

FIG. 3.-Area in Louisiana infested by Anthonomus grandis in December, 1903, and in December, 1904.

tory from planting cotton. the landowners and tenants being paid a cash rental by the commission and in addition being permitted to grow any crop, other than cotton, that they desired. 'The elimination of cotton from this area of course resulted in eradication of the weerils therefrom during 1904 .

Year Logansport an infestation corering a few acres was found in the early summer of 1904. having evidently been there the atutumn previous, but undetected. Extermination of this colony was accom- 
plished by destruction of the cotton plants in the area involved and by systematic hand picking of adult weevils and infested squares from trap plants.

Early in August of 1904, the special field agents of the Bureau of Entomology who were employed in Louisiana under the immediate personal supervision of Prof. H. A. Morgan, then entomologist of the crop pest commission, discovered boll weevils generally distributed in cotton fields where a few days before careful inspections had revealed none at all. Their numbers, as well as their occurrence in cotton fields several miles distant from the two original colonies, precluded all possibility of their being individuals which had escaped destruction at the time of extermination of these colonies. In all of the infested fields Professor Morgan and his assistants found only adult weevils, eggs, and very young larve, showing that the arrival of the adult weevils in fields many miles apart had been practically simultaneous.

Only one explanation of this phenomenon presented itself, and that was that these weevils had migrated from the infested cotton fields of Texas. Further examinations of cotton fields during the summer and autumn months of 1904, by Professor Morgan and the special field agents of the Bureau of Entomology, established the existence of a marked and clearly defined migratory movement of the weevil into new territory. This migratory habit of the weevil, which had previously been unknown and evidently unsuspected-as it is not mentioned in any of the writings upon this insect prior to that timeentirely revolutionized the methods to be employed in retarding its progress into new territory. The attempt to eradicate infestations within the territory covered by the yearly migrations became not only impracticable but impossible, as fields in which the cotton might be destroyed in the work of exterminating the insect would become reinfested from surrounding territory immediately upon cotton being again planted therein.

The migratory movement of 1904, while most marked and extensive during the latter part of August, continued with greater or less volume until frost, the weevil's movements during the latter part of the season being more or less continuous and hardly distinguishable as distinct migrations. The territory gained by the weevil during the month of August more than equaled in area all of the territory gained by it during September, October, and November. The area infested by the weevil in December, 1904, is seen in figure 3.

The winter of 1904-5 was one of the most severe that Louisiana has seen for many years, the temperature being much lower than usual and the rainfall much in excess of normal for the winter months. 
Careful examinations in cotton fields aggregating several thousand acres, between May 1 and August 1, 1905. showed that the weeril had not survired the winter in the eastern portion of the territory infested the previous autumn. In other words, the weevils were exterminated by meteorological conditions in that area which they did not occupy until after about the middle of September, 1904. and in which therefore they did not have opportunity to breed up to considerable numbers before the arrival of frost. The territory

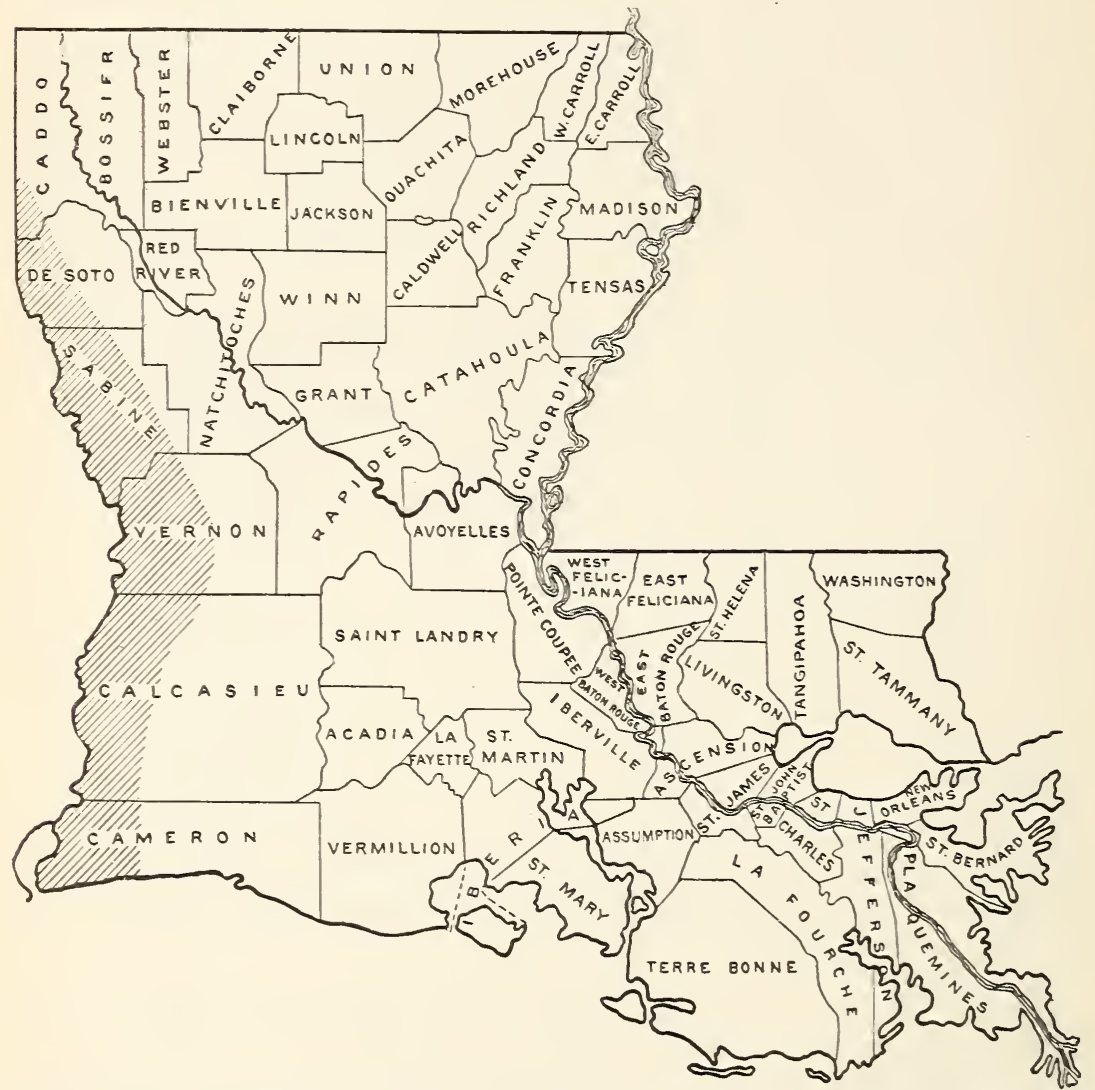

Fig. 4.-Area in Louisiana infested by Anthonomus yrandis in July, 1905 (see shaded portion of map).

infested in July, 1905, is shown by figure t, and by comparison with the eastern limit of infestation in December. $190 t$ (fig. 3). an idea will be had of the amount of territory actually lost by the insect. It is, of course, conceirable that an occasional weeril may have surrived the winter in this territory, but the examinations of so many cotton fields in different localities, and with different surroundings, by men thoroughly skilled and practiced in detecting eren the lightest infestations, and each of whom was in ignorance of the findings of the 
rest, seems to reduce the chance of any survivals in this area to one in several thousand.

Perhaps the most interesting point noticed in connection with this extermination of the weevil by meteorogical conditions was the fact that it was exterminated in Caddo, the northernmost parish of the State, and also at Cameron, the southernmost point at which the weevil has been found in Louisiana. As Cameron has about the highest average winter temperature of any locality in Louisiana, and as Caddo Parish has very nearly the lowest average winter temperature of any locality, it appears that the excessive moisture, rather than low temperatures, was responsible for this heavy mortality.

A similar loss of territory by the weevil in northern Texas has been noted by Mr. Hunter and his assistants the present season (1905); and so far as the writer is aware the winter of 1904-5 was the first in which meteorological conditions brought about anywhere near so great a decrease in the territory infested by this insect.

In 1905 the migratory movement of the weevil commenced about the middle of August and continued with more or less continuity until about November 20. The existence of certain quarantines throughout the State during August, September, and early October, on account of yellow fever, prevented the extensive field observations necessary to determine the exact time and extent of the migratory movements. Field work could not be resumed until the middle of October, and after that date an accurate survey was made to determine the eastern limit of the territory invaded.

The migrations of 1905 gained for the boll weevil practically all of the territory it lost during the winter, and a very considerable area in addition. Cameron, La., a community practically isolated from other cotton-growing sections by many miles of marsh, was the only locality not reinfested by the 1905 migrations, careful field examinations in this locality during December failing to reveal any indication of infestation.

In the eastern part of the area at present infested (fig. 5) the infestation is of course exceedingly light, maximum infestation and consequent severe injury not occurring before the second season of infestation and occasionally not before the third. In those portions of the State reached by the weevil in the fall of 1903, or the very early summer of 1904, the injury during the season just passed has been considerable. Roughly-outlined the area suffering severest weevil injury during 1905 is embraced in western Vernon and Sabine parishes and southwestern De Soto Parish. In western Sabine Parish the weevils are doubtless now as abundant as they ever will be, and it is interesting to note, incidentally, that the farmers in this section who have followed, even in a crude way, the cultural measures advocated by the Bureau of Entomology and the crop pest 
commission hare made approximately 90 per cent more cotton per acre than those who adhered to the use of big-boll, late-maturing rarieties and to indifferent and insufficient cultiration.

THE QTARANTINE MAINTAINED BY THE CROP PEST COMMISSION.

By virtue of the provisions of act No. 6 of the extra session of the Louisiana legislature of 1903, the crop pest commission is rested

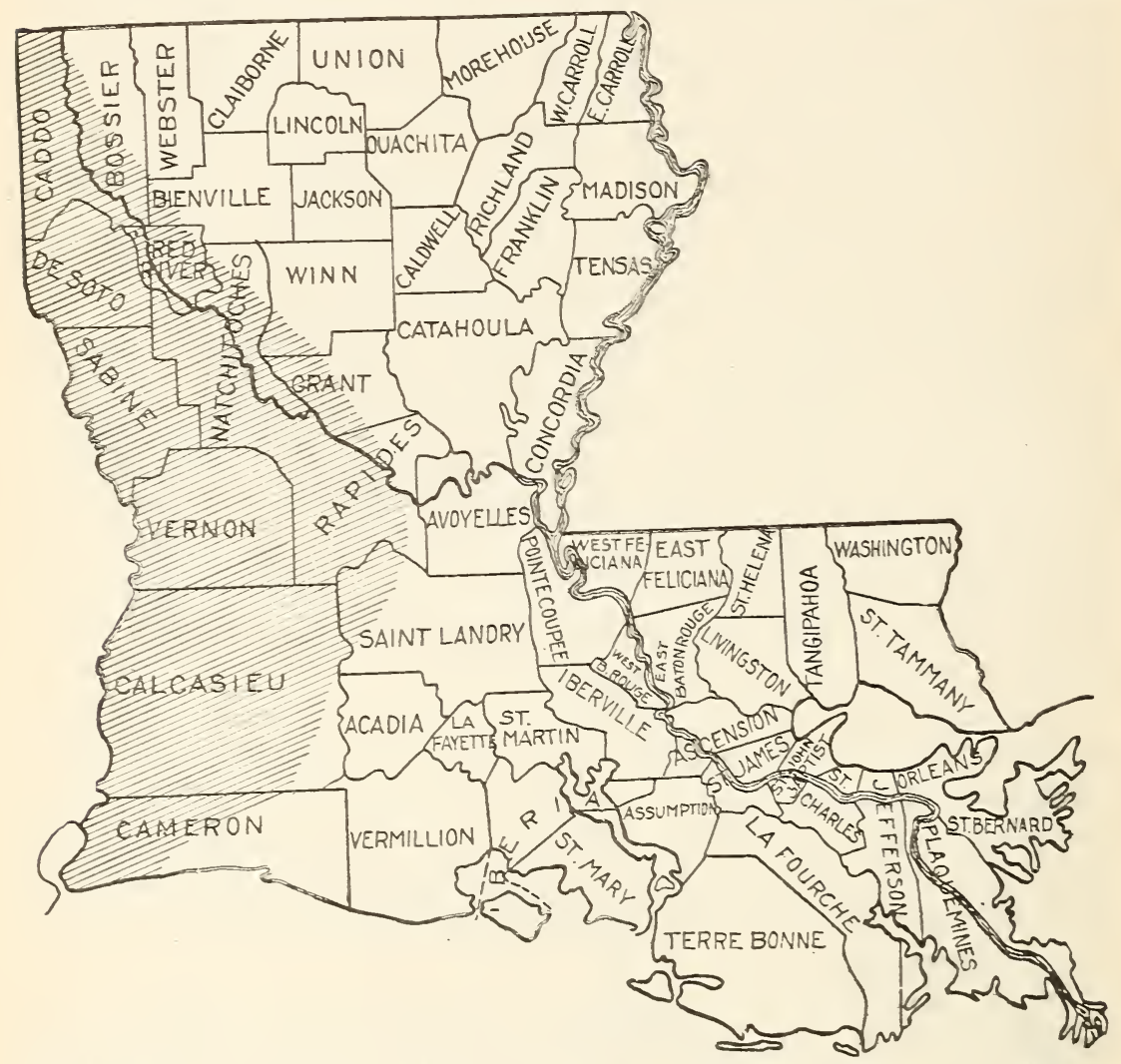

FIG. 5.-Area in Couisiana infested by Anthonomus grandis in December, 1905 (see shaded portion of map).

with authority to make and enforce quarantine regulations gorerning the morement of any material likely to disseminate the boll weevil or other seriously injurious insect.

The quarantine regulations at present maintained by the commission, in connection with the boll-weeril campaign. prohibit the movement of cotton seed. seed cotton. cotton-seed hulls, cotton-seed sacks (used), and seed-cotton sacks (used) from the infested territory of Texas and Louisiana to any point in the noninfested sections of Louisiana. 
The materials mentioned are those which experience has shown to be such as are most likely to contain living boll weevils, and the shipment of which to uninfested sections might therefore result in new infestations many miles ahead of the gradually advancing line of weevil infestation. Of the materials named, only one, cotton-seed hulls, is ever permitted to be shipped into the uninfested territory under any circumstances. The commission has perfected a method by which cotton-seed oil mills can so arrange their machinery as to handle the hulls after they leave the huller in a manner that will effectually prevent the dissemination of boll weevils with them; and to mills having a satisfactory arrangement of their machinery, as required by the commission, permits are given for the shipment of cotton-seed hulls to any point in the noninfested sections.

The commission is frequently confronted with the question: "So long as the boll weevil's progress by migratory flights can not be controlled, what is the use of trying to maintain a quarantine upon shipments likely to disseminate the weevil?" To any thinking man who will note the progress made by the weevil each year in its migrations and the loss of territory which the pest experienced last winter, the answer must be evident. Even though the insect is each year gaining additional territory, and even though ultimate infestation of the major portion of the cotton belt appears inevitable, much is to be gained by preventing the pest from obtaining a foothold many miles ahead of the gradually advancing frontier of infestation. For example, if infestations now occurred in the north central portion of Louisiana and at points along the Mississippi River, as well as in that portion of the State east of the river, it is evident that the entire State would become infested much sooner than if all such outbreaks were prevented and the weevil forced to limit its progress into new territory to actual bodily movement. Even if the advance of the pest can not be permanently prevented, there is certainly no justification for permitting it to be accelerated. To abandon quarantine measures simply because the weevil gains new territory each year by flight, would be analogous to the case of a large city in which a conflagration occurs, spreading gradually, and in which on that account the authorities permit other fires to be started in other portions of the city, each of which in turn would itself become a conflagration involving a large area.

It is pleasing to note that not a single case of infestation by the boll weevil is known to occur at any point east of the territory which has been occupied by the weevil in its migrations, the eastern limit of which is virtually coincident with the quarantine line established by the commission, and we have therefore every reason to believe that this quarantine has been entirely successful, and has thereby saved not only eastern Louisiana but States east of us from infestation through 
shipments of the articles referred to above. There is at least no evidence to indicate that the enforcement of these regulations by the commission has not accomplished as much in restricting the spread of the boll weeril as could be accomplished by any agency subject to human control.

THE CAMPAIGN AGAINST THE BOLL WEEVIL IN THE TERRITORY ALREADY INFESTED.

In the territory which is already infested by the boll weeril the commission has exerted every effort to furnish all planters and farmers with accurate and detailed information regarding those farming methods which must be employed to produce profitable crops of cotton in spite of the weeril. The commission adrocates, essentially, the remedial cultural methods perfected by Dr. L. O. Howard and Mr. IT. D. Hunter, of the Bureau of Entomology. The dissemination of this information has been through the press, by means of bulletins and circulars, by addresses at farmers' meetings, by the cooperation of local business men in the distribution of literature, and by actual field demonstrations in growing cotton in the heavily infested sections under the direction of the assistant entomologists in the employ of the commission. In addition to this work, the commission has conducted rather elaborate experiments in determining the value of the different steps involved in the "cultural remedy," as well as along kindred lines.

As Paris green has at times been enthusiastically adrocated as a sorereign boll-weeril remedy, the commission undertook during the season just passed exhaustive experiments in determining the value of this agent in the campaign against the weevil. The results were somewhat surprising, as they showed that not only was the boll weevil not affected by applications as heary as could be made without destroying the foliage of the cotton plants, but that the application of Paris green in late summer, by destroying the cotton worm (Alabama argitlacea Hbn.), indirectly increased the food supply of the weeril, facilitating breeding and furnishing an abundance of food. in the form of squares and young bolls. right up to the time of entering hibernation. thereby greatly increasing the weevils chances for successful survival of the rigors of winter.

A "hibernation experiment" with the boll weeril, at present under way. is perhaps the largest experiment that has ever been undertaken in " breeding cages." In the neighborhood of 35.000 adult boll weevils are being used in the experiment. distributed among 18 cages. each of which occupies 160 square feet of ground and has a height of about $S$ feet. These cages contain hibernating quarters offering varying degrees of protection from rain and cold, simulating as neariy as 
possible the different conditions which obtain upon the average Louisiana plantation.

The object of the experiment is, of course, to determine the per cent of weevils which survive under different conditions for hibernation and when forced to subsist for varying intervals without food before entering hibernating quarters in the fall. In addition to this we expect to determine next spring the date and temperature at which the first hibernating adults emerge from winter quarters, the time at which the bulk of hibernated weevils emerge, and the date at which the last individuals leave hibernation. An accurate knowledge of all the points involved is of the utmost importance in securing the maximum results in employing the cultural remedy.

THE INDIRECT METHOD OF REDUCING DAMAGE BY THE BOLL WEEVIL.

That the boll weevil has no food plant other than cotton has become almost an axiom. The farmer who produces crops other than cotton has nothing to fear from boll-weevil ravages, but unfortunately he finds other insect enemies threatening his success regardless of what crops he may undertake to substitute for cotton. The crop-pest commission does not overlook the fact that we are to continue in the future, as in the past, to produce cotton, but under the present labor and credit systems which prevail in Louisiana and adjacent States the profitable production of cotton, upon as large a scale as formerly, with the weevil present, will be impossible, and the growing of cotton to the practical exclusion of other crops must be succeeded by a diversified system of agriculture. By the control of insects seriously injurious to crops other than cotton and by devising and disseminating information concerning methods of successfully combating them, the profits derived from producing such crops are materially increased and the advent of a properly diversified system of farming is accordingly hastened.

In this connection it is sufficient to direct attention to the fact that as the territory infested by the boll weevil increases and as the present infested area approaches a state of maximum infestation, the warfare against other insects will become of much greater moment to the agriculture of the State than it is at present.

Mr. Marlatt, referring to the recommendation made in some of the papers for the encouragement of the cotton leaf-worm as a means of controlling the boll weevil, remarked that it should not be forgotten that the leaf-worm itself has proven in the past a very serious cotton pest, and that in the early years of its presence, before means of control were discovered or generally practiced, it caused a loss in single 
seasons quite as great as that now occasioned by the boll weeril. He felt, therefore, that the encouragement of the abundance of the leafworm was open to some question. and that such encouragement from official sources might lead planters to ignore the presence of this pest and omit the customary prompt treatment, with resulting great losses to the cotton crop.

Mr. Newell said that it was quite true that the cotton worm was at one time a most serious pest, and did great damage, but since then the planters have learned how to control it with certainty, and without the necessity of consulting an entomologist. It is doubtful whether there is any other single injurions insect which is subject to as full and certain control as is the cotton caterpillar.

In sections hearily infested by the boll weevil. the production of a so-called " top crop " is impossible, and it is rarely that the caterpillar ever destroys more than the top crop. In weeril-infested sections the top crop must be sacrificed, and in riew of this fact, it is preferable to allow the caterpillars to take it and thereby decrease the food supply and breeding places of the boll weeril.

The boll-weevil problem is most serious upon our allurial lands. where the cotton grows high and rank. If caterpillars are permitted to "rag" the foliage of such cotton in the latter part of summer. sunlight is permitted to reach the unopened bolls on the lower limbs. and the maturity of these bolls is accordingly hastened. Any factor which tends toward early maturity of the crop is of the utmost importance in the weevil sections.

It is not proposed to substitute one injurious insect for another. in attempting to utilize the caterpillar in the warfare against the weeril. but merely to let one injurious insect destroy the food-supply of the other. after all possibility of making additional fruitage is gone. When the caterpillar appears early in the season. it must be controlled. but the application of Paris green to the cotton never secures total extermination of the caterpillar, so that in such rears the caterpillars will become abundant enough to defoliate the plants in from three to four weeks after poisoning ceases. It is merely proposed to utilize the work of the caterpillar in those years when it is sufficiently abundant to completely defoliate the cotton three or four weeks before frost. such complete defoliation answering practically the same purpose as the fall destruction of the cotton plants by the planter. and at a much less cost.

Mr. Hunter said that it was true, as had been stated, that the leafworm was a dangerous insect many years ago. but the conditions have so changed that this is no longer true. One of the factors in this has been the cutting up of the larger plantations. Even before the boll weeril came; planters had come to regard a late risitation of 
the leaf-worm as beneficial. This is especially true in the alluvial soils, where the foliage is excessive in amount. Here, anything that will let in the light late in the season assists in the ripening of the cotton, and is therefore beneficial.

Mr. Morgan said that there was another aspect of the relation between these two insects that seemed of importance. The leaf-worm, by stripping the plants of foliage, deprives the boll weevil of food, and thus causes it to migrate farther. In this way, the spread of the insect was undoubtedly extended last year. If we let the leaf-worm come into our fields early, we hasten the spread of the weevil towards the more important cotton regions farther east. If, however, the caterpillar recommendation prevails, it seems important to emphasize the possible value of the caterpillar in connection with weevil suppression only when it (the caterpillar) appears late in the season; .otherwise careless planters might accept this recommendation as an excuse for neglect when caterpillar damage came too early and threatened the cotton crop.

Mr. Hinds called attention to the fact that when the leaf-worm is ahead of the weevil it actually delays the spread of the latter by rendering the conditions for its survival so precarious that few of those migrating live.

Mr. Newell said that we had commonly supposed that the existence of a defoliated area would tend to make the weevil go farther in its migratory flight in search of suitable food, and that, vice versa, an area in which the cotton was rank and luxuriant and not defoliated would have the effect of discouraging the weevil from extending its flight farther. With this in mind, it seemed not improbable that the migratory flight of 1905 would be limited by the Red River Valley. In reality, however, the weevils crossed the Red River Valley into the hills to the eastward, and the area covered by the 1905 migrations was as great as that covered by those of 1904 .

Mr. Hunter said that he had in mind especially, in discussing the probable spread of the boll weevil, the work of Professor Webster on the chinch bug. He could not see why the two insects were not likely to follow the same route.

Mr. Webster stated that he could see no good reason why the holl weevil should not follow the same trend of diffusion as had other insects that had spread from eastern Mexico into the United States, as, for illustration, the chinch bug. He thought that the trend of diffusion would be more rapid to the eastward than to the northward, but there were several facts to be taken into consideration. It present the spread was with the trend of commerce in cotton; after the Mississippi River had been crossed, the spread of the pest would be against this trend of commerce, which would be presumably to$31024-$ No. $60-06 \mathrm{M}-9$ 
ward the greatest cotton mart, New Orleans. Unless the winter weather prevented the pest from doing so, he saw no reason why the boll weevil should not spread eastward along the Gulf coast until it had passed the lower extremity of the Appalachian mountain system, and then go northward, possibly reaching Virginia before it did Missouri or extreme northern Arkansas, but in either case stopping only with the limit of cotton culture. This was the case with the harlequin cabbage bug, which had spread at one time as far north as Chicago, Ill., and had almost reached the shore of Lake Erie. in Ohio. A very severe winter, however, had killed it off to southern Illinois and Ohio, and it had not yet recorered this lost ground. and might not again in years.

Mr. Newell believed that climatic conditions are an important factor in determining the rate of spread of the boll weeril. It is certainly spreading much faster eastward than northward. and at the present rate will probably reach the eastern end of the cotton belt before it does the northern limit of cotton culture in the Mississippi Valley.

Mr. Sanderson stated that he was particularly interested in Mr. Hunter's remarks upon the relation of the boll weeril to the cotton crop of 190t. Since the last meeting of the Association he had revised the paper presented at Philadelphia concerning the injury done the cotton crop by the boll weevil. bringing the report up to include 1904 , and the article has finally been published as a bulletin of the Texas department of agriculture. He stated that from a careful statistical study of the acreage and crop produced by the counties of the State he felt that in 9 counties in central Texas a better than normal crop had been produced, rery largely due to following the directions of the entomologist. The following was quoted from the bulletin cited :

The injury in 1904 was quite different in many respects from that of ans previous rears. The total acreage injured showed a decrease from that of 1903 . due to the fact that 9 counties in central Texas, 5 of Central Group $A$, including Austin. Brazos, Burleson, Comal, and Fort Bend, and Bell, Hars. Limestone, and Williamson, having a total acreage of $S$ per cent of that of the State, and producing nearly 10 per cent of the total crop, produced better than a normal crop compared with the uninjured counties, though in 1903 they had all shown serious injury. In contrast to this encouraging feature. the 12 counties of Southern Group A, owing to a rery mild winter. early spring. and allowing stubble cotton to remain orer winter upon which the weevils commenced to multiply early. produced but half a normal crop. for the first time showing serious injury since 1899 . In addition to the injured area of 1903 . were 7 counties in eastern Texas and 10 southwestern counties, the outer limits of the area injured in 1904 being almost exactly those infested in 1902. except for the 10 counties of Central Group E. Blanco, Bosque. Burnet. Coryell. Ellis, Hamilton, Hill, Randall, Lampasas, McLennan, which showed a better than normal crop, though many of them had been well infested in 1903, and all more 
or less in 1902 . Together the 69 injured counties showed an "apparent" decrease of 0.14 bale per acre, which, with the increase of 0.08 bale per acre for the balance of the State, gave 0.22 bale per acre total loss, practically the same as in 1903 , making 586,478 bales decrease, slightly larger than for 1903 . In 1904 there was comparatively little injury from the bollworm and loss from flood, so that 550,000 bales may safely be charged to the boll weevil. Had the 9 counties which previously had shown a loss, but in 1904 made better than a normal crop, showed as much injury as those surrounding them, the total loss would have approximated 700,000 bales. Had the 10 counties of Central Group $\mathrm{E}$ been injured as much as the 7 eastern counties after two years of infestation, there would have been 175,000 bales further decrease. In other words, had the weevil been as injurious in the territory infested two years or over as previously, there would have been a loss of 875,000 bales of cotton due to the weevil in 1904 . That this was not the case, and that a phenomenal crop was made, was undoubtedly due to the extremely favorable season, an early spring hot summer, and a late growing season. These favorable weather conditions made possible the best possible results from the "cultural methods" of preventing injury by the weevil, consisting of early planting, early varieties, and thorough continued cultivation. These methods were widely practiced by progressive planters and undoubtedly were a large factor in producing a crop above the average for the uninjured counties, including 9 of the largest counties which had previously shown serious loss, as well as lessening the loss in other counties. It should be borne in mind, however, that in spite of the large total crop the loss to over one-third the acreage of the State was as severe as in 1903 and was fully one-half the crop of those counties. Had there been no loss by the boll weevil in 1904 Texas would probably have produced $3,750,000$ bales of cotton.

He believed, however, that the large crop was due, as a whole, to the very favorable weather conditions.

He commended the remarks of the paper of Mr. Conradi in showing that the control of the boll weevil had come to be largely a matter of agricultural methods, and expressed his belief that the advent of the boll weevil had really been a very great blessing to the farmers of Texas. Mr. Sanderson warmly commended the laboratory work and methods of Doctor Hinds, which he had carefully studied. The photographic prism mentioned by Doctor Hinds he believed he had mentioned to the Association before, since he was the first to use it, so far as is known, in Delaware in 1900, and has since found it exceedingly useful, especially for photographing larvæ and material in alcohol or liquid. The vertical attachment to the photographic stand described by Doctor Hinds had originated in Texas, and he had suggested the construction to Professor Quaintance, and since constructed one along the same lines for his use in New Hampshire. With larger laboratory room, however, he prefers the spring stand, which rests on the floor and may be moved about the room for photographing objects at a distance. He suggested that one of the most useful devices in photography is a universal arm lens holder made with several ball joints. In the clips may be inserted a bit of cork covered with white or black paper, upon which the insect is 
pinned. or a small glass plate, and the object may then be put to any desired angle or position with a touch. He expressed his opinion that enlargements should be used more in insect photography for publication. The great temptation was to attempt too great an enlargement immediately from the object. A clear. sharp negative. natural size, is much preferred, as it can then be enlarged as desired by making an enlargement from the negative. Mr. Sanderson stated that the effect of the cotton leaf-worm, as shown to Mr. Newell, had been frequently published in southern Texas by publishers there, and that they found the weevil much less abundant the following spring after a fall in which the caterpillar had attacked the foliage. He believed the leaf-rorm to be a most valuable ally. and pointed out the fact that usually the use of the leaf-roim did not occur until late in the season, so that with the growth of early cotton for the boll weeril the leaf-worm would rarely do any real injury. He deprecated, howerer, the tendency to place much emphasis upon the work of the leaf-worm as having a tendency to encourage the planters in their failure to destroy the cotton stalks in the fall by burning. Although the work of the leaf-worm should be encouraged by stopping the use of Paris green on the foliage for its destruction. it would be unfortunate if the planters should come to depend upon it.

He believed that the elementary solution of the control of the boll weeril depends upon the destruction of the stalks in the fall. and stated that so far as he was arare no experiments had demonstrated the ralue of this procedure upon individual farms if not adopted by neighboring farms. and that this seemed to be a most important matter. The ralue of the fall destruction of the stalks had been realized by entomologists and recommended by them from the first. but had been practically neglected by planters in general. He stated that observations made by him at Texas College showed the undoubted ralue of the destruction. eren upon one farm. but that the records, though convincing to an entomologist. would not prove the matter to the arerage planter.

He suggested the great desirability of an experiment on a large scale, taking in several square miles, where the stalks might be destroyed in the fall. so that the ralue of this method could be demonstrated on a large scale. The success of the growing of early cotton with thorough culture in Texas is due to the fact that farmers had seen an actual demonstration of the method on a large scale, and he believed that the burning of the stalks required a similar demonstration. He suggested the possibilities of sucli an experiment to the Louisiana crop-pest commission, who, he understood. had conditions under which they could prosecute such an experiment. Had the State of Texas furnished funds for such work, he should have 
made the experiment previously, and believed that it would be worth several thousand dollars.

Mr. Newell said that on a small farm, practically continuous with surrounding cotton areas, the destruction of the cotton plants in the fall is not likely to result in a great amount of good, unless the plants on adjacent farms are destroyed as well.

Upon large plantations of several hundred acres or more, and upon small farms which are isolated from neighboring cotton fields by a mile or more of fields not in cotton, or a half mile or more of forest, fall destruction of the plants will undoubtedly pay, even if other farmers in the community do not adopt the plan. In observations carried on in 1905 in an area in Sabine Parish, La., where no cotton was grown in 1904, it was found that the weevils did not reach the center of the area-a distance of 3 or 4 miles-until three to four weeks after they had appeared in the cotton fields outside this area where they hibernated. Delay in reaching any given cotton field in the spring means, of course, a corresponding postponement of the date at which maximum infestation will occur in that field, and opportunity for the plants to mature additional fruitage is a fforded.

There is, of course, no doubt that full cooperation on the part of all farmers, in this autumn destruction of cotton plants, is necessary to secure the maximum benefit therefrom. An experiment or demonstration over a large area, for the purpose of showing the public just what can be accomplished by the fall destruction of plants, is most desirable, but owing to the fact that the farmers in this area would have to be compensated at a rate satisfactory to them rather than at a rate really commensurate with the labor required, the experiment would doubtless cost several thousand dollars. It is also doubtful if all of the farmers in an area, as large as a township, for: example, could be induced to cooperate in a demonstration of this kind. Without full cooperation of all the farmers in such an area the experiment would fall far short of giving satisfactory results.

Mr. Flynn said that one of the main reasons why the destruction of the stalks is not practiced in Louisiana is that not more than onehalf of the cotton on the large plantations is picked by November 15 . This condition is due principally to the scarcity of cotton pickers at that season.

Mr. Webster stated that in 1904 he had predicted the advancement of the boll weevil into Louisiana, and these predictions had proven approximately correct, though he was inclined to believe that but for the influence of the Galveston hurricane the lines shown by $\mathrm{Mr}$. Newell might have been slightly modified, as this certainly drove the insect to the northward in Texas. 
AFTERTOOY SESSIOX, WEDNESDAY, JANUARY 3, 1906.

On motion, it was decided that the next annual meeting should be held in New York City in conjunction with the American Association for the Adrancement of Science.

Mr. IT. D. Hunter, chairman, presented the following report:

\section{REPORT OF COMMITTEE ON NATIONAL CONTROL OF INTRODUCED INSECT PESTS.}

Your committee is impressed with the great adrisability of some definite action, and considers that the time for the beginning of such action has arriced.

The Gorernment has delegated to certain bureaus full authority in the control of diseases of live stock that are likely to spread to such an extent as to cause great public loss. The committee belieres in the wisdom of the general polics established thereby. Inasmuch as similar cases have occurred in this country and are likely to occur again, in which the subject comes within the domain of the Bureau of Entomology of the Department of Agriculture, sour committee recommends the following plan of action:

(1) That this Association. by nomination. select a committee of fire member's to consider the matter carefully and report at the next meeting.

(2) That this committee be instructed to confer with the Chief of the Bureau of Entomologs in the preparation of its report.

(3) That the committee be instructed to confer with a committee charged with the formulation of plans for obtaining uniform nursery inspection regulations, selected at the last meeting of the National Association of Horticultural Inspectors.

(4) Your committee recommends the consideration of the following scheme:

(A) The granting to the Bureau of Entomology of full authority to inspect at the ports of entre all commodities likely to carry injurious insects.

(B) The granting of authority for the Bureau to take whaterer action mas be necessary in the eradication or control of species that hare been or mar be introduced accidentally, whererer, in the judgment of the chief of that Bureau. such action is practicable.

(C) That an effort be made toward the obtaining of uniformits in regulations relating to nursery inspection br either the passage of a Federal law or the charging of the Bureau of Entomology with the duty of inducing cooperative uniformity in the laws of the sereral states.
W. D. Huxter. Chairman.
L. O. Howard.
TI. E. Hixps.
E. D. SAxperson.
H. A. MoRgix.

On motion. the report of the committee was adopted. The chair called for nominations for the fire members of the committe prorided for in the above resolution. The following were nominated. and on motion the nominations were declared closed and the secretary was instructed to cast the ballot of the society for the members named: Messr's. A. L. Quaintance, IV. E. Hinds, IV. D. Hunter, C. L. Marlatt, and H. Osborn. 
'The committee on membership, consisting of H. E. Summers, chairman, IV. D. Hunter, and A. F. Burgess, reported as follows:

The committee recommends that in the future the Society exercise greater care as to the qualifications of candidates for election to membership, and that as regards active members particularly a considerably more conservative policy than has prevailed in the past should be adopted. In general, only those who are already associate members should be elected to active membership, and this should occur only after they have published a considerable amount of origina! matter on economic entomology based on their own independent investigations. The privileges of associate membership, however, may well be extended as a means of encouragement to young men who are expecting to pursue economic entomology as a profession, but who have not yet had time to show their capabilities by publication or otherwise.

In the case of active members who seem to have abandoned economic entomology permanently, as indicated by their adopting some other profession, they should be transferred to the associate list either permanently or until such time as they may reengage in work in economic entomology.

In accordance with these principles the committee recommends the following list for membership and for transfer :

For foreign membership: A. L. Herrera, Mexico City, Mexico.

For transfer from associate to active membership: R. I. Smith, Atlanta, Ga. ; H. J. Quayle, Ames, Iowa.

For associate membersinip: C. F. Adams, Fayetteville, Ark.; C. E. Bartholomew, Ames, Iowa; James II. Beattie, Washington, D. C.; R. W. Braucher, Chicago, Ill.; Edwin C. Cotton, Columbus, Ohio ; Alexander Craw, Honolulu, H. I. ; C. W. Flynn, Baton Rouge, La. ; A. B. Gahan, College Park, Md. ; J. B. Garrett, Baton Rouge, La.; E. S. Hardy, Shreveport, La. ; J. S. Houser, Wooster, Ohio; Fred Johnson, Washington, D. C.; Charles R. Jones, Dallas, Tex. ; Albert Koebele, Alameda, Cal. ; G. W. Kirkaldy, Honolulu, H. I. ; W. O. Martin, Shreveport, La.; R. S. Mackintosh, Auburn, Ala.; John F. Nicholson, Stillwater, Okla.; R. C. I. Perkins, Honolulu, II. I. ; J. L. Randall, Durham, N. H. ; E. R. Sasscer, Washington, D. C.; W. W. Yothers, Dallas, 'Tex.

For transfer from active to associate membership: E. E. Bogue, C. T. Brues, R. S. Clifton, Carroll Fowler, C. W. Hargitt, Gerald McCarthy, George W. Martin, C. V. Piper, W. II. Scott.

On motion, the report of the committee was adopted.

On motion by Mr. Osborn, it was

Resolved, That the secretary be requested to arrange, if practicable, in the next annual programme for a symposium on "Insect Legislation," and for one on "The Use of the Insectary in Entomological Research and Education."

It was moved by Mr. Marlatt and carried that a committee of three, with the secretary as chairman, be appointed to prepare the programme for the next meeting and to formulate suggestions relative to the method of presentation of papers and the discussion thereon. The chair appointed as such committee the secretary to be elected, Mr. Marlatt, and Mr. Summers.

The following papers on insecticides were presented, the discussion being postponed until the entire series was read: 


\section{TESTS OF LIME-SULPHUR WASHES IN CONNECTICUT IN 1905.}

By W. E. Britton, Nevo Haven, Conn.

In our experiments, 6,000 peach, apple, and pear trees in five different orchards, situated in Westville, West Haven, Westport, Southington, and Middletown, were sprayed in March and April, 1905. The spray mixtures were chiefly lime-sulphur washes, which were prepared after five different formulas, as follows:

BOILED WASHES.

No. 1.-Twenty pounds lime, 14 pounds sulphur, 40 gallons water. The sulphur was added to the slaking lime and boiled 45 minutes. The mixture was then strained into the pump barrel, diluted, and applied.

Vo. 2.-Twenty pounds lime, 14 pounds sulphur, 10 pounds salt, 40 gallons water. Prepared as in the preceding, the salt being added with the sulphur.

\section{"SELF-BOILED" WASHES.}

No. 3.-Twenty pounds lime, 10 pounds sulphur, 10 pounds sodium sulphide, 40 gallons water. The lime was started slaking, and sulphur added. When at greatest heat, the sodium sulphide was added, with constant stirring.

No. 4.-Twenty pounds lime, 14 pounds sulphur, 5 pounds caustic soda, 40 gallons water. Prepared like No. 3, caustic soda being used instead of sulphide.

No. 5.-Twenty pounds lime, 14 pounds sulphur, 10 pounds sal soda, 40 gallons water. Made like Nos. 3 and 4, except that hot water was used and sal soda was employed instead of caustic and sulphide.

In each of these "self-boiled" washes the materials were allowed to stand for about thirty minutes after the violent boiling had ceased before diluting and applying.

In comparison with these lime-sulphur washes the following kerosene-limoid mixture, containing about 25 per cent of kerosene, was employed :

Vo. 6.-Forty pounds limoid, 10 gallons kerosene, 30 gallons water. The kerosene was absorbed by the limoid, then by violent stirring and forcing through the pump this was mixed with the water.

Mixtures 1 and 2 were boiled; mixtures 3,4 , and 5 are called "self-boiled" because no heat is used in preparing them except that evolved by the slaking lime.

The cost of materials in making these mixtures varies from $\$ 0.54$ to $\$ 0.84$ in the lime-sulphur washe for enough to make a barrel of 40 gallons. Materials for the same quantity of mixture No. 6 (kero- 
sene limoid) cost $\$ 1.66$. These are all retail prices. Mixture No. 1 cost $\$ 0.54$ for materials, exclusive of boiling, which can probably be done in large quantities for $\$ 0.15$ to $\$ 0.25$ per barrel, according to equipment and conveniences.

Following our usual custom, twigs from a number of each kind of tree in each locality were examined before treatment. About 35 per cent of the wintering female scales had been killed by the winter. Late in June, just before the appearance of the young, twigs were again cut from the same trees and examined. This record showed the kerosenelimoid mixture to have killed about 88 per cent of the scales alive at the time of treatment, while the lime-sulphur washes killed from 91 to 95 per cent. These figures, though not marked, indicate the greater effectiveness of the latter, and observations made late in the season not only confirmed the indications, but showed a much greater difference in favor of the lime-sulphur washes. Large peach trees at Southington were sprayed, a portion with the kerosene-limoid mixture and another portion with the boiled lime-sulphur wash, the trees being well covered in each case, and all were badly infested with scale. In October I was greatly disappointed to find plenty of living scales on the trees sprayed with the kerosene-limoid mixture; some were as badly infested as before spraying.

Trees in adjoining rows sprayed with the lime-sulphur wash, though showing some living scales, were comparatively free from them, although there were plenty of dead ones. The evidence seems to show that though the kerosene-limoid mixture had in June killed nearly as great a proportion of the scales as the lime-sulphur washes, it apparently left the bark in a condition much more favorable to the presence of the scale, and therefore to reinfestation, than the latter. I have noticed that where lime-sulphur washes are applied the bark does not readily become again covered with scales; it is also possible that the scales counted as alive in June were injured to such an extent by the lime-sulphur wash that they failed to reproduce. Other experimenters have reported similar results.

Strange to say, the self-boiled wash of lime, sulphur, and sodium sulphide gave slightly better results than the boiled wash. The presence of salt in the boiled wash could not be detected by its effect on the scales nor by its adhesive qualities.

\section{EXPERIMENTS WITH INSECTICIDES ON THE SAN JOSE SCALE.}

By E. P. Felt, Albany, N. Y:

The insecticide campaign of recent years has been continued with gratifying results, so far as confirmation of earlier work is concerned. The tests have been limited largely to lime-sulphur washes, boiled and unboiled, and 20 and 25 per cent of the so-called limoid or $\mathrm{K}-\mathrm{L}$ 
mixtures. The lime-sulphur washes called for 20 pounds of lime and 15 pounds of sulphur, 25 pounds of lime and 20 pounds of sulphur, and 15 pounds each of lime and sulphur, to 50 gallons of water, the mixture in each case being actively boiled for about thirty minutes. Unboiled washes, using 20 pounds of lime, 15 pounds of sulphur, and 10 pounds of sal soda; 25 pounds of lime, 20 pounds of sulphur, and $12 \frac{1}{2}$ pounds of sal soda, and one composed only of 30 pounds of lime and 15 pounds of sulphur, were tested. Applications of these washes were made at Washingtonville, in the Hudson Valley, and also at Oyster Bay, on Long Island, for the purpose of observing their behavior under different conditions. The general results may be briefly summarized as follows:

There was very little difference between the behavior of the three boiled washes mentioned above. We still recommend the formula 20 pounds of lime, 15 pounds of sulphur, and 50 gallons of water, with at least thirty minutes active boiling, because this wash proved thoroughly efficient and calls for a minimum amount of material, except in the case of the one where equal quantities of lime and sulphur are employed. There seems to be a practical advantage in having some excess of lime, and as the cost of the additional 5 pounds is very slight we prefer the formula given above.

The unboiled washes-those depending on chemical activity to effect a combination-gave nearly, if not equally, as satisfactory results as those where fire was employed. The wash composed of 30 pounds of lime and 15 pounds of sulphur presents mechanical disadvantages, and as the one calling for 20 pounds of lime, 15 pounds of sulphur, and 10 pounds of sal soda is just as efficient an insecticide and gives a much more satisfactory mechanical and chemical combination, we do not hesitate to recommend it wherever small lots of wash are desired. Experience last season has shown that while this latter preparation can be made without adding any hot water, the mechanical condition is immensely superior when the reaction is started with a few pails of hot water, as described last year, and the chemical combination appears to be considerably better.

A very fine amorphous grade of sulphur, carefully mixed with lime which had been previously slaked and allowed to cool, was applied to a few trees and proved of no value in destroying the scale. Twenty and 25 per cent limoid or $\mathrm{K}-\mathrm{L}$ mixtures were tested, and, generally speaking, the results were not equal to those obtained with limesulphur washes, though we went to the trouble of securing the best grade of limoid with which to prepare them. There is no doubt that a certain amount of the scale was destroyed by the application. Nevertheless, the general results were disappointing, even in the hands of other parties, where the treatment was said to have been exceptionally thorough. 


\section{SULPHUR DIOXIDE AS AN INSECTICIDE.}

By C. L. Marlatt, Washington, $D . C$.

The fumes of burning sulphur, namely, sulphur dioxide with some sulphur trioxide, have long been one of the standard insecticide mases for the disinfection of rooms or dwellings of certain insect pests. Brimstone fumigation was urged by Dr. J. A. Lintner as a means of controlling the bedbug (Cimex lectularius L.) where liquid applications were inadvisable, and within the last few years Dr. Ch. Wardell Stiles, of the Bureau of Public Health and MarineHospital Service, has very successfully fumigated and disinfected frame cottages at a seaside resort for bedbug infestation by the sulphur treatment, burning the sulphur at the rate of 2 pounds of stick sulphur for each 1,000 cubic feet of space. Sulphur candles for such fumigation and for disinfection are a standard supply material to be purchased anywhere.

Sulphur has long been also one of the standard means of disinfection of premises or goods from disease germs, and in the later work against the Stegomyia calopus conducted by the Yellow Fever Institute of the United States Public Health and Marine-Hospital Service various experiments with sulphur as a means of destroying mosquitoes in houses were tried and the following conclusions reached: "From the limited number of experiments made and from previous experiments, we consider sulphur dioxide the best of the gaseons insecticides for this purpose." The other means tested included the fumes of tobacco, pyrethrum, and formaldehyde gas.

The chief objection to sulphur fumigation for insecticide or other work is the strong bleaching action of these fumes in the presence of moisture and their powerfully destructive action on vegetation. This latter effect has been exhibited very emphatically in the last few years in the large devastated areas surrounding the works of various smelting companies, where a great deal of sulphur is given off from the reduction of sulphide ores. As shown by the investigation of this sort of damage by Mr. J. K. Haywood, of the Bureau of Chemistry (see Bulletin 89 of that Bureau), the sulphur fumes given off from such reducing works are the same as those generated in the burning of stick sulphur, and their action is so powerful as to practically exterminate forests and other vegetation to a distance of from 2 to $y$ miles about the smelting plants. Referring to the form in which the sulphur is given off, Mr. Haywood says:

For each pound of sulphur burned 2 pounds of sulphur dioxide are formed and given off into the atmosphere, a part of which acts directly on the foliage of the trees. Sooner or later, however, all of the sulphur dioxire is changed by the action of the oxygen of the air into sulphur trioxide, and it is in this form 
that we may expect to find it in the foliage of trees. The moisture present in the air unites with this sulphur trioxide to form the highls corrosire compound, sulphuric acid, which in its turn acts upon the delicate foliage.

This same action may occur in the use of sulphur gas for disinfection of dwellings, and for all such uses the important consideration is to have a state of as complete dryness as possible to prevent the formation of sulphuric acid and the consequent bleaching of fabrics and wall papers and the corroding of metallic surfaces.

Opportunity offered during the past summer and autumn to resy thoroughly test the availability of sulphur dioxide and trioxide for various insecticide uses. Many of you probably have heard of Clayton gas. This gas is nothing more than the sulphur dioxide and trioxide referred to above, and is the same mixture which is obtained by burning ordinary stick sulphur or sulphur candles. It was originally employed as a means of extinguishing fires, particularly on shipboard, as in cargoes of cotton or of coal, and the recognition of its value against insects and rodents and other vermin by the company is an outcome merely of its use as a fire extinguisher. This method of disinfection has been very widely exploited by the Clayton Company, and has been adopted by the North German Lloyd Steamship Company for use on vessels transporting grain from South America and North American ports to Europe. It is used not only to destroy insects in cereals, but also to rid steamers of rats and other vermin, and, further, to disinfect vessels in which disease has broken out. The method has received such wide acceptance commercially that it seemed advisable to give it a thorough experimental test. The Clayton Company, furthermore, was anxious to have us make such a test, and was willing to furnish every assistance and meet whatever expense might be entailed. It being impracticable to conduct a long series of tests in New Tork, the company sent to Washington an expert in charge of a complete apparatus, which was made the subject of a good many experiments, covering a period of two months. These experiments are given in detail below. In explanation of the experiments with plants it may be stated that Doctor Galloway, of the Bureau of Plant Industry, was consulted, and he deemed it advisable to attempt to use the gas in as nearly a dry condition as possible on plants to determine its value, if any, for disinfecting living plant material. The violent destructive action of this gas on plants is very fully emphasized by these experiments, and it is shown conclusively that probably under no conditions of ordinary practical application can it be used as a means of disinfecting living plants.

With the Clayton apparatus the gas is prepared by the combustion of common roll brimstone in an oven or generator, and the principal 
features are large production of gas, the reduction of its temperature to nearly normal, and its control under pressure. The sulphur is burned on a grate and also on the floor of the oven as it melts and falls through, and a temperature is developed of from $700^{\circ}$ to $1,000^{\circ}$ F. To prevent the carrying over of flowers of sulphur the gas generated passes over two "baffle "plates before it reaches the outlet pipe. Through this outlet pipe the gas is carried to a cooler arranged like an ordinary steam boiler tank with numerous pipes around which water is kept constantly circulating. By this means the gas is cooled down to from $70^{\circ}$ to $100^{\circ} \mathrm{F}$., and is carried thence to the apartment or building or ship to be disinfected. The gas is forced through this apparatus and into the building to be fumigated by means of a blower operated by a small electric motor or by a gasoline engine. There are double grates to the furnace so that the supply of air can be either drawn from out of doors or from the building to be fumigated. In the latter case there is a circulation of air and gas between the apparatus and the building, the gas percentage becoming stronger all the time, but without pressure. When the supply of air for the apparatus is taken from without, the air and gas in the building or vessel is under heavy pressure and the penetration of the gas is much increased. The gas is tested from time to time by submitting it to water observation in a pipette, and any percentage of gas can be maintained, from a fraction of 1 per cent to 16 per cent or more.

The special claims made for the gas thus generated are its' strong toxic effect on insects, and great penetrating power. The penetration of the gas is both normal to it and very much increased by its being forced into the building under heavy pressure, so that every crevice and crack of the building is filled, and the gas escapes forcibly through every aperture. This apparatus has been tested by a committee of supervising inspectors of steam vessels acting under the authority of the Treasury Department and favorably reported on as a fire extinguisher. The apparatus has also been tested in a limited way by the Public Health and Marine-Hospital Service, and certain of the quarantine officers have been authorized to employ the apparatus for the fumigation of vessels under proper conditions. It has also been tested by foreign shipping companies and hygienic laboratories.

In the practical carrying out of the details of the experiments, and particularly the supplying of insect material, Messrs. Chittenden and Sanders rendered valuable assistance. The grain and various seeds were furnished by the Office of Seed and Plant Introduction and Distribution of the Bureau of Plant Industry. 
RECORD OF EXPERIMENTS WITH SULPHUR DIOXIDE.

Experiments 1 and 2 were conducted in the glass fumigating house of the Bureau of Plant Industry.

Experiment No. 1.

Four per cent gas pumped into house for 10 minutes. Subjects of experiment, various plants. Palms and pineapples were uninjured; all the other plants were killed.

In the course of this and the following experiment the escaping gas blown by the winds over and more or less into adjoining greenhouses killed a great many delicate plants, doing much damage, the tests showing conclusively the absolute impossibility of using this gas for the fumigation of growing plants. Where also the gas flowed for a few minutes over grass the latter was burned as though scorched by fire, and killed to the ground.

\section{EXPERIMENT No. 2.}

One hour treatment of several bushels of various kinds of seers, including Kafir corn, rice, rye, barley, and cowpeas. Beginning with a strength of 6 per cent, the gas was increased to 12 per cent at the end of half an hour, and to 16 per cent at the conclusion of the experiment, the forcing of the gas into the building being continuous and under pressure. The results of the germination tests of these seeds by Mr. E. Brown, botanist in charge of the Seed Laboratory, indicated that Kafir corn and rice were killed, the cowpeas were injured to the amount of 10 per cent, and the rye and barley were substantially uninjured, 95 per cent germinating.

Tests with insects were also made in jars very tightly plugged with cotton. The Bruchus in cowpeas died in 40 to 45 minutes. All free Calandras were killed; some still inclosed in the grain afterwards emerged. In bags of grain all free insects were killed. but some of the Calandras and Bruchus inclosed in grain and peas afterwards emerged.

Experiment No. 3. $a$

Two hours at 10 per cent, machine running 5 minutes. Jars containing insects were all tightly plugged with cotton, and none of the insects were killed.

Experiment No. 4.

Treatment for 3 hours at 5 per cent, the machine running 5 minutes. (The lid of the box in the meantime had been made more nearly air-tight by rubber packing.)

a Experiments 3 to 12 were conducted at the Department insectary: Nos. 3 to $S$ in a small, zinc-lined fumigating box, and 9 to 12 in a building 10 by 10 by 10 feet, especially constructed for the purpose. 
Results on insects.-Of insects at bottom of jars merely covered with cloth 2 out of 10 mealworms (Tenebrio) killed; in small sack made of ordinary grain sacking or heavy drilling everything was killed. Tho capacity of the sack was about half a peck.

\section{EXPERIMENT No. 5.}

Treatment for 1 hour with 7 to 8 per cent gas, machine running 30 minutes. Test at the end of the hour showed that the box contained full per cent gas. Insect tests made with four jars, two of which were covered with cloth and two lightly plugged with cotton, merely sufficiently to retain the insects. In the cloth-covered jars the insects were alive at the end of the hour, but the cotton was sufficient to retain more or less of the gas over night, and the insects were all dead the next day, indicating the value of the longer time gassing at a low percentage.

EXPERIMENT No. 6.

Two and one-half to 3 per cent of gas for 16 hours, the machine rumning for 5 minutes. At the end of the 16 hours less than 0.5 per cent of gas was found in the box. 'The free insects on the exterior' of the bags were killed, and those deeper down in the bags were uninjured. This test was made with three bags of rye infested with Calandra-ordinary grain bags, capacity of each about 2 bushels. It is probable that the machine, running but 5 minutes, had not at the end of this time caused the gas to penetrate these large bags, and the subsequent partial penetration of these bags would reduce the percentage of the gas considerably.

\section{Experiment No. 7.}

Five per cent gas, machine running 15 minutes, and then left for a total of 22 hours. At the end of 4 hours a sample of the gas taken from the fumigating box indicated a strength of over 2 per cent gas remaining. Some of this gas had doubtless escaped from the box, but probably a good deal of it had been absorbed by the grain in the large bags. The following morning the box was opened, and an examination of the contents showed the apparent destruction of all insect life. The bags of infested grain placed in the center and at the bottom of the large sacks with many living insects (Calandras) showed no living material. The same was true of Bruchus in cowpeas. All of this material was held for later examination, and there were no revivals. When the box was opened the gas was still very strong in the box, probably exceeding 1 per cent. This test seems to indicate that a low percentage of gas, say from 5 to 1 per cent, con- 
tinued for a long time, will destroy insects in grain and seeds, and has considerable penetrating power.

NotE.-In the case of all these tests 10 to 15 packages of various seeds were included to be tested for effect on germination. The reports on these tests are appended to this article.

\section{Experiment No. 8.}

An. experiment to determine the effect of the gas on miscellaneous insects, household pests, grain pests, and the powder-post beetle (Lyctus) in manufactured wood products-furnished by Doctor Hopkins. The insects submitted to the test (except those in the wood material) were in cloth-covered glass jars or in glass cylinders clothcovered at either end, containing grain. These were placed in the house, opposite the windows, so that the effect of the gas and the exact time of the death of the insects could be noted. The wood material was placed in the building, but of course the action of the gas on this material could not be followed. The experiment began at $2.15 \mathrm{p} . \mathrm{m}$. and continued until 10 o'clock the next morning, a total of nearly 20 hours. In charging the building, necessarily the beginning was with a low percentage of gas, which worked up to the full amount of 6 per cent in 30 minutes. After 15 minutes' pumping a test of the gas in the house indicated 2 per cent and after 25 minutes 5 per cent. Five minutes under pressure brought the gas up to 6 per cent in the building, 7 per cent at the machine, and further charging was discontinued. After 1 hour the gas in the building still indicated 6 per cent; after 2 hours, $5 \frac{1}{2}$ per cent ; after 4 hours, something more than 3 per cent, and at the end of the experiment, about 1 per cent.

The immediate effect on the insects noted below was chiefly with a very low percentage of gas; in other words, all effect noted prior to the expiration of 15 minutes was with gas of less than 2 per cent strength, and at 7 minutes the gas was doubtless less than 1 per cent in the building.

SUBJECTS OF EXPERIMENT.

(1) Honey bees (Apis mellifera L.) : Semiunconscious and fallen to bottom of jar in 7 minutes; all motion ceased at 10 minutes.

(2) German roaches (Blattella germanica L.) : Down and apparently dead in 7 minutes.

(3) Bedbugs (Cimex lectularius L.) : Down and motionless in 10 to 15 minutes.

(4) Monilema sp: Sluggish in 15 minutes; quiet in 20 minutes.

(5) Miscellaneous insects, several orders, including Orthoptera, Hymenoptera, Hemiptera, Diptera, and Arachnida (complete list be- 
low ): ${ }^{a}$ Most of these insects went down and became motionless in between 5 and 10 minutes. The Orthoptera remained active and uninjured for 15 miutes, but soon thereafter became motionless and apparently asphyxiated.

(6) Clothes moths, adults: Down and quiet in 10 to 15 minutes.

(7) Dermestes larvæ: Down and quiet in 10 to 15 minutes.

(8) Ants in jar with earth: Actual time of asphyxiation could not be noted; probably within 10 minutes, judging from the Hymenoptera in other jars.

(9) Corn meal containing Tribolium confusum Duv. and Silvanus surinamensis L., also parasitic four-winged flies: The beetles mentioned were asphyxiated within 10 minutes; the parasite, protected more or less in the mass of meal, in 30 minutes.

(10) Anthrenus verbasci L.: Time of asphyxiation not noted, but within 30 minutes.

$a$ The list of the miscellaneous species subjected to this test, as determined by Mr. Titus, and in addition to those noted above, follows. It includes 122 specimens, representing at least 30 genera.

Diptera (24 specimens).

1 Winthemia 4-pustulata Fab.

1 Lucilin copsur L.

1 Musca domestica L.

2 Culex pipiens $\mathrm{L}$.

3 syrphus sp.
5 sciara sp.

2 Drosophila punctulata Loew.

1 Drosophila busckei Coq.

3 Ortalids.

5 Unidentified (minute).

\section{Orthoptera (4 specimens).}

4 Melanoplus femur-rubrum De G.

Neuroptera (1 specimen).

1 Dragon-fly.

Coleoptera (10 specimens).

3 Minute species.

2 Megilla maculata De G.

5 Epitrix parvula Fab.

Hymenoptera (3 specimens).

1 Halictus sp.

1 Pimpla inquisitor Say.

1 Rhogas rileyi Cress.

Hemiptera (80 specimens).

27 Drceculacephala mollipes Say.

2 Deltocephalus inimicus Say.

2 Diedrocephala coccinea Forst.

3 stobera sp.

22 Cicadula sp.

1 Cicadula sp.
11 Empoasca (2 species).

1 Geocoris bullatus Say.

6 Lygus pratensis $\mathrm{L}$.

1 Nabis ferus L.

3 Macrosiphum (?) sp.

$31024-\mathrm{No} .60-06 \mathrm{M}-10$ 
(11) Calandra oryza L.: Asphyxiated within 30 minutes. In the same jar was Silvanus surinamensis and Tribolium confusum.

(12) Bean weevil (Bruchus quadrimaculatus Boh.): Asphyxiated within 30 minutes.

All of the material referred to above was left untouched for approximately 20 hours, at the end of which time no sign of life or evidence of possible resuscitation was manifested on exposure to air, and there were no later revivals. No signs of life were afterwards seen in the infested wood material, and a thorough examination made two months after treatment by Doctor Hopkins indicated that the insects had been reached in the wood and killed.

At the same time various objects were placed in the building to determine the bleaching effect of the gas-a good many colored papers and a good many fabrics, representing light-colored cotton linings and silk and cotton linings, black, and also men's tailoring goods of various colors and qualities. No bleaching effect was noted whatever in the heavier cloths. Some of the lining cottons showed slight bleaching. The papers were practically unbleached, except one of pink shade. The bookbinding cloths were very slightly bleached, not enough to be especially noticeable or to injure the appearance of the bindings. A highly polished bit of brass was completely darkened and tarnished.

Experiment No. 9.

This experiment was to determine the possibilities of penetration of a low percentage of gas, between 5 and 6 per cent, ending at the latter amount. Small bags of infested grain were placed at the bottom of an air-tight zinc-lined box haring a depth of 18 inches and a capacity of 3 or 4 bushels. Similarly small bags of infested grain were placed at the bottom of earthenware crocks having an inside depth of 14 inches. The gas could only get at these insects by penetrating through the grain directly from the top, 18 inches in one case and 14 in the other. This was necessarily a pretty severe test. inasmuch as there was no possibility of circulation of air. The gas was kept under pressure for one-half hour after reaching 6 per cent to increase the possibilities of penetration. The apparatus was then disconnected and the building left closed overnight for a total of some 22 hours. The gas in the building was tested from time to time after stopping the generator. After one-half hour 6 per cent gas was still found, and the same was true after an hour's time. After 2 hours the percentage had fallen to 5 per cent, and at the time of the opening of the building in the morning of the following day there was still at least 1 per cent of gas present.

Results.-Neither in the case of the zinc-lined box nor the crockery jars had the gas penetrated very deeply into the grain, and the insects 
in the small bags at the bottom were unaffected. (See Experiment No. 11.)

Experiment No. 10.

Designed to test the possibility of using the gas for the rum1gation of ships loaded with bananas. A bunch of green bananas was submitted to 6 per cent gas without pressure from 3 p. m. to 10 a. m., a total of some 19 hours. There was still 6 per cent gas found in the building an hour after disconnecting the apparatus, and practically the same amount 2 hours after. After 6 hours the percentage had fallen to 5 per cent, and at the end of the experiment there was apparently somewhat less than 1 per cent in the building. ${ }^{a}$

Results.-The bananas, which could be observed through the window, showed no bleaching effect for the first 5 or 6 hours, but the next morning were much bleached and yellowed and apparently somewhat softened, the fruit having in the meantime become moist from condensed moisture, which undoubtedly occasioned the bleaching noted. The indications are that, in view of the natural moisture which would be found in holds of banana-laden vessels, the use of this gas for fumigation would be rather disastrous to the appearance and quality of the fruit.

Experiment No. 11.

This experiment duplicated experiment No. 8, except for the strength of gas, and was designed to determine the penetration powers of a high percentage of gas rather than a low percentage, which had proven ineffective. The conditions were the same as in experiment No. 8. The generator was started at 4.10 p. m. By 4.30 a 5 per cent gas was being generated, and the gas was forced into the building under pressure at 4.40 . By 5 p. $\mathrm{m}$. 10 per cent gas was reached in the building, 12 per cent at the machine. By $5.45 \mathrm{p} . \mathrm{m}$. 15 per cent of the gas was secured in the building, and this percentage was kept up under pressure until $6 \mathrm{p}$. $\mathrm{m}$., when the generation of gas was stopped. The gas was therefore under pressure in the building about 1 hour and 20 minutes, and the total operation of the machine was 1 hour and 50 minutes. The gas in the building was tested at 7.50 p. m., and 10 per cent found at that time. At 9.50 in the morning, the following day, 5 per cent of the gas still remained in the building. The building was then opened and aired and the infested grain removed from the bottom of the jars and from the zinc-lined box. It was evident, from the odor, that the gas had penetrated to the bottom of both of these receptacles, and an examination of the infested grain showed the insects all apparently dead.

$a$ The retaining capacity of the building for the gas varied slightly with the condition of the external air, falling more quickly in windy weather than in still weather. 
The bags of infested grain used in this test were kept free from a chance of reinfestation, and two months later were carefully examined with the following results: The infested grain buried in the middle of the zinc-lined box, namely, at a depth of about 9 inches. contained only dead insects, the penetration and destruction of insect life being perfect in this case. The insects represented were principally Calandra oryza and Ateleopterus tarsalis Ashm., a parasite of Sitvanus surinamensis. The sack at the bottom of this chest, namely. at a depth of 18 inches, exhibited the same results, and contained, in addition to the above, Meraporus calandra How., a parasite of $C$. oryza, and one beetle of Tenebroides mauritanicus $L$.

The sacks of infested grain placed at the bottom of the earthenware jars, namely. at a depth of $1 \pm$ inches. exhibited, after two months standing, living insects. (All were dead, apparently, at the conclusion of the experiment.) The insects represented are Calandra oryza and its parasite, $M$. calandre, and of these only about 50 per cent had been killed. There was also found one living larra of $T$. mauritanicus. The test in this latter case was a very severe one. for the reason that the jars were narrow and the surface exposed at the top for direct penetration was only 5 or 6 inches in diameter. In the case of the zinc-lined chest there was a superficial area for direct penetration of 4 or 5 square feet.

\section{Experiment No. 12.}

To test the effect of the gas on wall paper and lacquered brass and nickel.

The material was subjected to 5 per cent of the gas for $3 \frac{1}{2}$ hours, with occasional pressure of a few minutes at a time to test the strength of the gas in the building. Some 12 samples of wall papers of different color and quality were submitted to the test, and also lacquered brass and a nickel-plated object. The fumigation chamber was unheated and was somewhat moistened from rains, and hence the air in the room was at a fairly high degree of saturation, which undoubtedly very much increased the bleaching power of the gats. Practically all the wall papers were considerably altered in color. either by notable bleaching or by an actual change in the tone of color, in one case becoming considerably darker than the original. The dark reds were least affected-almost none-and the pinks and greens were most. affected. These tests indicated that the use of this gas would be very apt to bleach wall papers in rooms or houses at all damp. With houses subjected to regular heating. as in early fall or winter. the bleaching probably would be reduced to a minimum. The lacquered brass was unaffected. The nickel-plated object was badly rusted. It was noted that in the damp weather which occurred at the time of this experiment the wall papers retained an odor of the gas for a long 
time after being removed from the fumigating chamber, indicating the formation of sulphuric acid by condensation.

\section{SUMMARY OF RESULTS.}

(1) Sulphur dioxide is very destructive to most growing plants and almost instantly deadly to succulent plants and grasses, even at low percentages. Palms and pineapples can, however, stand a moderate fumigation. This gas, therefore, has probably no value whatever as a means of disinfecting living plants, except perhaps for the very hardiest of dormant nursery stock and palms.

(2) The germinating power of grass, grain, and common garden seeds is quickly destroyed with even weak applications of the gas, and its employment is therefore impracticable for all seeds for planting. It does not, however, injure the feeding value or cooking quality of cereals, and the odor of the gas passes away fairly quickly and is not retained except where the grain or seeds are moist.

(3) A comparatively low percentage of the gas will kill practically all free insects after an exposure of from a few minutes to half an hour, but a much longer exposure is necessary to kill insects inclosed in grain or seeds, as Bruchus and Calandra. The best results are obtained by submitting such grains or seeds to a low percentage of the gas (from 1 to 5 per cent) for a period of 12 to 24 hours. Employed in this way the gas is a very effective means of disinfecting stored grain or similar products, and has the additional advantage of entirely eliminating the danger of explosion and fire.

(4) The bleaching quality of the gas on fabrics and wall papers is largely determined by the moisture in the air. In comparatively dry air such bleaching is inconsiderable, and in a heated house can probably be ignored. Its effects on metal surfaces, however, is more marked, and these are likely to be tarnished if the air be at all moist, and the protection of such surfaces during the treatment is therefore necessary. Under conditions of considerable or excessive moisture wall papers and the lighter fabrics are much bleached and all metal surfaces corroded.

(5) The penetration of a low percentage of gas (5 or 6 per cent) without pressure from above into exposed surfaces of grain is not very great; but a strong percentage (15 per cent) under high pressure for an hour or more has strong penetration to a depth of from 14 to 18 inches even where a comparatively small area for penetration is allowed. It should be noted here also that in the ordinary method of fumigating grains with the Clayton apparatus the gas is liberated through a perforated iron tube thrust into the bottom of the bin, and the gas forced in under pressure is made to permeate much more quickly and thoroughly the entire mass of grain.

(6) The test made with the fumigation of a bunch of bananas was, in a measure, unsatisfactory, as it was done in a very rainy, damp 
season, and the air in the building was the same as the exterior air and heavily charged with moisture. Under these conditions, however, the bananas were much bleached and softened. Nevertheless, it must be remembered that there will always be a great deal of moisture in the holds of ressels stored with bananas, and its use for the disinfection of such cargoes is therefore most questionable.

The general results of these experiments as indicated above seem to show that this gas has a very great value for the uses in which it is now employed, namely, the disinfection of ressels and cargoes of grain. Here all conditions are exceptionally farorable. The ressel furnishes a comparatively air-tight fumigating receptacle, and the gas is forced into it by circulation at first, and finally under pressure, and made to reach every portion of the vessel. The grain thus disinfected is practically always for consumption and not for planting; hence the effect on germination is comparatively immaterial. It seems probable also that it may be very useful in a similar way in elevators and flouring mills, eliminating the risk of fire and explosion. It is possible, further, that it may have distinct utility as a means of control of such diseases as yellow fever, where it is necessary to fumigate house after house over large areas in cities. It would be possible for this apparatus to move from house to house, thoroughly filling and fumigating each individual house in a comparatively short space of time, with no danger of overheating or fire from burning sulphur directly in the rooms or houses to be fumigated. These points of utility for the gas are in addition to its ralue as a fire extinguisher and as a general germicide. The Clayton apparatus is undoubtedly a most efficient means of quickly generating the gas. The process, however, is very simple and elementary. The danger in the use of the gas is in its corrosive action on metallic surfaces, and its strong bleaching power by its condensation in the presence of moisture and the formation of sulphuric acid, and its violent and destructive action on all plant life.

While having no lasting effects of serious nature, the odor of burning sulphur is very objectionable, and it is advisable in employing this means of disinfection to avoid breathing it as much as possible. The ill effects, however, are very temporary, and amount in the case of one not accustomed to the gas to a slight headache or sometimes to a slight effect on the stomach. It is apparently possible to get accustomed to the gas, and the expert who ran the apparatus paid little if any attention to it, and seemed to breathe it for indefinite periods and daily without injury.

There has been added, as an appendix, the detailed repo:t furnished by Mr. Edgar Brown, botanist in charge of Seed Laboratory, of the germination tests made with different grains anci seeds submitted to various strengths of the gas. 
United States Departient of Agriculture, Bureau of Plant Industry,

Botanical Investigations and Experiments, Seed Laboratory, Washington, D. C., October 3, 1905.

Final report of germination test of seed received September 22, 1905.

\begin{tabular}{|c|c|c|c|c|}
\hline $\begin{array}{c}\text { Test } \\
\text { number. }\end{array}$ & $\begin{array}{l}\text { Sender's } \\
\text { mark. }\end{array}$ & Name of seed. & $\begin{array}{l}\text { Dura- } \\
\text { tion of } \\
\text { test in } \\
\text { days. }\end{array}$ & $\begin{array}{l}\text { Germina- } \\
\text { tion, per } \\
\text { cent. }\end{array}$ \\
\hline 34573 & 12001 & Wheat, nonfumigated. & 4 & 91 \\
\hline 34574 & & Wheat, 1 hour at $7 \frac{1}{2}$ per cent. & 6 & 0 \\
\hline 34575 & 2 & Wheat, 2 hours at 10 per cent. & 6 & 0 \\
\hline 34576 & & Wheat, 3 hours at 5 per cent... & 6 & 0 \\
\hline 577 & 11760 & Rye, nonfumigated..... & 6 & 69.5 \\
\hline 34578 & 1 & Rye, 1 hour at $7 \frac{1}{2}$ per cent & 2 & 0 \\
\hline 3 & 2 & 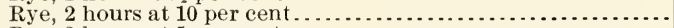 & 6 & 0 \\
\hline 8 & & Rye, 3 hours at 5 per cent.... & 6 & 0 \\
\hline 3 & 11215 & Timothy, nonfumigated ..... & 6 & 88.5 \\
\hline 3 & 1 & Timothy, 1 hour at $7 \frac{1}{2}$ per cent. & 6 & 0 \\
\hline 3 & 2 & Timothy, 2 hours at 10 per cent... & 6 & 0 \\
\hline 584 & $2 \mathrm{~A}$ & Cotton, 2 hours at 10 per cent... & 4 & 0 \\
\hline 3 & & Garden pea, nonfumigated .......... & 6 & \\
\hline 3 & 1 & Garden pea, 1 hour at $7 \frac{1}{2}$ per cent. & 6 & \\
\hline & 2 & 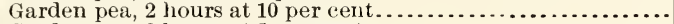 & 6 & 0 \\
\hline 888 & 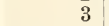 & Garden pea, 3 hours at 5 per cent.. & 6 & 8 \\
\hline
\end{tabular}

The actual value is the percentage of pure seed that will germinate. This is obtained by multiplying the percentage of pure seed by the percentage of total germination.

REMARKs.-Exposed to $\mathrm{SO}_{2}$ gas as above.

$$
\begin{gathered}
\text { E. BRown, } \\
\text { Botanist in Charge of Seed Laboratory. }
\end{gathered}
$$

\title{
United States Department of Agriculture,
} Bureau of Plant Industry, Botanical Investigations and Experiments, Seed Laboratory, Washington, D. C., October 3, 1905.

\begin{tabular}{|c|c|c|c|c|}
\hline $\begin{array}{c}\text { Test } \\
\text { number. }\end{array}$ & $\begin{array}{l}\text { Sender's } \\
\text { mark. }\end{array}$ & Name of seed. & $\begin{array}{l}\text { Dura- } \\
\text { tion of } \\
\text { test in } \\
\text { days. }\end{array}$ & $\begin{array}{l}\text { Germina- } \\
\text { tion, per } \\
\text { cent. }\end{array}$ \\
\hline 34589 & 12862 & Rice, nonfumigated. & 3 & 96 \\
\hline 34590 & 1 & Rice, 1 hour, at $7 \frac{1}{2}$ per cent. & 6 & 0 \\
\hline 34591 & 2 & Rice, 2 hours, at 10 per cent ... & 6 & 0 \\
\hline 34592 & & Rice, 3 hours, at 5 per cent .... & 6 & 0 \\
\hline 34593 & 11722 & Oats, nonfumigated.... & 6 & 52 \\
\hline 31594 & 1 & Oats, 1 hour, at $7 \frac{1}{2}$ per cent. & 6 & 0 \\
\hline 34595 & 2 & Oats, 2 hours, at 10 per cent .. & 6 & 0 \\
\hline 34596 & 3 & Oats, 3 hours, at 5 per cent ... & 6 & 0 \\
\hline 34597 & 12023 & Barley, nonfumigated ........ & 3 & 99.5 \\
\hline 34598 & 1 & Barley, 1 hour, at $7 \frac{1}{2}$ per cent.. & 6 & 76.5 \\
\hline 34599 & 2 & Barley, 2 hours, at 10 per cent. & 6 & 70 \\
\hline 34600 & & Barley, 3 hours, at 5 per cent ..... & 6 & 6 \\
\hline 34601 & 11267 & Flax, nonfumigated ............. & 6 & 82 \\
\hline 34602 & 1 & Flax, 1 hour, at $7 \frac{1}{2}$ per cent ... & 6 & 22.5 \\
\hline 34603 & & Flax, 2 hours, at 10 per cent. & 6 & 25 \\
\hline 34604 & 3 & Flax, 3 hours, at 5 per cent ... & 6 & 2 \\
\hline
\end{tabular}

Final report of germination test of seed received September 22, 1905.

The actual value is the percentage of pure seed that will germinate. This is obtained by multiplying the percentage of pure seed by the percentage of total germination.

REMARKS.-Exposed to $\mathrm{SO}_{2}$ gas as above.

\author{
E. Brown, \\ Botanist in Charge of Seed Laboratory.
}




\section{United States Departient of Agriculture, Bureau of Plant Ixdustry, \\ Botanical Investigations and Experiments, Seed Laboratory, Washington, D. C., October 3, 1905.}

Final report of germination test of seed receired September 22, 1905.

\begin{tabular}{|c|c|c|c|c|}
\hline $\begin{array}{c}\text { Test } \\
\text { number. }\end{array}$ & $\begin{array}{l}\text { Sender's } \\
\text { mark. }\end{array}$ & Name of seed. & $\begin{array}{l}\text { Dura- } \\
\text { tion of } \\
\text { test in } \\
\text { days. }\end{array}$ & $\begin{array}{l}\text { Germi- } \\
\text { nation, } \\
\text { per cent. }\end{array}$ \\
\hline 34605 & & Sweet corn, nonfumigated.......... & 4 & 94.5 \\
\hline $34605^{\circ}$ & & Sweet corn, 2 hours, at 10 per cent. & 4 & \\
\hline 34607 & & Sweet corn, 3 hours, at 5 per cent... & 4 & 0 \\
\hline 34608 & 13316 & Sorghum, nonfumigated......... & 6 & 75 \\
\hline 34609 & 1 & Sorghum, 1 hour, at $7 \frac{1}{2}$ per cent... & 5 & 0 \\
\hline 34610 & 3 & Sorghum, 3 hours, at 5 per cent. . & 6 & 0 \\
\hline 34611 & & 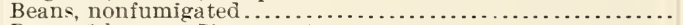 & 6 & 80. \\
\hline 34612 & 1 & Beans, 1 hour, at $7 \frac{1}{2}$ per cent...... & 4 & 12.5 \\
\hline 31613 & 2 & Beans, 2 hours, at 10 per cent.................................... & 4 & \\
\hline 34614 & 3 & 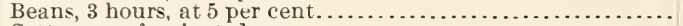 & 4 & 3.5 \\
\hline 34615 & 5939 & 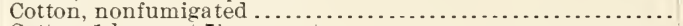 & 6 & 85 \\
\hline 34616 & 1 & 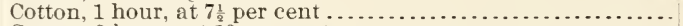 & 4 & 0 \\
\hline 34617 & 2 & 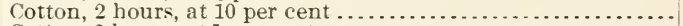 & 4 & \\
\hline 34618 & 3 & Cotton, 3 hours, at 5 per cent... & 4 & 0 \\
\hline
\end{tabular}

The actual value is the percentage of pure seed that will germinate. This is obtained by multiplying the percentage of pure seed by the percentage of total germination.

REMARKS.-Exposed to $\mathrm{SO}_{2}$ gas as above.

\section{E. Brown; \\ Botanist in Charge of Seed Laboratory.}

United States Departuent of Agriculture, Bureau of Plant Industry, Botanical Investigations and Experinents, SeEd Laboratory, Washington, D. C., October \%, 1905.

Report of germination test of beet seed receired September 22, 1905.

\begin{tabular}{|c|c|c|c|c|c|}
\hline $\begin{array}{c}\text { Test } \\
\text { number. }\end{array}$ & $\begin{array}{l}\text { Sender's } \\
\text { mark. }\end{array}$ & Name of rariety. & $\begin{array}{l}\text { Dura- } \\
\text { tion of } \\
\text { test in } \\
\text { days. }\end{array}$ & $\begin{array}{l}\text { Sprouts } \\
\text { from } 100 \\
\text { balls. }\end{array}$ & $\begin{array}{l}\text { Per cent } \\
\text { of balls } \\
\text { giving } \\
\text { sprouts. }\end{array}$ \\
\hline $\begin{array}{l}28149 \\
28150 \\
28151\end{array}$ & $\begin{array}{l}1 \\
2\end{array}$ & 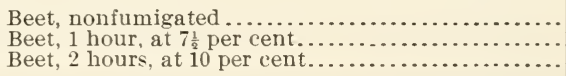 & $\begin{array}{r}10 \\
6 \\
6\end{array}$ & $\begin{array}{c}164.5 \\
0 \\
0\end{array}$ & \\
\hline
\end{tabular}

REMARKs.-Exposed to $\mathrm{SO}_{2}$ gas as above noted.

E. Browx, Botanist in Charge of Seed Laboratory. 
United States Department of Agriculture,

Bureau of Plant Industry,

Botanical Investigations and Experiments, Seed Laboratory, Washington, D. C., October 6, 1905.

Final report of germination test of seed received September 26, 1905.

\begin{tabular}{|c|c|c|c|c|}
\hline $\begin{array}{c}\text { Test } \\
\text { Number. }\end{array}$ & $\begin{array}{l}\text { Sender's } \\
\text { mark. }\end{array}$ & Name of seed. & $\begin{array}{l}\text { Dura- } \\
\text { tion of } \\
\text { te } t \text { in } \\
\text { days. }\end{array}$ & $\begin{array}{c}\text { Germi- } \\
\text { nation, } \\
\text { per cent. }\end{array}$ \\
\hline 34630 & & Rye, untreated. & 5 & 21 \\
\hline 34631 & & Rye, 2 to 5 per cent, 22 hou & 5 & 0 \\
\hline 34632 & & Beans, untreated ......... & 5 & 66 \\
\hline 3463 , & & Beans, 2 to 5 per cent, 22 hc & 5 & 0 \\
\hline 34634 & & Garden pea, untreated.... & 5 & 66 \\
\hline 34635 & & Garden pea, 2 t 5 per cent, 22 hours .... & 5 & 7 \\
\hline$\check{34636}$ & 13316 & Sorghum, untreated & 5 & 73.5 \\
\hline 34637 & 13316 & Sorghum, 2 to 5 per cent, $22 \mathrm{~h}$ & 5 & 0 \\
\hline 34638 & & Timothy, untreated. & 8 & 52 \\
\hline 34639 & 112.5 & Timothy, 2 to 5 per cent, 22 hours ... & 5 & 0 \\
\hline 34610 & & Oats, untreated. & 5 & 9 ; \\
\hline 34641 & 11722 & Oats, $2 t, 5$ per cent, 22 hou & 5 & 0 \\
\hline 3142 & 11268 & Flax, u $u_{\text {istreated.... }}$ & 5 & 81 \\
\hline $316 \cdot 3$ & 11268 & Flax, 2 to 5 per cent, 22 hours & 5 & 17 \\
\hline 3,644 & ....... & Cotton, untreated............... & 5 & 50 \\
\hline 31615 & & Cotton, 2 to 5 per cent, 22 hou & 5 & 0 \\
\hline
\end{tabular}

The actual value is the percentage of pure seed that will germinate. This is obtained by multiplying the percentage of pure seed by the percentage of total germination.

REMARKs.-Treated with $\mathrm{SO}_{2}$, as above noted.

E. Brown, Botanist in Charge of Seed Laboratory.

\section{United States Department of Agriculture,}

Bureau of Plant Industry,

Botanical Investigations and Experiments, Seed Laboratory, Washington, D. C., October 6, 1905.

Final report of germination test of seed received September 26, 1905.

\begin{tabular}{|c|c|c|c|c|}
\hline $\begin{array}{c}\text { Test } \\
\text { number. }\end{array}$ & $\begin{array}{c}\text { Sender's } \\
\text { mark. }\end{array}$ & Name of seed. & $\begin{array}{l}\text { Dura- } \\
\text { tion of } \\
\text { test in } \\
\text { days. }\end{array}$ & $\begin{array}{l}\text { Germi- } \\
\text { nation, } \\
\text { per cent. }\end{array}$ \\
\hline 34646 & 11780 & Barley, untreated..... & 5 & 94.5 \\
\hline 34647 & & Barley, 2 to 5 per cent, 22 hours. . & 5 & 9.5 \\
\hline 34648 & & Wheat, untreated................... & 3 & 94 \\
\hline 34649 & 12061 & 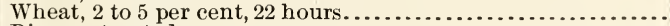 & 5 & 0 \\
\hline 34650 & .......... & Rice, untreated................ & 8 & 42.5 \\
\hline 34651 & .......... & Rice, 2 to 5 per cent, 22 hours.... & 8 & 0 \\
\hline 34652 & & Corn, untreated.................. & 5 & 94 \\
\hline 34653 & & Corn, 2 to 5 per cent, 22 hours ................. & 5 & 0. \\
\hline 34654 & & Sweet corn, untreated ............ & 5 & 97.5 \\
\hline 34655 & & Sweet corn, 2 to 5 per cent, 22 hours......... & 5 & \\
\hline
\end{tabular}

The actual value is the percentage of pure seed that will germinate. This is obtained by multiplying the percentage of pure seed by the percentage of total germination.

REMARKs.-Treated with $\mathrm{SO}_{2}$, as above noted.

E. BRown, Botanist in Charge of Seed Laboratory. 


\section{NOTES ON INSECTICIDES.}

By A. F. Burgess, Columbus, Ohio.

[Withdrawn for publication elsewhere.]

Mr. Britton said that he had used hydrocyanic-acid gas for bags of grain infested with the larræ of Plodia interpunctella Hbn. The silk spun by the larve formed a dense coating on the outside of the bags. One ounce of cyanide to 100 cubic feet was used, but after thirty-six hours the gas had failed to penetrate to the interior of the bags sufficiently to kill the Plodia larra, although those on the outside were all destroyed. Some live Tenebrio larva were also found in the bags.

Mr. Washburn asked if there were any data on the use of sulphur dioxide in flour mills.

Mr. Marlatt replied that he had not had any experience in actual mill work, but had tested it with sacks of flour and that it penetrated these rapidly.

Mr. Quaintance said that experiments had shown that penetration of hydrocyanic-acid gas into the soil is so slow that it is entirely impracticable to use it for soil fumigation in greenhouses. He also referred to a series of experiments in progress with the lime-sulphursalt wash by the Bureau of Entomology. Twenty-three or 24 formulas were tested during 1905 in western New York, in Maryland, and in Georgia, the work thus being extended orer a considerable range and likely to bring out differences due to climatic conditions. Mr. Quaintance further stated that washes containing less than 15 pounds of sulphur to 50 gallons of water in all cases proved inefficient in destroying the scale, and best results were secured from the use of washes containing considerably more sulphur, as 20 or 25 pounds to 50 gallons of wash.

Mir. Smith said that his experience in Georgia showed that instead of the ordinary method of mixing the sulphur with the lime after the water has been added to the latter, and while it is in the process of slaking, it is better to mix the sulphur with the water first while the latter is being heated by steam and then afterwards add the lime to the hot mixture.

Mr. Mackintosh asked for an opinion as to the difference between the so-called "flour of sulphur" and "flowers of sulphur." He said that he found difficulty in getting "flowers of sulphur" in Alabama. The former is used almost exclusively by the fruit growers and seems to give good results.

Mr. Quaintance said that in portions of the South, notably in Georgia, orchardists were using in the preparation of the lime- 
sulphur-salt wash a sulphur there known as "crystallized sulphur," which is practically the crude product as it comes from the mines.

The following papers were then read:

\section{SOME OBSERVATIONS ON THE SPINED SOLDIER BUG.}

\section{(Podisus maculiventris Say.)}

By A. W. Morrill, Washington, D.C.

The observations recorded in this paper, unless otherwise stated, are based on two specimens of Podisus maculiventris taken by the writer July 9, 1902, on a Camperdown elm tree at Amherst, Mass. The specimens were on that date in the fourth nymphal instar, and one of them had a nearly full-grown elm leaf-beetle larva impaled on its beak. They were taken to the laboratory, and until their death, which took place in each case over one and a half months later, were under daily observation, being caged in a lantern globe, covered at the top with cheese cloth.

The insects upon which my observations were made were kindly examined by both Mr. E. P. Van Duzee and Mr. O. Heidemann, who independently determined them as Podisus maculiventris Say, a name which has recently taken the place of the better known Podisus spinosus Dall.

As a beneficial insect this species has long held a high place in the esteem of economic entomologists, and consequently in entomological literature the references to it are very numerous. It has been noted as being especially useful as an enemy of the larva of the Colorado potato beetle (Leptinotarsa decemlineata Say), the elm leaf-beetle (Galemeclla luteola Müll.), the tent caterpillar, the cotton bollworm (Heliothis obsoleta Fab.), and the cotton leaf-worm (Alabama argillacea Hbn.). Undoubtedly some accounts of the destruction of injurious insects by Podisus maculiventris have been under the name $P$. serieventris Uhl., a species with which it is frequently confused. Van Duzee, in his Annotated List of the Pentatomidx, ${ }^{a}$ indicates his suspicion that the form treated of by Kirkland ${ }^{b}$ as $P$. serieventris is the same as the one he (Van Duzee) has called $P$. maculiventris. Whether or not the form known to some as $P$. serieventris be ultimately considered as a species distinct from $P$. maculiventris, its habits appear to be the same as those of the latter, and for a more general account than I shall give one should refer to the papers by Kirkland, which also contain an extended bibliography of the species of the genus.

$a$ Annotated List of the Pentatomidx Recorded from America North of Mexico, with descriptions of some new species. By Edward P. Van Duzee. Trans. An. Lint. Soc.. Vol. XXX, p. 71 , March, 1904.

$b$ Mass. Bd. Agric., Report on Gypsy Moth, 1896, pp. 392-403. Same, 1898, pp. 129-131. 


\section{INDIVIDUAL VARIATION IN ADULTS.}

The color of adults shows considerable variation even between parents and offspring. Nine specimens, including the two of the first

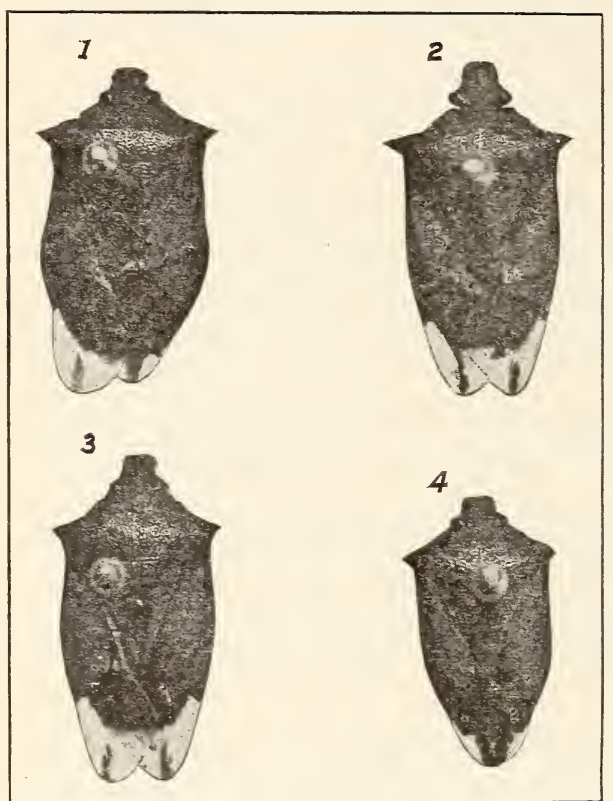

FIG. 6.-Podisus maculiventris, variation in form and size of parents and progeny: No. 1, female parent; No. 2, male parent; No. 3, largest specimen of seren of second generation, female; No. 4, smallest specimen of seren of second generation, male. Enlarged (original). and seren of the second generation, vary in ground color of the dorsum from a grayish to a reddish brown, and are marked with varying amounts of black. The rariation in the form and size in the same series (see fig. 6) is more striking. The humeral angles are more acutely produced in the male parent than in any of the other specimens in the series. The males average smaller and show a greater range of variation in size and form than the females. The abundance of food during the nymphal stages is the principal factor which determines the size attained by the adult. Certain
measurements have been made of each individual of the nine specimens, and are here given in tabular form:

Tariation in form and size of parents and offspring.

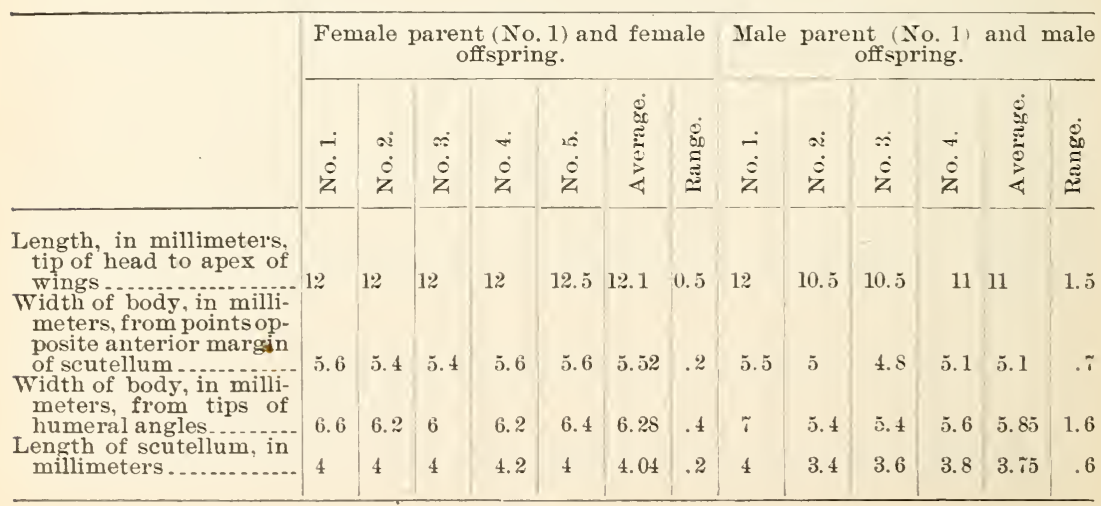


OBSERVATIONS ON EGG LAYING AND DURATION OF INCUBATION.

The female became adult on July 16 and deposited her first batch of eggs on the ninth day thereafter. The following table gives the data relating to eggs laid by this insect:

\section{Data on egg laying and incubation.}

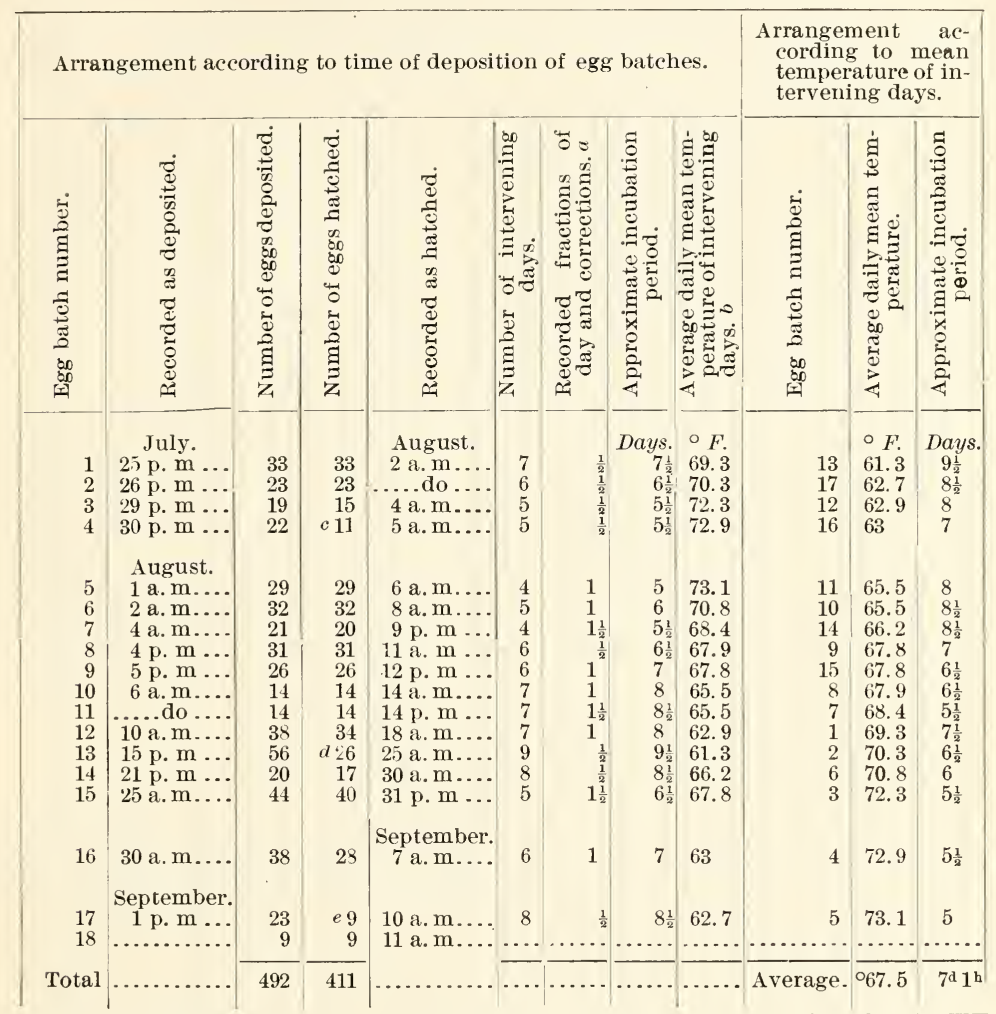

a The "recorded fraction" of a day is obtained as follows: For an egg batch recorded as deposited in the forenoon, one-half day (noon to midnight) has been added to the intervening days; if recorded as deposited in the afternoon, one-fourth day $(6 \mathrm{p} . \mathrm{m}$. to mid night) has been added to the intervening days; if recorded as hatching in the forenoon, one-fourth day (midnight to 6 a. m.) has been added to the intervening days; if recorded as hatching in the afternoon, one-half day (midnight to noon) has been added to the intervening days. "Corrections" are based on one-half of the sum of the period pre. ceding the record of deposition and the period preceding the record of hatching during which no observations were made. While in general the incubation periods without doubt. were made more nearly correct by the method of correction adopted, in some cases it resulted in slight discrepancies in the ratio of the incubation periods to the mean temperatures of the intervening days.

$b$ The temperature records are from the Bulletins of the Meteorological Observatory of the Massachusetts Agricultural College. The insects under observation were kept close to a north window which was open daily from 8 a. $\mathrm{m}$. to $6 \mathrm{p}$. $\mathrm{m}$. Under the conditions the daily mean temperature was probably very close to that recorded at the observatory.

$c$ Unhatched eggs fed upon by nymphs of batch No. 3.

${ }^{d}$ Fourteen infertile; $\mathbf{1 6}$ fertile, but failed to hatch.

$e$ Nine infertile; 5 fertile, but failed to batch. 
From the abore table can be deduced the approximate effect within the limits of these observations of a single degree of daily mean temperature on the period of incubation. If we consider only the three batches of eggs which matured with the lowest arerage daily mean temperature and the three batches which matured with the highest arerage daily mean temperature, we find that the former arerage was $62.3^{\circ} \mathrm{F}$. and the latter $72.7^{\circ} \mathrm{F}$., while the period of incubation is shortened with the increase in temperature from 8.6 to 5.3 days. In other words the decrease of $10.4^{\circ} \mathrm{F}$. represents an increase of 3.3 days in the incubation period or 0.32 day for each degree of temperature.

The average number of eggs deposited per day by the female during the entire adult life was 9.3. Omitting the first eight days during which no eggs were laid. the number of eggs after the beginning of the egg-laying period areraged 11.2 per day. The rate of production of eggs as well as the length of incubation period ras affected in a marked degree by the daily temperatures. The last fifteen days of the month of August were cooler than the first 15 ; the 5 warmest days of the month occurred consecutively from August 1 to 5, inclusive, and the 5 coolest days occurred consecutively from August 16 to 20 , inclusive. The relation of temperature to the production of eggs is shown in the following table. although allowance should be made for the influence of minor factors, the experience with one insect being too limited for anything more than general conclusions.

Relation of temperature to production of eggs.

\begin{tabular}{|c|c|c|c|c|c|c|}
\hline & Period, August, 1902. & $\begin{array}{l}\text { A verage } \\
\text { daily } \\
\text { mean } \\
\text { temper- } \\
\text { ature. }\end{array}$ & $\begin{array}{c}\text { Number } \\
\text { of egg } \\
\text { batches. }\end{array}$ & $\begin{array}{c}\text { Total } \\
\text { number } \\
\text { of eggs. }\end{array}$ & $\begin{array}{l}\text { Per cent } \\
\text { of total } \\
\text { number } \\
\text { of eggs } \\
\text { per } \\
\text { month. }\end{array}$ & $\begin{array}{l}\text { Arerage } \\
\text { number } \\
\text { of eggs } \\
\text { per day. }\end{array}$ \\
\hline $\begin{array}{l}1-15 \\
16-30 \\
1-5 \\
16-20\end{array}$ & 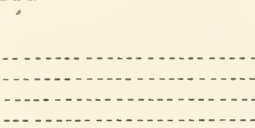 & $\begin{array}{l}\circ F . \\
6 \% .9 \\
63.9 \\
73 \\
59.3 .\end{array}$ & $\begin{array}{l}9 \\
3 \\
5\end{array}$ & $\begin{array}{l}2 \pi 1 \\
102 \\
139\end{array}$ & $\frac{\pi}{2 \pi}$ & $\begin{array}{r}18.6 \\
6.8 \\
2 \% .8 \\
\end{array}$ \\
\hline
\end{tabular}

It is worthy of note that the longest incubation period of the 17 records included the 5 coldest days of the month. while the shortest incubation period included $4 \frac{1}{2}$ of the 5 warmest days.

OBSERTATIONS ON DURATION OF NYMPH STAGES AND LENGTH OF ADULT LIFE.

The duration of the nymph stages depends for the most part on the temperature and perhaps more or less on food supply. Of the 18 batches of eggs obtained from the female under observation, the nymphs from only 1-No. 12-were bred to maturity in the laboratory. Thirty-four nymphs hatched on August 18 from egg batch No. 
12 , but, their number being reduced by insufficient food supply and by cannibalism, 7 only reached maturity. The first of these to become adult molted its fifth nymphal skin on September 23, and the last one of the seven to become adult molted its last nymphal skin on September 27 , making a range of from 36 to 40 days for the nymphal stages and from 44 to 48 days for all immature stages, including the egg. The average duration of the immature stages of the seven specimens was approximately 46 days, with an average daily mean temperature of $61.5^{\circ} \mathrm{F}$. The approximate total positive temperatures (above $32^{\circ} \mathrm{F}$.) during the developmental period in this case was $1,357^{\circ} \mathrm{F}$.; to which, if we add the approximate total positive temperature required by the female after reaching maturity, before any eggs are deposited, we get $1,708^{\circ} \mathrm{F}$. for the approximate total positive temperature of the life cycle in the instances here recorded. The total positive temperatures at Amherst, Mass., from the 1st of May to the 15 th of October, inclusive, would make a maximum of 3 annual generations possible at this rate, considering that earlier than the month of May and later than the 15th of October the development is practically nil. Of the two specimens under observation, the adult life of the female extended from July 16 to September 6 and that of the male from July 17 to August 29. The total number of days in the case of the female being 53 and the male 44, the average of the pair was $48 \frac{1}{2}$ days. Death took place very slowly in each case and was apparently due to natural causes.

\section{OBSERVATIONS ON THE FEEDING HABITS.}

Desiring to obtain a definite idea of the value of this species as an enemy of the elm leaf-beetle, the two specimens, from the time they were taken on July 9, were fed exclusively on the larvæ of this beetle as long as it was possible to obtain them in sufficient numbers. Before molting the fourth nymphal skin the two bugs ate four fullgrown elm leaf-beetle larvæ. 'Their food during the six days of their fifth nymphal or "pupal" stage and during their entire adult life is shown in the following tables:

Feeding record of two bugs in fifth nymphal instar.

Food : Elm leaf-beetle larvæ (Galerucclla luteola Müll.).

\begin{tabular}{|c|c|c|c|c|c|c|c|c|c|}
\hline \multirow{2}{*}{ Date, July, 1902.} & \multicolumn{2}{|c|}{ Full grown. } & \multicolumn{2}{|c|}{$\begin{array}{c}\text { Three-fourths } \\
\text { grown. }\end{array}$} & \multicolumn{2}{|c|}{$\begin{array}{l}\text { One-half } \\
\text { grown. }\end{array}$} & \multicolumn{2}{|c|}{$\begin{array}{l}\text { One-fourth } \\
\text { grown. }\end{array}$} & \multirow{2}{*}{$\begin{array}{c}\text { All } \\
\text { stages, } \\
\text { total } \\
\text { de- } \\
\text { stroyed. }\end{array}$} \\
\hline & Eaten. & $\begin{array}{l}\text { Partly } \\
\text { eaten. }\end{array}$ & Eaten. & $\begin{array}{l}\text { Partly } \\
\text { eaten. }\end{array}$ & Eaten. & $\begin{array}{l}\text { Partly } \\
\text { eaten. }\end{array}$ & Eaten. & $\begin{array}{l}\text { Partly } \\
\text { eaten. }\end{array}$ & \\
\hline 131216 & $\begin{array}{l}2 \\
2 \\
9\end{array}$ & 2 & $\begin{array}{l}3 \\
1\end{array}$ & 1 & $\ddot{2}$ & 1 & 2 & & $\begin{array}{r}2 \\
9 \\
15\end{array}$ \\
\hline Total, 6 days ........ & 13 & 2 & 4 & 1 & 3 & 1 & 2 & & 26 \\
\hline
\end{tabular}


Feeding record of two adults-male and jemaie.

[Food: Elm leaf-beetle larvæ.]

\begin{tabular}{|c|c|c|c|c|c|c|c|c|c|}
\hline \multirow{2}{*}{ Date. } & \multicolumn{2}{|c|}{ Full grown. } & \multicolumn{2}{|c|}{$\begin{array}{l}\text { Three-fourths } \\
\text { grown. }\end{array}$} & \multicolumn{2}{|c|}{ Half grown. } & \multicolumn{2}{|c|}{$\begin{array}{l}\text { One-fourth } \\
\text { grown. }\end{array}$} & \multirow{2}{*}{$\begin{array}{l}\text { All } \\
\text { stages, } \\
\text { de- } \\
\text { stroy. } \\
\text { ed. }\end{array}$} \\
\hline & Eaten. & $\begin{array}{l}\text { Partly } \\
\text { eaten. }\end{array}$ & Eaten. & $\begin{array}{l}\text { Partly } \\
\text { eaten. }\end{array}$ & Eaten. & $\begin{array}{l}\text { Partly } \\
\text { eaten. }\end{array}$ & Eaten. & $\begin{array}{l}\text { Partly } \\
\text { eaten. }\end{array}$ & \\
\hline July $16-18 . \ldots \ldots$. & 6 & & & & & & & & \\
\hline July $18-20 .$. & 6 & & 6 & & & & & & $\begin{array}{l}6 \\
6\end{array}$ \\
\hline July $21 \ldots$ & 6 & $\ldots \ldots$ & 4 & $\cdots$ & & & & & 11 \\
\hline $\begin{array}{l}\text { July } 22 . \ldots . . . \\
\text { July } 23 . \ldots .\end{array}$ & 4 & ........ & & ... & 7 & & & & 11 \\
\hline $\begin{array}{l}\text { July } 23.5 \ldots \ldots \ldots \\
\text { July } 24-28 \ldots \ldots\end{array}$ & 7 & (......... & 2 & $\cdots$ & 1 & & & & 9 \\
\hline July $29-30 \ldots \ldots \ldots$ & 12 & $\cdots \cdots$ & $\begin{array}{l}6 \\
2\end{array}$ & $\cdots$ & 1 & 1 & & $\cdots$ & 20 \\
\hline July $31 \ldots$. & 8 & 1 & & & & $\bar{i}$ & & & 10 \\
\hline August 1 . & & ... & 5 & & 3 & & & & 8 \\
\hline August 2 . & & & & $\cdots$ & 3 & & & $\cdots$ & j \\
\hline August $3 .$. & 15 & ….... & & .... & 4 & $\cdots$ & ..... & $\ldots$ & 19 \\
\hline August $4 \ldots .$. & 8 & 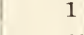 & & & & -. & & - & 9 \\
\hline $\begin{array}{l}\text { August } 5-6 \ldots \\
\text { August } 7 . . . .\end{array}$ & 5 & $\cdots$ & 2 & & & & & & $\frac{5}{7}$ \\
\hline August $8 . .$. & 6 & & & $\cdots$ & & & - & $\ldots$ & 6 \\
\hline August $9-10$. & 6 & 3 & & $\cdots$ & ...... & .. & . & - & 9 \\
\hline August 11-12. & 4 & 1 & 3 & ....... & $\cdots$ & ........ & $\ldots$ & - & 8 \\
\hline August $13-17$. & 15 & $\cdots$ & 3 & $\ldots$. & & $\cdots$ & & 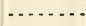 & 18 \\
\hline August 18-22. & 11 & $\ldots$ & & 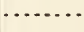 & & 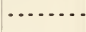 & $\cdots . .$. & $\ldots$ & 11 \\
\hline $\begin{array}{l}\text { August } 22-26 \text {. } \\
\text { August } 26-29 \text {. }\end{array}$ & $\begin{array}{r}9 \\
10\end{array}$ & $\cdots \cdot$ & & & & & & & $\begin{array}{r}9 \\
10\end{array}$ \\
\hline $\begin{array}{l}\text { August } 26-29 \text {. } \\
\text { August } 29 a .\end{array}$ & & & & & & & & & \\
\hline September 4 . & 10 & 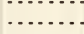 & & & & & & & 10 \\
\hline Total .. & 155 & 8 & 33 & 1 & 20 & 2 & 0 & 1 & 220 \\
\hline
\end{tabular}

$a$ Female only.

In addition to the elm leaf-beetle larvæ, the two adults destroyed an unknown lepidopterous larra about an inch in length on July 16 , and between August 26 and 29 they destroyed and partially ate six full-grown rosy-striped oak worms (Anisota iirginiensis Dru.).

The tables given above show 246 as the total number of elm leafbeetle larræ destroyed by the two bugs in the fifth nymphal and adult stages. The total number of days corered by the life of the female in these two stages being 59 and by the male 50 , the arerage number of beetle larræ destroyed by each bug per day is 2.3. In the adult stage alone the daily arerage is practically the same.

\section{SUMIIARY.}

The more important observations recorded in the foregoing paragraphs may be summarized as follows:

(1) Parents and progeny of Podisus maculiventris exhibit striking variations in form and color which might readily be mistaken for specific characters.

(2) Egg laying began on the ninth day after the female became adult and extended over a period of forty days, the rate of production apparently depending largely on the prevailing temperature. Eightcen batches, with a total of 492 eggs, were deposited by a single female. 
(3) With $67.5^{\circ} \mathrm{F}$. as the average daily mean temperature, the average period of incubation was seven days and one hour. The extremes in duration of incubation period of five days as the minimum and nine and a half days as the maximum corresponded with extrenes in average daily mean temperature of $73.1^{\circ}$ and $61.3^{\circ}$, respectively. Within this range $1^{\circ} \mathrm{F}$. decrease corresponded with 0.32 day's increase in the incubation period.

(4) The average duration of the immature stages of seven specimens, with an average daily mean temperature of $61.5^{\circ} \mathrm{F}$., was forty-six days. The average adult life of a male and a female specimen was forty-eight days.

(5) The two specimens of spined soldier bug under observation destroyed, during their last nymphal instar of six days, 26 elm leafbeetle larvæ. During their adult life the same bugs destroyed 220 elm leaf-beetle larvæ and 7 large caterpillars.

\section{DESTROYING THE WOOLLY MAPLE-LEAF SCALE BY SPRAYING.}

By W. E. Britton, New Haven, Conn.

The woolly maple-leaf scale, Phenacoccus acericola King (formerly Pseudococcus aceris Geoff.) has become quite a serious pest of the sugar-maple street trees in New Haven, Hartford, Bridgeport, and other Connecticut towns and cities.

On August 2 a New Haven seed firm sent me some maple leaves, brought in by one of their customers, which were infested with Phenacoccus acericola. I immediately visited the place. A sugar maple of 10 or 12 inches in trunk diameter was thoroughly infested, and many leaves had already dropped. Scarcely a leaf was free from the white waxy mass containing female and eggs, which are formed on the under surface. The upper portion of the trunk was completely covered with the larvæ. Two other small trees near by were infested, though less seriously. The owner was afraid that the trees would die, and wished to save them. As very little has been published about remedies, and as I had not then noticed Professor Cooley's paper ${ }^{a}$ giving his experience with remedial treatment in Massachusetts, I advised that the tree be sprayed with ordinary kerosene emulsion. This was done on August 4, the mixture used containing 2 gallons of kerosene, $\frac{1}{2}$ pound of common hard soap, and 1 gallon of water as a stock solution, which was diluted nine times before using. On going to examine the trees a few days later, the owner informed me that the spraying did no good, and I almost

$a$ Notes on some Massachusetts Coccidæ. By R. A. Cooley. Bul, 17, n. s.. Div. of Ent., U. S. Dept. Agric., p. 61, 1898.

$31024-$ No. $60-06 \mathrm{M}-11$ 
agreed with him. A few of the scales were killed, but most of them seemed to be uninjured by the spray.

On August 17 we again sprayed the trees, using this time an emulsion made with a soft naphtha soap and without hot water. Two gallons of kerosene, 1 pound of soap, and 1 gallon of water were the quantities used, and the whole diluted five times. At this spraying the trees were very thoroughly drenched, the spray being directed especially against the under side of the leaves and against the bark of the trunk, where the larvæ had gathered in the crevices. Even with this emulsion we found it somewhat difficult to moisten the egg masses, owing to the wax. The first spray striking a leaf usually rolls off in small drops, but if the nozzle is held in one place long enough the mass finally becomes soaked with the emulsion.

On examining the trees a few days later nearly all of the insects appeared to be dead. Some of the leares showed a little injury, as if from the emulsion, but it is often difficult to determine how much to attribute to the spray and how much to the insects.

I am satisfied that this insect is a difficult one to combat, and that if we use kerosene emulsion against it the spray should contain not less than 15 per cent of kerosene.

\section{THE RELATION OF DESCRIPTIONS TO ECONOMICAL METHODS OF ERADICATION IN THE FAMILY APHIDIDÆ.}

By Chas. E. Sanborn, College station, Tex.

The description of any species of Aphididx should contain that of the different apterous and migratory forms, the male, the true or sexual female, the egg, and in addition the scientific names of the host plant or plants with inclusive dates of infestation.

There has originated and continues to be a great deal of confusion concerning the specific names in the family Aphididx. It seems that early investigators supposed that every species of aphide colonized but one species of plant. Furthermore, the descriptions given by these authors are limited mainly to the general color of the insects at the time of their capture, and a common name of the host plant with no date of infestation.

Now it is necessary to know the scientific names of the plants on which specimens are captured, partly as a ready reference key to species. It must be borne in mind, howerer, that the name of the host plant is not always a true index for any species. Some species are quite cosmopolitan in their feeding habits and migrate from one host plant to another during the season and are changed sometimes in form, sometimes in color, and sometimes in both color and form.

Take for instance the common grape leaf-aphis. Soon after it 
first colonizes the grape its honey tubes elongate and its form partakes of the genus Macrosiphum. This same aphis when it colonizes the plum in early spring appears like the genus Myzus. Thus we see that a change of host plant affects not only the characteristics of a species but also those of the genus.

Now, if we depend upon the early system of description we may have one species described as many species and contained in more than one genus. One remedy is to follow a single species through its entire seasonal history and obtain the specific names of all its host plants, with descriptions of it containing all its changes in color ard form. By doing this one-form method will be discarded with several troublesome synonyms.

Another remedy will be found in a "host plant catalogue," which should contain all the scientific names of the plants, each followed by the species affecting it. The former is not only a list of beneficial or injurious plants which are affected by these insects, but it is also a good index key for identifying them. For instance, if a colony is found infesting okra (Iibiscus esculentus) there may be but little difficulty in identifying the species, because by looking into a late host plant catalogue for Hibiscus esculentus there will be found 1 phis gossypii Glov. and Rhopalosiphum dianthi Schrank. Then by comparing the descriptions of these species with the one in question an identification is sure to follow unless it is a new species to the plant in question. If the latter is true, a record of it should be made.

Another item of importance in this connection is the date or dates when a certain species is found to colonize a particular host plant. This is essential, since we might get several species from one form like Callipterus walshii Monell. The latter in July is frequently found with a mottled pulverulence on its body. In October it can be found with an entirely different coloration, consisting of no pulverulence, but with a background of brown color marked with dark spots and transverse bars. If the dates for these colorations or characteristics are given, the possibility of giving this species other names than its own can be eliminated.

Now, what is the bearing of an incomplete description upon methods of eradication? A conspicuous example in Texas is the "green bug" (Toxoptera graminum Rond). Whenever the natural conditions permit this aphis to flourish it can devastate all the wheat and oats that may be planted in its latitude of infestation. The financial losses are almost inconceivable. With the present incomplete life-history knowledge of this pest no artificial method of eradication seems possible. The only thing that can be depended on with any degree of success until the life history is known will be the inimical insects which prey upon it. 
As long as the life histories of these insects remain incompletely known no thoroughly practical method of extermination can be used. It is true that the aphides can be profitably combated, but they can be combated with a great deal more profit when that stage which contains the least number of individuals is known. This stage is that in which the true sexual forms occur, or when the first generation occurs, which is from the egg. At these times the common methods of spraying or fumigating can be used to eradicate instead of to combat, as they are now used on unfarorable stages of the insect.

In conclusion, some valuable aids in the study and description of species of this family may be obtained from the following outlines whenever a form is to be described. It will not only help to eliminate mistakes by including all the main characteristics, but it will also bring about an easy method of comparison of the same or different species. Since it is not easy to completely describe a specimen before it has been treated with clearing mixtures, it is necessary to keep two kinds of notes, the one bearing on field notes and colorations, the other on measurements and minute details. The investigator should have about 200 of these keys for a season's work. The "color key " should be printed on one side of a leaf and the "measure key" on the other side. The "keys" may then be arranged in the form of a pad, 6 by 9 inches or other conrenient size.

\section{DESCRIPTION THEME.}

[This key is followed when a final description is taken from the color and measure keys.]

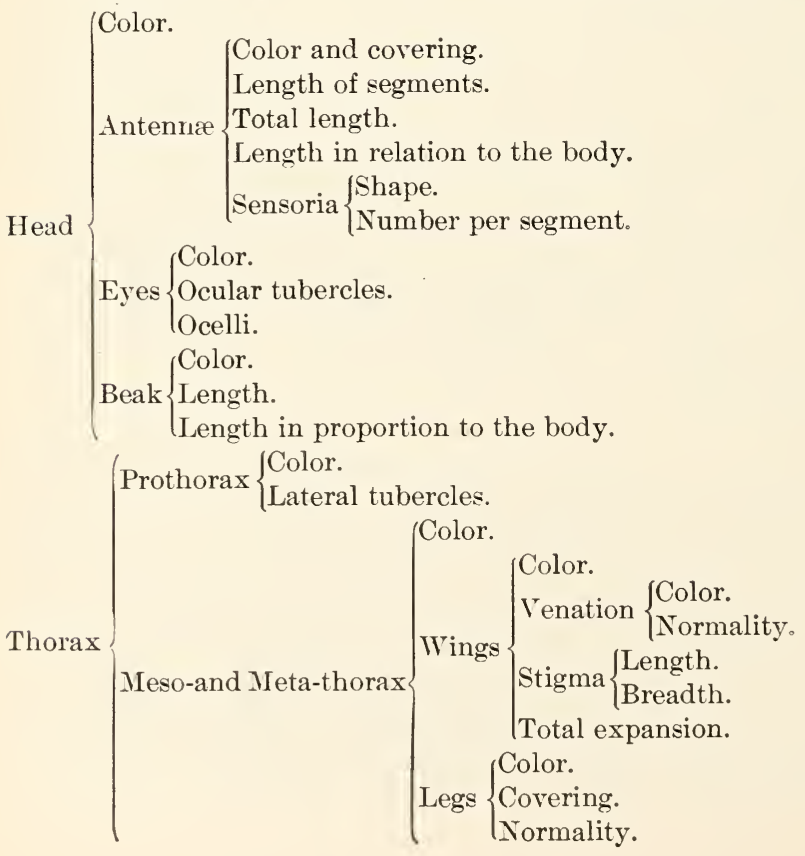




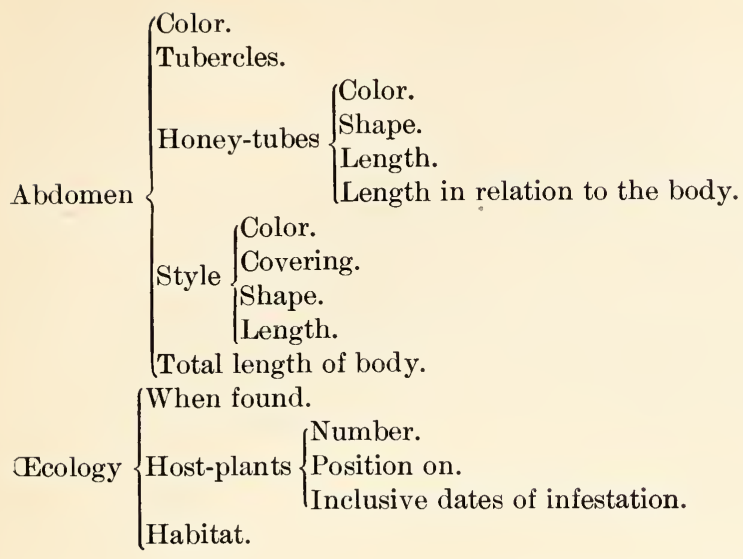

\section{Color Key.}

[Underscore terms used. Blanks are to be used for qualifying terms and comments.]

Locality

$$
\text { Acc. No. }
$$

Head-black, green, brown

Antennæ-concolorous

Eyes-black, red

Beak-concolorous

Prothorax-black, green, brown

Thorax-black, green, brown

Wings-deflexed, reposed

Wings-clouded, banded

Veins-black, brown

Host-plant: Common name

Parts affected-leaves, dorsal, ventral, marginal, petiole, twigs, fruit, distal, proximal, trunk, roots, gall, pseudogall

Habits-aerial, subterranean, sporadic, gregarious, viviparous, oviparous

Comments

\section{Measure Key.}

[Underscore terms used and fill out blanks.]

Acc. No........... Name.

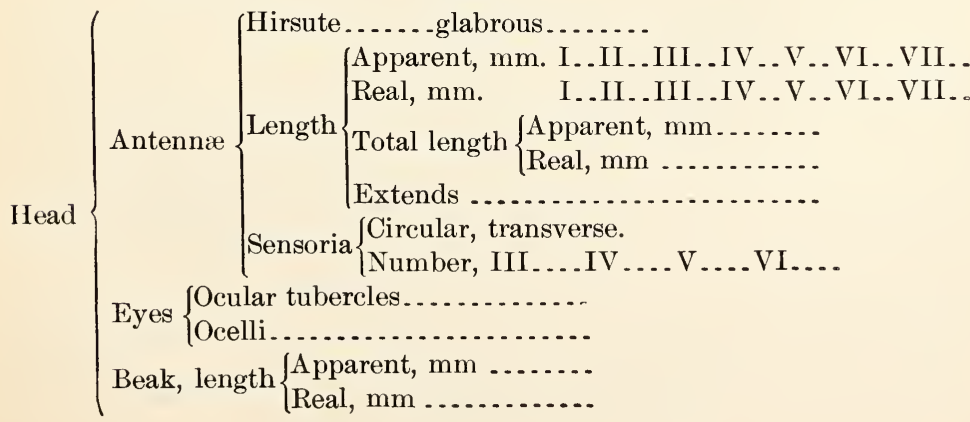

Date

Stigma-black, gray, brown......

Femora-black, green................

Tibia-black, green ..................

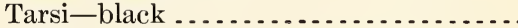

Abdomen-bare, pulverulent, cottony .. Abdomen-green, black, brown ........ Abdomen-other markings ............ Honey-tubes-black, green, brown...... Style-black, green, brown ........... _Genus. . . . . . . . . . . . . Sp . . . . . . . . . .

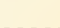


Prothoracic tubercles: Present, absent.

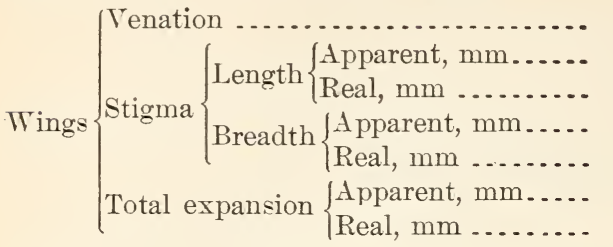

Tubercles .

Honey-tubes $\left\{\begin{array}{l}\text { Cylindrical, incrassate, clavate, tuberculate. } \\ \text { Extent, base of style, distal end.......... } \\ \text { Length }\left\{\begin{array}{l}\text { Apparent, mm....... } \\ \text { Real, mm ........... }\end{array}\right.\end{array}\right.$

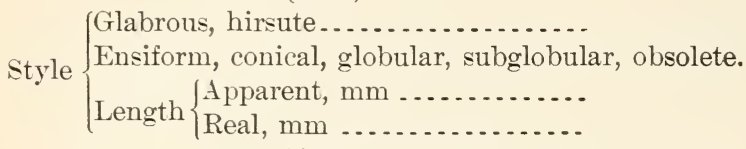

Total length of body $\left\{\begin{array}{l}\text { Apparent, mm ....... } \\ \text { Real, mm.......... }\end{array}\right.$

Width of abdomen $\left\{\begin{array}{l}\text { A pparent, mm ......... } \\ \text { Real, mm ........... }\end{array}\right.$

Mr. Osborn said that he wished to call especial attention to the fact that in this family the nymphs were of much ralue as a means of specific distinction.

In the absence of their authors the following papers were presented by the secretary.

\section{THE CURRANT ROOT-APHIS.}

(Schizoneuia fodiens Buckton.)

By Fred V. Theobald, M. A. (Cantab.), Wye, Engiand.

During the present autumn (1905) several notices have been sent me regarding the prevalence on the roots of currants of a woolly and mealy aphis. As such root forms are very easily distributed with young nursery stock, a few notes regarding this insect may serve a useful purpose to my fellow-workers in America and our colonies, should it be imported abroad.

The currant root-aphis. or currant woolly aphis, as it is sometimes called here. is undoubtedly the species described by Buckton in his Monograph of British Aphides ${ }^{a}$ as Schizoneura fodiens. This insect is roughly figured on Plate CVI (figs. 6 to 12) of that work, but the details are not sufficient to enable certain determination should the insect appear elsewhere. and it is hoped that the additional structural details given here will fill some of the gaps in the original description.

The appearances on the roots to some extent resemble those of the woolly aphis (Schizoneura lanigera Hausm.), and in consequence 
the pest has been confused with the apple and pear species in this country. In 1894 a number of these insects were sent me as woolly aphis from soil beneath apple trees in Kent, ${ }^{a}$ together with specimens of Pemphigus lactularius of Passerini. Some of these undoubtedly came from currant roots growing beneath the apple trees; others were free in cavities in the earth. At first I thought this must be a form of the well-known apple pest, but later winged forms came out of the ground and proved to be distinct. Many of these were found on the apple trunk. S. fodiens seems, therefore, to be able, under certain conditions, to live upon apple and other roots as well as on those of the currant, which was further recorded in

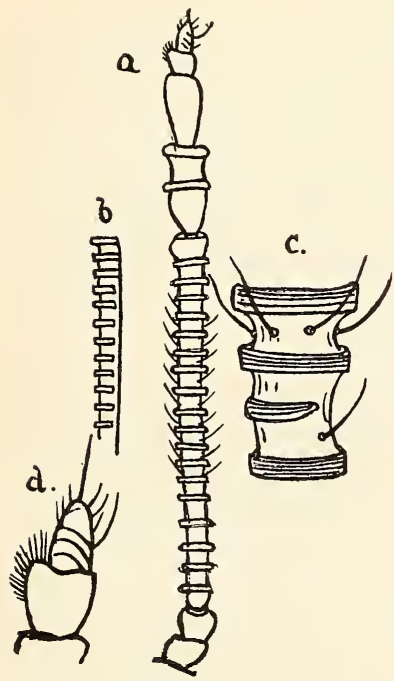

FIG. 7.-Schizoneura fodiens, antenna of winged viviparous female: $a$, dorsal view; $b$, lateral view of third segment; $c$, further enlarged rings of third segment; $d$, apical segment. $a$, much enlarged; $b, c, d$, more enlarged (original).

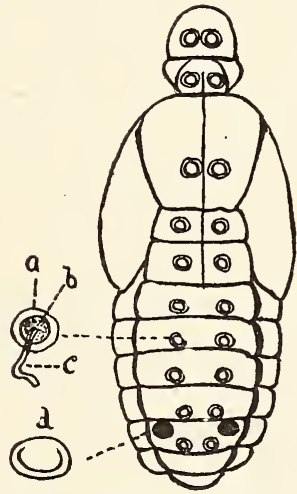

FIG. 8.-Schizoneura fodiens, pupal markings: $a$, ring of white meal; $b$, opening of gland; $c$, white fiber ; $d$, cornicle area. Much enlarged (original).

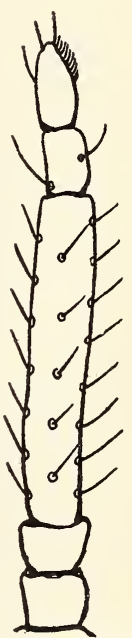

FIG.9.-Schizoneura fodiens : Antenna of pupa, very greatly enlarged (original).

$1897 .^{b}$ Since then I have several times seen real woolly aphis on the roots of apple, but the currant root-aphis occurs there now and again and may thus be confused with it by growers.

It is as a currant pest, however, that it is of such great importance. Buckton originally described the species from the roots of the black currant. No mention is made, however, of the variety attacked. During the present year I have observed it on the Black Naples and Baldwin varieties and on a cottage garden variety found in Kent, known as the Old Black Dutch. The worst attacks have, however, undoubtedly been on the red currant, all varieties seemingly ba- 
coming infested. So far I have not seen it on the white currants, but it probably will attack them just as readily as it does the red.

The effect on young stock is rery disastrous. not only checking growth, but in one instance, it was observed. killing the plants outright. A large number of year-old slips were found to have made such poor growth at Swanley Horticultural College that they were lifted, and all were found smothered with the aphis. Many of the cuttings had scarcely grown at all, and the best had not made more than a foot's growth during the summer. The effect on old-established bushes is not so marked, but I hare seen them die now and again under the attack, and even when a few aphides only are present on the roots the fruit runs off just before ripening.

The aphides live in three ways below ground. The majority live on the main stem, and there by the punctures of their proboscides they cause the rind to split and peel off and the wood to crack. Those that feed close to where the lateral roots come off cause large rounded, swollen, gall-like growths. Others may be seen feeding on the fine rootlets, and yet others in nest-like carities in the soil. Buckton found them from 4 to 6 inches underground. Those observed this season have been found a foot or more down.

The wingless forms appear to live in small colonies composed of from ten to fifty individuals. These colonies probably represent the progeny of one parent. As many as seventy colonies have been found on one small bush. Those that live in earth carities. through which a small root runs, line the nests with a mass of dull grayish white wool. Those that occur on the main roots do not produce so many fibers, but, nerertheless, a sufficient number to give the plant a distinct mealy appearance. which sometimes assumes a dull, almost gray, shade. The wingless females may be found on the roots all the year round.

During November many change to pupæ and winged riviparous females occur. These wander about in the soil and many make their way into the air and crawl onto the stems. After remaining there a short time they fly off to other bushes, where they deposit young close to the stem, often working their way into the soil. The production of these winged females goes on into December. Buckton says (p. 95) : " In October the larræ became very scarce, all the young passing into pupæ and winged insects." He also says that the wingless forms were taken plentifully up to the middle of Norember.

From what I have observed, the insects will go on breeding all the year underground, every now and then in Norember and December giving rise to winged forms. I have been unable to find out if these winged females fly elsewhere than to neighboring currant bushes. That they fly to the latter and there give rise to living young I have found to be the case during the present season.

Buckton figures what he describes as "a vermiform young insect 
fifteen minutes after birth," and says it is in all probability a sexual form. The figure looks just like an immature form of the asexual generation produced by the winged females I observed.

I have never found centipedes affecting the nests of this aphide as did Buckton. They were observed by him not to molest the schizoneuras.

The only record previous to Buckton's that I can find is in an old work entitled "A Treatise on the Insects Most Prevalent on Fruit Trees and Garden Produce," by Joshua Major, 1829, page 153. As this work is now very rare I reproduce what is said of this currant root-aphis:

The roots of the currant bush, particularly the small fibrous roots, are sometimes infested by a small species of the aphides. It is smaller in size than any of the preceding ones described. The body is of a buff or flesh color, produces a cotton-like envelopment similar to the Aphis lanigera on apples, and which probably might have been mistaken by Salisbury for the Eriosoma, or apple bug, on the root of the apple tree, as I am almost persuaded that the Eriosoma, or, as it is now called, Aphis lanigera, never feeds upon the roots, or at least after many investigations $I$ never found any feeding, or the least symptoms of their having fed there. The attacks of the root-aphis are generally from the middle of July to the latter end of September. At the last period they arrive at their perfect or winged state. They prevail principally in dry weather. Tokens of the visitations of these depredators are exhibited in the languishing or drooping of the foliage, occasioned by the loss of the ascending sap, which they draw out for their support.

No mention is made of this pest by Kaltenbach, Taschenberg, or more recent European writers, and I am not aware of its record outside the British Islands. Neither Ormerod nor Whitehead has referred to it, yet it is well known to many growers and gardeners. Recently it has been recorded from Ireland, and I have observed it in the northern part of Wales.

The winged viviparous female varies in length from 1.70 to $1.80 \mathrm{~mm}$., with antennæ 0.70 to $0.80 \mathrm{~mm}$., and a wing expanse of $5.50 \mathrm{~mm}$. The general color is dusky blackish-brown; head and thorax rather shiny black; abdomen deep blackish-gray. The legs and also the antennse are shiny brownish-black. The eyes are dull reddish and prominent. The antennse (fig. 7) are composed of seven segments, the two basal ones quite small, the second a little smaller than the first and rounded apically, the third segment very long with 18 prominent rings projecting around the central stalk; the base contracted; the apex normal, rather swollen, a few scattered hairs in whorls between the rings; fourth segment small, narrowed basally, with two rings, the one apical; fifth segment rather smaller than the fourth, narrowed basally, swollen apically, with a few hairs: the sixth closely applied to the fifth, about one-third the size; the seventh much narrower than the sixth, about the same length (with traces of three rings), and with numerous fine hairs. The rings apparently are only on one side of the long segment, not completely encircling it (fig. $7, b$ ). The proboscis reaches halfway between the prothoracic and the mesothoracic legs. Wings normal, the stigma ochreous-brown; cubital vein stopping short about the middle of the wing, forked once. Ungues large, expanded basally.

The pupa (fig. 8) varies from 1.40 to $1.80 \mathrm{~mm}$. in length, with antennæ 0.30 to 
$0.40 \mathrm{~mm}$. Head mealy with two dark spots ; pronotum mealy with two dark spots ; rest of the thorax ochreous with two spots and with a median line: venter fawn colored. Abdomen mealy-gray to dusky-brown, densely clothed with white meal, two dusky spots on each segment except at the apex (=8 ;airsi); a dusky line shows on each side owing to the conformation of the segments. At the base of the seventh segment are the two large round black areas, the position of the cornicles. When denuded of its mealy coat the abdomen varies from slaty gray to plum color or brownish ochreous. In a few cases I have seen them almost flesh colored, especially when first coming from the larval skin. The meal especially forms a ridge around each dusky spot, which is the opening of a gland from which the flattish white waxen threads are passed out. The rostrum is dark and short, reaching just beyond the base of the prothoracic legs. Antennæ (fig. 9) dark, with ocherous bands, short and thick, composed of five segments, the two basal ones small and of about equal size, the third long with a few prominent thick hairs of moderate length, ringed ventrally when about to hatch into the winged female; last two segments small, the apical one longer than the penultimate and bluntly pointed, with small fine pilosity and some longer hairs. The legs are dark brown and thick and short; tibiæ spinose, and a few spine-like hairs also on the tarsi. Coxæ very dark brown. The pupal legs are so short that the insect can not right itself if placed on its back.

The wingless viviparous female is more uniformly fawn colored, varying to ochreous and covered also with a mealy coat. The head is dusky brown. The dark spots are much as in the pupa. Legs deep brown. Antennæ grayish-brown. Eyes very small or absent. Rostrum long, reaching to beyond the base of the third pair of legs. Fatter and more globose than the pupa. Length, 1.35 to 1.70 $\mathrm{mm}$. ; of antennæ, 0.38 to $0.45 \mathrm{~mm}$.

Buckton describes the antennal segments as being more cup-shaped than in other stages. Unfortunately I have made no notes on their structure and allowed them all to enter the pupal stage.

In all the stages the body is more or less mealy, thus hiding the true color, which is very variable according to my observations. The waxy threads can be easily watched proceeding from the dorsal glands and are most pronounced in the wingless viviparous female. The waxy excretion remains on the currant stems long after the aphides have disappeared and after the specimen showing damage has been dried.

It has been found that the rootage is easily cleaned by first moving it through a tub of plain water and then for a couple of minutes in strong soft-soap solution, slightly warm. This should always be done where young stock is moved if any traces of the woolly aphis are observed.

When older bushes are attacked treatment of the soil with bisulphid of carbon is found most successful. Dry weather was found the best time to employ this remedy.

\section{BIBLIOGRAPHY.}

Taylor, Joshua. A Treatise on the Insects most Prevalent on Fruit Trees and Garden Produce. (1829.)

Buckton, G. B. Monograph of British Aphides, vol. iii. (1880.)

Theobald, F. V. Notes upon Insect Pests in 1894. (1895.)

Theobald, F. V. Notes on Injurious Insects observed in 1896. Journal Southeastern Agricultural College, No. 6, p. $18 . \quad$ (1897.) 


\section{THE PLAGUE LOCUST OF NATAL.}

(Acridium purpuriferum Walk.)

By Claude Fuller, Pietermaritzburg, Natal.

So far as economic entomology is concerned the most important and interesting work done in this colony is the annual campaign against the invading plague locust (Acridium purpuriferum). Briefly, this locust invaded Natal about thirty-six years ago; the exact date is somewhat legendary, for we are still a very young colony, and our official records were all burned some seven years ago. The invading swarms did very little damage, laid no eggs, and disappeared. Then, in 1894 there was an invasion again, and in 1895 and 1896 further and devastating invasions occurred, the locusts swarming over the whole colony and depositing their eggs from the littoral to the high veldt (5,000 feet altitude). The damage they did was enormous, and the farmers and planters were in a hopeless position. The rapidly undulating nature of this country, where plains are absent and comparatively level areas seldom more than 50 to 100 acres in extent, and exceptional at that, precluded the use of your wellknown hopperdozers and rollers. The government of the day paid out vast sums for eggs, bands of natives were organized, and the young locusts were thrashed with wire flails, made up like the old pedagogue's birch. No outside advice or help, so far as I can ascertain, was sought, and the people worked in the dark and unavailingly. I am told that a dead locust was sent to an eminent naturalist of Europe with a request that he should say how such insects could be readily killed. He seriously replied, it is said, that such a desired effect might be most easily procured by pulling off their heads. For the veracity of the story I can not vouch.

The next move forward was the discovery (I use the word advisedly) of the efficiency of arsenic solution sweetened with treacle as a destructive agent, by Messrs. Anthony and Gilbert Wilkinson, sugar-cane planters. By this time the locust tronble had become rather a coast than an upland question, and the arsenic-soda solution was immediately brought into use from north to south of the littoral. This innovation of the Messrs. Wilkinson was recognized by Parliament, and the colony presented them with a handsome piece of plate inscribed with the people's appreciation of their services. A material consequence of the general application of arsenic solution was a greatly increased demand for arsenic. Planters' orders for the poison in one season amounted to 50 tons; and, curiously enough, the increased demand from Natal, for a time, put up the price on the London market. 
Late in 1899 I arrived in Natal, and was, as you may well imagine, rapidly involved in what is known here as "the locust question." I was quickly forced to recognize the efficiency and local applicability of the arsenic solution. I found that it was applied in the following ways: In the cane fields gangs of "Indians" (chiefly women) were kept constantly at work laying down between the rows baits made by dipping begasse in the solution. In the grass lands gangs of Kaffirs, each with a paraffin (kerosene) tin full of solution, stalked about placing the poison upon grass and herbage about the swarms, applying it crudely by switches made by bundling together a few twigs.

I brought with me an American knapsack pump fitted with a cyclone nozzle, and had the liquid sprayed on instead of switched. It was even more efficacious, and in actual practice we found that one man could get as far in an hour with 1 gallon of solution as 70 men could get with 70 gallons in seventy hours by the other method. That spray pump was the first of its sort in Natal. Nowadays several hundred are imported annually for the destruction of locusts. Owing to the rough handling the machines are subjected to by the Kafirs, we find now that it pays us best to use the bucket pump instead of the knapsack pump, the loss in labor, time, etc., with this machine not being equal to the damage sustained by the copper tanks.

You will gather that we deal only with immature locusts. Nothing is attempted with the winged individuals. This is so for two excellent reasons :

(1) Such work is impracticable (until the days of aerial navigation, when we can perhaps try net fishing).

(2) We sustain no damage from the flying locusts.

The latter statement requires some qualification, and to explain it I must digress a little.

Acridium purpuriferum deposits its eggs regularly each year between the first part of December and the middle of January in Natal. The majority of eggs are laid just before mid-December; earlier and later deposits are, in a sense, abnormal. These eggs hatch in thirty days; therefore, about the middle of January the infested areas (the littoral, as a rule) are swarming with young locusts. These locusts will acquire wings when about 90 days old. During this interval we wage war against them, wherever they may be, upon Crown lands or in native locations (areas of country set aside for occupation by natives only); and at the same time our locust officers, in the course of their duties, inspect private lands to see that owners and occupiers are destroying the hopping locusts upon their properties, as provided by law.

The cost of this work to the State depends mainly, of course, upon 
the area infested. The season of 1901-2 cost us $£ 494$; that of 1902-3, $£ 8,000$, and that of $1908-4, £ 4,500$. For this year's campaign Parliament has voted $£ 4,600$. The appreciation of the value of this work-for the money is saved over and over again in crops and in the prevention of famine among the natives-is strongly evidenced at this present moment. Despite a falling revenue and severe retrenchment in every branch of administration, the locust vote stands intact.

Now, what we do is simply this: We destroy all the progeny of the locusts which come into the country. By attacking them at this season we prevent the destruction of young crops throughout the growing season, and we have no winged locust swarms feeding about the country for nine months in the year. Occasional swarms of invading locusts will appear in Natal as early as August-they come, I believe, from the native territories to the south of us-but their mischief is very slight. November and December see the main invasion. Hordes of locusts fly in clouds from north to south across the county. These insects, however, do not feed, and simply migrate southward to oviposit.

Just one word in conclusion with regard to the "locust poison." Our old formula used to be :

Pounds.

White arsenic 1

Washing soda $\frac{1}{2}$

Treacle or treacle sugar 6

Boil in 2 gallons of water for one-fourth of an hour, then add sufficient water to make 16 gallons of solution.

For the past three years, however, we have adopted arsenite of soda with equally efficient results:

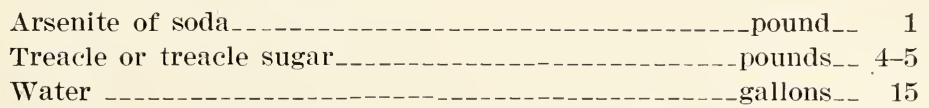

Treacle is used only when mills are convenient. Treacle sugar is just as efficacious. To-day I have just made payment for 8 tons of this commodity, 5 of which will be used in our work in the wilds of Zululand. The young locusts are passionately fond of the sirup, and you can see them lapping up the drops of liquid on the grass stems. The treacle aroma entices them to their death, when otherwise they might pass by the poison.

To you the amount of poison used will appear enormous, and so it is; but what we want is rapid work. To see the locusts dead before passing to a new camp is the most satisfactory way of knowing that the work is well done, and, further, in the last molt we find that the poison is none too strong.

The effect of the arsenic upon grass lands is purely temporary. Cattle feeding over the land afterwards have suffered no deleterious 
effects. but the farmers think them always the better for a little locust poison, arsenic being a much-used drug in farm reterinary work.

Let me say definitely that I never use the locust fungus. I say unhesitatingly that. if the unknown conditions suitable to its derelopment arise, it breaks out-in the ordinary acceptance of the termspontaneously. Further, I feel certain that if those conditions were to prevail for from four to six weeks during the summer we would have no work to do until the following season.

The use of Paris green for locusts is not practicable: contact insecticides. i. e.. soap solutions and kerosene emulsion. are occasionally employed for the insects in the first larral stage. but in practice the same results are never obtained as with the arsenic solution.

Begasse baits are still largely used in the cane fields, but nowadays many planters leare the trash on the older leares and spray that. In many cases, howerer, adrantage is taken of the habit displayed by the roung locusts of learing the cane lands to moult in the grass of the headlands or veld in their proximity.

I have not listed the plants which these locusts do not attack, but it is curious to note that while they feed readily on the foliage of the orange. they never touch that of the mandarin orange. Tea plantations are also exempt from them.

\section{DOES THE SILVER-FISH (LEPISMA SACCHARINA L.) FEED ON STARCH AND SUGAR?}

\section{By H. GARMAx. Lexington, Kr.}

In all the accounts of the food habits of the silrer-fish with which I am familiar no doubt is expressed as to the food being starch. sugar. or both. Observations made by the writer a few rears ago convinced him that the silver-fish common in dwellings in Kentucky. and presumably the same as that found everywhere in the country, feeds freely upon substances of animal origin.

My attention was first drawn to the habit by the scored condition of some relox photographic prints hanging on a rall in a drelling, the film haring been remored in irregular patches (see fig. 10) while the starch used in mounting them remained untouched. The injury was traced to silver-fish. They were found to be exceptionally common about a shingled balcony opening into the room. Itwas decided to set a bait for them. and with the statements of writers as to their fondness for starch and sugar in mind these substances were at first used. But the insects paid not the slightest attention to them in any condition in which they were employed. moist or dry. I was surprised at this, but in the course of my experiments noticed that killed or disabled silver-fish were fed upon by the others, often three or four gathering 
about a dead individual while I was engaged in placing bait at night. This, of course, suggested an animal bait, and at the same time a suspicion entered my mind that the injury to the binding of books with which they are charged might be the result of eating glue instead of starch. They were then tried with bits of white glue, which they ate readily, alone and also when dusted with Paris green.

In the light of this observation, statements in some of the earlier accounts of the insect are suggestive of a fondness for animal food. The surface of calendered paper is said sometimes to have been abraded by the jaws of silver-fish. Sizings used on such papers contain animal matter (leather), and it seems very probable that it was

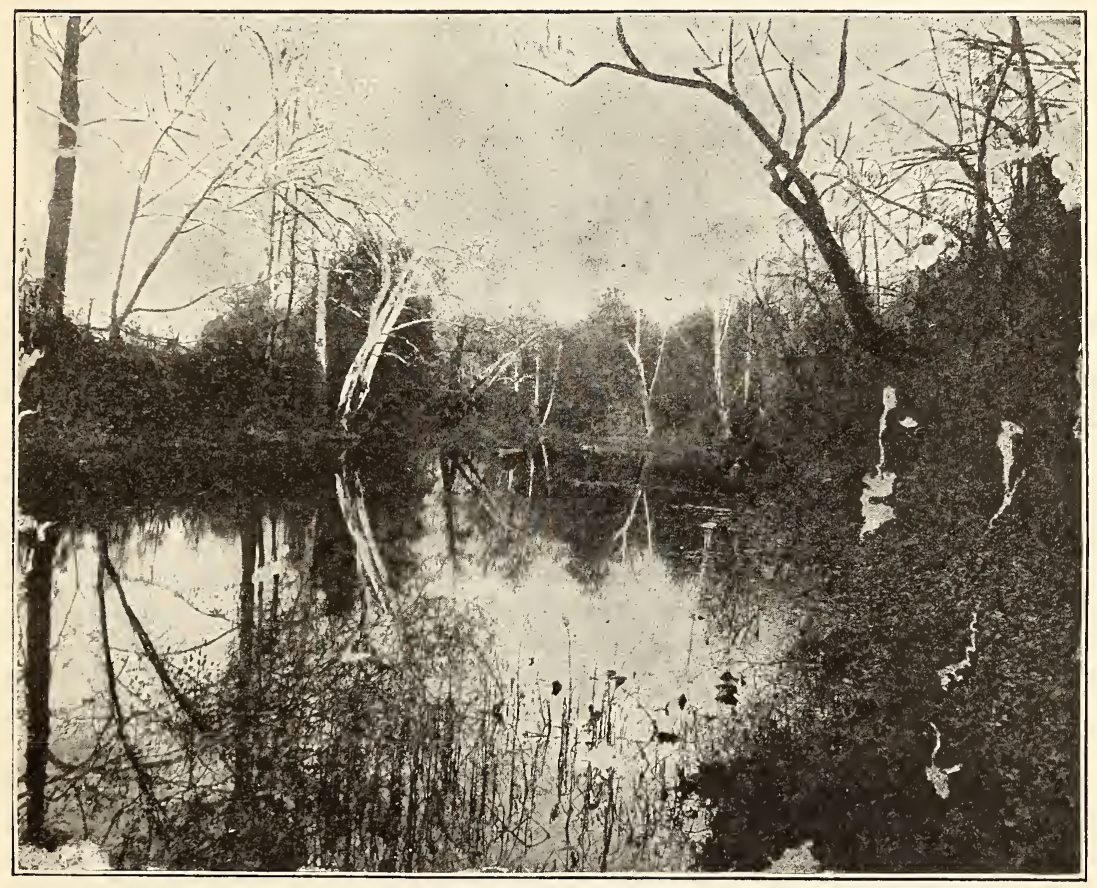

FIG. 10.-Photographic print injured by silver-fish (Lepisma saccharina). (Original.)

the sizing alone and not the fiber-which could not furnish nutriment anyway-that they were after. Mr. P. R. Uhler, of the Peabody Library, of Baltimore, is said to have observed that the gnawings of silver-fish cause the white labels on the backs of books to become detached. Here plainly the glue used to stick the labels to the books is the attraction. Again, gilt lettering has been observed to be removed from the backs of books. In this case the insect might be attracted either by sizing used in securing the gold leaf to the books or by that used on the binding. It happens that we have in the Kentucky experiment station library some volumes that were at 
one time stored in a basement. A good deal of the lettering is removed from several of them, but they are cloth-bound volumes, and the surface is scored freely everywhere, the evident purpose of the gnawing having been to secure the dried glue used as sizing in the cloth. No food could be obtained from the gold leaf itself, and the perfect condition in which the fibers of the cloth are left in the gnawed regions leaves no ground for supposing that the insects were after anything but the ghe with which the cloth is impregnated. Silk is sometimes attacked, but silk is a nitrogenous gluey product.

Does the silver-fish feed on sugar and starch?

Both Messrs. Washburn and Sanderson said that they felt convinced that, despite the observations recorded in the paper, Lepisma would feed upon starch. The former described one observation in support of this.

The committee on resolutions presented the following report:

Resolved, That we hereby express our appreciation and thanks to the local committee of arrangements, the citizens of New Orleans, and officials of Tulane University for courtesies extended to this Association during its meetings.

Resolved, That we hereby express our appreciation to the Secretary of Agriculture for his courtesies in publishing the proceedings of previous meetings, and we would respectfully ask him to publish the proceedings of this meeting.

Resolved, That the Association express to the officers of the Association its thanks for the efficient and painstaking manner in which they have executed their official duties during the past year.

Resolved, That the Association hereby express to the retiring president, Prof. H. Garman, its hearty thanks for his admirable presidential address, and extend to him the compliments of the season with wishes for his speedy recovery, and that the secretary be hereby instructed to forward to Professor Garman a copy of this resolution.

Resolved, That we commend to the careful consideration of our members the following important features and suggestions, which we consider of greatest moment, contained in the president's admirable address :

First. That the economic entomologist should be offered sufficient opportunity for investigation in order that he may put before the people the greatest number of facts gained through investigation, and thereby be less obliged to resort to more or less compilation.

Second. That while a certain amount of Latin and Greek work is recognized as necessarily supplemental in the study of the biological sciences, it is nevertheless evident that a proper study of entomology, or a closely related science, would offer equally as good mental training for students, and would in addition prove of much greater practical value, and that therefore the teaching of entomology should have a more prominent place in the curriculum of our high schools, colleges, and universities, especially those institutions receiving the benefits of the Morrill Act.

Third. That more attention should be given to entomology in relation to human diseases, to the relation of insects and plant diseases, and to the relation existing between insects and flowers. 
Fourth. That more attention should be given to apiculture and sericulture, not only because of their importance in the arts, but aiso because of their instructional value.

Your committee respectfully suggests the desirability of a careful revision of both the membership and the qualifications therefor, to comply with the standard required by the American Association for the Advancement of Science, and that the following be substituted for section 2, Article II, of the by-laws :

"The annual dues of active members shall be one dollar and the dues of associate members fifty cents. The funds derived from the annual dues shall be used in the employment of a stenographer at the annual meetings, compensation for the secretary for his services, and for other necessary expenses. The secretary shall render an account of this fund at each annual meeting."

Your committee recommends that hereafter, on the death of a member of this Association, the president shall appoint a committee of three to prepare for the Proceedings an obituary notice, to be properly illustrated when possible to do so.

Wilmon Newell.

F. M. WEBSTER.

T. B. Symons.

On motion, the report was adopted.

The committee on nominations, consisting of Messrs. Quaintance, Conradi, and Osborn, nominated the following as officers for the ensuing year:

For president, A. H. Kirkland, Malden, Mass.

For first vice-president, W. E. Britton, New Haven, Conn.

For second vice-president, H. A. Morgan, Knoxville, Tenn.

For secretary-treasurer, A. F. Burgess, Columbus, Ohio.

For member of the committee on nomenclature, to serve three years, Herbert Osborn, Columbus, Ohio.

For members of the council, American Association for the Advancement of Science, H. E. Summers, Ames, Iowa ; E. A. Schwarz, Washington, D. C.

The secretary was, on motion, directed to cast the ballot of the Association for the persons nominated, and they were declared elected.

The meeting was then adjourned.

H. E. Summers, Secretary.

$31024-$ No. $60-06$ м -12 


\title{
LIST OF MEMBERS OF THE ASSOCIATION OF ECONOMIC ENTOMOLOGISTS.
}

\author{
ACTIVE MEMBERS.
}

Aldrich, J. M., Agricultural Experiment Station, Moscow, Idaho.

Alwood, William B., Charlottesville, Va.

Ashmead, William H., U. S. National Museum, Washington, D. C.

Baker, C. F., Agricultural Experiment Station, Santiago de las Vegas, Cuba.

Ball, E. D., Agricultural Experiment Station, Logan, Utah.

Banks, C. S., Manila, P. I.

Banks, Nathan, U. S. Department of Agriculture, Washington, D. C.

Bethune, C. J. S., 500 Dufferin a renue, London, Ontario, Canada.

Benton, Frank, U. S. Department of Agriculture, Washington, D. C.

Bishopp, F. C., U. S. Department of Agriculture, Washington, D. C.

Britton, W. E., New Haven, Comn.

Bruner, Lawrence, Agricultural Experiment Station, Lincoln, Nebr.

Burgess, Albert F., State Department of Agriculture, Columbus, Ohio.

Busck, August, U. S. Department of Agriculture, Washington, D. C.

Caudell, A. N., U. S. Department of Agriculture, Washington, D. C.

Chambliss, C. E., Clemson College, S. C.

Chittenden, F. H., U. S. Department of Agriculture, Washington, D. C.

Cockerell, T. D. A., Boulder, Colo.

Comstock, J. H., Cornell Unirersity, Ithaca, N. Y.

Cook, A. J., Pomona College, Claremont, Cal.

Cook, Mel. T., Agricultural Experiment Station. Santiago de las Vegas, Cuba.

Cooley, R. A., Agricultural Experiment Station, Bozeman, Mont.

Coquillett, D. W., U. S. Department of Agriculture, Washington, D. C.

Cordley, A. B., Agricultural Experiment Station, Corvallis, Oreg.

Crawford, J. C., Box 208, Dallas, Tex.

Dickerson, Edgar L., Agricultural Experiment Station, New Brunswick, N. J.

Dyar, H. G., U. S. National Iuseum, Washington, D. C.

Ehrhorn, E. M., Mountainview, Cal.

Felt, E. P., Geologic Hall, Albany, N. Y.

Fernald, C. I., Agricultural College, Amherst, Mass.

Fernald, H. T., Agricultural College, Amherst, Mass.

Fiske, W. F., U. S. Department of Agriculture, Washington, D. C.

Fletcher, James, Central Experimental Farm, Ottara, Canada.

Forbes, S. A., University of Illinois, Urbana, Ill.

French, G. H., Carbondale, Ill.

Garman, H., Agricultural Experiment Station, Lexington, Ky.

Gibson, Arthur, Central Experimental Farm, Ottawa, Canada.

Gillette, C. P., Agricultural Experiment Station, Fort Collins, Colo.

Girault, A. A., I. S. Department of Agriculture. Washington, D. C.

Gossard, II. A., Agricultural Experiment Station, Wooster, Ohio.

Gregson, P. B., Blackfolds, Alberta. Northwest Territory, Canada. 
Hart, C. A., University of Illinois, Urbana, Ill.

Heidemann, Otto, U. S. Department of Agriculture, Washington, D. C.

Hinds, W. E., U. S. Department of Agriculture, Washington, D. C.

Hine, J. S., Ohio State University, Columbus, Ohio.

Holland, W. J., Carnegie Museum, Pittsburg, Pa.

Hopkins, A. D., U. S. Department of Agriculture, Washington, D. C.

Houghton, C. O., Agricultural Experiment Station, Newark, Del.

Howard, L. O., U. S. Department of Agriculture, Washington, D. C.

Hunter, S. J., University of Kansas, Lawrence, Kans.

Hunter, W. D., U. S. Department of Agriculture, Washington, D. C.

Johnson, S. Arthur, State Agricultural College, Fort Collins, Colo.

Kellogg, Vernon L., Stanford University, Cal.

Kincaid, Trevor, University of Washington, Seattle, Wash.

KirkJand, $\Lambda$. H., Malden, Mass.

Kotinsky, J., Honolulu, H. I.

Lochhead, William, Macdonald College, Montreal, Canada.

Marlatt, C. L., U. S. Department of Agriculture, Washington, D. C.

Morgan, H. A., University of Tennessee, Knoxville, Tenn.

Morrill, A. W., U. S. Department of Agriculture, Washington, D. C.

Murtfeldt, Miss M. E., Kirkwood, Mo.

Newell, Wilmon, La. Crop Pest Comm., Baton Rouge, La.

Osborn, Herbert, Ohio State University, Columbus, Ohio.

Parrott, P. J., Geneva, N. Y.

Pergande, Th., U. S. Department of Agriculture, Washington, D. C.

Perkins, G. H., Agricultural Experiment Station, Burlington, Vt.

Pettit, R. H., Agricultural Experiment Station, Agricultural College, Mich.

Phillips, J. L., Agricultural Experiment Station, Blacksburg, Va.

Phillips, W. J., U. S. Department of Agriculture, Washington, D. C.

Pierce, W. Dwight, Box 208, Dallas, Tex.

Popenoe, E. A., Agricultural Experiment Station, Manhattan, Kans.

Pratt, F. C., U. S. Department of Agriculture, Washington, D. C.

Quaintance, A. L., U. S. Department of Agriculture, Washington, D. C.

Quayle, H. J., Agricultural Experiment Station, Ames, Iowa.

Reeves, George I., U. S. Department of Agriculture, Washington, D. C.

Rumsey, W. E., Agricultural Experiment Station, Morgantown, W. Va.

Sanborn, C. E., College Station, Tex.

Sanderson, E. Dwight, Agricultural Experiment Station, Durham, N. H.

Saunders, William, Central Experimental Farms, Ottawa, Canada.

Schwarz, E. A., U. S. Department of Agriculture, Washington, D. C.

Sherman, Franklin, jr., Div. of Entom., State Dept. of 'Agric., Raleigh, N. C.

Sirrine, F. A., Agricultural Experiment Station, Jamaica, N. Y.

Skinner, Henry, 1900 Race street, Philadelphia, Pa.

Slingerland, II. V., Agricultural Experiment Station, Ithaca, N. Y.

Smith, J. B., Agricultural Experiment Station, New Brunswick, N. J.

Smith, R. I., Atlanta, Ga.

Snow, F. H., Lawrence, Kansas.

Stedman, J. M., Agricultural Experiment Station, Columbia, Mo.

Summers, H. L., Agricultural Experiment Station, Ames, Iowa.

Surface, H. A., State Zoologist, Harrisburg, Pa.

Symons, T. B., Agricultural Experiment Station, College Park, Md.

Taylor, E. P., University of Illinois, Urbana, Ill.

Titus, E. S. G., U. S. Department of Agriculture, Washington, D. C.

Van Dine, D. L., Government Entomologist, Hawaiian Exp. Sta., Honolulu, H. I.

Viereck, H. L., Agricultural Experiment Station, New Haven, Conn, 
Walden, B. H., Agricultural Experiment Station, New Haven, Conn. Walker, C. MI., Amherst, Mass.

Washburn, F. L., Agricultural Experiment Station, St. Anthony Park, Minn. Webster, F. M., U. S. Department of Agriculture, Washington, D. C. Weed, C. M., Agricultural Experiment Station, Durham, N. H. Wilcox, E. V., U. S. Department of Agriculture, Washington, D. C. Woodworth, C. W., Agricultural Experiment Station, Berkeles, Cal.

\section{ASSOCIATE MEMBERS.}

Adams, C. F., Fayetterille, Ark.

Barber, H. S., U. S. National Museum, Washington, D. C.

Bartholomew, C. E., College Station, Tex.

Beattie, James H., U. S. Department of Agriculture, Washington, D. C. Beckwith, H. M., Elmira, N. Y.

Bentley, Gordon M., University of Temnessee, Knoxville, Tenn.

Bogue, E. E., Agricultural College, Mich.

Braucher, R. W., Lincoln Park, Chicago, Ill.

Brues, C. T., Milwaukee Public Museum, Milwaukee, Wis.

Bullard, W. S., 301 Lafayette street, Bridgeport, Conn.

Burke, H. E., U. S. Department of Agriculture, Washington, D. C. Campbell, J. P., Athens, Ga.

Clifton, R. S., U. S. Department of Agriculture. Washington, D. C. Conradi, A. F., College Station, Texas.

Cotton, Edwin C., Ohio State Dept. of Agr., Columbus, Ohio.

Couden, F. D.. U. S. Department of Agriculture, Washington. D. C.

Craw, Alexander, Hawaiian Sugar Planters' Exp. Sta., Honolulu, H. I. Currie, Rolla I'.. U. S. Department of Agriculture. Washington, D. C. Dean, Harper, jr.. State Board of Entomology, Atlanta, Ga.

Doran, E. W., Champaign, Ill.

Engle, Enos B., Department of Agriculture, Harrisburg, Pa.

Flynn, C. W., Asst. Ent., La. Crop Pest. Comm., Baton Rouge, La.

Fowler, Carroll, Duarte, Cal.

Frost, H. L., 21 South Market street, Boston, Mass.

Gahan, A. B., College Park, Md.

Garrett, J. B., Asst. Ent., La. Crop Pest Comm., Baton Rouge, La. Gifford, John, Mays Landing, N. J.

Gould, H. P., U. S. Department of Agriculture, Washington, D. C. Green. E. C., College Station, Texas.

Hardy, E. S., Asst. Enț., La. Crop Pest Comm., Shreveport, La.

Hargitt, C. W., Syracuse University, Syracuse, N. I.

Harrington, W. H., Post-Office Department, Ottawa, Canada.

Hooker, W. A., U. S. Department of Agriculture, Washington, D. C. Houser, J. S., Asst. Ent., Ohio Exp. Sta., Wooster, Ohio.

Hudson, G. H., Normal and Training School, Plattsburg, N. Y.

Isaac, John, Sacramento, Cal.

Johnson, Fred, U. S. Department of Agriculture, Washington, D. C. Johnson. W. G., 52 La fayette place, New York. N. Y.

Jones, Chas. R.. Box 208. Dallas, Tex.

King, George B., Lawrence, Mass.

Kirkaldy, G. W., Hawaiian Sugar Planters' Exp. Sta., Honolulu. H. I.

Koebele. Albert, Alameda, Cal.

Mackintosh, R. S., Auburn. Ala.

Mann, B. P., 1918 Sunderland place, Washington, D. C. 
Martin, Leslie, U. S. Department of Agriculture, Washington, D. C.

Martin, George W., State Entomologist, Nashville, Tenn.

Martin, W. O., Asst. Ent., La. Crop Pest Comm., Shreveport, La.

MacGillivray, A. D., Cornell University, Ithaca, N. Y.

IcCarthy, Gerald, care of Crop Pest Commission, Raleigh, N. C.

Morgan, A. C., Box 208, Dallas, Tex.

Mosher, F. H., 283 Pleasant street, Malden, Mass.

Nicholson, John F., Stillwater, Okla.

Niswander, F. J., 2121 Evans street, Cheyenne, Wyo.

Palmer, R. M., Victoria, British Columbia.

Perkins, R. C. L., Hawaiian Sugar Planters' Exp. Sta., Honolulu, H. I.

Phillips, E. F., U. S. Department of Agriculture, Washington, D. C.

Piper, C. V., U. S. Department of Agriculture, Washington, D. C.

Price, H. L., Agricultural Experiment Station, Blacksburg, Va.

Randall, J. L., Durham, N. H.

Rane, F. W., Agricultural Experiment Station, Durham, N. H.

Rankin, Jolm M., U. S. Department of Agriculture, Washington, D. C.

Reed, E. B., Esquimault, British Columbia.

Riley, W. A., Cornell University, Ithaca, N. Y.

Rolfs, P. H., Experiment Station, Mountain Grove, Mo.

Sanders, J. G., U. S. Department of Agriculture, Washington, D. C.

Sasscer, Ernest R., Bureau of Entomology, Washington, D. C.

Scott, W. M., U. S. Department of Agriculture, Washington, D. C.

Southwick, E. B., Arsenal Building, Central Park, New York, N. Y.

Stimson, James, Redwood City, Cal.

Swezey, O. H., Hawaiian Sugar Planters' Exp. Sta., Honolulu, H. I.

Thaxter, Roland, 3 Scott street, Cambridge, Mass.

Toumey, J. W., Yale Forest School, New Haven, Conn.

Townsend, C. H. T., Hotel Alabama, 13-15 East Eleventh street, New York, N.Y.

Webb, J. L., U. S. Department of Agriculture, Washington, D. C.

Yothers, W. W., Box 208, Dallas, Tex.

Young, D. B., Albany, N. Y.

\section{FOREIGN MEMBERS.}

Ballou, H. A., Imperial Department of Agriculture, Barbados, West Indies.

Berlese, Dr. Antonio, R. Stazione di Entomologia Agraria, Firenze, Italy.

Bordage, Edmond, Directeur de Musée, St. Denis, Réunion.

Bos, Dr. J. Ritzema, Agricultural College, Wageningen, Netherlands.

Carpenter, Dr. George H., Royal College of Science, Dublin, Ireland.

Cholodkosky, Prof. Dr. N., Institut Forestier, St. Petersburg, Russia.

Collinge, W. E., University, Birmingham, England.

Danysz, J., Laboratoire de Parasitologie, Bourse de Commerce, Paris, France.

Enock, Fred, 13 Tufnell Park road, Holloway, London, N., England.

French, Charles, Department of Agriculture, Melbourne, Australia.

Froggatt, W. W., Department of Agriculture, Sydney, New South Wales.

Fuller, Claude, Department of Agriculture, Pietermaritzburg, Natal, South Africa.

Giard, A., 14 Rue Stanislaus, Paris, France.

Goding, F. W., Newcastle, New South Wales.

Grasby, W. C., Grenfell street, Adelaide, South Australia.

Green, E. E., Royal Botanic Gardens, Pundaluoya, Ceylon.

Helms, Richard, 136 George street, North Sydney, New South Wales.

Herrera, A. L., Mexico City, Mexico. 
Horrath, Dr. G., Musée Nationale Hongroise, Budapest, Austria-Hungary. Jablonowski, Josef, Budapest, Hungary.

Lampa, Prof. Sren, Statens Entomologiska, Anstalt, Stockholm, Sreden.

Lea, A. M., Department of Agriculture, Hobart, Tasmania.

Leonardi, Gustaro, Portici, Italy.

Lounsburs, Charles P., Department of Agriculture, Cape Torn, South Africa. Mally, C. W.. Department of Agriculture, Grahamstown. Cape Colony.

Marchal, Dr. Paul, 16 Rue Claude, Bernard. Paris, France.

Musson, Charles T., Hawkesbury Agricultural College, Richmond. New South Wales.

Nawa, Yasushi, Gifu, Japan.

Newstead, Robert, Unir. Sch. of Tropical Medicine, Lirerpool, England. Peal, H. W., Indian Museum, Calcutta, India.

Porchinski, Prof. A.. Ministère de l'Agriculture, St. Petersburg, Russia. Reed. E. C., Rancagua, Chile.

Reuter, Dr. Enzio. Fredriksgatan 45. Helsingfors, Finland, Russia. Sajo. Prof. Karl, Gödöllö-Veresegyhaz, Austria-Hungary.

Schoyen. Prof. Tr. M.. Zoological Museum, Christiania, Norway.

Shiples, Prof. Arthur E., Christ's College. Cambridge, England.

Simpson. C. B., Pretoria, Transraal. South Africa.

Tepper, J. G. O.. Norrood, South Australia.

Theobald. Frederick V., Wye Court, Wye, Kent County, England.

Thompson. Rer. Edward H., Franklin. Tasmania.

Tryon, H., Queensland Museum, Brisbane, Queensland, Australia.

Urich, F. W., Victoria Institute, Port of Spain, Trinidad, West Indies.

Vermorel, V., Villefranche, Rhone, France.

Whitehead, Charles, Barming House, Maidstone, Ḱent, England. 


\section{NDEX.}

Acacia koa, infestation by inseets in Hawaii .

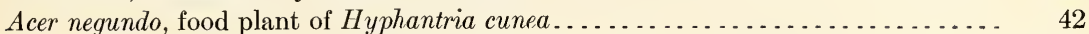

Acridium purpuriferum, arsenic-soda solution a remedy................. . 171-174

arsenite of soda a remedy . . . . . . . . . . . . . . . . . . . 173

campaign against the species in Natal . . . . . . . . . . . . 171-174

Adoretus umbrosus, eaten by toads in Hawaii. . . . . . . . . . . . . . . . . . . . . . 61

Agraulis vanillæ, on Passiflora in Cuba . . . . . . . . . . . . . . . . . . . . . . . 70

Aguacate. (See Persea gratissima.)

Alabama argillacea. (See also Cotton leaf-worm.)

factor in control of boll weevil. . . . . . . . . . . . . . . . . . . . 109-110

in Georgia . . . . . . . . . . . . . . . . . . . . . . . . . . . 80

Podisus maculiventris an enemy.................... 155

unfortunate destruction by Paris green against boll weevil .... . 126

Alfalfa, food plant of Epicauta vittata . . . . . . . . . . . . . . . . . . . . . . 68

Melanoplus femur-rubrum. ....................... . 84-85

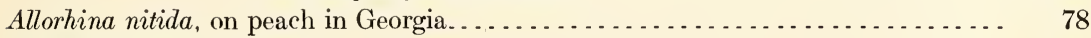

Anarsia lineatella, in Georgia. . . . . . . . . . . . . . . . . . . . . . . . . . $\quad 78$

lime-sulphur wash a remedy ........................ 78

Angoumois grain moth. (See Sitotroga cerealella.)

Animals, and animal products of the United States, estimated value . . . . . . . . . .

domestic, association of insects........................... . . . . 17

Federal quarantine and control of diseases. . . . . . . . . . . . 101-102

noxious, legislation against importation . . . . . . . . . . . . . . . . . . 101-102

Anisota virginiensis, fed to Podisus maculiventris....................... 160

Anona, food plant of Gonodonta maria . . . . . . . . . . . . . . . . . . . . . . . . . 70

Anopheles maculipennis, relation to malaria . . . . . . . . . . . . . . . . . . . . 17

Ant, associated with corn root-aphis . . . . . . . . . . . . . . . . . . . . . . . . . . . 29

little red. (See Monomorium pharaonis.)

New Orleans. (See Iridomyrmex humilis.)

Anthonomus grandis. (See Boll weevil.)

Anthrenus verbasci, sulphur dioxide as insecticide . . . . . . . . . . . . . . . . . . 145

Ants, relations with Aphis forbesii . . . . . . . . . . . . . . . . . . . . . . . . . . 40

sulphur dioxide as insecticide................................. 145

A panteles catalpæ, Horismenus microgastri a parasite in Ohio............... 73

Hypopteromalus tabacum a parasite in Ohio . . . . . . . . . . . $\quad 73$

parasite of Ceratomia catalpæ in Ohio .................. 73

Apate carmelita, on Persea gratissima in Cuba . . . . . . . . . . . . . . . . . . . 70

Aphelinus diaspidis, parasite of Lepidosaphes beckii in Hawaii . . . . . . . . . . . 63

Aphides, abundance after cold wet spring. . . . . . . . . . . . . . . . . . . . . . 91

Coccinella repanda an enemy in Hawaii. . . . . . . . . . . . . . . . . . . . . . 61

factors governing abundance. . . . . . . . . . . . . . . . . . . . . . . . 94

injury to vegetables in Cuba . . . . . . . . . . . . . . . . . . . . . . . . 70

Platyomus lividigaster an enemy in Hawaii. . . . . . . . . . . . . . . . . . . 61

termed "blight" in Hawaii . . . . . . . . . . . . . . . . . . . . . . . . . . . . . . 59 
Aphididæ, descriptive keys....... . . . . . . . . . . . . . . . . . . . . . . . . . . 164-166

relation of descriptions to economical methods of eradication . . . . . . 162-166

value of nymphs in specific distinction. . . . . . . . . . . . . . . . . . . 166

Aphis forbesii, relations with ants................................... 40

gossypii, in New Hampshire.... . . . . . . . . . . . . . . . . . . . . . . . 75

on cotton in Georgia . . . . . . 81

garden crops in Texas . . . . . . . 68

Hibiscus esculentus . . . . . . . . . . . . . . . . . . . . . . . . 163

maidi-radicis, danger threatening corn crop . . . . . . . . . . . . . . . . . 29-30

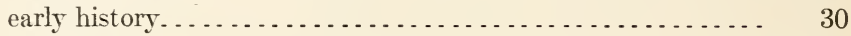

food plants . . . . . . . . . . . . . . . . . . . . . . . . . $34-35,37$

injury to corn. . . . . . . . . . . .

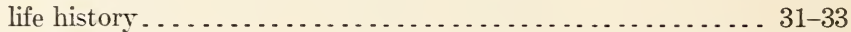

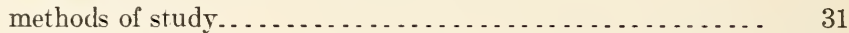

natural checks on increase . . . . . . . . . . . . . . . . . . . . . 36-37

practical economic measures . . . . . . . . . . . . . . . . . . . 37-38

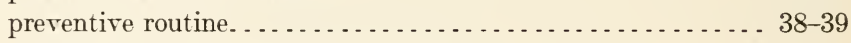

relations with Lasius niger americanus . . . . . . . . . . . . 34-35, 37

melon. (See Aphis gossypii.)

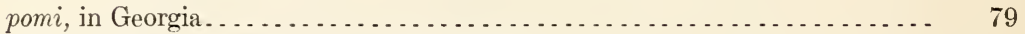

southern grain. (See Toxoptera graminum.)

woolly. (See also Schizoneura lanigera.)

tobacco dust a remedy . . . . . . . . . . . . . . . . . . . . . . . . . . . . 92-93

Apiculture, importance to farmer and entomologist . . . . . . . . . . . . . . . . . . 18 20

teacher of entomology . . . . . . . . . . . . . . . . . . . . . 18-20

Apis mellifera. (See also Bee, honey.)

sulphur dioxide as insecticide............................. 144

Apple aphis. (See Aphis pomi.)

caterpillar, red-humped. (See Schizura concinna.)

yellow-necked. (See Datana ministra.)

food plant of Carpocapsa pomonelia . . . . . . . . . . . . . . . . . . . . . . 83, 89

Cingitia catenuria ................................. 74

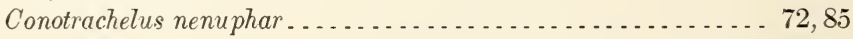

Hyphantria cunea ................................. 42

Lepidosaphes ulmi... . . . . . . . . . . . . . . . . . . . . 79,83

Lygus pratensis....................................... 78

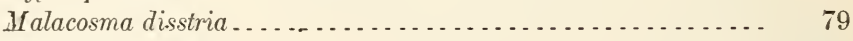

Schizoneura fodiens................................ 167

lanigera................................ 78

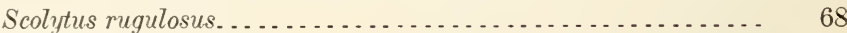

maggot. (See Rhagoletis pomonella.)

spraying with lime-sulphur and kerosene-limoid. . . . . . . . . . . . . . . . . 136-137

tent caterpillar. (See Mfalacosoma americana.)

Aramigus fulleri, in Hawaii . . . . . . . . . . . . . . . . . . . . . . . . . . . . . 64

Aristolochia, food plant of Ithobalus polydamas . . . . . . .

Army worm. (Sce Heliophila unipuncta.)

fall. (See Laphygma frugiperda.)

worms, abundance after cold wet spring........................ 91

Arsenate of lead, remedy for Conotrachelus nenuphar.................... 72

Arseni'-soda solution, remedy for Acriuium purpuriferum. . . . . . . . . . . . . . 171-174

Arsenite of soda, remedy for Acridium purpuriferum . . . . . . . . . . . . . . . . 173

Ash, food plant of Podosesia syringæ . . . . . . . . . . 85

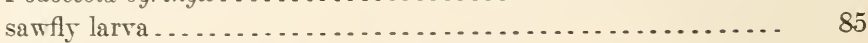

Aspen, American. (See Populus tremuloiles.) 
Aspidiotus forbesi, in Georgia

Page.

perniciosus. (See also Scale, San Jose.)

in Georgia .

Maryland... . . . . . . . . . . . . . . . . . . . . . . . . . . 82-83

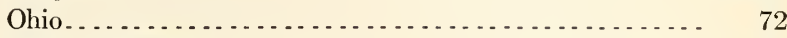

remedies discussed . . . . . . . . . . . . . . . . . . . . . . . . . . . . 77

Association of Economic Entomologists. (See Entomologists, Association of Economic.)

Ateleopterus tarsalis, sulphur dioxide as insecticide

Atta insularis, injury to orange in Cuba . . . . . . . . . .

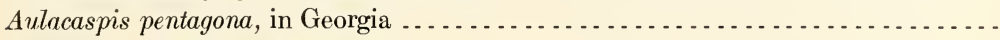

Avocado. (See Persea gratissima.)

Bacillus tuberculosis, in excreta of flies.

Bacterium, in disease of Cingilia catenaria

Bagworm. (See Thyridopteryx ephemeræformis.)

Bananas, sulphur dioxide as fumigant.

Barkbeetle, fruit-tree. (See Scolytus rugulosus.)

Barley, germinating power injured by sulphur dioxide.

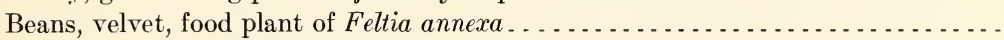

Bean weeril. (See Bruchus quadrimaculatus.)

Bedbug. (See Cimex lectularius.)

Bee, honey. (See also Apis mellifera.)

as illustrative material in teaching

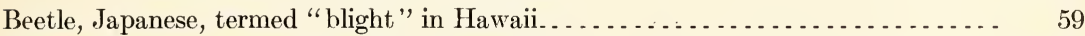

Begasse, use in poisoning Asridium purpurifcrum . . . . . . . . . . . . . . . . . . . 172, 174

Berger, E. W., paper, "Observations upon the migrating, feeding, and nesting habits of the fall webworm (Hyphantria cunea Dru.)". . . . . . . . . . . . . . . . . . . . . . 41-51

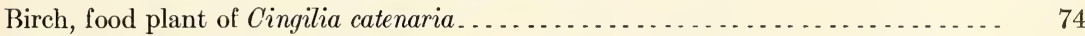

Blattella germanica, sulphur dioxide as insecticide ..................... 144

"Blight," general use of term in Hawaii . . . . . . . . . . . . . . . . . . . . . . . . . . 59

Blights, carriage by insects . . . . . . . . . . . . . . . . . . . . . . . . . . . . . . . . 18

Blissus leucopterus. (See also Chinch bug.)

in Minnesota . . . . . . . . . . . . . . . . . . . . . . . . . . . . . . . . . 84

Boll weevil, Alabama argillacea (the cotton leaf-worm) a factor in control . . . . . . 109-110,

$127-129,132$

campaign in infested territory in Louisiana. . . . . . . . . . . . . . . . . 126-127

climatic conditions affecting rate of spread ..................... . 130

conditions governing migration....... . . . . . . . . . . . . . . . . . 129-130

consideration of cultural system of control . . . . . . . . . . . . . . . . 107-111

cotton leaf-worm a factor in control. . . . . . . . . . . . . . . 109-110, 127-129, 132

early planting of cotton in control . . . . . . . . . . . . . . . . . . . . . 108

fall destruction of cotton stalks in control... . . . . . . . . 108-110, 111, 132-133

Federal appropriation . . . . . . . . . . . . . . . . . . . . . . . . . . 102

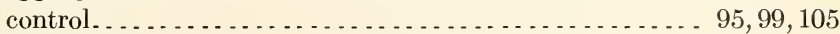

fertilizers in control . . . . . . . . . . . . . . . . . . . . . . . . . . . . . . . . . . 111

hibernation . . . . . . . . . . . . . . . . . . . . . . . . . . . . . . . . . . . . . . 108-109

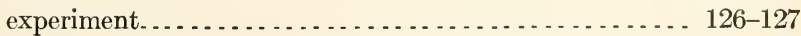

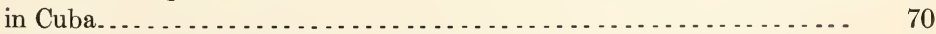

indirect method of reducing damage. . . . . . . . . . . . . . . . . . . . . . . . 127

infestation in Louisiana in 1903 . . . . . . . . . . . . . . . . . . . . . . . 119-120

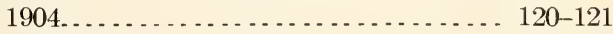

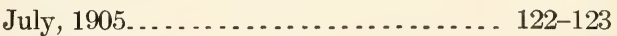

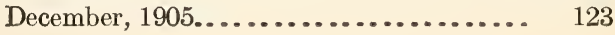


investigations, laboratory methods. . . . . . . . . . . . . . . . . . . . . 111-119

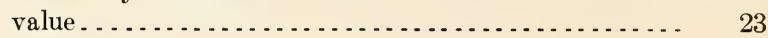

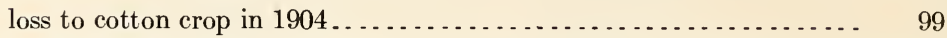

meteorological conditions effecting local extermination in Louisiana. . 122-123

methods in study . . . . . . . . . . . . . . . . . . . . . . . . . . . . . . . 111-119

migratory habit previously unknown . . . . . . . . . . . . . . . . . . . . 121

Paris green as alleged remedy ............................. 126

present status ....................................... 106

prevention of spread in Louisiana. . . . . . . . . . . . . . . . . . . . 119-126

quarantine of Louisiana crop pest commission . . . . . . . . . . . . . . . . 124-126

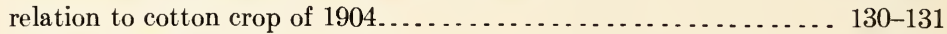

shallow cultivation of cotton in control.................... 108, 111

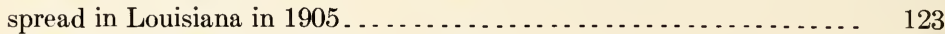

thorough cultivation of cotton in control. . . . . . . . . . . . . . . 110, 111

trend of diffusion as compared with chinch bug. . . . . . . . . . . . . . . 129-130

work of Louisiana crop pest commission . . . . . . . . . . . . . . . . . . . 119-127

Bollworm. (See Heliothis obsoleta.)

"Book-lice." (See Troctes divinatoria.)

Boophilus annulatus. (See also Tick, cattle.)

conveyor of Texas fever. . . . . . . . . . . . . . . . . . . . . .

Box-elder. (See also Acer negundo.)

injury by cecidomyiid galls. . . . . . . . . . . . . . . . . . . . . . .

Boxwood. (See Cornus sp.)

Brass, lacquered, unaffected by sulphur dioxide fumigation . . . . . . . . . . . . . . . 148

Breeding box, for boll weevils and parasites.................. . . . . . . . 112-113

cages, in boll weevil "hibernation experiment". . . . . . . . . . . . . . . . . . 126-127

jar, in boll weevil study. . . . . . . . . . . . . . . . . . . . . . . . . . . . . 112

Brimstone fumigation. (See Sulphur dioxide.)

Britton, W. E., paper, "Tests of Lime-Sulphur Washes in Connecticut in 1905". 136-137

"Destroying the Woolly Maple-Leaf Scale by Spraying". . 161-162

Brown-tail moth. (See also Euproctis chrysorrhœa.)

Federal control. . . . . . . . . . . . . . . . . . . . . . . . 95, 99, 105, 106

Bruchophagus funebris, reared from crimson clover in Minnesota . . . . . . . . . . . . 85

Bruchus, in cowpeas, sulphur dioxide as insecticide . . . . . . . . . . . . . . . . 142, 143, 149

quadrimaculatus, sulphur dioxide as insecticide. . . . . . . . . . . . . . 146

Budworm, corn. (See Diabrotica duodecimpunctata.)

Burgess, A. F., paper, "Notes on Insecticides" . . . . . . . . . . . . . . . . . . . . . . . 154

"Some Economic Insects of the Year in Ohio" . . . . . . . . . 71

Cabbage bug, harlequin. (See also Murgantia histrionica.)

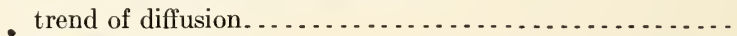

butterfly. (See Pontia rapæ.)

food plant of Feltia annexa .............................. 70

Malacosoma disstria.................................... 79

Murgantia histrionica............................... 82

Plutella maculipennis.......................... $\quad 70$

Pontia monuste................................. 70

hair-worm. (See Mermis albicans.)

Holland variety not affected by Pegomya brassicæ... . . . . . . . . . . . . . . 89

maggot. (See Pegomya brassicæ.)

maggots, carabids probable enemies. ......................... 95

worms, green, in Minnesota ................................ 85

Cages, in study of boll weevil in the field......................... 114-115 
Page.

Calandra, in grain, sulphur dioxide as insecticide

granaria, in stored corn in Texas. .......................... 69

oryza, in stored corn in Georgia............................. 82

Texas. . . . . . . . . . . . 69

Meraporus calandræ a parasite ........................ 148

sulphur dioxide as insecticide. . . . . . . . . . . . . . . . . . . . . . 146, 148

Calendula, food plant of Vanessa cardui............................... 85

Callipterus walshii, seasonal differences in color....................... 163

Calocoris rapidus, on cotton in Georgia . . . . . . . . . . . . . . . . . . . . . . 81

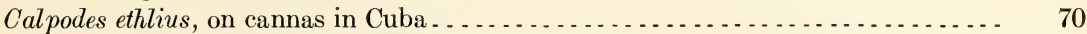

Camera stand used in boll weevil investigations . . . . . . . . . . . . . . . . . . . . 117-118

Canestel. (See Lucuma rivicoa.)

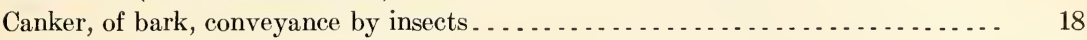

Canna, food plant of Calpodes ethlius . . . . . . . . .

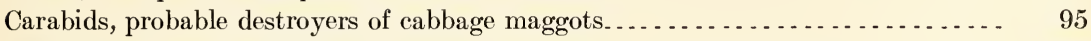

Carbolic emulsion, remedy for Pegomya brassicæ $\ldots \ldots \ldots \ldots \ldots$

Carbon bisulphid, fumigation of corn and cowpeas . . . . . . . . . . . . . . . . . . . . 91

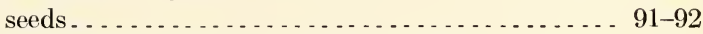

ineffective against eggs of Mediterranean flour moth. . . . . . . . . 91

remedy for "corn weevils". ... . . . . . . . . . . . . . . . . . . . 69

Schizoneura fodiens....................... 170

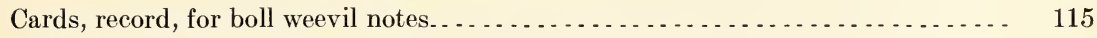

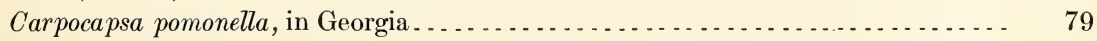

Maryland..................................... 83

New York.

spraying for control .................................. 72

Case-bearer, European elm. (See Coleophora limosipennella.)

Casuarinas, food plants of Icerya purchasi ... . . . . . . . . . . . . . . . . . . 59

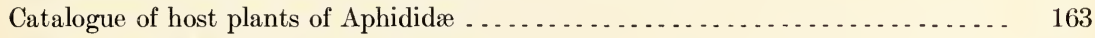

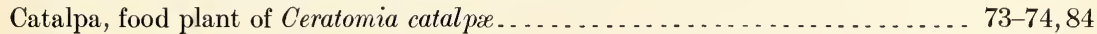
sphinx. (See Ceratomia catalpæ.)

Cecidomyiid galls, on soft maple and box-elder in Minnesota.................. $\quad 85$

Celtis occidentalis, food plant of Hyphantria cunea . . . . . . . . . . . . . . . . . . . . 41

Centipedes, in nests of Schizoneura fodiens . . . . . . . . . . . . . . . . . . . . . . 169

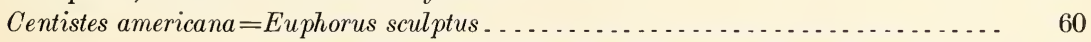

parasite of Coccinella abdominalis introduced into Hawaii . . . . 60

repanda in Hawaii. . . . . . . . . . . . . . 61

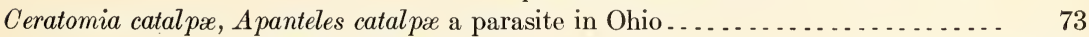

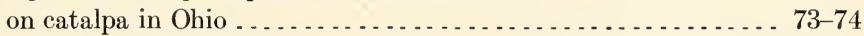

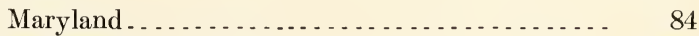

Cereals, destruction of insect pests by sulphur dioxide . . . . . . . . . . . . . . . . . 140

Ceroplastes rubens, destruction by parasites introduced into Hawaii... . . . . . . . . 63

"Chain-dotted geometer." (See Cingilia catenaria.)

Chart making, in boll weevil laboratory ... . . . . . . . . . . . . . . . . . . . . . . . 118-119

Cherry scale. (See Aspidiotus forbesi.)

wild, egg punctures of Cicada erratica............................ 57

food plant of Cingilia catenaria . . . . . . . . . . . . . . . . . . . . . 74

wild black. (See Prunus serotina.)

Chilocorus bivulnerus, introduction into Hawaii . . . . . . . . . . . . . . . . . 60,61

circumdatus, enemy of Lepidosaphes beckii in Hawaii. . . . . . . . . . . . 63

Chinch bug. (See also Blissus leucopterus.)

trend of diffusion compared with boll weevil . . . . . . . . . . . . . . . 129-130

Chionaspis furfura, in New York.............................. . 89-90 


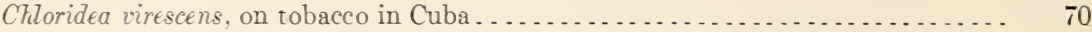

Choke-cherry. (See Prunus virginiana.)

Cholera, probable spread br flies . . . . . . . . . . . . . . . . . . . . . . . . . . . 17

Chrysomphalus obscurus, in Georgia . .................................

Cicada erratica, alleged egg punctures in hoe handles... . . . . . . . . . . . . . .

description of egg punctures and eggs ...................

(nigriventris), distribution discussed........................ 94

egg punctures in roof boards..................... 57

enemy to cotton and corn........................... $52-58$

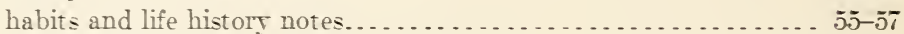

predaceous enemy reported......................... 55

remedies suggested...................................... 58

nigriventris, earls determination of Cicada erratica ................ 52, 53

Cicadula spp., sulphur dioxide as insecticide....................... 145

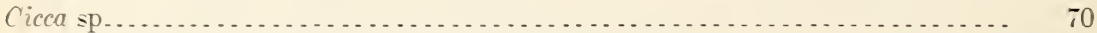

Cimex lectularius, sulphur fumigation in control... . . . . . . . . . . . . . . . 139, 141

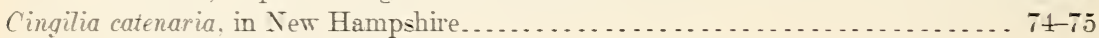

Citrus trees, infestation by Icerya purchasi......... . . . . . . . . . . . . . . 59

sared br Coccinella repanda and Platyomus Tividigaster........... 61

Classics, instructional ralue orerrated. . . . . . . . . . . . . . . . . . . . . . . . . 12 .13

Clayton gas. (See Sulphur dioxide.)

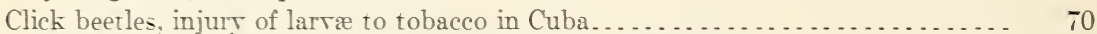

Climatic conditions, affecting rate of spread of boll weeril... . . . . . . . . . . . . . 130

differences, effect on ralue of insecticides.... . . . . . . . . . . . . . . . . . 93-94

Clothes moth, sulphur dioxide as insecticide ... . . . . . . . . . . . . . . . . . 14 j

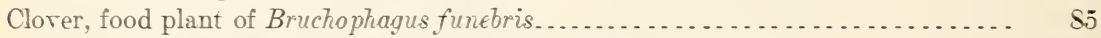

Coccinella abdominalis, Centistes americana a parasite................. 60

introduction into Haraii. . . . . . . . . . . . . . . . . 59

repanda, Centistes americana a parasite in Hawaii................ 61

enemr of aphides in Hawaii........................ 61

sares citrus, Hibiscus, and sugar cane in Hawaii........... 61

Coccinellidæ, killed br Paris green against boll weeril . . . . . . . . . . . . . . . . . . 94

Coccinellids, introduction into Hawaii............................. 61

Cockerell, T. D. A., paper, "The Care of Entomological Types" ... . . . . . . . . . . 51-52

Codling moth. (See Carpocapsa pomionella.)

Coffee bean, egg punctures of Cicada ematica .............................. $5 i$

food plant of Leucoptera coffeella............................ 70

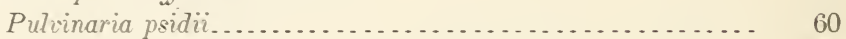

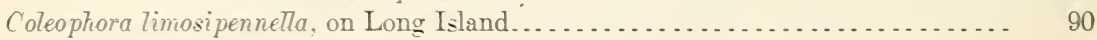

Coleopterous larræe, injury to corn, sugar cane, and regetables in Cuba......... 70

Collard, food plant of Murgantia histrionica........................ $\$ 2$

Color differences in Caltipterus walstiii. . . . . . . . . . . . . . . . . . . . . . . 163

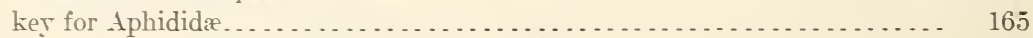

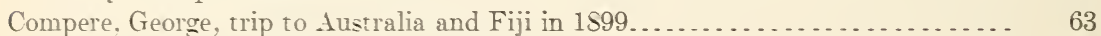

Conotrachelus nenuphar, arsenate of lead a remedr...........................

methods of control in Georgia.................... is

on apple in Ohio............................. $\tau_{2}$

and plum in Minnesota............... $\$ 5$

peach in Texas.............. 69

Paris green inefficient . . . . . . . . . . . . . . . . . . . .

Conradi, A. F., paper, "A Consideration of the Cultural Srstem for the Boll Weeril

in the Light of Recent Obserrations "............ 107-111

"Notes from Texas" ........................... . $6 i-69$ 
Contarinia tritici, injury to wheat attributed.

Page.

Cook, Mel. T., abstract of paper, "Insects of the Year in Cuba",

"Preliminary Observations on the Variations of Utetheisa venusta Dalman"................. .

Copidosoma truncatellum, introduction into Hawaii . . . . . . . . . . . . . . . . .

Corn budworm. (See Diabrotica duodecimpunctata.)

Cicada erratica an enemy.

ear worm. (See Heliothis obsoleta.)

food plant of coleopterous larvæ.

Crambus pascuellus.

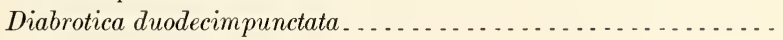

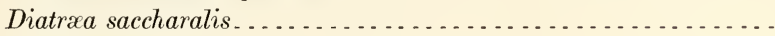

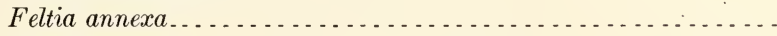

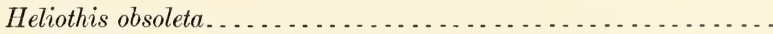

hemipterous insects ................................. 70

Laphygma frugiperda............................... 70

fumigation with carbon bisulphid. . . . . . . . . . . . . . . . . . . . . . . . 91

leaf-hopper. (See Peregrinus maidis.)

meal, fumigation with sulphur dioxide . . . . . . . . . . . . . . . . . . .

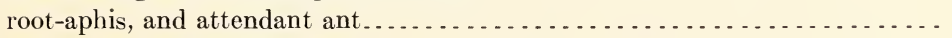

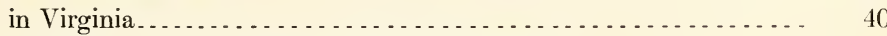

root-worm, southern. (See Diabrotica duodecimpunctata.)

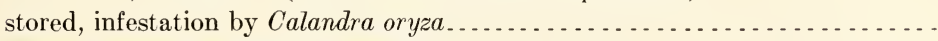

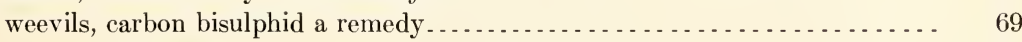

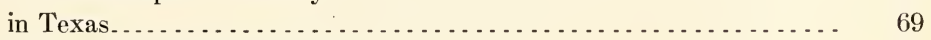

Cornus sp., food plant of Hyphantria cunea .......................... 41

Cotton beetle, new. (See Luperodes brunneus.)

boll weevil. (See Boll weevil.)

caterpillar. (See Alabama argillacea.)

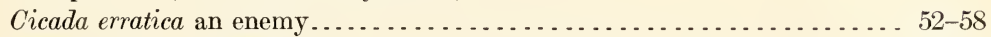

crop of 1904, relation to boll weevil . . . . . . . . . . . . . . . . . . . . . . 130-131

early planting in boll weevil control ... . . . . . . . . . . . . . . . . . . . . . 108

fall destruction of stalks in boll weevil control . . . . . . . . . 108-110, 111, 132-133

food plant of Anthonomus grandis . ....................... $\quad 70$

Aphis gossypii.................................... 81

Calocoris rapidus.................................... 81

Eriophyes gossypii............................... 70

Loxostege similatis..................................... 68

Luperodes brunneus. . . . . . . . . . . . . . . . . . . . . . . . . 80-81

Nezara hilaris..................................... 81

Oncometopia undata ............................... 81

Tetranychus gloveri. ............................... 81

Uranotes melinus. .............................. 67

germinating power unaffected by immersion of seed in carbon bisulphid. . 92

leaf-worm. (See also Alabama argillacea.)

present economic status. . . . . . . . . . . . . . . . . . . . . 127-129, 132

preparation of seed bed for early planting . . . . . . . . . . . . . . . . . . . . 108

shallow cultivation in boll weevil control . . . . . . . . . . . . . . . . . . . . 108, 111

thorough cultivation in boll weevil control, what is it . . . . . . . . . . 110, 111

tineids in Hawaii. . . . . . . . . . . . . . . . . . . . . . . . . . . . . . . . . 64

Cottonwood. (See also Populus deltoides.)

egg punctures of Cicada erratica............................ 57

food plant of Plectrodera scalator .......................... 69 
Cow

Cow-dung maggots, introduction of enemies into Hawaii................... 62

Cowpeas, fumigation with carbon bisulphid ......................... 91

sulphur dioxide against Bruchus.................. 143

germinating power destroyed by sulphur dioxide ................. 142

Crambus pascuellus, on corn in Georgia........ . . . . . . . . . . . . . . . . . 81-82

vulgivagellus, on grass in New York.

Crickets, injury to regetables in Cuba..........

Crop rotation. (See also Cultural methods.)

remedy for Toxoptera' graminum ........................ 67

Cryptolæmus montrouzieri, considered more valuable than Vedalia cardinalis....... $\quad 61$ enemy of male Pseudococcus filamentosus in Hawaii .... . 61

Pulvinaria psidii in Hawaii ... . . . . . . . . . . . 61

introduction into Hawaii. ....................... 61

Cryptopristus, inefficient in holding jointworm in check . . . . . . . . . . . . . 91

n. sp., parasite of Isosoma sp. in Ohio..................... 71

Cryptorhynchus lapathi, on willow in Ohio . . . . . . . . . .

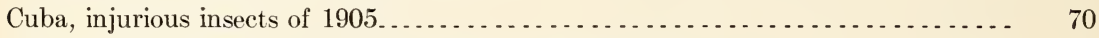

Cuckoo, black-billed, feeding on Hyphantria cunea larvæ. . . . . . . . . . . . . . . . . 47

Cucumber family, blight carried by insect pests....................... 18

food plant of Diaphania hyalinata.......................... 70

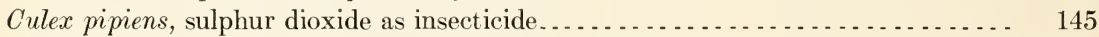

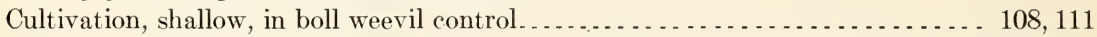

thorough, in boll weevil control, what is it . . . . . . . . . . . . . . . . 110, 111

Cultural methods, in control of Aphis maidi-radicis . . . . . . . . . . . . . . . . . . . 37-39

boll weevil (see also under Boll weevil) ........ . 107-111

Cicada erratica, suggested.................... 58

Fidia viticida........................ 90

Sphenophorus obscurus.................... 63

Toxoptera graminum........................... 67

Currant root-aphis. (See Schizoneura fodiens.)

varieties attacked by Schizoneura fodiens. . . . . . . . . . . . . . . . . . . 167-168

Custard apple. (See Anona.)

Cutworms, abundance after cold wet spring ........................ 91

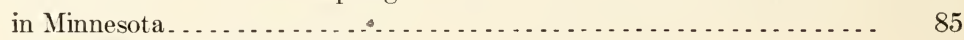

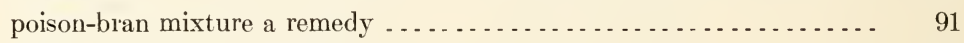

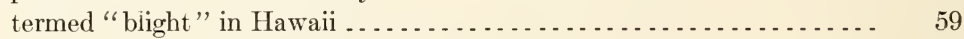

Datana ministra, experiments with a bacterium. . . . . . . . . . . . . . . . $\quad 75$

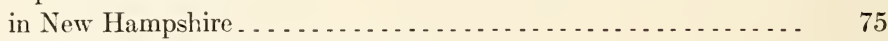

Deltocephalus inimicus, sulphur dioxide as insecticide. . . . . . . . . . . . . . 145

Dermestes beetle, toothed. (See Dermestes vulpinus.)

larvæ, sulphur dioxide as insecticide. . . . . . . . . . . . . . . . . . . . 145

vulpinus, injury to staves of ice-cream freezers. . . . . . . . . . . . . . 76

Descriptions, in the family Aphidide. . . . . . . . . . . . . . . . . . . . . . . 162-166

Description themes, for Iphididæ.. . . . . . . . . . . . . . . . . . . . . . . . . . . 164-166

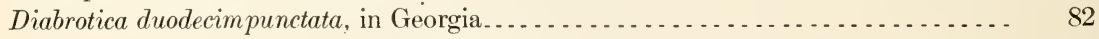

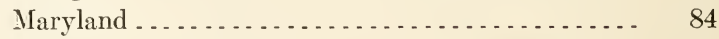

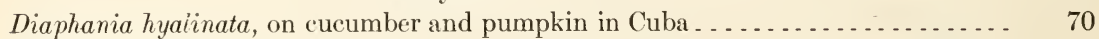

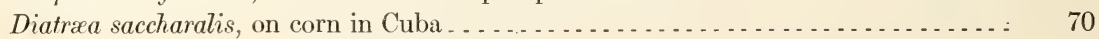

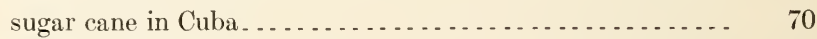

Diedrocephala coccinea, sulphur dioxide as insecticide . . . . . . . . . . . . . . . . 145

Diversified farming, importance in Louisiana . . . . . . . . . . . . . . . . . . . . . . 127

Dræculacephala mollipes, sulphur dioxide as insecticide................... 145

Dragon-fly, sulphur dioxide as insecticide . . . . . . . . . . . . . . . . . . . 145 
Drosophila buskei, sulphur dioxide as insecticide

Page.

punctulata, sulphur dioxide as insecticide ................... 145

Earthworm, food of Lasius niger americanus . . . . . . . . . . . . . . . . . . . . . 34

Ecthrodelphax fairchildii, parasite of Perkinsiella saccharicida in Hawaii. . . . . . . . 65

Egg laying, of Podisus maculiventris . . . . . . . . . . . . . . . . . . . . . . 157-158, 160

plant, food plant of Lineodes integra.................................. 70

Elm. (See also Ulmus americana.)

case-bearer, European. (See Coleophora limosipennella.)

food plant of Coleophora limosipennella ...........................

Hyphantria cunea .......................... . 42, 43

leaf-beetle. (See Galerucella luteola.)

red, galls of Pemphigus ulmifusus................................... 85

white, cockscomb galls........................................... 85

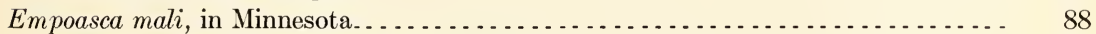

spp., sulphur dioxide as insecticide. . . . . . . . . . . . . . . . . . . . 145

Entomological types, care . . . . . . . . . . . . . . . . . . . . . . . . . . . . . 51-52

Entomologist, economic, groups of animals studied............... 8

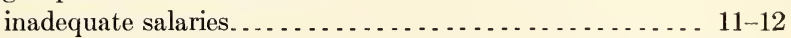

opportunities for investigation................... 11-12

summary of important future work . . . . . . . . . . . . . . . . . 23

Entomologists, Association of Economic, active members . . . . . . . . . . . . . . . . 178-180

associate members. . . . . . . . . . . . . . . . 180-181

foreign members . . . . . . . . . . . . . . . . . . 181-182

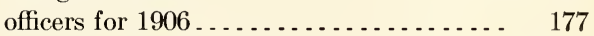

Entomology, and human diseases . . . . . . . . . . . . . . . . . . . . . . . . 16-17

economic, compilation and repetition. . . . . . . . . . . . . . . . . $9-10$

estimate of annual literature ..................... 9

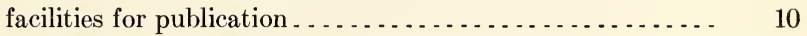

false heralds . . . . . . . . . . . . . . . . . . . . . . . . . . 10 11

history in Hawaii. . . . . . . . . . . . . . . . . . . . . . . . . . 58 66

scope and status............................. 5

estimate of annual literature . . . . . . . . 5

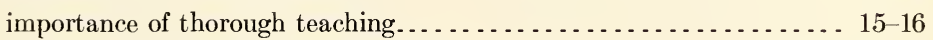

practical, estimate of annual literature.................... 9

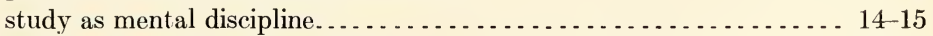

teaching in agricultural colleges . . . . . . . . . . . . . . . . . . . . . . . . . 12-14

Ephestia kuehniella, hydrocyanic-acid gas fumigation.................. 86-88

Epicauta vittata, on alfalfa in Texas . . . . . . . . . . . . . . . 68

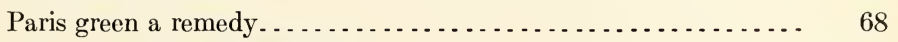

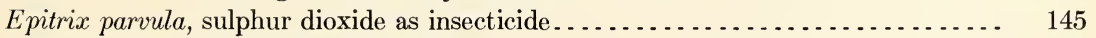

Erebus odora, on Leguminosæ in Cuba............................ 70

Eriophyes gossypii, on cotton in Cuba . . . . . . . . . . . . .

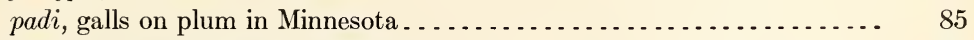

Eudamus proteus, on Leguminosæ in Cuba . . . . . . . . . . . . . . . . . . . 70

Eulecanium nigrofasciatum, in Georgia.............................. 77

lime-sulphur wash in control.................. 77

Eupelmus allynii, parasite of Isosoma sp. in Ohio . . . . . . . . . . . . . . . . 71

n. sp., parasite of Isosoma sp. in Ohio . . . . . . . . . . . . . . . . . . 71

Euphorus sculptus, Centistes americana a synonym .................... 60

Euproctis chrysorrhea. (See also Brown-tail moth.)

in New Hampshire. . . . . . . . . . . . . . . . . . . . . . $\quad 75$

Farm products of the United States, estimated value. $\ldots . \ldots \ldots \ldots$

Federal control, of introduced insect pests....................... 95-106 
Felt, E. P., paper, "Experiments with Insecticides on the San Jose scale ". . . . . 137-138

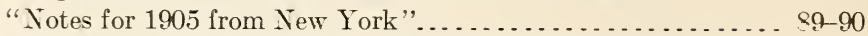

Feltia annexa, on cabbage, corn, tomato, tobacco, and velvet beans in Cuba...... 70

Fertilization, of flowers by insects............................... 18

Fertilizers, in control of boll weevil.... . . . . . . . . . . . . . . . . . . . . . . 111

Fever, spotted, probable conveyance by insect or tick . . . . . . . . . . . . . . . . 17

Texas, conveyance by Boophilus annulatus...................... 17

Fidia viticida, cultural methods in control . . . . . . . . . . . . . . . . . . . . 90

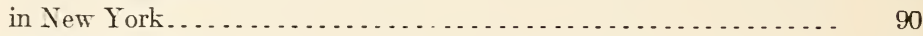

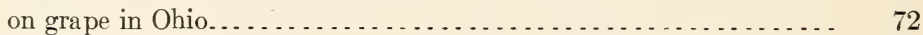

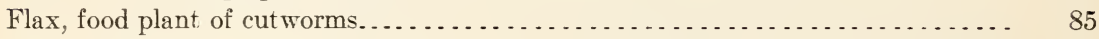

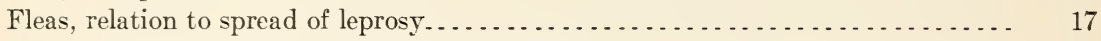

Flies, probable conveyors of Bacillus tuberculosis. . . . . . . . . . . . . . . . . . 17

Flour, fumigation with sulphur dioxide. . . . . . . . . . . . . . . . . . . . . . . . . 154

moth, Mediterranean. (See Ephestia kuehniella.)

Forbes, S. A., paper, "The Corn Root-Aphis and its Attendant Ant" . . . . . . . . . . . . 29-39

Forest insects, in Hawaii . . . . . . . . . . . . . . . . . . . . . . . . . . . . . . 64

Ohio.... . . . . . . . . . . . . . . . . . . . . . . . . . . . . . $72-74$

Formaldehyde gas, tests against Stegomyia calopus. . . . . . . . . . . . . . . . . . . 139

Foxtail grass. (See Setaria.)

Fruit, destruction by Rhagoletis pomonella....................... 89

flies, in Hawaii . . . . . . . . . . . . . . . . .

trces, egg punctures of Cicada erratica.......................... 57

injury by Ithycerus noieboracensis............................. 85

Fruit-tree barkbeetle. (See Scolytus rugulosus.)

Fuller, Claude, paper, "The Plague Locust of Natal". . . . . . . . . . . . . . . . . . . . . . 171-174

Fuller's rose beetle. (See Aramigus fulieri.)

Fumigation of nursery stock, for Aspidiotus perniciosus $\ldots \ldots \ldots \ldots$

practical difficulties........................ 22

Fungous disease, death of Cingitia catenaria from effects. . . . . . . . . . . . . . . . 74-75

Fungus, not used against locusts in Natal. . . . . . . . . . . . . . . . . . . . . . . 174

sooty, on citrus trees and casuarinas in Hawaii . . . . . . . . . . . . . . . 59 59

termed "blight" in Hawaii... . . . . . . . . . . . . . . . . . . . . . . . 59

Galerucella luteola, in New York . . . . . . . . . . . . . . . . . . . . . . . . 90

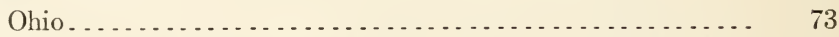

Podisus maculiventris an enemy. . . . . . . . . . . . . . 155, 159-160, 161

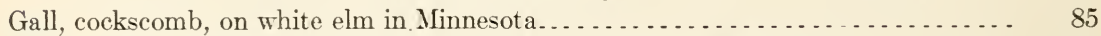

makers, cecidomyiid, on soft maple and box-elder in Minnesota ......... 85

Galls, of Eriophyes padi on plum in Minnesota........ . . . . . . . . . . . 85

Galveston hurricane, influence on spread of boll weevil . . . . . . . . . . . . . . . 133

Garden crops, injury by Aphis gossypii. . . . . . . . . . . . . . . . . . 68

Garman, H., paper, "Does the Silver-Fish (Lepisma snccharina L.) Feed on Starch

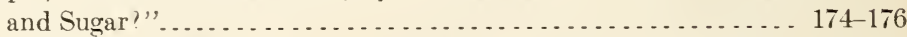

presidential address, "The Scope and Status of Economic Entomology" 5-23

Geocoris bullatus, sulphur dioxide as insecticide .................... . . . . . . . .

Geometer, chain-dotted. (See Cingilia catenaria.)

Georgia, injurious insects of 1905 . . . . . . . . . . . . . . . . . . . . . . . . . . 77-82

Germination power, of seeds, injured or destroyed by sulphur dioxide . . . . . . . . . 142,

$149,150,151-153$

Gerrhonotus carinatus, introduction into Hawaii............................... 62

Gloomy scale. (See Chrysomphalus obscurus.)

Glue, food of Lepisma saccharina . . . . . . . . . . . . . . . . . . . . . . . . . . 175

Gonodonta maria, on custard apple (Anona) in Cuba.................. 70 
Grain aphis, southern. (See Toxoptera graminum.)

Page.

fumigation with carbon bisulphide.......................... 92

germinating power destroyed by sulphur dioxide . . . . . . . . 142, 149, 150, 151-153

insects in Ohio . . . . . . . . . . . . . . . . . . . . . . . . . . . . . . . . . . 71

sulphur dioxide as insecticide.............. 142, 143, 144, 146, 148, 149

moth, Angoumois. (See Sitotroga cerealella.)

Granary weevil. (See Calandra granaria.)

Grape berry moth. (See Polychrosis botrana.)

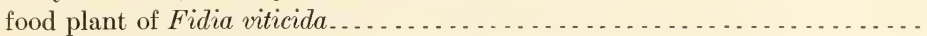

Polychrosis botrana................................... 72

Typhlocyba comes............................. 83

leaf-aphis, structural differences between grape and plum colonizing forms. 162-163

leaf-hopper. (See Typhlocyba comes.)

root-worm. (See Fidia viticida.)

wild. (See Vitis vulpina.)

Grass, crab, food plant of Laphygma frugiperda . . . . . . . . . . . . . . . . . . .

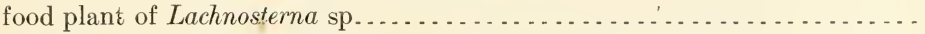

injury by army worm, webworm, and white grubs.............. 90

"Green bug." (See also Toxoptera graminum.)

Texas name for Toxoptera graminum. ........................ 67

Grosella, food plant of Melanchroia geometroides ....................... . . . 70

Guava scale, cottony. (See Pulvinaria psidii.)

Gypsy moth. (See also Porthetria dispar.)

Federal control.

$95,97-98,99,103-104,105$

invasion of New Hampshire... . . . . . . . . . . . . . . . . . . . . . . . . . 97-98

Hackberry. (See Celtis occidentalis.)

Hæmatobia serrata, in Hawaii.

Spalangia hirta, a parasite in Hawaii... . . . . . . . . . . . .

Hair-worm, cabbage. (See Mermis albicans.)

Halictus sp., sulphur dioxide as insecticide.

Hawaii, economic entomology .

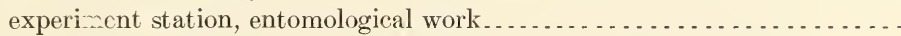

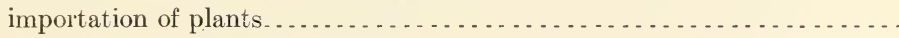

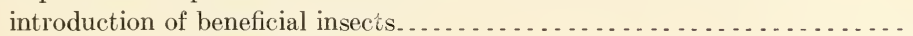

injuriovis insects. . . . . . . . . . . . . . . . . . . . . . . . . . . 58 58

Territorial Board of Agriculture and Forestry, entomological force. . . . . . 65, 66

Hawaiian Sugar Planters' Association Experiment Station, entomological force. . . $\quad 66$

Heliophila unipuncta, in Maryland . . . . . . . . . . . . . . . . . . . . . . . . . . . . 83-84

New York ... . . . . . . . . . . . . . . . . . . . . . . 89

on sugar cane in Cuba......................... 70

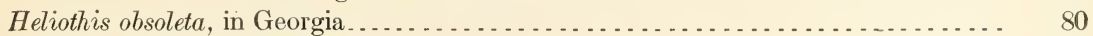

Minnesota..................................... 85

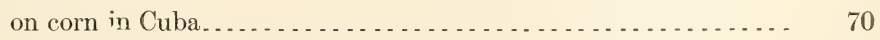

Podisus maculiventris an enemy...................... 155

Hellebore, ineffective against Lachnosterna sp ... . . . . . . . . . . . . . . . . . . 85

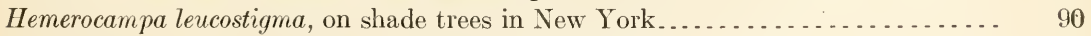

Hemipterous insects, on corn and sugar cane in Cuba.................. $\quad 70$

Hessian fly. (See also Mayetiola destructor.)

distribution in the United States........................ 91

double-brooded in North Dakota.......................... 91

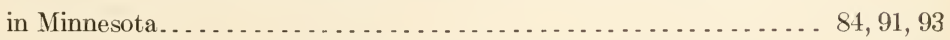

Hibernation of boll weevil..... . . . . . . . . . . . . . . . . . . . . . . . . . . . 108 109

experiment to determine conditions. ........... . . . 126-127

$31024-N o .60-06$ x- -13 


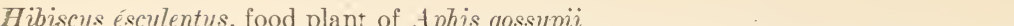

Rhopalosiphum dianthi................. 163

sared br Coccinella repanda and Platyomus lividigaster................ 61

Hickory, food plant of Hyphantria cunea ..........................

Malacosoma disstria ............................ 79

Hinds, W. E., paper, "Laboratory Methods in the Cotton Boll Weeril Investiga-

tions" $"$. . . . . . . . . . . . . . . . . . . . . . . . . . . . . . . . . . . . . . . . 111-119

Hollyhock, food plant of Tanessa cardui . . . . . . . . . . . . . . . . . . . . .

Honey bee. (See Apis mellifera and Bee, honer.)

dew, on citrus trees and casuarinas in Hawaii.................... 59

Hop-tree. (See Ptelea trifoliata.)

Horismenus microgastri, parasite of Apanteles catalpæ in Ohio.................

Hornfly. (See Hæmatobia serrata.)

Horseflies, probable ralue of petroleum in control . . . . . . . . . . . . . . . . . .

Horsefly, green-headed. (See Tabanus lineola.)

Host plant catalogue of Aphididre . . . . . . . . . . . . . . . . . . . . . . . . . 163

Household insects, sulphur dioxide as insecticide...................... 144

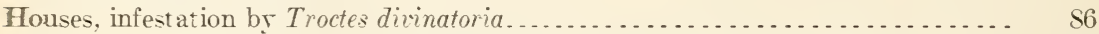

Hunter, W. D., paper, "The Present Status of the Mexican Cotton Boll Teeril". . 106

Hydrocranic-acid gas, against Ephestia kuehniella ...................... . . S6-Ss

Plodia interpunctella and Tenebrio............. . . 154

Troctes divinatoria ...................... $\$ 6$

impracticable for soil fumigation in greenhouses......... 151

tarnishing of silrer and nickel from fumigation......... . S6

Hyperaspis, introduction of sereral species into Hawaii ... . . . . . . . . . . . . 60

undulata, introduction into Hawaii.......................... 60

Hyphantria cunea. color variation of larræ. . . . . . . . . . . . . . . . . . . . . . . . 50-51

division and union of broods, etc . . . . . . . . . . . . . . . . . $18-\tilde{\varepsilon} 0$

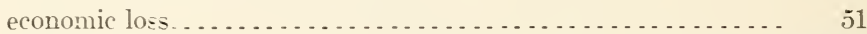

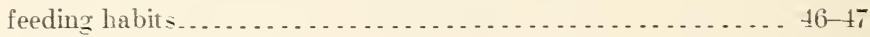

food plants. . . . . . . . . . . . . . . . . . . . . . . . . . . . $41-43$

growth and molting................................. 4 . 48

habits on walnut, hackberry, and choke-cherry . . . . . . . . . . . $43-46$

in New Hampshire . . . . . . . . . . . . . . . . . . . . . . . . . . 75

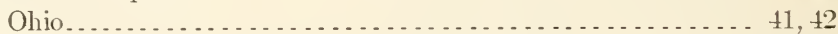

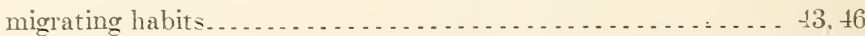

remedies........................................... 51

textor, in New York...................................... s0

Hypocala andremona, on Japanese persimmons in Cuba ................. . 70

Hypopteromalus tabacum, parasite of A panteles catalpæ in Ohio............... 73

Icerya purchasi, on citrus trees and casuarinas in Hawaii... . . . . . . . . . . . . . 59

Importation of plants into Hawaii . . . . . . . . . . . . . . . . . . . . . . . . . 59

"Inchworm." (See Cingitia catenaria.)

Incubation, duration in Podisus maculiventris . . . . . . . . . . . . . . . . . 15i-15s, 161

Incubator, in study of temperature effects on boll weevil . . . . . . . . . . . . . . . . 113

Insect, does some species conver spotted ferer?...................... 17

pests, introduced. National control . . . . . . . . . . . . . . . . . . . . . 95-106

report of committee.............. 134

photographr, methods. . . . . . . . . . . . . . . . . . . . . . . . 131-132

phrlogenr, significance of wing origin......................... 29

Insecticide, sulphur dioxide . . . . . . . . . . . . . . . . . . . . . . . . . . . . . . . 139-153

Insecticides, experiments against San Jose scale . . . . . . . . . . . . . . . . . 13i 138

influence of climatic differences on efficiency.................. . . 93-94 
Insecticides, kerosene-limoid tests

lime-sulphur washes.

notes.

report of committee.

Insects, affecting domestic animals.

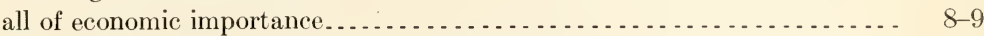

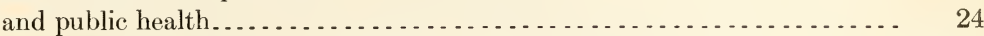

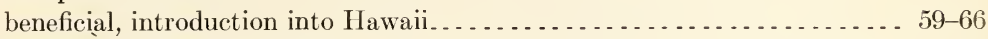

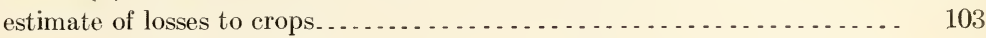

number of species................................ 8

fertilizers of flowers. . . . . . . . . . . . . . . . . . . . . . . . . . . 18

injurious, introduction into Hawaii . . . . . . . . . . . . . . . 5 . 5 . 50

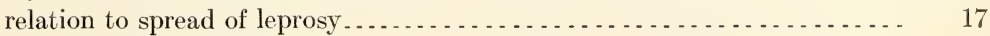

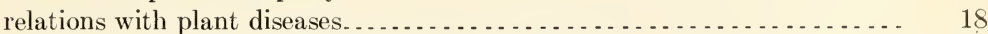

volumes required for treating all species, estimate. . . . . . . . . . . . . . 9

economic species, estimate............. 9

known North American species, estimate... 9

voluntary dissemination by wind . . . . . . . . . . . . . . . . . . 40

Iridomyrmex humitis, Federal control . . . . . . . . . . . . . . . . . . . . . . . . . 99

Isosoma sp., Cryptopristus n. sp., a parasite in Ohio. . . . . . . . . . . . . . . 71

Eupelmus allynii, a parasite in Ohio........................ 71

n. sp., a parasite in Ohio.......................... 71

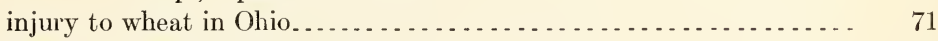

Ithobalus polydamas, on Aristolochia in Cuba . . . . . . . . . . . . . . 70

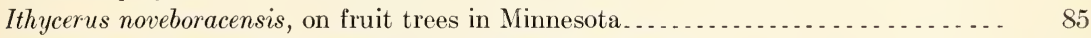

Jarring, for Conotrachelus nenuphar not general in Georgia _ . . . . . . . . . . . . . 78

Lachnosterna inversa and hirticula ........................ 80

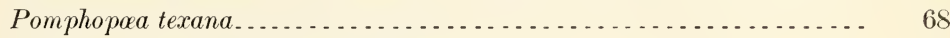

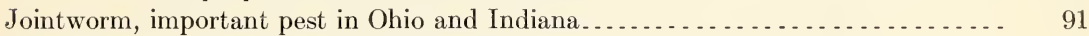

Juglans nigra, food plant of Hyphantria cunea . . . . . . . . . . . . . . . . . . 41

June beetle, southern. (See Allorhina nitida.)

Kafir corn, effect of sulphur dioxide on germinating power . . . . . . . . . . . . 142

Kerosene emulsion against first larval stage of Acridium purpuriferum . . . . . . . . 174

remedy for Lygus pratensis...................... 78

Tetranychus gloveri.............................. 81

Schizoneura lanigera............................... 79

strength necessary against Phenacoccus acericola.......... 162

Kerosene-limoid mixtures, experiments on San Jose scale . . . . . . . . . . . . . . 137-138

tests in Connecticut . . . . . . . . . . . . . . . 136-137

Kerosene-soap emulsion, summer remedy for Aspidiotus perniciosus . . . . . . . . 77

Kero-water, remedy for Empoasca mali. . . . . . . . . . . . . . . . . . . . 88

K-L. (See Kerosene-limoid.)

Koa. (See Acacia koa.)

Koebele, Albert, entomological work for Hawaii

engagement by Hawaiian sugar planters in 1893 . . . . . . . . . . 60

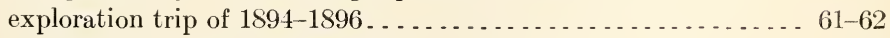

methods in economic entomology . . . . . . . . . . . . . . . . . 58

trip to America in 1898 ... . . . . . . . . . . . . . . . . . . 62

Australia and Fiji in 1899 ........................ 63

in $1891 \ldots \ldots \ldots \ldots \ldots$

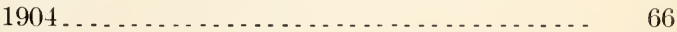

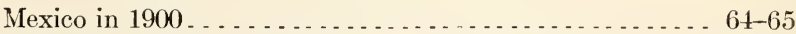

Kotinsky, Jacob, paper, "History of Economic Entomology in Hawaii" . . . . . . . 58-66 


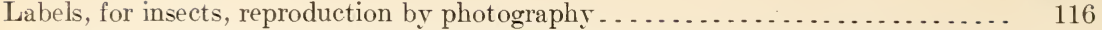

Laboratory methods, in boll-weevil investigations . . . . . . . . . . . . . . . . . . . . 111-119

Lacyy Act . . . . . . . . . . . . . . . . . . . . . . . . . . . . . . . . . . . 101

Lachnosterna hirticula, on pecan in Georgia . . . . . . . . . . . . . . . . . . . . 80

inversa, on pecan in Georgia......................... 80

sp., injury to lawns in Minnesota.......................... 85

Languages, ancient, instructional value orerrated. . . . . . . . . . . . . . . . . . 12-13

modern, value in science studies . . . . . . . . . . . . . . . . . . . . . . 12-13

Lantana, introduction of insect enemies into Hawaii . . . . . . . . . . . . . . . . 64-65

pest to ranchmen in Hawaii . . . . . . . . . . . . . . . . . . . . . . . . . 62

scale. (See Orthezia insignis.)

Laphygma frugiperda, in Georgia . . . . . . . . . . . . . . . . . . . . . 81

on cotton in Cuba ............................ 70

Lasioderma testaceum, in stored tobacco in Cuba . . . . . . . . . . . . . . . . . 70

Lasius niger americanus, association with Aphis maidi-radicis . . . . . . . . . . . 29, 27

food habits . . . . . . . . . . . . . . . . . . . . . . . . . . 34,37

Leaf caterpillar. (See Cotton leaf-worm and Alabama argillacea.)

Leaf-beetle, elm. (See Galerucella luteola.)

Leaf-bug, cotton. (See Calocoris rapidus.)

Leaf-hopper, apple. (See Empoasca mati.)

corn. (See Peregrinus maidis.)

grape. (S`e Typhlocyba comes.)

sugar-cane. (Sre Perkinsiella saccharicida.)

Leaf-worm, cotton. (See Alabama argillacea and Cotton leaf-worm.)

Lecanium, peach. (See Eulecanium nigrofasciatum.)

Legislation, against insect pests . . . . . . . . . . . . . . . . . . . . . . . . . . 9 95-106

Lens holder, universal arm, in insset photography . . . . . . . . . . . . . . . . 131-132

Lepidosaphes beckii, Aphelinus diaspidis a parasite in Hawaii . . . . . . . . . . . 63

Chitocorus circumdatus an enemy in Hawaii . . . . . . . . . . . 63

Orcus chalybeus an enemy in Hawaii ................. 63

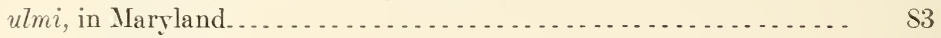

Ohio. ...

on apple in Georgia............................... 79

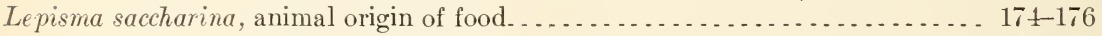

cannibalistic habits. . . . . . . . . . . . . . . . . . . . 174-175

does it feed on starch and sugar? . . . . . . . . . . . . . . . . . 17t-176

Leprosy, possible converance by fleas and other insects . . . . . . . . . . . . . . . . . 17

Leptinotarsa decemineata. (See also Potato beetle.)

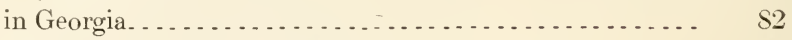

Podisus maculicentris an enemy................ 155

Lencoptera coffeella, on coffee in Cuba . . . . . . . . . . . . . . . . . . . . . . . 70

Lewis, A. C., R. I. Smith and, paper, "Some Insects of the Year in Georgia".... . . 77-S2

Lime, air-slaked, against Pegomya brassicx . . . . . . . . . . . . . . . . . . . . . . . 89

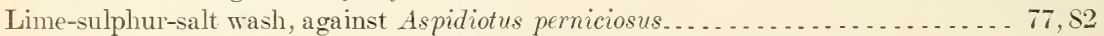

Eulecanium nigrofasciatum . . . . . . . . . . . . . .

washes, formulas giving best results . . . . . . . . . . . . . . . . $15 t$

tests by Bureau of Entomology................ 154

Lime-sulphur wash, best method of preparation . . . . . . . . . . . . . . . . . 15 t

remedy for Anarsia lineatella...................... 78

washes, against San Jose scale . . . . . . . . . . . . . . . . . . . 137-138

tests in Connecticut . . . . . . . . . . . . . . . . . . . . . . . 136-137

Limoid mixtures, against San Jose scale in New York . . . . . . . . . . . . . . . 137-138

Limoid-kerosene wash, tests in Connecticut . . . . . . . . . . . . . . . . . . . . . . . 136-137 
Lineodes integra, on egg-plant in Cuba .

Lizard, rock. (See Gerrhonotus carinatus.)

Locust beetle, leaf-mining. (See Odontota dorsalis.)

food plant of Odontota dorsalis.

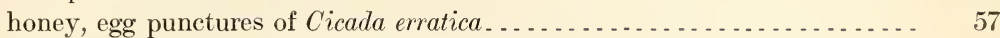

red-legged. (See Melanoplus femur-rubrum.)

the plague species of Natal. (See Acridium purpuriferum.)

Louisiana crop pest commission, work against boll weevil _ . . . . . . . . . . . . 119-127

Loxostege similalis, on cotton in Texas. . . . . . . . . . . . . . . . . . 68

Paris green a remedy . . . . . . . . . . . . . . . . . 68

Lucitia cæsar, sulphur dioxide as ins cticide . . . . . . . . . . . . . . . . . . . . 145

Lucuma rivicoa, food plant of Robinsonia formula . . . . . . . . . . . . . . . . 70

Luperodes brunneus, on cotton in Georgia . . . . . . . . . . . . . . . . . . $80-81$

Paris green recommended as remedy ............... 80

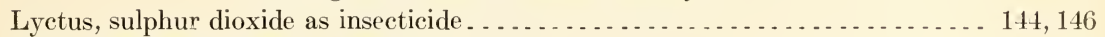

Lygus pratensis, kerosene emulsion a remedy . . . . . . . . . . . . . . . . . 78

on apple and pear in Geo gia. . . . . . . . . . . . . . . . . 78

sulphur dioxide as insecticide. . . . . . . . . . . . 145

Macrodactylus subspinosus, depredations in New York. . . . . . . . . . . . . . 89

Macrosiphum, resemblance of grape-colonizing form of grape leaf-aphis . . . . . . . 163

Macrosiphum(?) sp., sulphur dioxide as insecticide . . . . . . . . . . . . . . . . . . 145

Maggot, apple. (See Rhagoletis pomonella.)

Malacosoma americana, bacterial experiments contemplated . . . . . . . . . . . .

in Georgia. . . . . . . . . . . . . . . . . . . . . . .

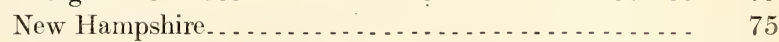

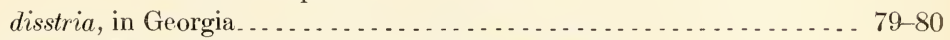

Malaria, carriage by Myzomyia funesta and Pyretophorus costalis . . . . . . . . . . 17

relation with Anopheles maculipennis .......................... 17

Maple, food plant of Chrysomphalus obscurus . . . . . . . . . . . . . . . . . . 78

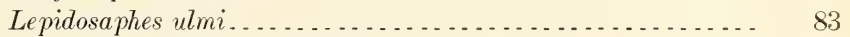

Phenacoccus. (See Phenacoccus acericola.)

scale, cottony. (See Pulvinaria innumerabilis.)

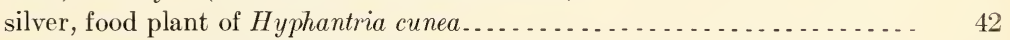

soft, injury by cecidomyiid galls. . . . . . . . . . . . . . . . . . . . 85

sugar, food plant of Hyphantria cunea . . . . . . . . . . . . . . . . . . . 42

infestation by Phenacoccus acericola. . . . . . . . . . . . . . . . 161

Maple-leaf aphide, woolly. (See Pemphigus acerifolii.)

scale, woolly. (See Phenacoccus acericcla.)

Marlatt, C. L., paper, "Sulphur dioxide as an Insecticide" . . . . . . . . . . . . . . 139-153

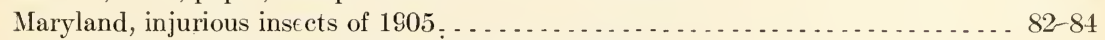

"Maui blight," Hawaiian name for Orthezia insignis . . . . . . . . . . . . . . . 65

Mayetiola destructor. (See also Hessian fly.)

in Georgia.. $.6 \ldots \ldots \ldots$

Ohio ........................................... 71

Mealworm. (See Tenebrio.)

Measure key, for Aphididæ.

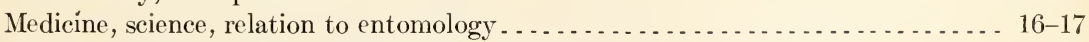

Megilla maculata, sulphur dioxide as insecticide. . . . . . . . . . . . . . . . . . . . 145

Melanchroia geometroides, on grosella in Cuba. . . . . . . . . . . . . . . . 70

Melanoplus femur-rubrum, on alfalfa in Minnesota . . . . . . . . . . . . . . 84-85

sulphur dioxide as ins oticide ................ 145

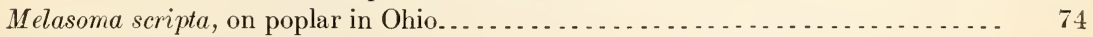


Melon aphis. (See Aphis gossypii.)

Page.

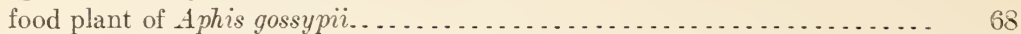

Membership, report of committee . . . . . . . . . . . . . . . . . . . . . . . . . 13 .

Meraporus calandræ, parasite of Calandra oryza ..................... 148

sulphur dioxide as insecticide . . . . . . . . . . . . . . . . $1 \pm 8$

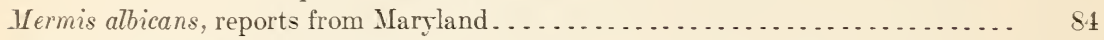

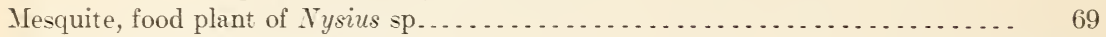

Meteorological conditions, affecting spread of boll weeril. . . . . . . . . . . . . . . 122-123

Methods in study of boll weevil. . . . . . . . . . . . . . . . . . . . . . . . . . . . 111-119

Migration, of boll weevil, governing conditions.... . . . . . . . . . . . . . . . . 129-130

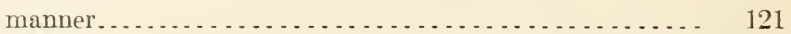

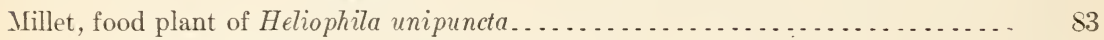

German; food plant of Laphygma frugiperda.................... . . 81

Minnesota, injurious insects of $1905 \ldots \ldots \ldots \ldots \ldots$

Mite. (See Eriophyes padi and Eriophyes gossypii.)

Mongoose, destructive to toads in Hawaii........ . . . . . . . . . . . . . . 61

Monilema sp., sulphur dioxide as insecticide........................ 114

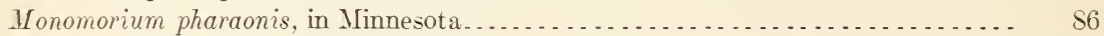

Morrill, A. W., paper, "Some Obserrations on the Spined Soldier Bug" . . . . . . 15 $\tilde{y}_{-161}$

Mosquito, yellow ferer. (See Stegomyia calopus.)

Mosquitoes, of Maryland, investigation............................. $\$ 4$

Ohio, mention of list............................. 74

If urgantia histrionica. (See also Cabbage bug, harlequin.)

in Georgia . . . . . . . . . . . . . . . . . . . . . . . . . . $\$ 2$

Musca domestica, sulphur dioxide as insecticide. . . . . . . . . . . . . . . . . . 14 j

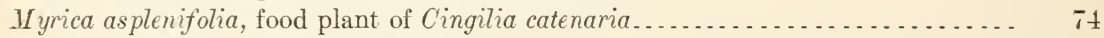

Myzomyia funesta, carrier of malaria . . . . . . . . . . . . . . . . . . . . . . . 17

Myzus, resemblance of plum colonizing form of grape leaf-aphis . . . . . . . . . . 163

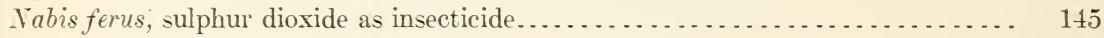

Naphtha soap, in making kerosene emulsion for Phenacoccus acericola .......... 162

National control of introduced insect pests. . . . . . . . . . . . . . . . . . . . $95-106$

report of committee.............. 134

Vature study, religious aspects. . . . . . . . . . . . . . . . . . . . . . . . . . 14

Newell, Wilmon, paper, "Notes upon a New Insect Enemy of Cotton and Corn". . . 52-58

"The Work of the State Crop Pest Commission of Louisiana on the Cotton Boll Weevil" ................. 119-127

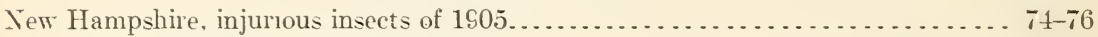

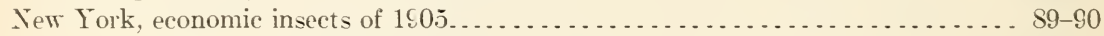
weeril. (See Ithycerus noveboracensis.)

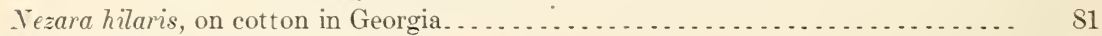

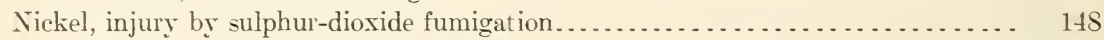

Nomenclature, report of committee ............................. 25-27

Nursery inspection, defects in Minnesota law . . . . . . . . . . . . . . . . . . $8 s$

desirability for uniform State laws................. 23

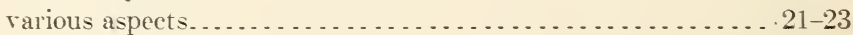

Tysius sp., on potato, mesquite, and wheat in Texas................. 69

Oak, food plant of Chrysomphalus obscurus......................... is

Malacosoma disstria............................ 79

worm, roș-striped. (See Anisota virginiensis.)

Odontota dorsatis, on locust in Ohio ................................

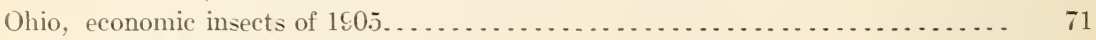

Okra. (See Hibiscus esculentus.)

"Olinda bug," Hawaiian name for Aramigus fulleri..................... 64

Oncometopia undata, on cotton in Georgia........................ $s 1$ 
Orange, mandarin, foliage not attacked by Acridium purpuriferum. . . . . . . . . 174

Oranges, injury by Atta insularis. . . . . . . . . . . . . . . . . . . . . . . . 70

Pachnæus litus. ...................................... 70

Solenopsis geminata .............................. 70

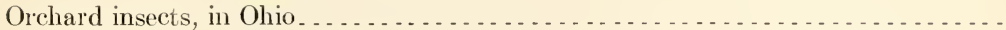

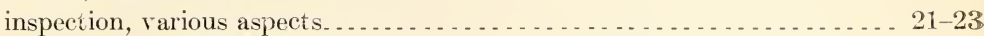

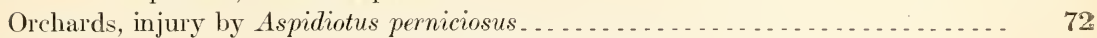

Orcus chalybeus, enemy of Lepidosaphes beckii in Hawaii. . . . . . . . . . . . . 63

Ortalids, sulphur dioxide as insecticide. . . . . . . . . . . . . . . . . . . . . . 145

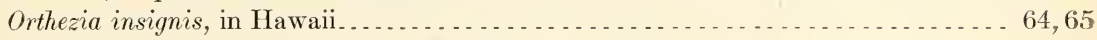

Osage orange, is it a food plant of IIyphantria cunea? . . . . . . . . . . . . . . 42

Osbor'n, Herbert, paper, "The Problem of Wing Origin and its Significance in Insect

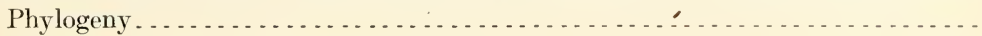

Oyster-shell scale. (See Lepidosaphes ulmi.)

Pachnæus litus, injury to oranges in Cuba .

Palms, uninjured by moderate sulphur-dioxide fumigation

Papaipema nitela, in Minnesota. . . . . . . . . . . . . . . . . . . . . . . . 85

Papilio polydamas =Ithobalus polydamas .

polyxenes, on umbelliferous planıss in Cuba........ . . . . . . . . . 70

Paris green, abundance of aphides following use on cotton . . . . . . . . . . . . . 94

against Conotrachelus nenuphar............................. 72

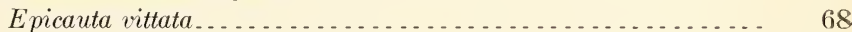

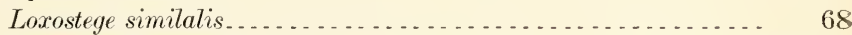

Luperodes brunneus. . . . . . . . . . . . . . . . . . . . . . 80-81

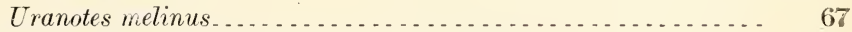

experiments to determine value against boll weevil. . . . . . . . . . . 126

impracticable against locusts in Natal . . . . . . . . . . . . . . . . 174

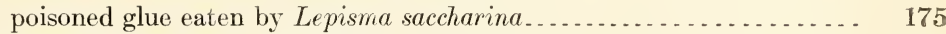

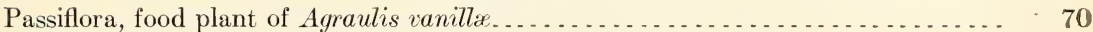

Passion flower. (See Passiflora.)

Peach borer. (See Sanninoidea exitiosa.)

borers, attack of Scolytus rugulosus following their work . . . . . . . . . . . .

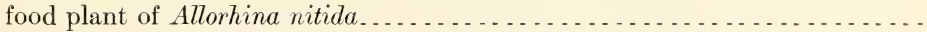

Conotrachelus nenuphar . . . . . . . . . . . . . . . . .

Eulecanium nigrcfasciatum . . . . . . . . . . . . . . . . .

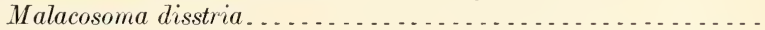

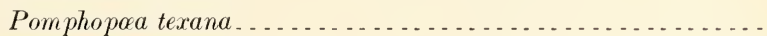

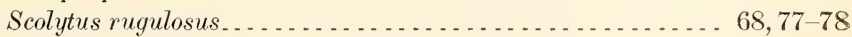

lecanium. (See Eulecanium nigrofasciatum.)

scale, West Indian. (See Aulacaspis pentagona.)

spraying with lime-sulphur and kerosene-limoid . . . . . . . . . . . . . . 136-137

twig borer. (See Anarsia lineatella.)

Pear blight, conveyance by insects. . . . . . . . . . . . . . . . . . . . . 18

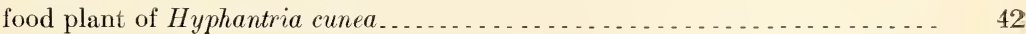

Lygus pratensis............................................ 78

spraying with lime-sulphur and kerosene-limoid . . . . . . . . . . . . . 136-137

Pecan, egg punctures of Cicada erratica. . . . . . . . . . . . . . . . . . . . . 57

food plant of Lachnosterna hirticula . . . . . . . . . . . . . . . . . . . . 80

inversa ................................. 80

Pegomya brassicæ, experiments in control . . . . . . . . . . . . . . . . . . . . . . . 88 . 89

maggots preyed on by beetles. . . . . . . . . . . . . . . . . 89

Pseudeucoila gillettei a parasite in Minnesota.............. 89

Pemphigus acerifolii, in Delaware, Maryland, and Texas. . . . . . . . . . . . . 93

New York. ................................ 90 
ulmifusus, galls on red elm in Minnesota. . . . . . . . . . . . . . . . .

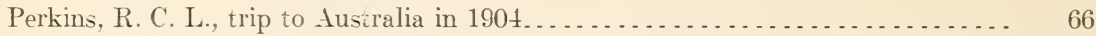

Perkinsiella saccharicida, Ecthrodelphax fairchildii a parasize in Hawaii . . . . . . . . . 65

enemy to sugar-cane in Hawaii . . . . . . . . . . . . . . . . . 65-66

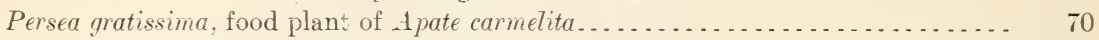

Persimmon, Japanese, food plant of Hypocala andremona......... . . . . . . . . 70

Petroleum, increase of horseflies following abandonment against mosquito la:ræ . . . 90

Phenacoccus acericola, destruction by spraying . . . . . . . . . . . . . . . . . . . 161-162

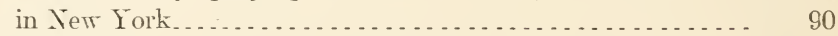

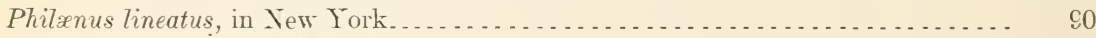

spumaria, in New York........................................... 90

Phlegethontius sexta, on tobacco in Cuba. . . . . . . . . .

Photographic prints, injury by Lepisma saccharina . . . . . . . . . . . . . . . . $\quad 176$

Photography, apparatus and methods in boll-weeril invescigacions . . . . . . . . . . . 116-119

of insects, methods. . . . . . . . . . . . . . . . . . . . . . . . . 131-132

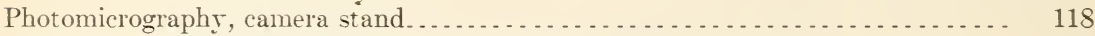

Phylogeny of insects, significance of wing origin ...... . . . . . . . . . . . . . . 29

Pigeon grass, food plant of Aphis maidi-radicis . . . . . .

Pimpla inquisitor, sulphur dioxide as insecticide . . . . . . . . . . . . . . . . . . . . 14 5

Pineapples, uninjured by moderate sulphur-dioxide fumigation. . . . . . . . . . . . . 142, 149

Plague locust of Natal. (See Acridium purpuriferum.)

Plant bug, tarnished. (See Lygus pratensis.)

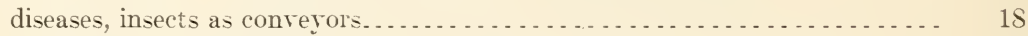

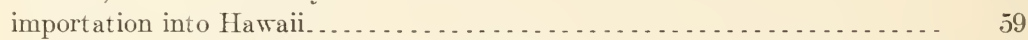

products, of the Uniced Sia.es, estimated ralue . . . . . . . . . . . . . . 103

Plants, living, destructive action of sulphur dioxide . . . . . . . . . . . . . . . . 140, 142, 149

Platyome lividigaster, enemy of aphides in Hawaii... . . . . . . . . . . . . . . . 61

sares citrus, Hibiscus, and sugar cane in Hawaii. . . . . . . . 61

Plectrodera scalator, on cottonwood in Texas. . . . . . . . . . . . . . . . . . . 69

Plodia interpunctella, hydrocyanic-acid gas as insecticide. . . . . . . . . . . . . . . . . 154

Plum curculio. (See Conotrachetus nenuphar.)

food plant of Eulecanium nigrofasciatum. . . . . . . . . . . . . . . . . . .

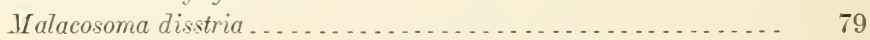

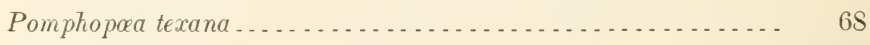

galls of Eriophyes padi... . . . . . . . . . . . . . . . . .

Plumeria, food plant of Pseudospfinx tetrio ... . . . . . . . . . . . . . . . . . . $\quad 70$

Plutella maculipennis, on cabbage in Cuba. . . . . . . . . . . . . . . . . . . 70

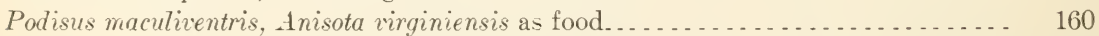

confusion of Podisus serieventris. . . . . . . . . . . . . . . . . . 155

duration of nymph stages and length of adult life . . . . . 158, 159, 161

egg la ying and duration of incubation. . . . . . . . . 157-15s, 160, 161

enemy of Alabama argillacea . . . . . . . . . . . . . . . . . 155

Galeruculla luteola . . . . . . . . . . . . . . . . . 155, 159-160, 161

Helioth is olsolta . . . . . . . . . . . . . . . . . . . 155

Leptinotarsa decemlineata . . . . . . . . . . . . . . . . 155

tent caterpillar. . . . . . . . . . . . . . . . . . . 155

feeding habits . . . . . . . . . . . . . . . . . . . . . . . . . . 159-160, 161

paper... . . . . . . . . . . . . . . . . . . . . . . . . . 155-161

Podisus spinosus a synonym... . . . . . . . . . . . . . . . 15 j

rariation in form and size of adults . . . . . . . . . . . . . 156, 160

serieventris, confusion with Podisus maculiventris................ 155

spinosus $=$ Podisus macuivientris . . . . . . . . . . . . . . . . . . 
Page.

Podosesia syringx, on ash in Minnesota . . . . . . . . . . . . . . . . . . . . 85

Poison-bran mixture, remedy for cutworms. . . . . . . . . . . . . . . . . . . . . 91

Polychrosis botrana, on grape in Ohio . . . . . . . . . . . . . . . . . . . 72

Pomphopora texana, jarring as remedy ... . . . . . . . . . . . . . . 68

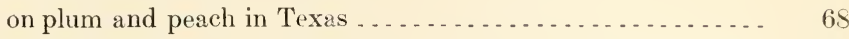

Pontra monuste, on cabbage in Cuba. . . . . . . . . . . . . . . . . . . . 70

rapæ, parasites introduced into Hawaii . . . . . . . . . . . . . . . . . 62

Poplar, balsam. (See Populus balsamifera.)

European white. (See Populus alba.)

food plant of Melasoma scripta . . . . . . . . . . . . . . . . . . . . .

Poplars. (See Populus alba and P. balsamifera.)

Populus alba, food plant of Hyphantria cunea. . . . . . . . . . . . . . . . . . 42

balsamifera, food plant of Hyphantria cunea . . . . . . . . . . . . . . . . 42

deltoides, food plant of Hyphantria cunea. . . . . . . . . . . . . . . . . . 42

tremuloides, food plant of Hyphantria cunea ... . . . . . . . . . . . . . 42

Porthetria dispar. (See also Gypsy moth.)

in New Hampshire.

Potato beetle. (See Leptinotarsa decemlineata.)

food plant of Nysius sp . . . . . . . . . . . . . . . . . . . . . . . . . 69

Powder-post beetle. (See Lyctus.)

Prodenia commelinx, on tobacco in Cuba . . . . . . . . . . . . . . . . . .

eudiopta, on tobacco in Cuba . . . . . . . . . . . . . . . . . . 70

Programme for 1906 meeting, appointment of committee . . . . . . . . . . . . 135

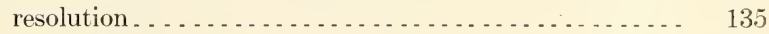

Prunus serotina, food plant of Hyphantria cunea . . . . . . . . . . . . . . . 41

virginiana, food plant of Hyphantria cunea. . . . . . . . . . . . . . . 41

Pseudeucoila gillettei, parasite of Pegomya brassicæ in Minnesota . . . . . . . . . . . 89

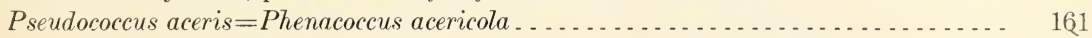

filamentosus, Cryptolæmus montrouzieri an enemy in Hawaii. . . . . . . . . 61

nipæ, Cryptolæmus montrouzieri an enemy of males only in Hawaii _. - 61

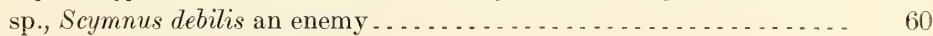

Pseudosphinx tetrio, on Plumeria in Cuba . . . . . . . . . . . . . . . . . . . 70

Ptelea trifoliata, little injured by Hyphantria cunea . . . . . . . . . . . . . . . 45

Pulvinaria innumerabitis, in Minnesota . . . . . . . . . . 55

psidii, Cryptolæmus monirouzieri an enemy in Hawaii. . . . . . . . . . 61

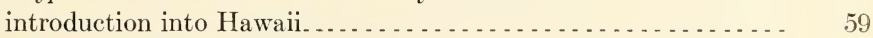

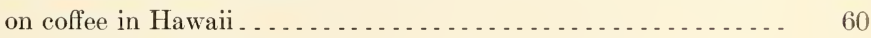

Pumpkin, food plant of Diaphania hyalinata . . . . . . . . . . . . . . . . 70

Purple scale. (See Lepidosaphes beckii.)

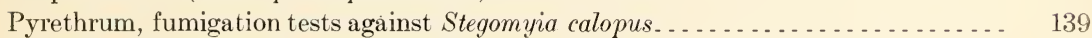

Pyretophorus costalis, carrier of malaria _ . . . . . . . . . . . . . . . . 17

Pyrosoma hominis, some insect or tick probably an intermediate host . . . . . . . 17

Quarantine, against boll weevil in Louisiana. . . . . . . . . . . . . . . . . . . . 124-126

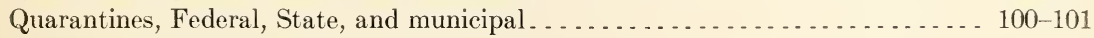

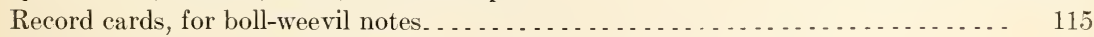

Red spider, cotton. (See Tetranychus gloveri.)

Refrigerator, special, in study of temperature effects on boll weevil. . . . . . . . . . 113-114

Report of committee on cooperative testing of insecticides . . . . . . . . . . . . . 28

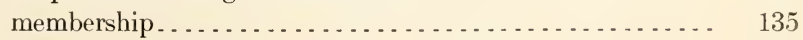

national control of introduced insect pests . . . . . . . . . . 131

nomenclature. . . . . . . . . . . . . . . . . 25-27

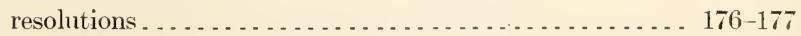

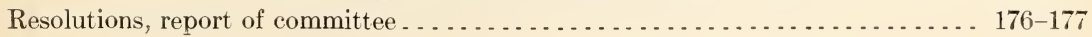


Rhagoletis pomonella, injury in New York.

Rhizobius lophanth $x$, introduction into Hawaii.

ventralis, enemy of Pseudococcus nipæ in Hawaii . . . . . . . . . . . . . .

introduction into Hawaii

Rhogas rileyi, sulphur dioxide as insecticide

Rhopalosiphum dianthi, on Hibiscus esculentus . . . . . . . . . . . . . . . . . . 163

Rice, destruction of germinating power by sulphur dioxide. . . . . . . . . . . . . . . . 142 weevil. (See Calandra oryza.)

Roach, German. (See Blattella germanica.)

Robinsonia formula, on Lucuma rivicoa in Cuba

Rock lizard. (See Gerrhonotus carinatus.)

Root-aphis, strawberry. (See A phis forbesii.)

Root-worm, grape. (See Fidia viticida.)

southern corn. (See Diabrotica decempunctata.)

Rose beetle. (See Macrodactylus suhspinosus.)

Rots, of fruits, conreyance by insects . . . . . . . . . . . . . . . . . . . . . .

Rust, on wheat in Ohio . . . . . . . . . . . . . . . . . . . . . . . . . . . . .

Rye, destruction of germinating porrer by sulphur dioxide . . . . . . . . . . . . . .

fumigation with sulphur dioxide against Calandra.

Salix sp., food plant of Hyphantria cunea ... . . . . . . . . . . . . . . . . . . . .

Sanborn, Chas. E., paper, "The Relation of Descriptions to Economical Methods of

Eradication in the Family Aphididæe" . . . . . . . . . . . . . . . . . . . . . . . . . . . . . 162-166

Sanderson, E. Dwight, paper, "National Control of Introduced Insect Pests" . . . . 95-104 "Notes from New Hampshire" . . . . . . . . . . . . . . 74-76

San Jose scale. (See Scale, San Jose, and Aspidiotus perniciosus.)

Sanninoidea exitiosa, discussion of remedies

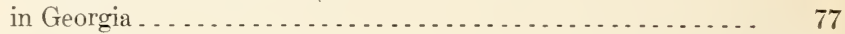

Sawfly larva, on ash in Minnesota . . . . . . . . . . . . . . . . . . . . . . . . . . . . . 85-86

Scale, cherry. (See Aspidiotus forbesi.)

cottony guara. (See Puliinaria psidii.)

maple. (See Pulvinaria innumerabitis.)

Forhes's. (See Aspidiotus forbesi.)

gloomy. (See Chrysomphalus obscurus.)

insects, termed "blight" in Hawaii. . . . . . . . . . . . . . . . . . . . . . . . . . .

oyster-shell. (See Lepidosap.res ulmi.)

San Jose. (See also Aspidiotus perniciosus.)

experiments with insecticides

Federal control

insect legislation result of introduction

scurfy. (See Chionaspis furfura.)

West Indian peach. (See Aulacaspis pentagona.)

wooly maple-leaf. (See Phenacoccus acericola.)

Scales, spraying with lime-sulphur and kerosene-limoid . . . . . . . . . . . . . . . . 137

Schizoneura fodiens, apple an occasional food plant. . . . . . . . . . . . . . . . . . 167

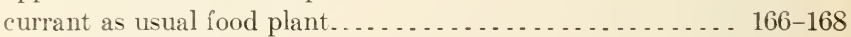

description of forms. . . . . . . . . . . . . . . . . . . . . . . . . 169-170

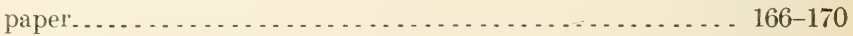

remedies...

lanigera, in Georgia . . . . . . . . . . . . . . . . . . . . . . . . . . 78

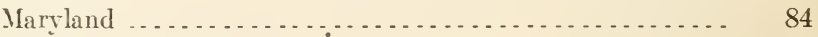

remedies ... . . . . . . . . . . . . . . . . . . . . . . . . . . . . . $78-79$

similar work of Schizoneura fodiens .................. 166-167

Schizura concinna, in New Hampshire............................ $\quad 75$ 
Page.

Sciara sp., sulphur dioxide as insecticide. . . . . . . . . . . . . . . . . . . . . . . 145

Scolytus rugulosus, in Georgia . . . . . . . . . . . . . . . . . . . . . . . . . $77-78$

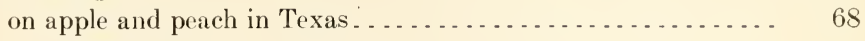

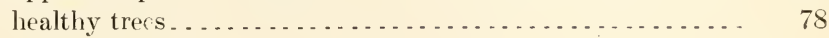

Scurfy scale. (See Chionaspis furfura.)

Scymnids, introduction into Hawaii. . . . . . . . . . . . . . . . . . . . .

Scymnus debiiis, enemy of Pseudococcus sp. introduced into Hawaii. . . . . . . . .

Seeds, sulphur dioxide destructive to germinating power . . . . . . 142, 149, 150, 151-153

fumigation with carbon bisulphid . . . . . . . . . . . . . . . . . . . . . . . 91-92

Sericulture, importance to entomologist. . . . . . . . . . . . . . . . . . . . 21

prospects in United States. . . . . . . . . . . . . . . . . . . . . 20-21

Setaria, food plant of Aphis maidi-radicis. . . . . . . . . . . . . . . . . . . . 35

Shade-tree insects in Ohio. . . . . . . . . . . . . . . . . . . . . . . . . . . . . . $72-74$

Shade trees, injury by Hemerocampa leucostigma . . . . . . . . . . . . . . . . . . . 90

Sharpshooter. (See Oncometopia undata.)

Shot-hole borer. (See Scolytus rugulosus.)

Silk culture. (See also Sericulture.)

in Hawaii.

sometimes eaten by Lepisma saccharina. . . . . . . . . . . . . . . . . . 176

Silkworm, as illustrative material in teaching. . . . . . . . . . . . . . . . . . . 21

Sitvanus surinamensis, Ateleopterus tarsalis a parasite . . . . . . . . . . . . . . 148

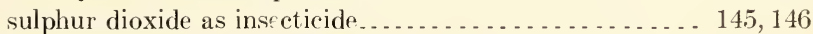

Silver-fish. (See Lepisma saccharina.)

Sitotroga cerealella, in stored corn in Texas. . . . . . . . . . . . . . . . . .

Smartweed, food plant of Aphis maidi-radicis. . . . . . . . . . . . . . . . . . 34-35

Smith, R. I., and A. C. Lewis, paper, "Some Insects of the Year in Georgia" . . . . . 77-82

Soap solution, remedy for Schizoneura fodiens . . . . . . . . . . . . . . . . . . . 170

solutions, against first larval stage of Acridium purpuriferum . . . . . . . . . . 174

Soil fumigation, in greenhouses, impracticability of hydrocyanic-acid gas. . . . . . . 154

Soldier bug, spined. (See Podisus maculiventris.)

Solenopsis geminata, injury to oranges in Cuba. . . . . . . . . . . . . . . . .

Spalangia hirta, parasite of Hæmatobia serrata in Hawaii. . . . . . . . . . . . . .

Sphenophorus obscurus, cultural me thods as remedy . . . . . . . . . . . . . .

introduction into Hawaii. . . . . . . . . . . . . . . 59

Sphinx, catalpa. (See Ceratomia catalpæ.)

Spined soldier bug. (See Podisus maculiventris.)

Spirillum of cholera, spread by flics. . . . . . . . . . . . . . . . . . . . .

Spittle insects. (See Philænus linєatus and P. spumaria.)

Spray outfit, the one used against Acridium purpurferum . . . . . . . . . . . . .

Stalk borcr. (See Papaiperra nitela.)

Starch, not eaten by Lepisma saccharina. .

Staves, of ice-cream freezers, injury by Dermestes vulpinus

Stegomyra (calopus) at St. Louis . . . . . . . . . . . . . . . . . . . . .

calopus, formaldehyde fumigation tests. . . . . . . . . . . . .

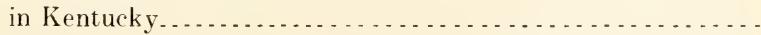

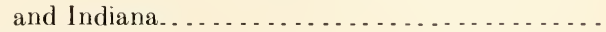

not yet taken in Ohio. . . . . . . . . . . . . . . . . . . . . . .

prevention of breeding in control of yellow fever.........

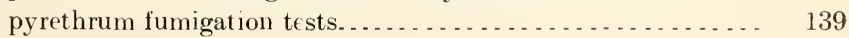

sulphur fumigation in control. . . . . . . . . . . . . . . . . . . . 139

tobacco fumigation tests . . . . . . . . . . . . . . . . . . . . . . 139

fasciata $=$ Stegomyra calopus.

Stereopticon, use in chart making in boll-weevil laboratory. 
Stobera sp., sulphur dioxide as insecticide

Page.

Strawberry root-aphis. (See Aph is forbesii.)

Sugar-cane borer. (See Sphenophorus obscurus.)

food plant of coleopterous larrie........................ 70

Diatræa saccharalis........................... 70

Heliophila unipuncta........................ 70

hemipterous insects............................. 70

Perkinsiella saccharicida........................ 65

] teaf-hopper. (See Ptrkinsiella saccharicida.)

sared by Coccinella repanda and Platyomus lividigaster............ 61

Sugar, not caten by Le pisma saccharina ... . . . . . . . . . . . . . . . . . . . . . . 174

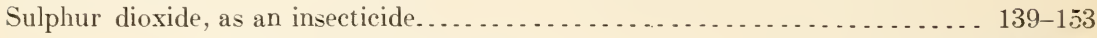

destructire to living plants. . . . . . . . . . . . . . . . . . . . 139, 140, 142

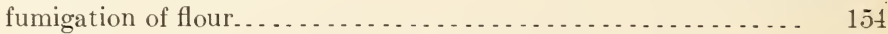

preparation and application with Clayton apparatus........ . 140-141

various uses as Clayton gas. ....... . . . . . . . . . . . . . . . . . 140

forms used in preparation of lime-sulphur wash . . . . . . . . . . . . . : 151-155

fumes, bleaching and tarnishing action in presence of moisture . . . . . . . 139

$140,146,148,149$

destructire action on regetation explained. . . . . . . . . . . . . . . . . . 139-140

fumigation, in destruction of Stegomyia calopus . . . . . . . . . . . . . . . . 139

remedy for Tetranychus gloveri............................. s s1

trioxide, formation in atmosphere from sulphur dioxide . . . . . . . . . . . . 139-140

"Sweet fern." (See Myrica asplenifolia.)

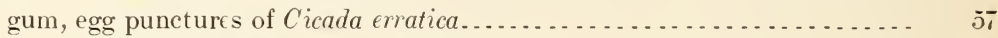

food plant of Malacosoma disstria........................ 79

Symons, T. B., paper, "Entomological Notes from Maryland" . . . . . . . . . . . . . . . \$2-\$4

Syrphus sp., sulphur dioxide as insecticide .......................... 145

Tabanus lineola. (See also Horseflies.)

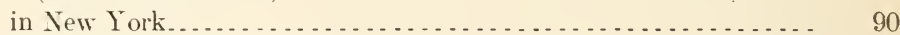

Tags, for boll-weeril records in field cages. . . . . . . . . . . . . . . . . . . . . . 115

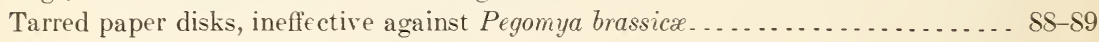

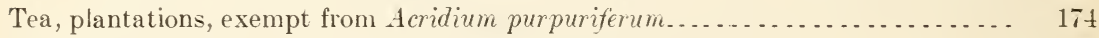

Temperature, effects on boll weevil, apparatus for study . . . . . . . . . . . . . . . . 113-11t

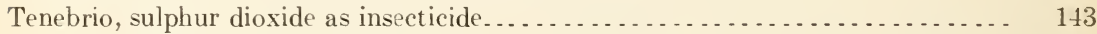

larvæ, hydrocyanic-acid gas as insecticide...... . . . . . . . . . . . . 154

Tenebroides maurtancus, sulphur dioxide as insceticide................. 148

Tent caterpillar. (See also Malacosoma americana.)

forest. (See Malacosoma disstma.)

Podisus maculiventris an enemy ...................... 155

Tetranychus gloveri, kerosene emulsion a remedy .................... 81

on cotton in Georgia........................... 81

sulphur a remedy.............................. 81

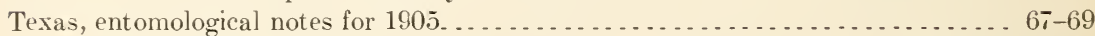

ferer, Federal control . . . . . . . . . . . . . . . . . . . . . . . . . . . . 101-102, 105, 106

Theobald, Fred. V., paper, "The Currant Root-1phis" . . . . . . . . . . . . . . . . 166-170

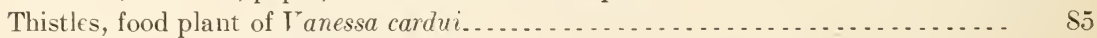

Thyridopteryx ephemeræformis, in Ohio.................................

Tick, cattle. (See also Boophilus annulatus.)

possibility of extermination............................. 106

relation to Texas fercr................................. 106

is some species a conveyor of spotted ferer?..................... 17

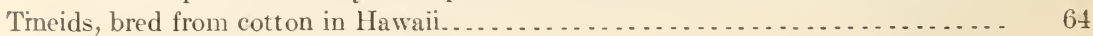


Toads, destruction by mongooss in Hawaii.

feeding on Hyphantria cunea larvæ.

introduction into Hawaii.

Tobacco decoction, remedy for A phis pomi.

dust, remedy for Schizoneura lanigera

woolly aphis. . . . . . . . . . . . . . . . . . . . . . . 92

food plant of Chloridea virescens . . . . . . . . . . . . . . . . . . . $\quad 70$

click-betle larvæ............................. $\quad 70$

Feltia annexa ................................. 70

Phlegethontius sexta.......................... 70

Prodenia commelinx.......................... 70

eudiopta............................. 70

fumigant, remedy for Aphis gossypii........................ 68

fumigation, tests against Stegomyia calopus... . . . . . . . . . . . . . . . . 139

solution, ineffective against Lachnosterna sp................... . . . 85

stored, injury by Lasioderma testaceum . . . . . . . . . . . . . . . . . . $\quad 70$

water, remedy for woolly aphis. . . . . . . . . . . . . . . . . . . . . . . . . 92-93

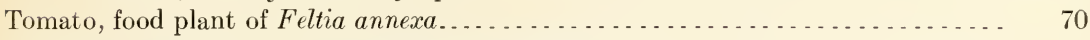

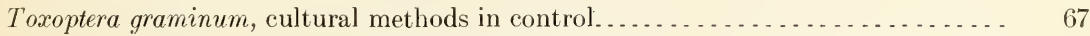

impossibility of eradication with incomplete life-history knowledge... . . . . . . . . . . . . . . . . . . . . . . . . . . . . 163-164

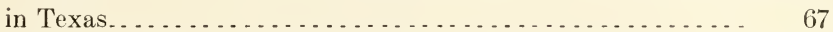

Treacle and treacle sugar, in poisoned bait against Acridium purpuriferum . . . . . . 173

Tribolium confusum, sulphur dioxide as insecticide............. . . . . . . 145, 146

Troctes divinatoria, hydrocyanic-acid gas a remedy . . . . . . . . . . . . . . . 86

infestation of houses in Minnosota.................... 86

Tuberculosis, probable conveyance by flies. . . . . . . . . . . . . . . . . . . . . . . 17

Turnip, food plant of Murgantia histrionica. . . . . . . . . . . . . . . . . . . . . . . . 82

Tussock moth, white-marked. (See Hemerocampa leucostigma.)

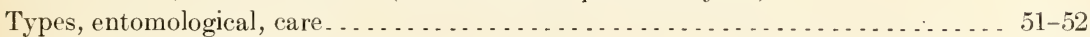

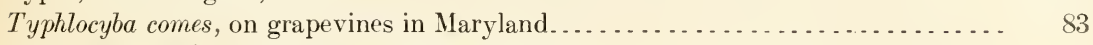

Ulmus americaña, food plant of Hyphantria cunea ... . . . . . . . . . . . . . . 41

Umbelliferous plants, food plants of Papitio polyxenes.................. 70

Uranotes melinus, on cotton in Texas. . . . . . . . . . . . . . . . . . . . . 67

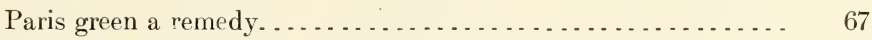

Utetheisa bella $=$ Utetheisa venusta, var............................. 29

hybrida $=$ Utetheisa venusta, var. . . . . . . . . . . . . . . . . . . . 29

ornatrix $=$ Utetheisa venusta, var.............................. 29

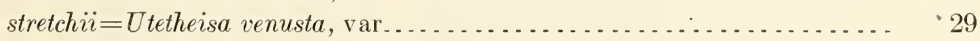

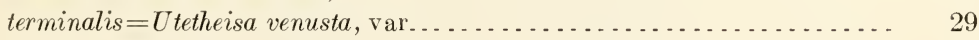

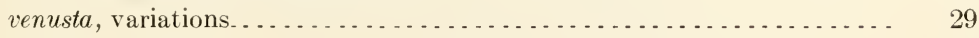

Vanessa cordui, in Minnesota... . . . . . . . . . . . . . . . . . . . . . . . . . 85

Variation, in color of Hyphantria cunea larvæ. . . . . . . . . . . . . . . . . . . . 50-51

form and size of Podisus maculiventris adults . . . . . . . . . . . . . . . 156, 160

Utetheisa venusta................................... 29

Vedalia cardinalis, Cryptolæmus montrouzieri considered more valuable........... $\quad 61$

introduction into Hawaii... . . . . . . . . . . . . . . . . . 59

Vegetables, injury by aphides, coleopterous larvæ, and crickets............. 70

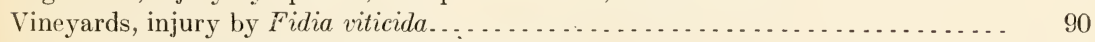

Vitis vulpina, food plant of Hyphantria cunea . . . . . . . . . . . . . . . . . . . 41

Wall papers, bleaching from sulphur-dioxide fumigation. . . . . . . . . . . . . . . . 148

Walnut. (See Juglans nigra.)

Washburn, F. L., paper, "Injurious Insects of 1905 in Minnesota". . . . . . . . . . . . . . . 84-89 
Weather conditions, study, in forecasting abundance of insects.

Tebworm, fall. (Sce also Hyphantria cunea and Hyphantria textor.)

observations on migrating, feeding, and nesting habit

Thebworms. (See Crambus vulgivagellus.)

Teevil, New York. (See Ithycerus noveboracensis.)

Teerils. (See Calandra granaria and Calandra oryza.)

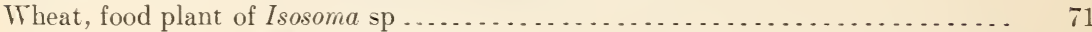

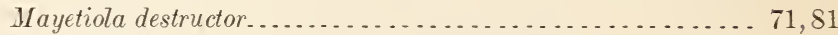

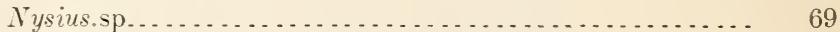

Toxoptera graminum............................... 6 T

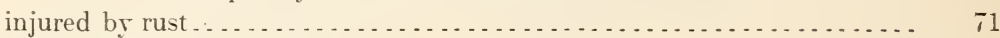

midge. (See Contarinia tritici.)

White grubs. (See also Lachnosterna.)

injury to grass in New York. . . . . . . . . . . . . . . . . . . . . 90

Willow borer. (See Cryptorhynchus lapathi.)

food plant of Cryptorhynchus lapathi ............................ 74

Malacosoma disstria .................................. 79

Wing origin and insect phylogeny . . . . . . . . . . . . . . . . . . . . . . . . . 29

Winthemia quadripustulata, sulphur dioxide as insecticide . . . . . . . . . . . . 145

Wood products (staves of ice-cream freezers), injury by Dermestes vulpinus . . . . . 76

Woolly aphis. (See Aphis, woolly, and Schizoneura lanigera.)

currant. (See Schizoneura fodiens.)

maple-leaf aphide. (See Pemphigus acerifolii.)

scale. (See Phenacoccus acericola.)

Yellow ferer, and other insect-borne diseases, symposium. . . . . . . . . . . . . 2S

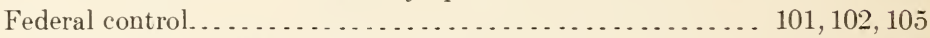

in Connecticut in 1794, probable origin. . . . . . . . . . . . . . 24

mosquito. (See also Stegomyia calopus.)

resolution praying Federal extermination .......... 102

sulphur dioxide in control .................. 150

Yucca filamentosa, fertilization. . . . . . . . . . . . . . . . . . . . . . . 18 


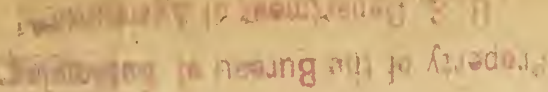

U. S. DEPARTMENT OF AGRICULTURE, BUREAU OF ENTOMOLOGY - BULLETIN No. 60.

L. O. HOWARD, Entomologist and Chief of Bureau.

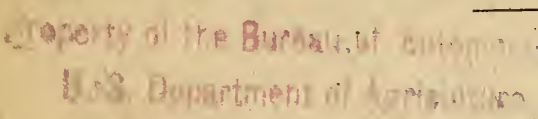

\section{PROCEEDINGS}

OF THE

\section{EIGHTEENTH ANNUAL MEETING}

OF THE

\section{asSOCIATION OF ECONONIC RATONOLOGISTS.}

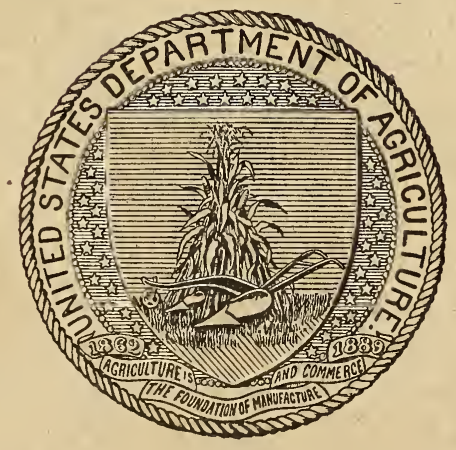

\section{WASHINGTON :}




\section{BLREAT OF ENTOMOLOGY.}

L. O. Howard, Entomologist and Chief of Bureau.

C. L. Marlatt, Entomologist and Acting Chief in absence of Chief.

R. S. Cliftox, Chief Clerk.

F. H. Chittendex, in charge of breeding experiments.

A. D. Hopkixs, in charge of forest insect investigations.

IV. D. Huxter, in charge of cotton boll weevil ineestigations.

F. M. WeBster, in charge of cereal and forage-plant insect investigations.

A. L. Quantaxce, in charge of deciduous-fruit insect investigations.

Fraxk Bextox, in charge of apicultural investigations.

D. M. Rogers, in charge of gypsy and brown-tail moth work.

A. W. Morrill, engaged in white fly investigations.

E. A. Schwarz, D. W. Coquillett, Th. Pergaxde, Nathax Baxks, Assistant Entomologists.

E. S. G. Titus, August Busck, Otto Heidemany, R. P. Currie, J. G. Saxders, A. N. Caudell, F. D. Couden, E. R. Sasscer, J. H. Beattie, I. J. Condit, Assistants.

Lilliax L. Hotensteix, Frederick Kxab, Artists.

Mabel Colcord, Librarian.

H. E. Brrke, W. F. Fiske, J. L. WebB, J. F. Stratss, engaged in forest insect investigations.

W. E. Hinds, J. C. Crawford, W. A. Hooker, W. W. Yothers, A. C. Morgax, W. D. Pierce, F. C. Bishopp, C. R. Joxes, F. C. Pratt, C. E. Sanborx, J. D. Mitchell, Wilmox Nenell, J. B. Garkett, C. W. Flyxy, .A. W. Brckiner, R. A. Cushmax, W. H. Gilsox, engaged in cotton boll weevil inrestigations.

G. I. Reeves, W. J. Phillips, C. N. Arsslie, engaged in cereal and forage-plant insect investigations.

Fred Johrson, A. A. Girault, A. H. Rosenfeld, Dedpley Moultox, engaged in deciduous-fruit insect investigations.

E. F. Phillips, J. M. Rankix, Leslie. Martix, engaged in apicultural inestigations.

C. J. Gilliss, T. A. Keleher, W. A. Keleher, engaged in silk investigations. 




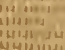

